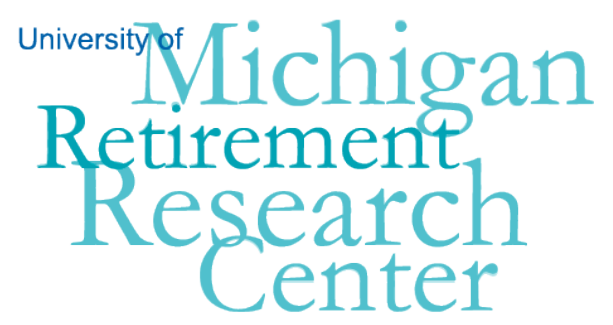

Working Paper

WP 2013-290

\title{
Technical Review Panel for the Pension Insurance Modeling System (PIMS)
}

Olivia S. Mitchell, Christopher C. Geczy, Robert Novy-Marx, Raimond Maurer, Donald E. Fuerst, Christopher M. Bone, Donald J. Segal, Martin G. Clarke, Frank J. Fabozzi, Deborah Lucas, and David F. Babbel

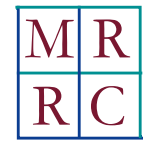

Project \#: UM13-Q2 



\title{
Technical Review Panel for the Pension Insurance Modeling System (PIMS): An Overview
}

\author{
Olivia S. Mitchell \\ Wharton School, University of Pennsylvania \\ September 2013 \\ Michigan Retirement Research Center \\ University of Michigan \\ P.O. Box 1248 \\ Ann Arbor, MI 48104 \\ www.mrrc.isr.umich.edu \\ (734) 615-0422
}

\section{Acknowledgements}

This work was supported by a grant from the Social Security Administration through the Michigan Retirement Research Center (Grant \# 5 RRC08098401-05-00). The findings and conclusions expressed are solely those of the author and do not represent the views of the Social Security Administration, any agency of the Federal government, or the Michigan Retirement Research Center.

\section{Regents of the University of Michigan}

Mark J. Bernstein, Ann Arbor; Julia Donovan Darlow, Ann Arbor; Laurence B. Deitch, Bloomfield Hills; Shauna Ryder Diggs, Grosse Pointe; Denise Ilitch, Bingham Farms; Andrea Fischer Newman, Ann Arbor; Andrew C. Richner, Grosse Pointe Park ; Katherine E. White, Ann Arbor; Mary Sue Coleman, ex officio 


\title{
Technical Review Panel for the Pension Insurance Modeling System (PIMS): An Overview
}

\begin{abstract}
In April of 2013, the Pension Research Council of the Wharton School at the University of Pennsylvania convened a Technical Review Panel, comprising ten experts whose task it was to review the Pension Benefit Guaranty Corporation’s (PBGC) Pension Insurance Modeling System (PIMS), including inputs, outputs, and model assumptions. The review was intended to provide a formal evaluation of the technical adequacy of the model by outside experts. Each expert participating on the Technical Panel was asked to review background material (see References) and focus on a particular aspect of the PIMS model. The list of panelists and topics was developed by the Council in discussion with the Social Security Administration (SSA). This report and the appended papers herein from our Technical Panel comprise the Final Report under this project.

The Panel's key findings may be summarized as follows: (1) The PIMS models are an important and valuable tool in modeling the Agency's liability risk. To the best of our knowledge, there is no other model that can do a comparable job. (2) Nevertheless, some improvements could be integrated in the Agency's approach to modeling. Those deserving highest priority attention in the experts' view are the following: (a) Incorporating systematic mortality risk (i.e., treat mortality and longevity as stochastic variables); (b) Including new asset classes increasingly found in defined benefit plan portfolios (e.g., commercial real estate, private equity funds, infrastructure, hedge funds, and others); (c) Developing a more complex model for the term structure of interest rates; and (d) Incorporating an option value approach to pricing the insurance provided. (3) The Agency could also do more to communicate the range of uncertainty and potential for problems associated with the PBGC's financial status. This could include additional information including the Conditional Value at Risk (CVaR), and perhaps an 'intermediate,' 'optimistic,' and 'pessimistic' set of projected outcomes, as well as the expected 'date of exhaustion' for assets backing pension benefits insured by the PBGC.
\end{abstract}

\section{Citation}

Mitchell, Olivia S. (2013). "Technical Review Panel for the Pension Insurance Modeling System (PIMS): An Overview,” University of Michigan Retirement Research Center (MRRC) Working Paper, WP 2013290(a). Ann Arbor, MI.

\section{Authors’ Acknowledgements}

The research reported herein was pursuant to a grant from the U.S. Social Security Administration (SSA) funded as part of the Retirement Research Consortium (RRC); the author also acknowledges support from The Pension Research Council at The Wharton School. All findings and conclusions expressed are solely those of the author and do not represent the views of the SSA or any agency of the federal government, the MRRC, the PRC, or The Wharton School at the University of Pennsylvania. All findings, interpretations, and conclusions of this paper represent the views of the authors and not those of the Wharton School or the Pension Research Council. (C2013 Pension Research Council of the Wharton School of the University of Pennsylvania. All rights reserved. 


\title{
Technical Review Panel for the Pension Insurance Modeling System (PIMS): An Overview
}

\author{
Olivia S. Mitchell
}

\section{Introduction}

The Pension Benefit Guaranty Corporation (PBGC) is a federal corporation founded under the Employee Retirement Income Security Act (ERISA) of 1974. Its goal is to protect benefits promised by the private sector defined benefit (DB) pension plans in the United States via two insurance programs covering, respectively, single employer and multiemployer plans. To carry out its work, the Agency has developed two simulation models over the past two decades, the Single Employer Pension Insurance Modeling System (SE-PIMS), and the Multiemployer Pension Insurance Modeling System (ME-PIMS). These use several input parameters regarding actuarial assumptions, capital market developments, the evolution of assets and liabilities, and plan terminations, to model how the Agency’s financial status might unfold over the next decade or two. These models require running many simulations to derive a range of possible estimates of the PBGC’s future financial status.

The meeting in April 2013 of the Technical Panel followed up on an earlier Technical Panel review in 1996 hosted by the Pension Research Council at the Wharton School. The prior discussion offered expert commentary on an early version of the SE-PIMS model then just under development. For the 2013 Panel, we invited ten experts to provide their views and judgment regarding the soundness and applicability of the current version of the PIMS models, regarding economic, finance, statistical, and actuarial principles and reasonableness of key assumptions and program inputs. These experts also were asked to offer their assessments on how actuarial and statistical calculations are undertaken in the models, model calibrations, and presentation of 
output. The goal of this meeting, as in 1996, was to offer suggestions on how the PIMS systems could be made more useful for analysis and policy.

\section{Background}

The Pension Benefit Guaranty Corporation (PBGC) is, according to the 2012 Annual Report, a "federal corporation...[that] guarantees payment of basic pension benefits earned by nearly 43 million of America's workers and retirees participating in nearly 26,000 private-sector defined benefit pension plans. The Corporation receives no funds from general tax revenues. Operations are financed by insurance premiums paid by companies that sponsor defined benefit pension plans or from the plans' assets, investment income, and assets from terminated plans." Its governance structure includes a Director appointed by the President and confirmed by the Senate; the Agency is overseen by a Board of Directors chaired by the Secretary of Labor and includes the Secretaries of Commerce and Treasury (ex officio).

The PBGC has two components to its pension insurance program. One covers defined benefit pensions offered by employers in the private sector under the Single Employer Plan program (SE) involving almost 33 million active and retired workers in about 24,000 pension plans. The other covers so-called Taft-Hartley plans under the Multiemployer program (ME) which includes about 10 million active and retired employees in some 1,500 pension plans. In 2013, single employer plans paid to the PBGC in insurance premiums a flat amount of $\$ 42$ perworker or retiree and also a variable amount of $\$ 9$ per $\$ 1000$ of unfunded vested benefits. ${ }^{1}$ Multiemployer plans paid a flat premium of $\$ 12$ per worker or retiree. Retiree benefits are guaranteed by the PBGC up to a cap: in 2013, covered employees claiming benefits at age

\footnotetext{
1 All 2013 data are taken from http://www.pbgc.gov/res/factsheets/page/pbgcfacts.html
} 
65 could receive a maximum of $\$ 4,789.77 /$ month $(\$ 57,477.24 /$ year) for the single employer plan, payable as a single life annuity. In the multi-employer arena, the annual benefit guaranteed can be up to $\$ 12,870 .^{2}$ In the multi-employer arena, the annual guaranteed benefit is up to $\$ 12,870$. The guaranteed amount is reduced actuarially for earlier claimants (or for those having survivor benefits). The guarantee is increased for those who claim post-age 65 .

For a variety of reasons, the PBGC's finances are not in long-term balance. ${ }^{3}$ The Agency's 2012 Annual Report noted that the SE program had liabilities of $\$ 112.1$ billion and assets of $\$ 83.0$ billion, for a deficit of $\$ 29.1$ billion. For the ME program, the Agency reported liabilities of $\$ 7$ billion and assets of $\$ 1.8$ billion, producing a deficit of $\$ 5.2$ billion. The Agency also projects future income and payout streams for 10 or 20 years into the future, though it acknowledges substantial uncertainty regarding these projections. Estimates of the SE program's financial position in FY 2022 range from a $\$ 66$ billion deficit at the $15^{\text {th }}$ percentile to a $\$ 1$ billion surplus at the $85^{\text {th }}$ percentile, with a mean estimate of a $\$ 32$ billion deficit, all values expressed in present value terms. Estimates of the ME program's financial position in FY2022 range from a $\$ 43$ billion deficit at the $15^{\text {th }}$ percentile to a $\$ 9$ billion deficit at the $85^{\text {th }}$ percentile, with a mean estimate of a $\$ 26$ billion deficit, all values expressed in present value terms. These "long-term" estimates include "probable terminations" from plans that it is likely to have to take over in the future, but the Agency does not book as losses those plans it deems to be "reasonably possible terminations"; both "probable terminations" and "reasonably possible terminations" are determined in accordance with the FASB Accounting Standards Codification Section 450, Contingencies.

${ }^{2}$ Multiemployer information is available at http://www.pbgc.gov/res/factsheets/page/pbgcfacts.html.

${ }^{3}$ All data in this paragraph are taken from the PBGC 2012 Exposure Report 


\section{Key Findings from the Technical Panel Review}

The Technical Panel offered several comments and suggestions regarding the way the PIMS models assets, liabilities, and the interactions between the two. Moreover the Panel provided suggestions on how the PBGC might enhance the way it reports its status to policymakers and the public, so as to better communicate the risks and opportunities the Agency faces. We briefly discuss each in turn, and we refer interested readers to the individual expert papers produced under the Panel's auspices, for further detail (see References).

\section{Modeling Defined Benefit Pension and PBGC Liabilities}

PBGC liabilities consist of the vested accrued benefits payable under Title IV of ERISA (i.e., guaranteed and, in some circumstances, non-guaranteed benefits provided under the law) of already-terminated pension plans, as well as the Title IV benefits of insured underfunded plans that are likely to terminate in the future. Several of the experts on the Technical Panel had comments and suggestions regarding how the PIMS models treat such liabilities.

The cash flows owed by the PBGC consist of pension benefits promised to active, terminated vested, and retired workers under each plan's benefit rules. In terminated SE plans, these are relatively straightforward to model as they are fixed as of the date of the plan's termination. As Novy-Marx (2013) and others note, at plan termination, the PBGC takes over the plan's accrued benefit obligation (ABO), with benefits computed given known formulas and frozen wage, tenure, and age distributions as of the termination date.

Nonetheless, even here, important unknowns remain, such as when participants will retire and how long participants (and their survivors) will live in the future. Thus demographers and economists have modeled systematic mortality shocks that could pose substantial risk to PBGC solvency in the future. Maurer (2013) notes that this form of uncertainty can now be modeled 
and, accordingly, may be integrated into the PIMs model to determine the future path of the Agency's payouts. The Agency could also cost out how expensive it would be to hedge stochastic mortality risk. And the PIMS model currently includes only single male mortality tables; these could be extended allowing for both female and survivor tables. ${ }^{4}$

Greater uncertainty pertains to the possible time path of benefits associated with future terminations, inherently a more complex process and one which, in the experts' views, may understate the size of the problem faced. One reason is that PIMS assumes that plans will only be terminated in distress, and hence it assumes no voluntary (i.e., standard) termination of fully funded pensions. But as several of the experts note, this is increasingly not the case. Fuerst and Bone point out that many single employer DB plans have recently de-risked by outsourcing their pensions to insurers. This reduces the future premiums payable to the PBGC, and it also diminishes the asset pool available to the Agency in the event of future terminations. ${ }^{5}$ Segal notes that allowing for newer plans of the hybrid and cash balance variety could also imply the need for different ways to model future liabilities.

In the case of ME plans, benefit payouts can be reduced under certain circumstances; it is unclear whether this flexibility in benefit payments will be extended to SE plans in the future. Yet as Bone points out, the ME program appears to be in a worse condition than the SE program, as ME plans come to the Agency for financial assistance when they have no assets to pay the promised benefits. For this and other reason (e.g., the extremely low premium), costs associated with the ME plans may pose more risk to the PBGC than does SE plan underfunding.

\footnotetext{
4 The Agency has noted in comments to the Panel's report that, although there is no direct adjustment for female mortality, the initial PIMS liabilities are recalibrated to each plans' reported liabilities which indirectly adjusts them to reflect the plan's female mortality.

5 The Agency has noted in comments to the Panel's report that concern about the diminution of the asset pool in the event of future terminations is unwarranted in the context of standard terminations, since these are fully funded.
} 
Much of the Panel discussion focused on how to bring an options-based approach into PIMS models. The goal of doing so would be to link the factors that drive plan sponsor terminations and plan underfunding to stock market risk. ${ }^{6}$ The options approach differs from a Net Present Value (NPV) method, by taking into account the possibility that company management will react to market changes dynamically and strategically. That is, this approach models alternative scenarios to identify the best corporate action given different outcomes. Since companies are modeled as reacting sensibly to uncertain financial outcomes, the plan sponsors can take advantage of uncertainty to reduce volatility in profitability compared to a conventional NPV metric. The risk-neutral valuation methodology takes into account the probability distribution of risk and typically discounts outcomes using a risk-free rate.

Lucas notes that such an approach could be usefully built on top of the plan-specific computations that the PIMS models already incorporate. The Congressional Budget Office in 2005 developed a somewhat simplified method of modeling the PBGC's problem which demonstrated proof of concept. This work focused on the joint probabilities of sponsor bankruptcy and DB plan underfunding, and it generated much larger estimates of funding shortfalls; these resulted from projected smaller asset recoveries, less premium income, and higher liabilities than the actuarial approach. ${ }^{7}$ That effort suggested that taking into account risk in this way would roughly double premium costs. One important reason for this is that the distribution of liabilities is likely to be characterized by so-called "fat tails," referring to the potential for large losses in the worst-case scenarios, as Segal, Bone, and Novy-Marx point out.

\footnotetext{
${ }^{6}$ The Agency has noted that, in the current PIMS model, both plan sponsors' bankruptcy risks and plan funding are linked to stock market risk and both links can be shown to have significant effects in PIMS projections. Nevertheless, the Agency has not published extended model output demonstrating the sensitivities of those links.

${ }^{7}$ PBGC has done similar analysis using the current model framework but this has been used internally and is not publicly available.
} 
A related theme that the Panel debated was how to summarize the system's liabilities at any point in time and over future time periods. Current practice is to report expected present discounted values (PVs) using Treasury rates to do the discounting. But as Lucas notes, this approach has a fundamental but potentially fixable shortcoming: it cannot be used to answer questions about market valuation of future streams of cash flows. Moreover, as Novy-Marx points out, which liability concept to use depends on the observer's vantage point. From the perspective of the covered insured active and retired pension plan participants, the guarantee embodies some risk: the system's assets are insufficient to meet all future benefits that might be paid, and the PBGC's guarantee is not backed by the full faith and credit of the Federal government. Absent a large transfer from Congress to cover its future cash flows, it is unlikely that all benefits can be paid in the long run. ${ }^{8}$ From an insurer's perspective, the right way to measure possible liabilities is to measure the risk-neutral valuation of the insurance. An approach favored by some would be to have the PBGC provide the distribution of projected future cash flow paths it guarantees

\section{Modeling Assets}

Next we summarize the Panel's key suggestions regarding how the PBGC models assets in the PIMS. Geczy notes that the current approach estimates risk and return patterns drawing on historical data, assuming a fixed real interest rate and holding constant historical correlations. But having experienced the recent global financial crisis, we now know that tail risk is far more of a concern than previously anticipated. Accordingly, most of the experts felt that the PIMS model would benefit from stress testing in terms of its sensitivity to extreme events and time-

\footnotetext{
${ }^{8}$ The PBGC's projections suggest that the SE program will be able to cover promised benefits for the next decade given its assumptions, whereas the ME program is likely to run short.
} 
varying returns, relaxing the 'random walk' approach to modeling risk.

A related point emphasized by Maurer was that the PIMS model currently relies heavily on a relatively simple model for a single interest rate - the 30 year Treasury rate. This is important since the interest rate model is used as an input for actuarial valuation of liabilities of terminated and ongoing plans; to determine minimum contribution rates; to specify the return on PBGC assets for terminated plans; to set the yield for corporate bonds; to set the inflation rate; to set the nominal benefit growth (since inflation is related to the nominal interest rate); and to calculate the present value of PBGC claims. Yet modern tools now exist for more complete and comprehensive models of the complete term structure of interest rates, and several experts felt this could be a fertile area for model development.

Additionally, several Panel members highlighted the fact that the DB plan asset mix is currently assumed in the PIMS model to be a 60/40 US stock/bond split. But as Geczy, Maurer, and Fabozzi emphasize, today's pension plans hold more alternatives and are more internationally diversified. These alternative assets are quite varied, and they include commercial real estate, private equity funds, infrastructure investments, hedge funds, and other holdings. Evidently, including additional relatively illiquid assets in the PIMS model would be complex. As Fabozzi notes, there is a tradeoff between the speed at which the model can be run, versus more complex assumptions about the assets held and the pattern of capital market returns.

\section{Considerations Regarding the Modeling of PBGC Insurance Protection}

Several presentations by Technical Panel members suggest that the PIMS model could be adapted to better integrate how risks affect both pension assets and liabilities jointly. Additionally most felt that these could be fruitfully co-managed using an Asset/Liability Management framework. In the past, PBGC assets have, during some periods, been invested 
independently from the Agency's liabilities, with investment policy changing back and forth over time between maximizing expected returns and a liability- driven approach. Some Panel members argue that it would be important to model particular industries and sectors posing most risk to the Agency, in which case the PIMS model could be used to align the Agency's investment policy with this broader attention to risks.

It is also worth emphasizing that, unlike a private-sector insurer, the PBGC's insurance premiums are set by Congress; that is, the PBGC has no statutory ability to set its own premiums or to deny coverage to extremely risky plans. As Babbel and several other Panel members note, this is problematic since the Agency faces large legacy costs and is unlikely to be able to close its funding gap with feasible premium increases. Additionally, the recently enacted legislation entitled Moving Ahead for Progress in the 21st Century Act (MAP-21) again deferred contribution hikes, thus exacerbating the problem. In the UK, by contrast, the Pension Protection Fund (PPF) has substantially more flexibility in setting premiums and specific objectives. Thus Clark reports that the PPF uses a stochastic approach to evaluate the risks and set risk-based premiums in a manner consistent with the Board's risk tolerance. As a consequence, the PPF's model is more cognizant of a variety of risks not currently embedded in the PBGC model, and the PPF prices for self-sufficiency in 2030.

A related issue is that the PIMS program does not incorporate potential moral hazard issues that could result from insured plans reacting to changes in PBGC or Congressional policy. The ME PIMS model does take into account the chance that mass withdrawals could result from a given plan, or that a plan could be rendered insolvent prior to a mass withdrawal. But the model does not permit the examination of how individual plan sponsors might respond, and a longer-term project would include the integration of such feedbacks. 


\section{Communication of Risk and Uncertainty}

The Technical Panel also devoted attention to how PBGC risk is communicated. This is important since key stakeholders, including Congress, plan participants, plan sponsors, and taxpayers, need to more clearly comprehend what might happen in bad states of the world which have become more salient than previously.

One way to explain pension system risk more intuitively is proposed by Maurer who points to the usefulness of a Conditional Value-at-Risk (CVaR), also known as the expected shortfall or "expected tail loss." This is widely used as a loss measure depicting the worst-case loss scenarios at a particular level of risk. This author recommends it as a possibly better risk measure that could be used when explaining the possible losses that might result from a PBGC shortfall.

Another issue under discussion is the time period over which system assets and liabilities are reported. Currently the PBGC reports mean values, along with the 'high' and 'low' 15 percentiles of the 5,000 SE simulations and $500 \mathrm{ME}$ simulations carried out, for 10 years into the future. Of course, as projections are made further into the future, the extent of uncertainty grows. Yet focusing on only a decade ahead implicitly downweights the liabilities that the Agency may have to pay in years thereafter. As a matter of fact, open plans today continue to accrue benefit promises that will need to be paid many more decades into the future.

It is worth noting that several other government entities that pay benefit promises long into the future, such as the Social Security Administration, are required to offer projections 75 years into the future, as well as "in perpetuity." Additional sensitivity to longer payout periods in the PBGC context would offer additional perspective on future solvency considerations. ${ }^{9}$ Some

\footnotetext{
${ }^{9}$ Some argue that long-term projections may make more sense for a program like Social Security
} 
Panel members also favor highlighting the "date of exhaustion" of the PBGC's assets backing benefit promises, since this is a concept that is relatively easy to explain. Nevertheless, such information also has a history of being used to deflect attention from PBGC problems. For instance, some might ask why premiums should be raised today on plan sponsors, if the Agency has sufficient assets to pay more than 10 years of benefits.

The PBGC has also seen non-intuitive results in projections of the asset exhaustion date (at least in the SE program); for instance, the size of the deficit and the date of asset exhaustion often move in opposite directions. One reason is that large claims increasing the deficit may extend the date of asset exhaustion due to the inflow of plan assets when PBGC takes over a plan. And ultimately if Congress were to decide to bail out the PBGC in the event of insolvency, it is unclear which would be worse: a bailout that came sooner, or one that was later and probably more costly? In this case, one could reasonably question whether asset exhaustion dates belong on a short list of highlighted information points always provided by PBGC projections.

\section{Conclusions}

ERISA marks its $40^{\text {th }}$ anniversary in 2014. Despite the fact that this law was designed to ensure that participants in private sector defined benefit plans would have a secure retirement, concerns continue to mark debate over the future of US defined benefit plans. Few new DB plans are being created; many existing DB plans are frozen; some large plans continue to hover on the

which is projecting more predictable flows. The PBGC is subject to most of the same long-run uncertainties as Social Security, but this Agency has additional uncertainties that are more sensitive to difficult to predict events, including sponsor bankruptcies, voluntary components of funding decisions, voluntary decisions over sponsorship of PBGC insured plans, pension-related legislative changes (major changes have occurred in every recent decade), and market returns of different risky asset classes. Some panel members agreed with the limited value of longer-run projections of corporate bankruptcies, for instance. 
brink of termination; and the recent wave of de-risking suggests that fewer premiums will be flowing into the PBGC than anticipated. Moreover, many of the suggestions and recommendations outlined in the Technical Panel's comments would imply that a large transfer will be required, or insurance premiums raised substantially, and/or benefits curtailed, if the system is to be able to continue to provide some benefits to all of those who were promised retiree payouts.

The Technical Panel concurred that the PIMS models are an important and valuable tool in modeling the Agency's liability risk. To the best of our knowledge, there is no other model that can do a comparable job. Nevertheless, some improvements could be integrated in the Agency's approach. Among those deserving attention in the Technical Panel's view are the following:

- Incorporating systematic mortality risk;

- Including new asset classes increasingly found in defined benefit plan portfolios;

- Developing an updated model for the term structure of interest rates; and

- Incorporating an option value approach to pricing the insurance provided.

The Agency could also do more to communicate the range of uncertainty and potential for problems associated with the PBGC's financial status. This could include additional information including the Conditional Value-ay-Risk (CVaR), and perhaps an "intermediate," "optimistic," and a "pessimistic" set of projected outcomes, as well as the expected "date of exhaustion" for assets backing pension benefits insured by the PBGC. 


\section{References}

\section{Technical Panel Papers ${ }^{10}$}

Babbel, D. (2013). “Evaluating Pension Insurance Pricing,” Pension Research Council Working Paper WP2013-16. Philadelphia, PA: Pension Research Council.

Bone, C. (2013). “Actuarial Perspectives on Defined Benefit Pension Risk - Modeling Emerging Issues,” Pension Research Council (PRC) Working Paper WP2013-11. Philadelphia, PA: Pension Research Council.

Clarke, M. (2013). “Modeling Risk-based Pension Insurance Premiums in the UK," Pension Research Council (PRC) Working Paper WP2013-13. Philadelphia, PA: Pension Research Council.

Fabozzi, F. (2013). "Measuring and Explaining Pension System Risk," Pension Research Council Working Paper WP2013-14. Philadelphia, PA: Pension Research Council.

Fuerst, D. (2013). “Actuarial Assumptions \& Models for DB Pensions,” Pension Research Council Working Paper WP2013-10. Philadelphia, PA: Pension Research Council.

Geczy, C. (2013). "Financial Market Assumptions \& Models for Pension Plans: A Technical Comment on the PIMS Model Assumptions for Asset Markets," Pension Research Council Working Paper WP2013-07. Philadelphia, PA: Pension Research Council.

Lucas, D. (2013). “Joint Risk of DB Pension Underfunding and Sponsor Termination: Incorporating Options-Based Projections and Valuations into PIMS,” Pension Research Council Working Paper WP2013-15. Philadelphia, PA: Pension Research Council.

Maurer, R. (2013). “Integrated Risk Management for Defined Benefit Pensions: Models and Metrics," Pension Research Council Working Paper WP2013-09. Philadelphia, PA: Pension Research Council.

\footnotetext{
${ }^{10}$ These Technical Panel papers are available on the Pension Research Council website
} (www.pensionresearchcouncil.org). 
Novy-Marx, R. (2013). "Economic and Financial Approaches to Valuing Pension Liabilities,"

Pension Research Council Working Paper WP2013-08 Philadelphia, PA: Pension Research Council.

Segal, D. (2013). “An Actuarial Perspective on Pension System Risk,” Pension Research Council Working Paper WP2013-12. Philadelphia, PA: Pension Research Council.

\section{Materials Supplied to the PIMS Technical Panel for Review}

Material Supplied by the SSA.

Lynchval Systems (2012). "Multiemployer PIMS - Known Limitations in ME-PIMS, Version 2.0"

(Disclosures for Validation). Chantilly, VA: Lynchval Systems Worldwide, Inc., February

10.

Pension Benefit Guaranty Corporation (PBGC) (2009). “SE PIMS PPG App B," Tech Architecture vFY09. Washington, DC: PBGC.

Pension Benefit Guaranty Corporation (PBGC) (2010). “A Brief Description of PIMS' Source Code," SE PIMS Programmers Guide. Washington, DC: PBGC.

Pension Benefit Guaranty Corporation (PBGC) (2010). “SE PIMS User Guide.” Washington, DC: PBGC.

Pension Benefit Guaranty Corporation (PBGC) (2010). “SE PIMS System Description.” Washington, DC: PBGC.

Pension Benefit Guaranty Corporation (PBGC) (2010). "ME PIMS System Description." Washington, DC: PBGC, September 22.

Pension Benefit Guaranty Corporation (PBGC) (2010). “SE PIMS PPG App A,” Pension Insurance Modeling System (PIMS) Input Data Structure vFY09.1. Washington, DC: PBGC.

Pension Benefit Guaranty Corporation (PBGC) (2411). "PIMS Technical Specification - Update 
ME-PIMS Code to Accommodate ME Provisions of PRA 2010” (ME PIMS Pre-Rollout Specs 1 and 2, ME PIMS Post-Rollout Specs). Washington, DC: PBGC, February 6.

Pension Benefit Guaranty Corporation (PBGC) (2011). “Overview,” Multiemployer PIMS System-

Validation Documentation. Washington, DC: PBGC, February 7.

Pension Benefit Guaranty Corporation (PBGC) (2011). "Key Differences Between SE-PIMS and

ME-PIMS,” Multiemployer PIMS System-Validation Documentation. Washington, DC:

PBGC, February 7.

Pension Benefit Guaranty Corporation (PBGC) (2011). “SE PIMS Environment Plan FY11,” rev.

March 25. Washington, DC: PBGC.

Pension Benefit Guaranty Corporation (PBGC) (2011) “Overview of the Pension Insurance

Modeling System (PIMS).” Washington, DC: PBGC, April 27.

Pension Benefit Guaranty Corporation (PBGC) (2012). “A Brief History of PIMS.” Washington, DC: PBGC, September 27.

Other Material

Buck Consultants (2012). “ME-PIMS Peer Review Report,” Letter from Buck Consultants to Larry Shirley of the Pension Benefit Guaranty Corporation. Berwyn, PA: Buck

Consultants, September 12.

Congressional Budget Office (CBO) (2005). “The Risk Exposure of the Pension Benefit Guaranty Corporation.” Washington, DC: CBO, September.

U.S. Government Accountability Office (GAO) (1997). 1997 PBGC Report. Washington, DC: GAO.

Pension Benefit Guaranty Corporation (PBGC) (2012). "Excellence in Customer Service,” FY2012 Annual Report. Washington, DC: PBGC.

Pension Benefit Guaranty Corporation (PBGC) (2012). "Press Release: FY 2012 PBGC Exposure Report." Washington, DC: PBGC. 
Society of Actuaries (SOA) (2012). "Proposed Pension Funding Stabilization: How Does It Affect the Single-Employer Defined Benefit System?" SOA Research Report. Schaumburg, IL: SOA. 


\section{Appendix: Meeting Agenda}

\section{Technical Review Panel for the PIMS Model}

Hosted by the Pension Research Council, \& Michigan Retirement Research Center

April 24, 2013, The Wharton School

Moderator and Organizer:

Olivia S. Mitchell, The Wharton School of the University of Pennsylvania

\section{Understanding Defined Benefit Plan Asset and Liability Risk}

Chris Geczy, The Wharton School: "Financial Market Assumptions \& Models for Pension Plans:

A Technical Comment on the PIMS Model Assumptions for Asset Markets"

Robert Novy-Marx, University of Rochester: "Economic and Financial Approaches to Pension Liabilities"

Raimond Maurer, Goethe University, Frankfurt: "Integrated Risk Management for Defined Benefit Pensions: Models and Metrics"

\section{Actuarial Perspectives on Defined Benefit Pension Plan Risk}

Don Fuerst, American Academy of Actuaries: “Actuarial Assumptions \& Models for DB Pensions"

Chris Bone, Edth Ltd.: “Actuarial Perspectives on Defined Benefit Pension Risk - Modeling Emerging Issues"

Don Segal, former President, Society of Actuaries: “An Actuarial Perspective on Pension System Risk"

\section{Keynote}

Martin Clarke, Pension Protection Fund (UK): "Modeling Risk-based Pension Insurance Premiums in the UK"

\section{III.Understanding Pension System Risk}

Frank Fabozzi, EDHEC: "Measuring and Explaining Pension System Risk"

Debbie Lucas, MIT: Joint Risk of DB Pension Underfunding and Sponsor Termination: Incorporating Options-Based Projections and Valuations into PIMS.

\section{Pension Insurance: Risk Pricing Perspectives}

David Babbel, Wharton (Emeritus): "Evaluating Pension Insurance Pricing" 


\title{
Financial Market Assumptions \& Models for Pension Plans: A Technical Comment on the PIMS Model Assumptions for Asset Markets
}

\author{
Christopher C. Geczy \\ The Wharton School, University of Pennsylvania \\ September 2013 \\ Michigan Retirement Research Center \\ University of Michigan \\ P.O. Box 1248 \\ Ann Arbor, MI 48104 \\ www.mrrc.isr.umich.edu \\ (734) 615-0422
}

\section{Acknowledgements}

This work was supported by a grant from the Social Security Administration through the Michigan Retirement Research Center (Grant \# 5 RRC08098401-05-00). The findings and conclusions expressed are solely those of the author and do not represent the views of the Social Security Administration, any agency of the Federal government, or the Michigan Retirement Research Center.

\section{Regents of the University of Michigan}

Mark J. Bernstein, Ann Arbor; Julia Donovan Darlow, Ann Arbor; Laurence B. Deitch, Bloomfield Hills; Shauna Ryder Diggs, Grosse Pointe; Denise Ilitch, Bingham Farms; Andrea Fischer Newman, Ann Arbor; Andrew C.

Richner, Grosse Pointe Park ; Katherine E. White, Ann Arbor; Mary Sue Coleman, ex officio 


\title{
Financial Market Assumptions \& Models for Pension Plans: A Technical Comment on the PIMS Model Assumptions for Asset Markets
}

\begin{abstract}
The financial market assumptions of the PBGC's PIMS model are critical inputs to simulations for most apparent uses of the system. They currently appear to be based on a reduced form, "classical" approach to assessing and forecasting the distribution of returns on various classes of input assets, allowing for a fairly sophisticated and useful approach to understanding simulated distributions of potential pension insurance outcomes as well as the net financial status of the PBGC. This technical note discusses some of the capital market side assumptions utilized in the model. It also comments on important related assumptions including the assumed asset allocations of insured plans, making suggestion for possible modification of input assumptions of the model to reflect time variation in financial market return behavior as well as time variation in observed plan allocations.
\end{abstract}

\section{Citation}

Geczy, Christopher C. (2013). "Financial Market Assumptions \& Models for Pension Plans: A Technical Comment on the PIMS Model Assumptions for Asset Markets,” University of Michigan Retirement Research Center (MRRC) Working Paper, WP 2013-290(b). Ann Arbor, MI.

\section{Authors' Acknowledgements}

The author thanks Jeff Brown and staff members of the DOL, PBGC and SSA for helpful comments and Kyle Binder, Alimu Abudu, and Ankur Dadhania for helpful research assistance. The research reported herein was pursuant to a grant from the U.S. Social Security Administration (SSA) funded as part of the Retirement Research Consortium (RRC); the author also acknowledges support from The Pension Research Council at The Wharton School. All findings and conclusions expressed are solely those of the author and do not represent the views of the SSA or any agency of the federal government, the MRRC, the PRC, or The Wharton School at the University of Pennsylvania. Comments welcome. 


\section{Financial Market Assumptions \& Models for Pension Plans: A Technical Comment on the PIMS Model Assumptions for Asset Markets

\author{
Christopher C. Geczy
}

\section{Introduction and Scope}

In this technical comment, we address a subset of the modeling assumptions of the PIMS system developed and employed by the PBGC, focusing our attention on the capital market expectations of asset classes assumed to represent holdings of plans insured by the agency as well as those asset class allocation assumptions themselves. Examination of such suppositions and their modeling implications can of course be quite important. However, we hasten to add that without understanding or perhaps guessing about the implications of changes in assumptions, the ultimate import of this examination has natural limitations. Nonetheless, what follows represents an assessment of a few of what we see as the most important assumptions for capital market behavior as well as some apparent quickly moving industry trends that also likely affect outputs in important ways and might fruitfully be treated in the modeling assumptions of PIMS. While it seems logical that because simulations can be sensitive to certain assumptions (and expected outputs are complex functions of inputs) and because we view our comments as important both econometrically and as part of powerful industry trends that are potentially important to PBGC outcomes, it is surely the case that only when changes to the PIMS capital market and asset allocation assumptions are directly incorporated in the model will we come to understand the actual importance of what emerges. Finally, it is highly worthwhile to note that the PBGC staff is likely to be aware of the ideas outlined in the comment below and have indicated at various points in the system documentation and associated literature that future versions of the system may include modifications incorporating these ideas. 


\section{Overview of the PIMS Model Assumptions}

The Pension Insurance Modeling System (PIMS) is a simulation modeling framework developed by the Pension Benefit Guarantee Corporation (PBGC) that was "designed to quantify the uncertainty that surrounds pension insurance" and to be used as a tool to characterize potential distributions of pension insurance claims on the PBGC and, importantly, the agency's surplus (or deficit). ${ }^{1}$ The PBGC is clear that the system is not a predictive system intended to identify point estimates of the future financial condition of the agency but to provide ranges of simulated distributions of outcomes (Ibid.). The system has been designed and maintained by the agency (presumably with input from outside parties, contractors and other stakeholders via various direct interactions with the model as well as via technical reviews such as this one) to give an understanding of how pension plans insured by the PBGC behave under various shocks to internal and external parameters (which characterize economic and other conditions), including being able "accurately [to] portray underfunding among the insured universe under a wide variety of economic conditions" as long as the assumptions, constraints and reflections of pension plan and governing rule data are accurate. Of course, modeling decisions about granularity of the system components and data used and measured must have been made, and the system cannot be possibly expected to capture all possible relevant inputs or reflect all possible scenarios.

The system accommodates inputs from a subsample of large insured pensions including actuarial inputs such as current plan demographics and benefit formulas, data on the financial condition of sponsors, fund portfolio compositions and the PBGC's own financial position. We

\footnotetext{
1 “Pension Insurance Modeling System: PIMS System Description,” Version 1.0, Revision 9/22/2010.
} 
understand that, typically, PIMS simulations (say 5,000 or 10,000 in number of draws over different economic scenarios) are used, say, to project 10 years of future economic events in the financial markets (Overview 2011). First, interest rates, stock returns, and related variables (e.g., inflation, wage growth, and multiplier increases in flat-dollar plans) are drawn according to the stochastic equations listed in Table 1 . In the model, it appears that the 30-year Treasury bond is presumed to follow a random walk while corporate bond yields, which are viewed as highly correlated over time, are mean reverting to historical estimates of their spread over Treasury yields of comparable maturity. Real rates are assumed to be a constant level (e.g., 1.64 percent), and inflation is calculated as the as the spread between nominal and real rates. The term structure of interest rates does not directly enter into the equations, per se (Overview 2011).

Returns on equities seem to be modeled as mean reverting to a long run average value estimated from historical data (e.g., 10.4 percent plus noise according to one historical document, or 8.6 percent or 8.2 percent according to other documents) using data ranging from 1926, which is when the famous Stock, Bonds, Bills and Inflation (SBBI) data from Ibbotson begin (PBGC FY 2012 Exposure Report, hereafter referred to as Exposure Report). Innovations are drawn IID over time, presumably from a calibrated multivariate Gaussian distribution. Correlations between stock returns and bond yields appear strictly to be based on historical estimates from the time period 1973-2007 (Exposure Report), with the implication being that of contemporaneous negative correlation between stock returns and bond yields (also as shown in the 2012 Exposure Report, the model assumes a positive correlation between Treasury Bond returns and stocks). Plan asset returns are determined by a two factor model that combines stock return premia over nominal rates and bond premia, both adjusted for sensitivies to these premia via estimates of beta a la a two factor market model, against which plan asset returns are regressed. Note that in a one 
factor case, this model might be thought of as the time series estimation equation made famous by the Capital Asset Pricing Model of Sharpe (1964). It is important to note that the PBGC has indicated that it has Form 5500 data on reported plan asset allocations, which it incorporates. My comments below on the changing nature of plan allocations must be conditioned with this information. Historically, asset mixes of plan portfolios have assumed roughly to be a 60 percent allocation to equities and 40 percent allocation to bonds (Buck Consultants 2012) or "a weighting based on the average of the estimated rate mixtures: 48 percent stock market returns, 23 percent long-term Treasury bond returns, 30 percent long-term Treasury bond yield and a -2.5 basis points additive adjustment." (Exposure Report: 17) With the inclusion of actual Form 5500 data, the model can incorporate important potential diversification characteristics as outlined below. However, modeling the increased span of risks introduced in this manner also may require more sophisticated models than the two factor model described above.

Simulations of the model first appear to presume that sponsors make the minimum statutory contributions implied by the tax code. If a sponsor goes bankrupt in the simulation, it does not contribute from the previous year. The PBGC adjusts premia based on sponsor historical choices to fund plans above the minimum in avoidance of higher premiums. PIMS simulations allow plan participants to retire, leave the firm and to die according to actuarial data and assumptions. Benefits and salaries for a given age and service time grow with inflation plus a productivity factor (Overview 2011 and see Table 1).

As mentioned above, sponsor health is measured by equity-to-debt ratios, cash flows, firm equity, and employment levels. Here, equity-to-debt and cash flow ratios are mean-reverting to long run historical averages. Employment and firm equity are essentially modeled as correlated random walks. Innovations in the equations for sponsors appearing in Table 1 are 
assumed to be correlated to one another and to innovations in financial market returns, with correlations estimated from history. Finally, bankruptcy is modeled as a random function with parameters estimated by historical bankruptcies and data on the health of companies over the period 1980 to 1998 (Exposure Report). These data are not industry-specific. If a firm goes bankrupt at the same time a plan is less than $80 \%$ funded, the plan represents a loss and is included in average loss calculations across simulations and scenarios (Exposure Report). Formerly, the model incorporated parameter uncertainty by including estimations as part of the simulation procedures by estimating certain parameters within simulation iterations. Currently parameter uncertainty is no longer accounted for.

Table 1 here

\section{PIMS Capital Market Assumptions vs. the Assumptions of Others}

Table 2 outlines the baseline capital market expectations used/produced by the PIMS system. It also provides a listing of the capital market assumptions recently compiled by Horizon Actuarial Services, LLC in its annual survey of seventeen large multi-employer consultancies². While the assumptions utilized by plans insured by the PBGC themselves are not available (at least to me), and the use of third party capital market assumptions is fraught with its own

${ }^{2}$ Consultancies included are Callan Associates, CAPTRUST Financial Advisors, A.J. Gallagher / Independent Fiduciary Services, Hewitt EnnissKnupp, Investment Performance Services, LLC, R.V. Kuhns \& Associates, Marco Consulting Group, Marquette Associates, Meketa Investment Group, J.P. Morgan, Morgan Stanley/Graystone Consulting, NEPC, Pension Consulting Alliance, The PFM Group, SEI Towers Watson and Wurts \& Associates. 
problems, not the least of which is the prima facie problem that that the respondents are service providers to plan sponsors and are paid by them, they serve to raise several important issues for consideration. In addition, it is reasonable to assume that when these advisors, as likely fiduciaries under both the Advisors Act of 1940 and under ERISA, provide their expectations which likely serve as a base for sponsor assumptions, these consultancies are required to provide their advice in an un-conflicted manner as required under the law, and these consultancies advise both single-employer and multi-employer plans in their fiduciary advisory capacities. Also, they use a wide variety of models that are forward looking as well as historical data.

\section{Table 2 here}

The results in Table 2, Panel A indicate a substantial discrepancy between the expected returns used in the PIMS system (where we note that we have multiple sources describing the PIMS assumptions) $)^{3}$ and large consultancies who either serve or a like those that serve the plans insured by the PBGC. Part of the discrepancy surely arises directly from the fact that consultancies have different approaches to assessing future capital market investment performance. Apparently, some use forward-oriented models such as a form of the dividend discount model for equity returns (for example, possibly accumulating some measure of earnings growth, earnings yield or dividend yield, and expected return from multiples expansion as well as inflation expectations). Certainly some use historical data or at least calibrate their models based on historical data. Such forward-looking models might allow initial conditions important

\footnotetext{
${ }^{3}$ Here we use those model simulation averages reported in the PBGC FY 2012 Exposure Report (2012). However, we also note that the expected returns reported in the Buck Consultants third party review very closely resemble those appearing in Table 2.
} 
for the accommodation and inclusion time-varying expected returns, critical for the calculation of funding ratios and for many conceivable outputs of the model to be incorporated.

Also, while information is sparse on how all 17 consultancies compute their forecasts, the importance of this discrepancy is that if plan sponsors base their allocations on them, and, as a result, their allocations and the implications that the portfolios allocations reported via Form 5500 are potentially more complex that what the two factor model for plan assets may suggest. Also, the mere fact that reasonable analysts can rely on different models for asset returns at least raises the chalice of testing of robustness by the PBGC with respect to its own assumptions regarding its two factor model.

As we show in Section 5 below, evidence that corporate plans allocate much differently than presumed by the PBGC seems undeniable. They allocate to more asset classes that are represented in the U.S. stock/bond two-factor model assumption, and some of those allocations are to classes of assets that are highly likely to be exposed to risks simply outside the risks of U.S. domestic stocks and bonds. Thus, as apparent in the unconditional expected returns, risks and correlations assumptions presented in Table 2, higher volatilities for foreign classes and classes outside the narrow confines of the PIMS assumption would likely result in higher volatilities and more extreme outcomes, were the alterative presumptions to be more accurate. Moreover, since the volatility attribution implied by the stock/bond assumption clearly indicates that this asset allocation, which has arisen historically in the financial industry (and academic literature ${ }^{4}$ ) as components in the so-called "balanced" portfolio, is in fact not at all balanced. Its risk is heavily dominated by the risk of the equity component of the assumption. All this said, we hasten to add that the assumptions of the average consultant may not accurately reflect the

\footnotetext{
${ }^{4}$ See for example, Brinson, Hood and Beebower (1986).
} 
forecasts of reasonable models. In Section 4 below, we turn to models that, in a forward looking way, calibrate market expectations.

\section{PIMS Capital Market Assumptions and the Stochastic Character of Asset Prices}

Since no later than the work of Mandelbrot, Fama and others, the non-Gaussian character of asset prices has been a topic of intense study in academia and industry. The gist of that body of research and practice suggests that asset returns are have greater extremes than presumed by the type of stochastic assumption embedded in the PIMS system. In addition, at least one source of that heavy-tailed character is the time-varying nature and auto-correlated nature of first and higher moments. The PIMS model assumptions on one hand incorporate a form of this autocorrelation (e.g., the well-known autocorrelation of bond yields). On the other hand, they appear to ignore the time-varying nature of volatility in the short and long runs.

There are numerous ways to illustrate this critical point. The approach we take here is first to illustrate basic levels of predictability in asset returns. We do this graphically (Figure 1, Panels A and B), although much research has demonstrated how both reduced form and more structural approaches may be estimated econometrically. ${ }^{5}$ We then make the point that volatility is time-varying using implied volatilities in the form of the VIX (Figure 2), ex post realized volatilities over the long run (Figure 3, Panels A and B), demonstrating the strongly different implications for the assumption of time-varying volatility for outcomes with a greater frequency of extremes in simulations.

Figures 1-3 here

\footnotetext{
${ }^{5}$ Although we hasten to add that some researchers like Welch (2008) indicate that much of the predictability documented in the academic finance literature arises due to data mining.
} 
Since PBGC insurance both conceptually and as modeled in PIMS is expected to pay at times when plans are underfunded and sponsors are in distress, having a more accurate representation of equity market extremes seems quite important. Moreover, the diversification benefits normally attributed to asset allocation varies with time and with market volatility. We show below - again, graphically (Figures 4 and 5) - how the correlation between stocks and bonds varies across both business and volatility cycles.

\section{Figures 4 and 5 here}

To illustrate the first point, Figure 1, Panel A relates starting 5-year Treasury yields (same axes) to future annualized returns on Treasuries from January 1955-January 2013, and Figure 1, Panel B relates the current dividend yield on U.S. Large Cap stocks (reflected most recently in the S\&P 500) over the period January 1871 - January 2013. Both graphs make two strong points, ones that the academic literature has spent considerable effort in understanding over approximately the last three decades. First, the graphs imply that it is impossible to assert that either equity returns are simply random walks with IID innovations or that bond returns are simply mean reverting with IID innovations. Also, since the entire term structure of interest rates clearly is important for model outcomes across the future time span of simulations, it might be highly useful to incorporate, factor models for the term structure. Second, the investment opportunity set is highly time-varying and correlates strongly with simple instruments (for instance, the period correlation between $\mathrm{d} / \mathrm{p}$ and subsequent 7-year return in Figure 1, Panel B is just under 70 percent). Especially since insurance claims are a strong function of these two forcing variables in the PIMS system and since they track economic conditions, it may be useful to incorporate this notion into the assumptions of the model. 
Another feature of real-world data that today does not appear to be as controversial as it was when first introduced is the property of asset returns to have fat tails, highly autocorrelated conditional volatilities and time-varying implied volatilities that reflect the pricing of systematic risk. Again, there may be innumerable ways to make this point, and one guesses that there may be thousands of academic and practitioner papers and dissertations written on the topic, but we again here take a graphical approach (later we build a simulation model that accommodates timevarying volatility). Figure 2 presents the Chicago Board of Options Exchange VIX index over the period January 2007 - December 2012 (CBOE 2013), and Figure 3, Panel A presents ex post realized volatility estimated over 18-month rolling windows. Both graphs tell a similar story of time-varying volatility with that variation corresponding to business and market cycles over a recent period of market disruption and, in fact, in the very long run (at least by U.S. standards). Moreover, 99 percent of positive daily changes in the VIX index correlate with negative S\&P 500 index returns. That is, equity values are negatively correlated with increases in volatility. Finally, over the long run, cycles like those apparent in the recent financial crisis are reflected in realized volatility. Again, while sophisticated modeling assumptions and technologies capturing this effect may take many different forms, the graphs point out clearly that the modeling assumptions of the PIMS system may usefully incorporate conditional heteroskedasticity in asset returns, or at least for equity returns, likely the most important source of systematic variability in plan and in fact corporate solvency, on average.

To illustrate this point, Figure 3, Panel B incorporates our understanding of the PIMS equity return assumptions from Table 1 in modeling simulated returns that are either random walks like those from the PIMS model (which we label "IID") or a calibrated random walk (cleverly labeled "Calibrated") using in-sample estimates of the period represented by each point 
on the graph for actual returns. Apparent in this graph is that the actual spikes in volatility arising in the real world are not reflected in the IID approach of the PIMS model estimated based on long-run, constant variance assumptions. Moreover, while local calibration helps over the rolling horizons of the model (and it should, as it benefits from perfect hindsight!), it is not able to match the observed spikes in volatility in the historical record. The implication of these figures is that, again, because volatility is so strongly inversely correlated with bad outcomes for asset valuations, in our view a model of insurance may fruitfully incorporate these effects.

Unfortunately, it turns out that spikes in volatility due, in our view, both to characteristics of asset returns themselves and possibly to ancillary effects (like runs on liquidity that arise during financial crises and times of systemic stress, which have happened so commonly throughout modern human history (e.g., see Kindleberger and Aliber 2012)). One way among many to understand this effect is to think simply how components of classes of assets like those to which insured plans have exposure relate in their variations to the classes as a whole. Consider, for example, the traditional portfolio theoretic measure, $\mathrm{R}^{2}$. The fundamental definition of $\mathrm{R}^{2}$ for an asset in an investment context is as the ratio of its systematic (e.g., market) risk to its total risk which is the sum of systematic and idiosyncratic, non-market risk. The previous figures indicate that the numerator and the first part of the denominator, systematic or market risk, change over time and with widespread pricing of equity risk, and, at times, spike. Unless idiosyncratic risk compensates for changes in systematic risk, $\mathrm{R}^{2}$ s may vary as well. Moreover, formulaically, $\mathrm{R}^{2}$ is defined as the square of correlation between the asset and the asset class being modeled. That is, just when the diversification power of lower-than-higher correlations are most important, they may be fleeting. Altogether, this indicates that just when assumptions about constant correlations may be important, they may actually go up. This effect 
may be especially important to the PBGC because sponsor contributions are functions of financial distress of sponsor firms, which is likely correlated with shocks common to equities. Even more, PBGC assets may themselves be subject to this behavior, making claims (and other difficult outcomes) and their backstop move more negatively in bad times. To illustrate this point, Figure 4 plots the implied correlations of the S\&P 500 components via the term structure of the CBOE S\&P 500 implied correlation indexes, ${ }^{6} \mathrm{JCJ}, \mathrm{KCJ}$ and ICJ, over time, in which it is notable that correlations implied by options prices are both time-varying and correlated with volatility spikes in the previous graphs. Finally, Figure 5, Panels A and B plot rolling realized correlations between and index of U.S. large cap stocks (represented most recently by the S\&P 500) with 20-year Treasury returns, without and with $95 \%$ confidence intervals. While the PIMS model assumptions presume a fairly strong negative correlation between stock and bond yields, and a positive correlation between stock and Treasury Bond returns, it is clear at least from the perspective of Figure 5, this last presumption may be appropriate only at certain times. It may be useful to note that the times of particularly negative observed correlations in Figure 5 often arise over estimation periods covering intervals of market distress, perhaps making the PIMS stock/bond return correlation assumption a bit removed from market experience. Again, more generally, it may be beneficial for the PIMS system to incorporate time-varying second moments in a multivariate context for asset returns, particularly if, as discussed in Section 5, the system would be moving toward consideration of more asset classes than just the components of the stock/bond portfolio in the modeling of plan allocations.

\footnotetext{
${ }^{6}$ See http://www.cboe.com/micro/impliedcorrelation/.
} 


\section{PIMS and Models for Capital Market Expectations}

As the treatment in Section 2 above highlights, there exist strong differences between the capital market assumptions for the simple asset classes of the PIMS model and the assumptions of large consultancies assumed to be providing investment advice to the sponsors of insured plans. To assess further the PIMS assumptions about equities, we estimate two additional models for future asset returns, focusing on equity returns: The dividend discount model and a model based upon dividend yield as an instrument which accommodates the time-varying nature of expected returns in the academic and practitioner literature. With respect to future expected returns on bonds, the evidence in Figures $1 \mathrm{a}$ and $1 \mathrm{~b}$ relating yields to future returns over time indicates that, based on the assumption of current yields being unbiased predictors of future returns (an assailable presumption, but a reasonable one here as long as residual correlations are maintained), future bond returns might actually be quite a bit lower than presumed by the PIMS systems, based upon our assessment. While this indication is not a direct comment about the modeling character of the system, it points out a difference that arises based upon modeling choices of the system.

\section{Asset and Risk-Based Allocations of Pension Plans and Their Implications}

In this section we demonstrate that the asset allocation of the PIMS system, which in a sense presumes a domestic stock/bond split, does not comport with the allocation of many plans today or with trends in plan allocations and, thus, may not reflect the actual risk of plans on average. The risks of those plans differ substantially from that of the so-called "balanced" approach of the famous 60/40 allocation, which is in the PIMS model essentially a U.S.-based model, based on its two factor model assumption. First, Table 3 provides allocations across a 
fairly highly aggregated depiction of asset classes from various sources in the PIMS documentation set as well as for U.S. corporate plans, U.S. public plans and a sample of U.S. defined benefit plans (the largest 100 corporate plans in 2012), according to Pensions \& Investments Research (2013). The column labeled PIMS Model refers to the allocations reported to me assumed in the Exposure Report, and the columns labeled Single Employer Funds/Plans represent a summary and subjective aggregation of the allocations reported in the PBGC Annual Report for 2012. The columns labeled as corporate and public plans are also those that appear for 2011 in Figure 6, Panels A-C from the P\&I annual plan surveys.

\section{Table 3 here}

Table 3 indicates that the U.S. stock/bond assumption of the two factor PIMS assumption for plan assets quite different from plan allocations across the board which recently have lower levels of equity allocations than the assumption of PIMS. In addition, the allocations observed for plans in the real world are more diversified into alternatives. Moreover, as indicated above, the PIMS model assumptions are calibrated to U.S. data, again an assumption which does not match reality, although due to the aggregations in Table 3, those subtleties are averaged away. The bottom line is that pension plans insured by the PBGC have potentially drastically different allocations (implying vastly different effective capital market assumptions) than the PIMS system contemplates, either on a dollar basis or on a "risk allocation" or variance contribution basis (see Table 4). In addition, with the inclusion of increasing allocations to alternative investments (see Figure 6, Panel C, for instance), PBGC insured plans are taking on risks not even contemplated by the PIMS model. It is useful to note that in one sense, the over-allocation in the model assumptions to equity risks may actually be conservative if less accurate than matching observed allocations reported by plans on Form 5500 might be. Domestic equity risk 
dominates the risk allocation of the 60/40 allocation historically and in the capital market assumptions-based Table 3. More diversified plans may in fact have fewer incidences of underfunding as a result if those alternative allocations do indeed end up providing diversification benefits on average and at times of general market distress.

Table 4 and Figure 6 here

\section{Conclusions and Recommendations}

The financial market assumptions of the PIMS system, which is itself apparently a highly sophisticated, thoughtfully constructed and quite useful simulation tool for the PBGC, are nonetheless ones upon which it is possible to improve. While here it is impossible - without running the system itself with suggested changes beyond those illustrated above - to confirm how useful suggestions provided here might prove to be, the issues we point out arise directly from characteristics of the real-world investment environment. The time-varying nature of asset returns described here and the associated potential liabilities of ignoring their characteristics may be especially pronounced in the short put setting of an insurer of pension plans. With the heavytailed behavior of markets that extends the likelihood of extreme events being outside the PIMS assumptions, and with those extreme events connected to the time-varying nature of higher moments of asset returns, we believe it is important to consider both as part of the innovation path of the model as it continues to live and breathe. In addition, because not only risks and rewards change over time in markets but also because the allocations of plan portfolios can and have changed over time in a manner that sees them admitting risks not necessarily related to the stock and bond risk of the model, it is potentially quite important for the model to reflect those changes in its assumptions. That said, the heavy equity allocation of the model may have an 
upside in that equity risk, while it has enjoyed a high reward to risk ratio (in the U.S. at least), is a strong contributor to overall plan volatility. In other words, there is one sense in which it might be viewed as conservative with respect to extremes of plan performance that might not otherwise have been diversified away. Nonetheless, the use of long-run historical data from the United States, without consideration of the upward bias that the U.S. equity experience represents, may be adding an unintended layer of risk important for the agency. 


\section{Table 1 PIMS Equations}

\begin{tabular}{|c|c|c|}
\hline \multicolumn{3}{|c|}{ Table 2-1: System Summary } \\
\hline \multirow{8}{*}{$\begin{array}{l}\text { Stochastic } \\
\text { Equations }\end{array}$} & nominal interest & $\Delta \ln \left(\mathrm{i}_{\mathrm{t}}\right)=\alpha_{\mathrm{i}}+\beta_{\mathrm{i}} \Delta \ln \left(\mathrm{i}_{\mathrm{t}-1}\right)+\varepsilon_{\mathrm{i}, \mathrm{t}}$ \\
\hline & real stock return & $\ln \left(1+\mathrm{s}_{\mathrm{t}}\right)=\alpha_{\mathrm{s}}+\beta_{\mathrm{s}} * \ln \left(1+\mathrm{s}_{\mathrm{t}-1}\right)+\varepsilon_{\mathrm{s}, \mathrm{t}}$ \\
\hline & equity-to-debt & $\ln \left(E D_{t}\right)=\alpha_{E D}+\beta_{E D} \ln \left(E D_{t-1}\right)+\gamma_{E D} F+\varepsilon_{E D, t}$ \\
\hline & Employment & $\Delta \ln \left(\mathrm{N}_{\mathrm{t}}\right)=\alpha_{\mathrm{N}}+\beta_{\mathrm{N}} \Delta \ln \left(\mathrm{N}_{\mathrm{t}-1}\right)+\varepsilon_{\mathrm{N}, \mathrm{t}}$ \\
\hline & cash flow-to-assets & $\left(\mathrm{CFA}_{\mathrm{t}}\right)=\alpha_{\mathrm{CFA}}+\beta_{\mathrm{CFA}}\left(\mathrm{CFA}_{\mathrm{t}-1}\right)+\gamma_{\mathrm{CFA}} \mathrm{F}+\varepsilon_{\mathrm{CFA}, \mathrm{t}}$ \\
\hline & firm equity & $\Delta \ln \left(\mathrm{E}_{\mathrm{t}}\right)=\alpha_{\mathrm{E}}+\beta_{\mathrm{E}} \Delta \ln \left(\mathrm{E}_{\mathrm{t}-1}\right)+\varepsilon_{\mathrm{E}, \mathrm{t}}$ \\
\hline & bankruptcy probability & $\mathrm{p}_{\mathrm{t}}=\mathrm{e}^{\mathrm{X} \beta} /\left(1+\mathrm{e}^{\mathrm{X} \beta}\right)$ \\
\hline & plan asset return & $\mathrm{ER}_{\mathrm{t}}=\alpha+\beta_{\mathrm{S}}\left(\mathrm{s}_{\mathrm{t}} *-\mathrm{i}_{\mathrm{t}}\right)+\beta_{\mathrm{B}}\left(\mathrm{R}_{\mathrm{Bt}}-\mathrm{i}_{\mathrm{t}}\right)+\varepsilon_{\mathrm{t}}$ \\
\hline \multirow{5}{*}{$\begin{array}{l}\text { Deterministic } \\
\text { Equations }\end{array}$} & Inflation & $\left(1+\rho_{\mathrm{t}}\right)=\left(1+\mathrm{i}_{\mathrm{t}}\right) /(1+\mathrm{r})$ \\
\hline & real interest & $\mathrm{r}=$ user input $(\sim 1.64 \%)$ \\
\hline & $\begin{array}{l}\text { nominal benefit (wage) } \\
\text { growth }\end{array}$ & $\left(1+\mathrm{w}_{\mathrm{t}}\right)=\left(1+\rho_{\mathrm{t}}\right)(1+\mathrm{pd})$ \\
\hline & productivity growth & $\mathrm{pd}=$ user input $(1.07 \%)$ \\
\hline & bankruptcy recovery & $\mathrm{R}_{\mathrm{t}}=\mathrm{U}_{\mathrm{t}} *$ Recovery Percent $(\sim 5 \%)$ \\
\hline
\end{tabular}

Source: "Pension Insurance Modeling System: PIMS System Description," Version 1.0, Revision 9/22/2010. 
Table 2 Capital Market Expected Returns and Volatilities: PIMS vs. Others

Asset Class

\begin{tabular}{|l|}
\hline Horizon CME's \\
\hline US Equity - Large Cap \\
US Equity - Small/Mid Cap \\
Non-US Equity - Developed \\
Non-US Equity - Emerging \\
\hline US Fixed Income - Investment \\
US Fixed Income - High Yield \\
Non-US Fixed Income - Developed \\
Non-US Fixed Income - Emerging \\
\hline Treasuries (Cash Equivalents) \\
TIPS (Inflation-Protected) \\
Real Estate \\
Hedge Funds \\
Commodities \\
Infrastructure \\
Private Equity
\end{tabular}

PIMS System

\begin{tabular}{|cc|}
\hline \multicolumn{1}{|c|}{$E[R]$} & StdDev \\
\hline $5.40 \%$ & $10.30 \%$ \\
\hline $8.20 \%$ & $20.60 \%$ \\
& \\
& \\
& \\
& \\
& \\
& \\
& \\
& \\
& \\
& \\
\end{tabular}

\section{Horizon \\ Horizon}

\begin{tabular}{|c|c|c|c|}
\hline$E[R]$ & StdDev & Avg Return & StdDev \\
\hline $7.31 \%$ & $11.04 \%$ & - & - \\
\hline $9.37 \%$ & $18.23 \%$ & $11.67 \%$ & $18.75 \%$ \\
\hline $10.54 \%$ & $23.01 \%$ & $13.12 \%$ & $19.89 \%$ \\
\hline $9.89 \%$ & $20.41 \%$ & $10.27 \%$ & $17.26 \%$ \\
\hline $12.61 \%$ & $28.27 \%$ & $14.64 \%$ & $24.15 \%$ \\
\hline $4.13 \%$ & $5.89 \%$ & $6.20 \%$ & $6.73 \%$ \\
\hline $7.37 \%$ & $12.28 \%$ & $6.05 \%$ & $10.54 \%$ \\
\hline $3.77 \%$ & $7.28 \%$ & $7.42 \%$ & $7.69 \%$ \\
\hline $7.23 \%$ & $13.21 \%$ & $10.55 \%$ & $12.72 \%$ \\
\hline $2.77 \%$ & $1.89 \%$ & $3.31 \%$ & $0.65 \%$ \\
\hline $3.49 \%$ & $6.01 \%$ & $6.89 \%$ & $5.76 \%$ \\
\hline $7.56 \%$ & $11.73 \%$ & $4.18 \%$ & $21.92 \%$ \\
\hline $7.25 \%$ & $9.00 \%$ & $7.29 \%$ & $5.80 \%$ \\
\hline $7.29 \%$ & $18.72 \%$ & $5.72 \%$ & $14.97 \%$ \\
\hline $8.29 \%$ & $13.78 \%$ & $10.25 \%$ & $12.90 \%$ \\
\hline $12.90 \%$ & $25.14 \%$ & $12.42 \%$ & $22.30 \%$ \\
\hline
\end{tabular}

Source: Author's calculations. 


\section{Table 3 Capital Market Expected Correlations: PIMS vs. Horizon}

Asset Class
\begin{tabular}{|l|l|l|l|}
\hline Long-Term Treasury Yield & & & \\
\hline $\begin{array}{l}\text { Return on 30-yr Treasury Bond } \\
\text { Equity }\end{array}$ & -0.29 & 1.00 & \\
\cline { 2 - 5 } & -0.11 & 0.23 & 1.00 \\
\hline
\end{tabular}

\begin{tabular}{|c|c|c|c|c|c|c|c|c|c|c|c|c|c|c|c|}
\hline Asset Class & 1 & 2 & 3 & 4 & 5 & 6 & 7 & 8 & 9 & 10 & 11 & 12 & 13 & 14 & 15 \\
\hline US Equity - Large Cap & 1.00 & 0.86 & 0.80 & 0.68 & 0.19 & 0.62 & 0.07 & 0.51 & 0.03 & 0.02 & 0.33 & 0.58 & 0.25 & 0.55 & 0.76 \\
\hline US Equity - Small/Mid Cap & 0.86 & 1.00 & 0.71 & 0.66 & 0.11 & 0.59 & 0.02 & 0.48 & 0.00 & -0.02 & 0.23 & 0.55 & 0.23 & 0.50 & 0.71 \\
\hline Non-US Equity - Developed & 0.80 & 0.71 & 1.00 & 0.72 & 0.13 & 0.55 & 0.25 & 0.45 & 0.00 & 0.04 & 0.29 & 0.58 & 0.32 & 0.55 & 0.67 \\
\hline Non-US Equity - Emerging & 0.68 & 0.66 & 0.72 & 1.00 & 0.05 & 0.54 & 0.10 & 0.59 & -0.02 & 0.06 & 0.23 & 0.58 & 0.36 & 0.54 & 0.59 \\
\hline US Fixed Income - Investment & 0.19 & 0.11 & 0.13 & 0.05 & 1.00 & 0.34 & 0.49 & 0.44 & 0.23 & 0.65 & 0.05 & 0.15 & 0.06 & 0.19 & 0.04 \\
\hline US Fixed Income - High Yield & 0.62 & 0.59 & 0.55 & 0.54 & 0.34 & 1.00 & 0.16 & 0.61 & 0.00 & 0.22 & 0.22 & 0.47 & 0.24 & 0.52 & 0.52 \\
\hline Non-US Fixed Income - Developed & 0.07 & 0.02 & 0.25 & 0.10 & 0.49 & 0.16 & 1.00 & 0.26 & 0.12 & 0.43 & -0.04 & 0.11 & 0.13 & 0.32 & -0.01 \\
\hline Non-US Fixed Income - Emerging & 0.51 & 0.48 & 0.45 & 0.59 & 0.44 & 0.61 & 0.26 & 1.00 & 0.05 & 0.28 & 0.05 & 0.46 & 0.27 & 0.42 & 0.39 \\
\hline Treasuries (Cash Equivalents) & 0.03 & 0.00 & 0.00 & -0.02 & 0.23 & 0.00 & 0.12 & 0.05 & 1.00 & 0.16 & 0.13 & 0.11 & 0.04 & 0.05 & 0.04 \\
\hline TIPS (Inflation-Protected) & 0.02 & -0.02 & 0.04 & 0.06 & 0.65 & 0.22 & 0.43 & 0.28 & 0.16 & 1.00 & 0.06 & 0.15 & 0.28 & 0.22 & -0.04 \\
\hline Real Estate & 0.33 & 0.23 & 0.29 & 0.23 & 0.05 & 0.22 & -0.04 & 0.05 & 0.13 & 0.06 & 1.00 & 0.23 & 0.26 & 0.35 & 0.38 \\
\hline Hedge Funds & 0.58 & 0.55 & 0.58 & 0.58 & 0.15 & 0.47 & 0.11 & 0.46 & 0.11 & 0.15 & 0.23 & 1.00 & 0.37 & 0.48 & 0.52 \\
\hline Commodities & 0.25 & 0.23 & 0.32 & 0.36 & 0.06 & 0.24 & 0.13 & 0.27 & 0.04 & 0.28 & 0.26 & 0.37 & 1.00 & 0.37 & 0.26 \\
\hline Infrastructure & 0.55 & 0.50 & 0.55 & 0.54 & 0.19 & 0.52 & 0.32 & 0.42 & 0.05 & 0.22 & 0.35 & 0.48 & 0.37 & 1.00 & 0.50 \\
\hline Private Equity & 0.76 & 0.71 & 0.67 & 0.59 & 0.04 & 0.52 & -0.01 & 0.39 & 0.04 & -0.04 & 0.38 & 0.52 & 0.26 & 0.50 & 1.00 \\
\hline
\end{tabular}

Source: Author's calculations. 
Table 4 Asset Allocations and Risk (Variance Contribution) Allocations Assumed by PIMS and Selections of Pension Plans

\begin{tabular}{|l|c|c|c|c|c|c|c|c|c|c|c|c|}
\hline & \multicolumn{2}{|c|}{$60 / 40$ Portfolio } & \multicolumn{2}{|c|}{ PIMS Model } & \multicolumn{2}{c|}{$\begin{array}{c}\text { Single Employer Funds/Plans } \\
\text { US Corporate Pension Funds }\end{array}$} & \multicolumn{2}{c|}{ US Public Pension Funds } & \multicolumn{2}{c|}{ US Defined Benefit Plans } \\
& Asset Allocation & Risk Allocation & Asset Allocation & Risk Allocation & Asset Allocation & Risk Allocation & Asset Allocation & Risk Allocation & Asset Allocation & Risk Allocation & Asset Allocation & Risk Allocation \\
\hline
\end{tabular}

Source: Author's calculations. 


\section{Figure 1}

Panel A. Treasury yields as predictors of future returns.

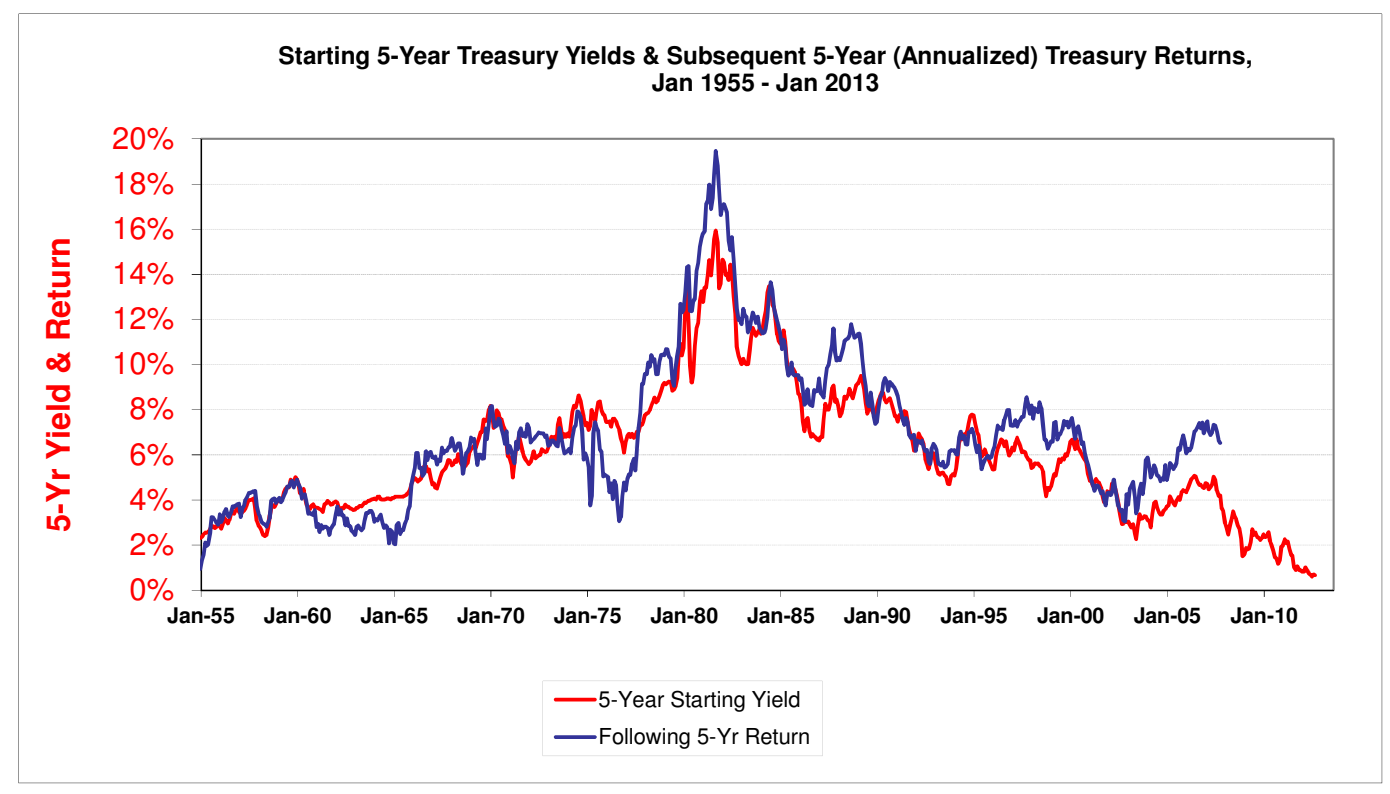

Source: Federal Reserve, Ibbotson Associates

Panel B. Dividend yields as predictors of future returns.

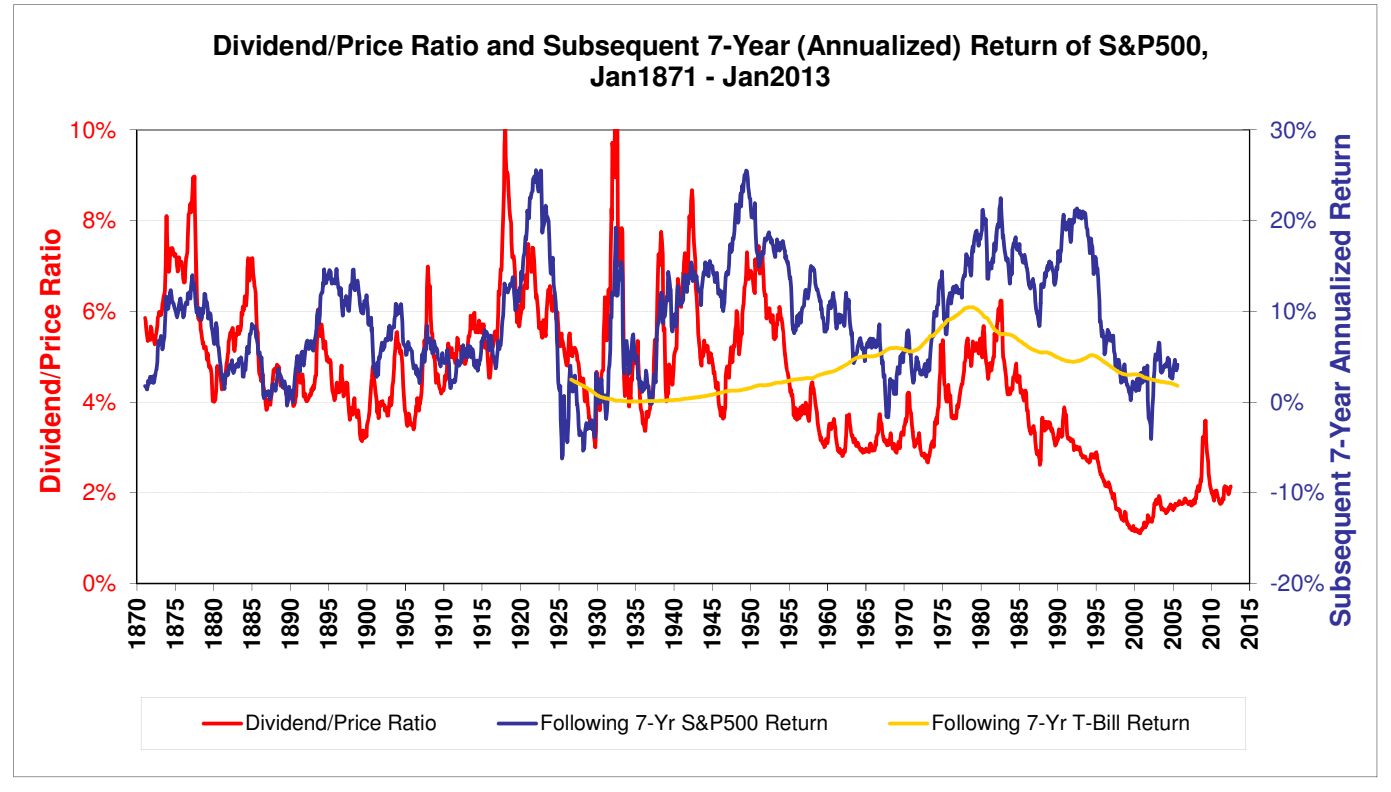

Source: Shiller (2013). 


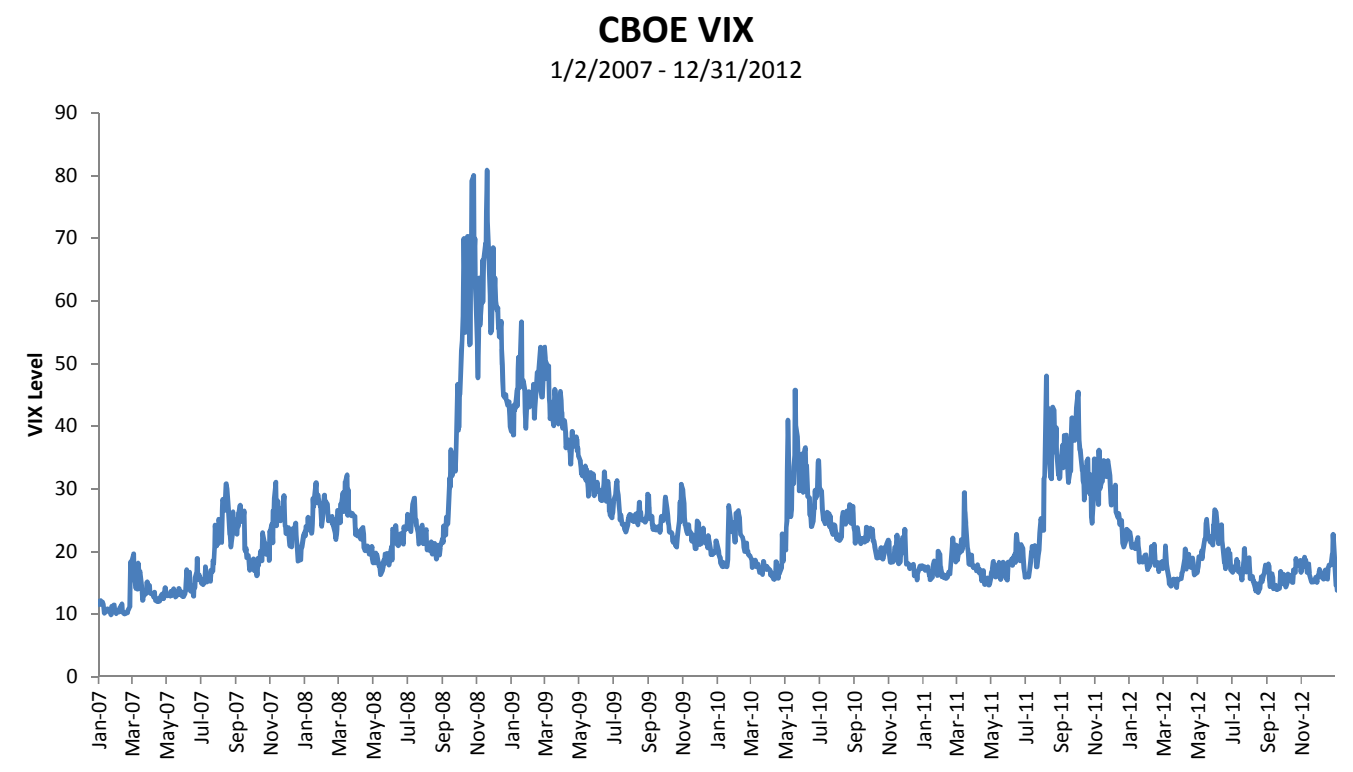

Figure 2. Implied S\&P 500 volatility (VIX). Source: CBOE (2013). 


\section{Figure 3.}

Panel A. Realized large U.S. firm market capitalization stock index return volatility.

\section{Annualized Standard Deviation of Monthly S\&P 500* Returns}

(18-Month Rolling)

$1802-2012$

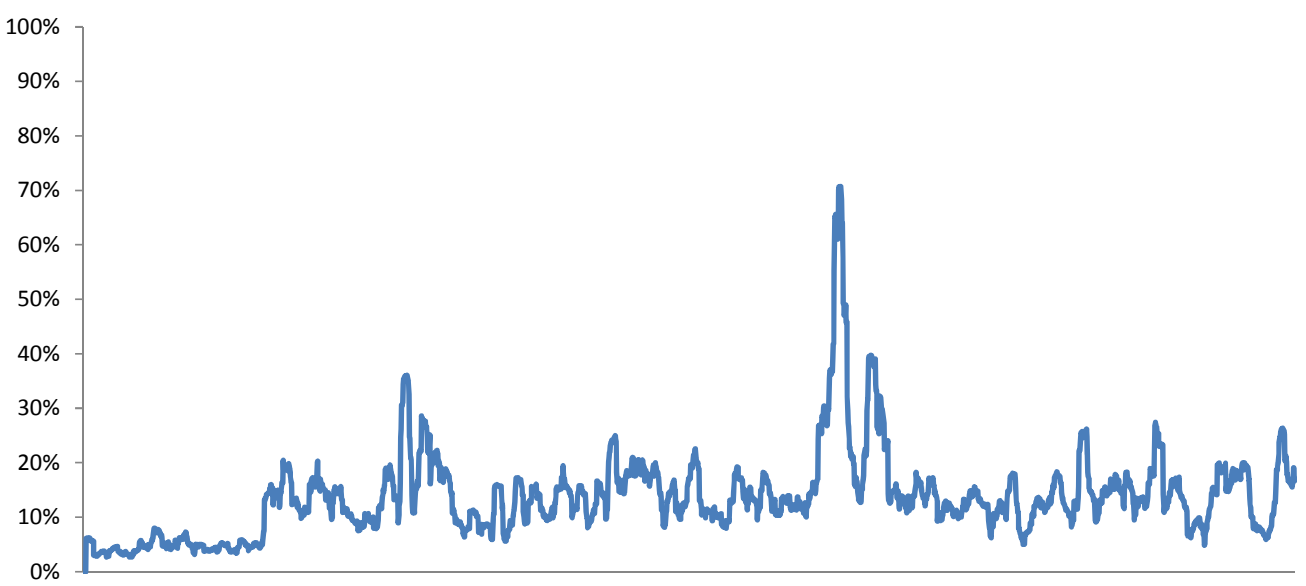

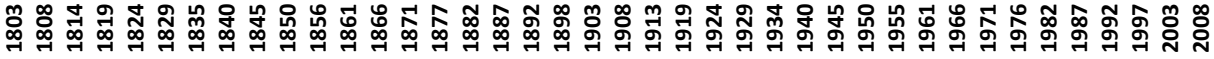

* Geczy \& Samanov (2012)

Panel B. Implications of PIMS model assumptions vs. realized large U.S. firm market capitalization stock index return volatility.

\section{Rolling 18-Month Annualized Volatility}

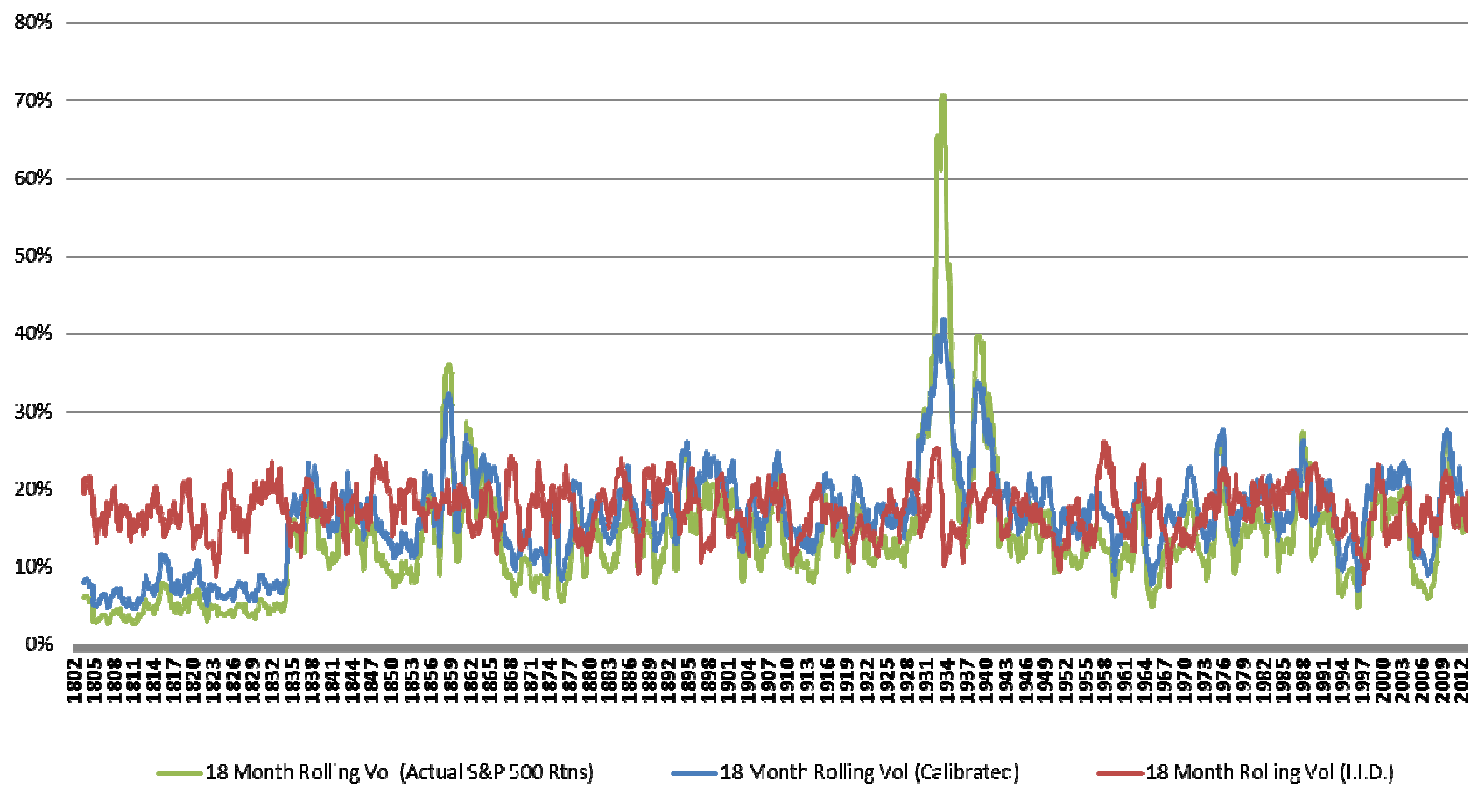

Source: Author's calculations. 


\section{CBOE S\&P 500 Implied Correlation Index}

January 3, 2007 - Dec 31, 2012

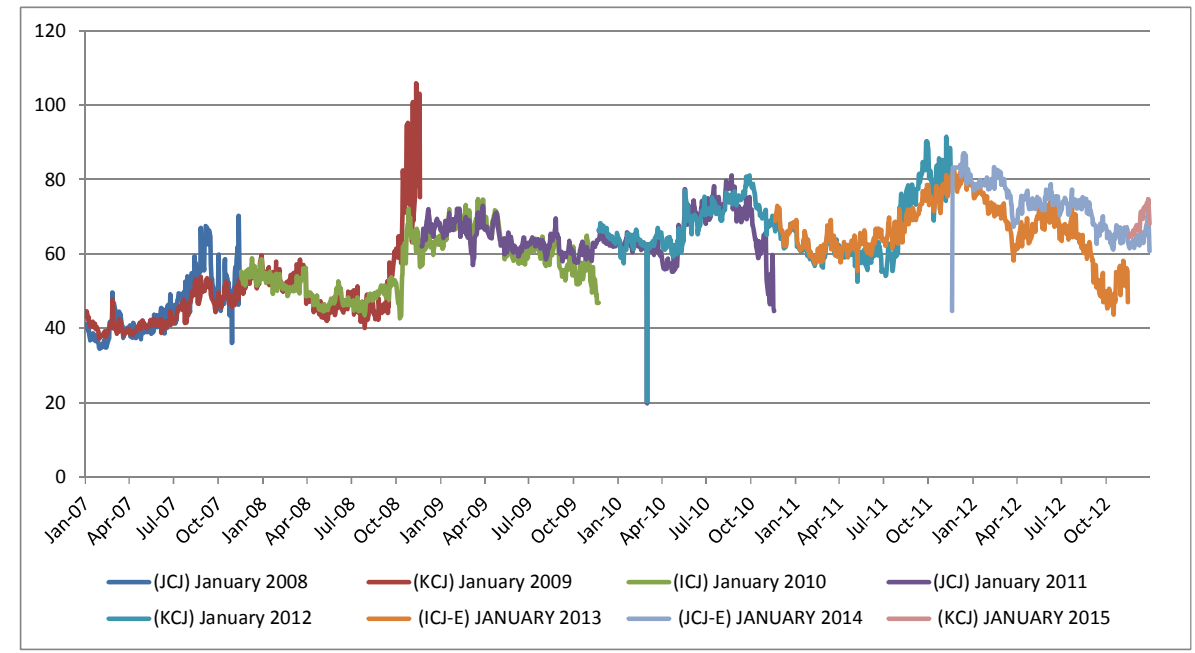

Figure 4. Implied S\&P 500 correlations. Source: Author's calculations. 
Figure 5.

Panel A. Realized correlations between U.S. large cap stocks and 20-year Treasury returns.

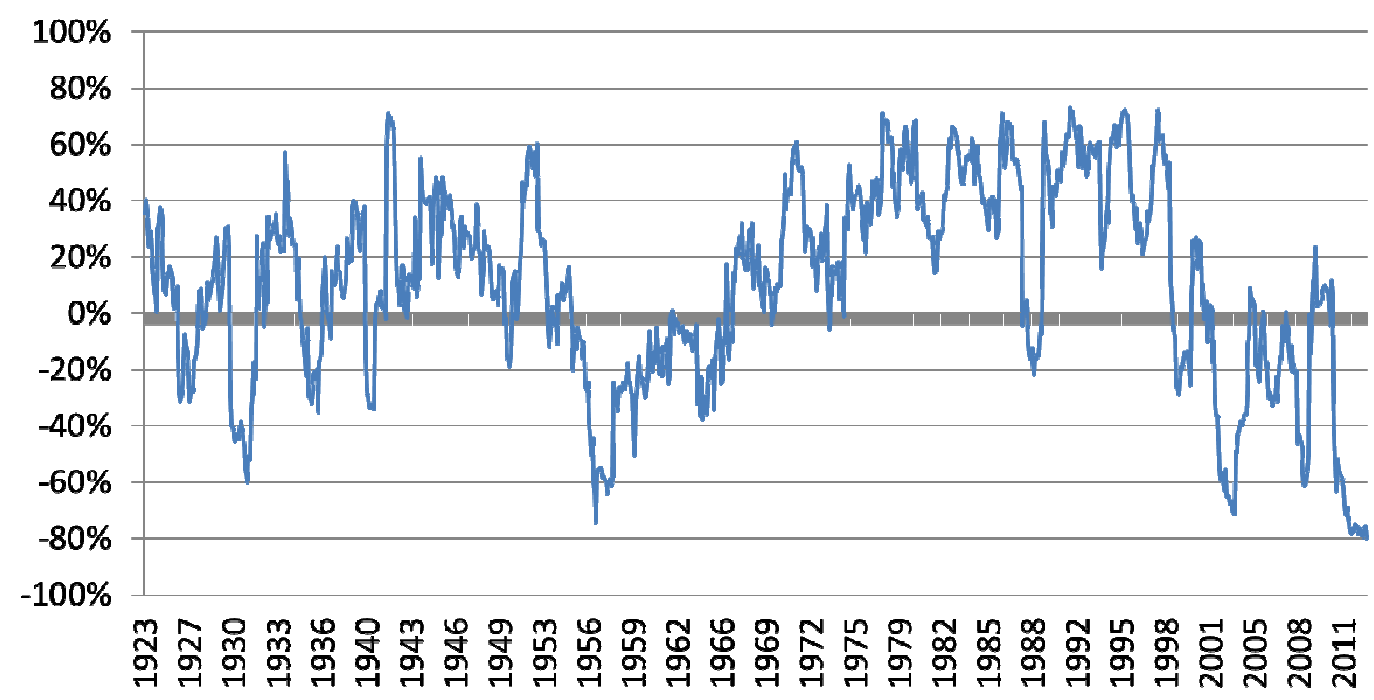

Panel B. Realized correlations between U.S. large cap stocks and 20-year Treasury returns with block-bootstrapped 95 percent C.I.s.

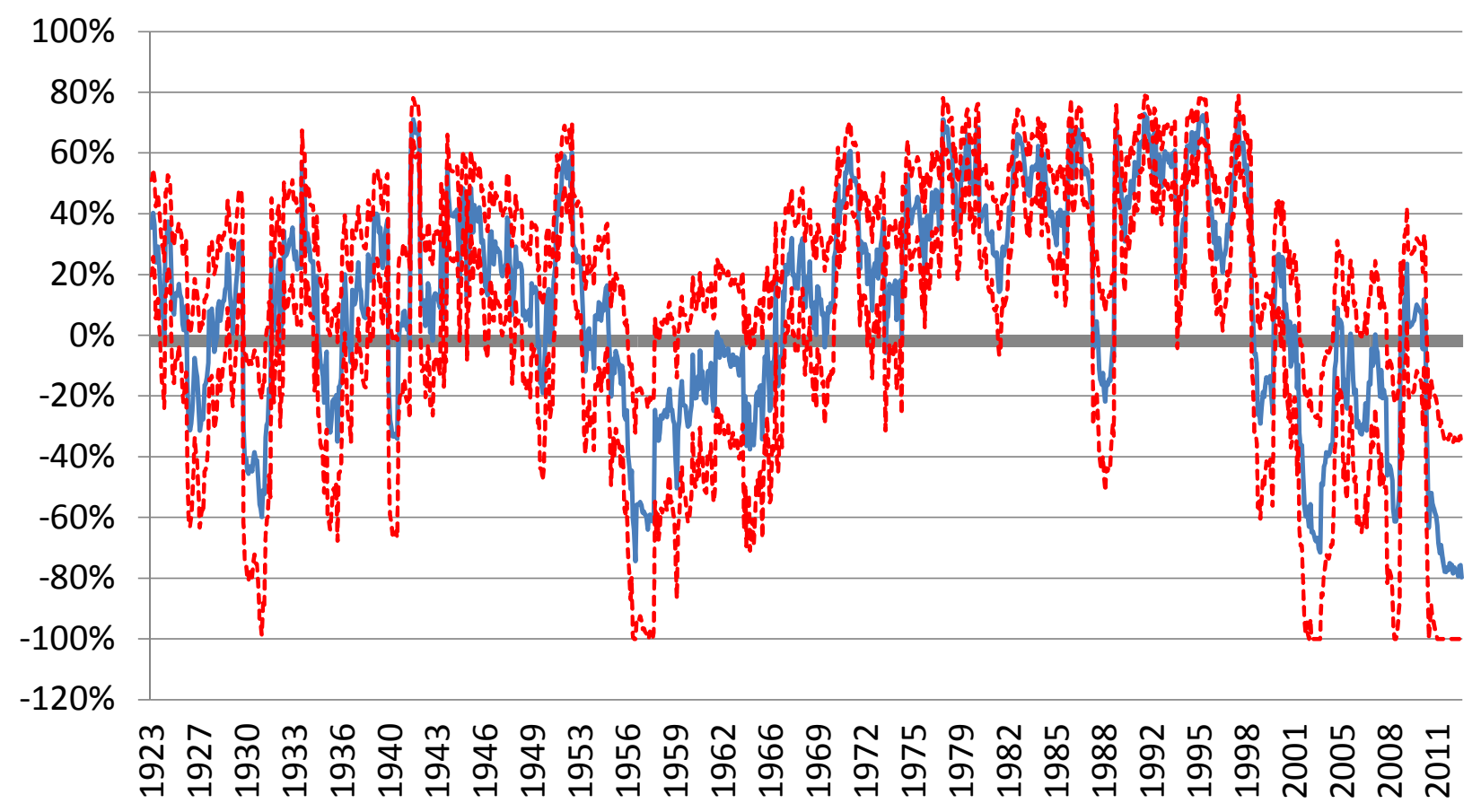

Source: Author's calculations. 


\section{Figure 6.}

Panel A. Allocation trends of U.S. corporate pension plans.

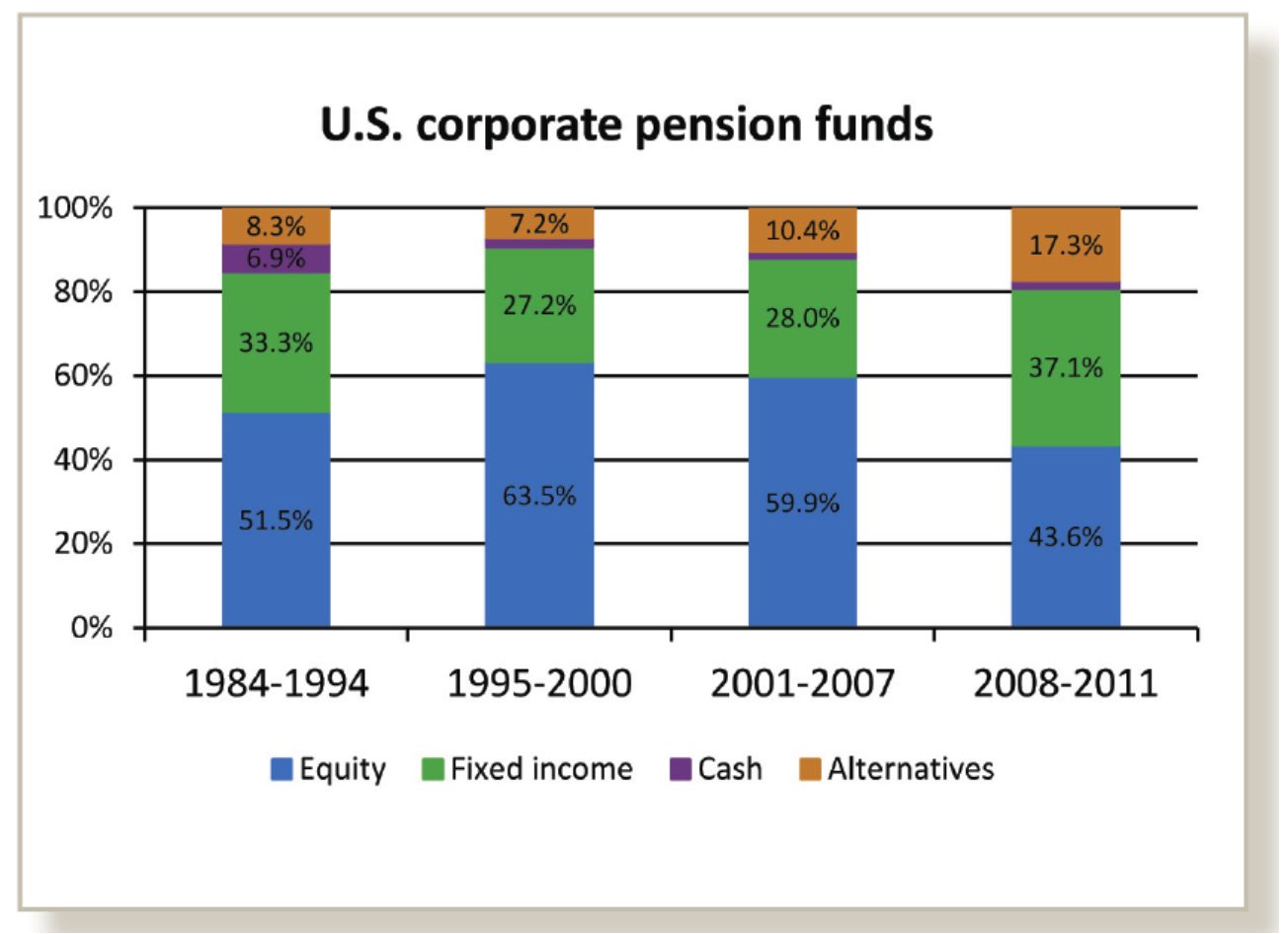

Panel B. Allocation trends of U.S. public pension plans.

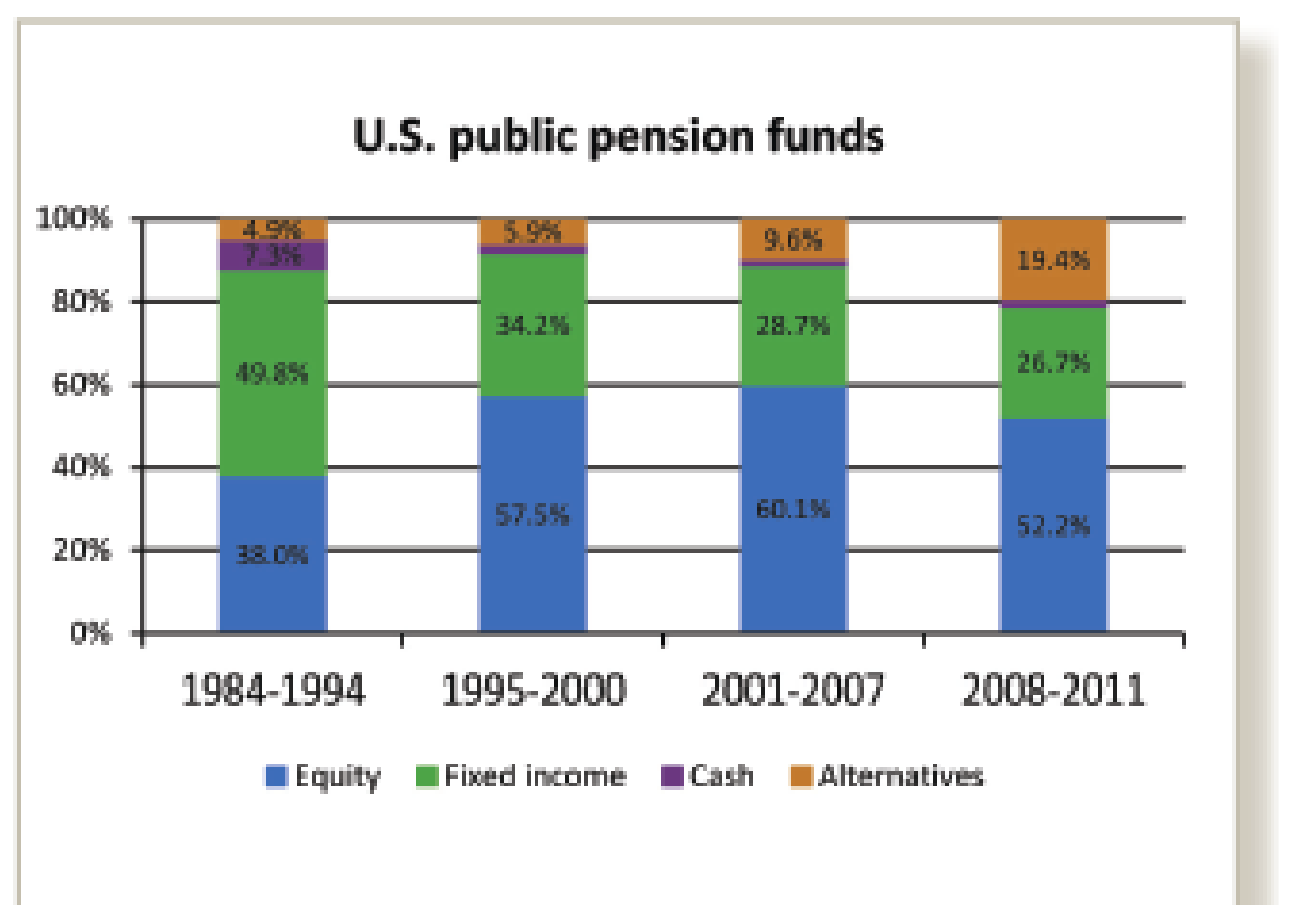


Panel C. Alternative asset allocation trends of U.S. corporate pension plans, public pension plans and university endowments and foundations.

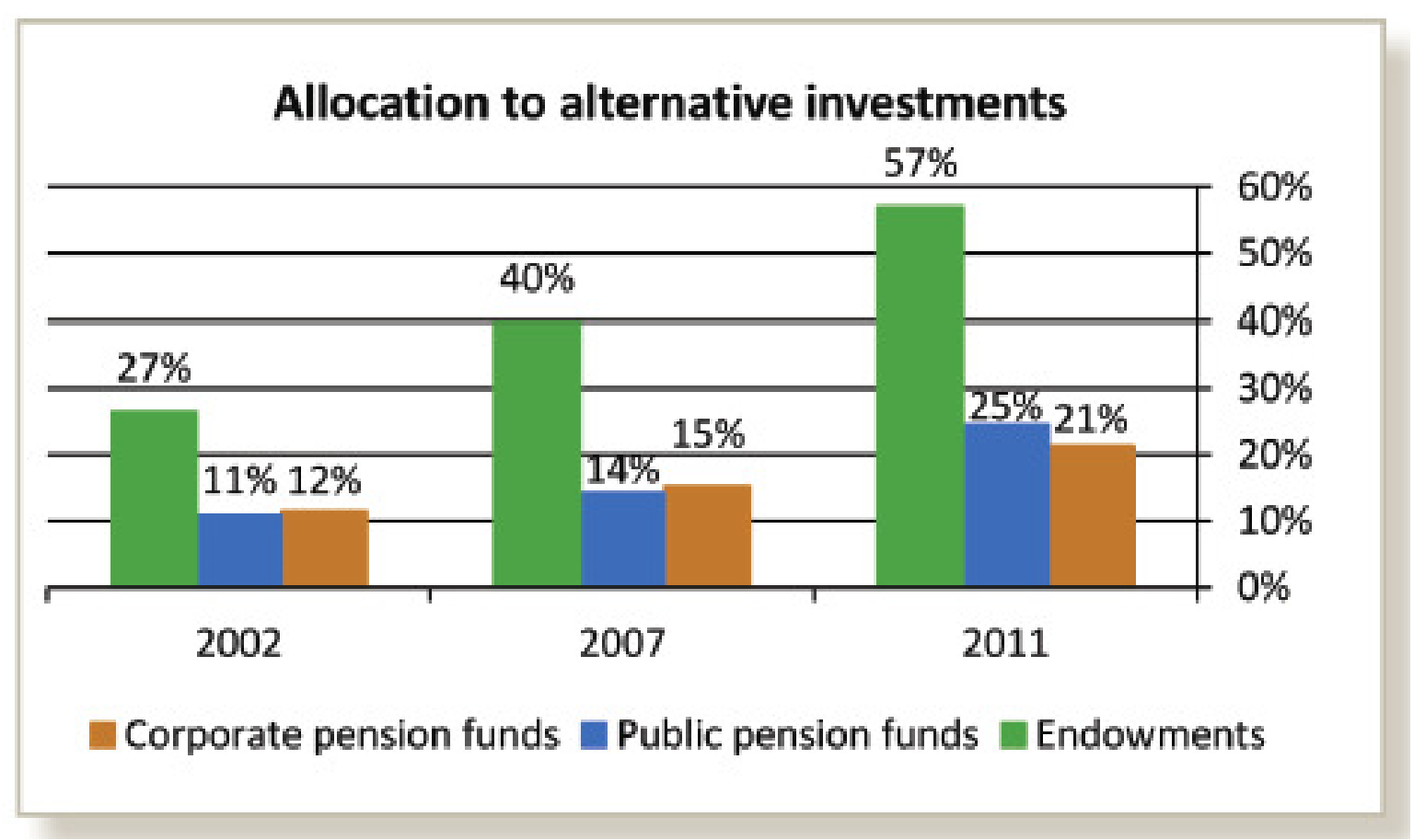

Source: Pensions \& Investments Research (2013). 


\section{References}

Brinson, G. P., L. R. Hood, and G. L. Beebower (1986). "Determinants of Portfolio Performance," Financial Analysts Journal (July/August 1986): 39-44.

Buck Consultants (2012). "ME-PIMS Peer Review Report,” Letter from Buck Consultants to Larry Shirley of the Pension Benefit Guaranty Corporation. Berwyn, PA: Buck Consultants, September 12.

Chicago Board Options Exchange (CBOE) (2013). CBOE® S\&P 500® Implied Correlation Index. Chicago, IL: CBOE. http://www.cboe.com/micro/impliedcorrelation/

Horizon Actuarial Services, LLC (2012). Survey of Capital Market Assumptions 2012 Edition. Washington, DC: Horizon Actuarial Services.

Pensions \& Investments Research (2013). "2012 Survey of the Top 200 Pension/Employee Benefit Funds" (selected data provided by Pensions \& Investments Research). http://researchcenter.pionline.com/rankings/plan-sponsors/overview

Pension Benefit Guaranty Corporation (PBGC) (2010). "Pension Insurance Modeling System: PIMS System Description for PIMS SOA ‘Core' (vFY09.1)” Version 1.0, Revision 9/22/2010. Washington, DC: PBGC.

Pension Benefit Guaranty Corporation (PBGC) (2011) "Overview of the Pension Insurance Modeling System (PIMS).” Washington, DC: PBGC, April 27.

Pension Benefit Guaranty Corporation (PBGC) (2012). "Excellence in Customer Service," FY2012 Annual Report. Washington, DC: PBGC. 
Pension Benefit Guaranty Corporation (PBGC) (2012). "Press Release: FY 2012 PBGC Exposure Report.” Washington, DC: PBGC.

Sharpe, W. F. (1964). "Capital Asset Prices - A Theory of Market Equilibrium Under Conditions of Risk," Journal of Finance 19(3): 425-442.

Shiller, R. J. (2013). Robert Shiller - Online Data. Yale University Economics Department, website of Prof. Robert J. Shiller. New Haven, CT: Yale University. http://www.econ.yale.edu/ shiller/data.htm

Welch, I. (2008). “The Consensus Estimate for the Equity Premium by Academic Financial Economists in December 2007." Cambridge, MA: National Bureau of Economic Research (NBER). 


\title{
Economic and Financial Approaches to Valuing Pension Liabilities
}

\author{
Robert Novy-Marx \\ Simon School of Business, University of Rochester \\ September 2013 \\ Michigan Retirement Research Center \\ University of Michigan \\ P.O. Box 1248 \\ Ann Arbor, MI 48104 \\ www.mrrc.isr.umich.edu \\ (734) 615-0422
}

\section{Acknowledgements}

This work was supported by a grant from the Social Security Administration through the Michigan Retirement Research Center (Grant \# 5 RRC08098401-05-00). The findings and conclusions expressed are solely those of the author and do not represent the views of the Social Security Administration, any agency of the Federal government, or the Michigan Retirement Research Center.

\section{Regents of the University of Michigan}

Mark J. Bernstein, Ann Arbor; Julia Donovan Darlow, Ann Arbor; Laurence B. Deitch, Bloomfield Hills; Shauna Ryder Diggs, Grosse Pointe; Denise Ilitch, Bingham Farms; Andrea Fischer Newman, Ann Arbor; Andrew C. Richner, Grosse Pointe Park ; Katherine E. White, Ann Arbor; Mary Sue Coleman, ex officio 


\title{
Economic and Financial Approaches to Valuing Pension Liabilities
}

\begin{abstract}
Financial economics holds that payment streams should be valued using discount rates that reflect the cash flows' risks. In the case of pension liabilities, the appropriate discount rate for a pension fund's liabilities is the expected rate of return on a portfolio that would be held under a liability-driven investment policy. The valuation of defined benefit (DB) pension obligations involves choices revolving around deciding 1) what future benefit payments to recognize today (i.e., which liability concept to use); and 2) from whose point of view to value the liabilities. Moving towards modeling the distribution of future liabilities using a "risk-neutral" framework would allow for calculating the present value of the future liabilities more accurately. This would provide policymakers with information more relevant for decision making, and it would also permit easier communication of the risks facing the Pension Benefit Guaranty Corporation's PIMS model via a single univariate statistic.
\end{abstract}

\section{Citation}

Novy-Marx, Robert (2013). "Economic and Financial Approaches to Valuing Pension Liabilities,” University of Michigan Retirement Research Center (MRRC) Working Paper, 2013290(c). Ann Arbor, MI.

\section{Authors’ Acknowledgements}

The research reported herein was pursuant to a grant from the U.S. Social Security Administration (SSA) funded as part of the Retirement Research Consortium (RRC); the author also acknowledges support from The Pension Research Council at The Wharton School. All findings and conclusions expressed are solely those of the author and do not represent the views of the SSA or any agency of the federal government, the MRRC, the PRC, or The Wharton School at the University of Pennsylvania. All findings, interpretations, and conclusions of this paper represent the views of the authors and not those of the Wharton School or the Pension Research Council. (C2013 Pension Research Council of the Wharton School of the University of Pennsylvania. All rights reserved. 


\title{
Economic and Financial Approaches to Valuing Pension Liabilities
}

\begin{abstract}
Robert Novy-Marx
Price is expected discounted payoff. This fundamental relation underlies all of asset pricing. The discount factor is an index of "bad times." Because investors are willing to pay more for assets that do well in bad times, the risk premium on any asset is determined by how it co-varies with the discount factor. All of asset pricing comes down to techniques for measuring a discount factor in a way that is useful for specific application.
\end{abstract}

- Cochrane and Culp, in Modern Risk Management

Payment streams should be valued using discount rates that reflect the cash flows' risks. This bedrock principle of financial economics goes back at least to the development of the capital asset pricing model (CAPM) in the 1960s (Treynor 1961; Sharpe 1964; Lintner 1965). The standard modern application involves discounting cash flows at rates that depend on the cash flows' covariance with multiple priced risks (Ross 1976; Fama and French 1993). In the case of pension liabilities this may be interpreted concretely, as saying that the appropriate discount rate for a pension fund's liabilities is the expected rate of return on an optimal "hedge portfolio," where this is the portfolio that would be held under a liability-driven investment policy (i.e., the portfolio of traded assets that has cash flows that most closely approximates the funds expected future benefit payments).

While the basic methodology for valuing liabilities payments is well understood, its application to the valuation of defined benefit (DB) pension obligations involves choices that are 
context-specific and which have a material impact on the calculation. The choices primarily revolve around deciding 1) what future benefit payments to recognize today (i.e., which liability concept to use); and 2) from whose point of view to value the liabilities.

\section{Liability concept}

DB pensions are a form of delayed compensation. For work performed today, employees receive, in addition to their wages, promises of benefits to be paid after retirement. In order to value these benefits, one must first decide what expected future benefits should be recognized today. The broadest concept, the present value of benefits (PVB), recognizes all future expected benefit payments. This is analogous to accounting for the net present value of all of an employee's expected future wages as a current liability, something that seems unreasonably broad for most applications. The public sector commonly recognizes pension liabilities using a concept called the pension benefit obligation (PBO), or a closely related methodology called the entry age normal (EAN). These account for future wage growth but not future service, and thus they recognize only a fraction of the PVB. The PBO recognizes the PVB in proportion to the fraction of an employee's service earned to date, relative to the expected total at retirement. The EAN recognizes the PVB in proportion to the fraction of an employee's discounted total wages earned to date relative to the expected total at retirement. The narrowest commonly used liability concept for DB pension plans is the accrued benefit obligation (ABO). This concept only recognizes the benefit payments that have been earned to date, and bases projected benefit payments off of an employee's current wage history. It corresponds quite closely to the benefits that a worker would receive if the plan to which they belonged was shut down today, and is thus often called the "termination liability." 
Broad measures of pension liabilities that account for wage growth (e.g., the PBO, EAN, or PVB) need to be discounted at higher rates. Wages are exposed to priced risks. Wage growth, the stock market, and the economy more broadly, must all be positively correlated, at least over longer horizons. According to Black (1989), "stocks go up when it looks like times will be good. In good times, wages and salaries and benefits all tend to grow faster than usual. Thus the broader your view of the pension liability, the more stocks you will need for hedging." Lucas and Zeldes (2006) develop a framework for estimating appropriate risk-adjusted discount rates for DB pension liabilities, which account for future pension benefit payments' exposure to the market through the wage growth channel. These issues are less relevant for the $\mathrm{ABO}$, which is not exposed to wage risk, and the $\mathrm{ABO}$ is the most relevant liability concept for the Pension Benefit Guaranty Corporation (PBGC).

Bulow (1982) argues that the is $\mathrm{ABO}$ is the appropriate liability concept for corporate plans quite generally, because broader concepts unreasonably imply an "implicit contract under which young workers accept lower total compensation in return for an informal agreement that they be highly paid later in their career." This has implications beyond those directly related to exactly which benefits are currently recognized. Bulow (1982) suggests that an "example of the effect of such an assumption is that many mistakenly believe that if a worker's benefits are tied to final salary, he is protected against inflation until retirement.” The existence (or lack thereof) of inflation protection impacts the appropriate discount rate to use for discounting liabilities, regardless of which exact liabilities are recognized. Bodie (1990) suggests that the "failure of pension funds to show any significant interest in inflation-protected investment products such as CPI-linked bonds is clear evidence that they [the plan sponsors] do not view their liabilities as indexed for inflation." 
Most importantly, under U.S. law, the PBGC's guarantee only extends to benefits accrued prior to a firm's bankruptcy filing. New (insured) accruals thus stop in plan terminations, or even before if bankruptcy predates a plan's termination. The PBGC's liability consequently only extends to the $\mathrm{ABO}$ liabilities, making it the most relevant liability concept when valuing DB pension liabilities for PBGC insurance purposes ${ }^{1}$.

\section{Valuation: promises, or expected payments?}

The value of the same pension promises may not be the same from the point of view of different stake-holders. For example, retired participants of a plan administrated by a firm near bankruptcy may value their claims under the assumption that they are relatively safe, at least partly because of the existence of the PBGC insurance. These same expected benefit payments may be valued much lower by the firms' stockholders, who have limited liability. Valuation of DB pension liabilities thus requires a decision, either explicit or implicit, about exactly which payments are being valued. This is basically a question of whether the payments being valued are the promised payments, or the payments that are actually expected to be made.

For the last decade, the Employee Retirement Income Security Act (ERISA) has required private sector firms to discount expected pension payments for reporting and funding purposes using corporate bond rates ${ }^{2}$. These prescribed discount rates implicitly value pension liabilities from the point of view of a firm's equity holders. Corporate bond rates reflect the possibility that

\footnotetext{
${ }^{1}$ Broader concepts may be more appropriate in the public sector, where future benefit accruals often have statutory protections.

${ }^{2}$ For the previous 25 years, ERISA prescribed even lower discount rates, the 30-year Treasury yield.
} 
firms may default on their debts. These rates thus account for fact that expected payments are smaller than promised payments (because of the possibility of default). They also include a risk premium that arises because defaults co-vary with priced risks (i.e., because defaults are more likely in bad times, when extra dollars are particularly valuable). ERISA thus prescribes that firm managers value the pension payments that the plan sponsor expects to actually make, not the payments the plan participants expect to receive ${ }^{3}$.

The distinction arises from limited liability, and from the value of PBGC insurance itself. From the point of view of plan participants, PBGC insurance is a valuable asset. The insurance makes the future benefit payments (up to a limit) almost risk-free, and thus the stream of payments retirees expect to receive more valuable. From the point of view of the plan sponsor, PBGC insurance is less valuable, because in the event the insurance pays off, it is the participants, and not the sponsor, that receives the payments ${ }^{4}$. For the sponsor, limited liability essentially acts as a valuable put option, which reduces the value of the stream of benefits it promises. Under certain conditions, a sponsor's liability is limited to the value of a plan's assets, which is economically equivalent to owning an option to deliver the plan's assets in exchange for the value of the plan's liabilities.

\footnotetext{
${ }^{3}$ Technically these are valued as if other similar firms were responsible for the payments, because the ERISA-specified rate is not the firm-specific borrowing rate, but a high grade corporate index rate.

${ }^{4}$ PBGC insurance is not without value to the sponsor, because firms negotiate with employees over total compensation. PBGC insurance, which increases the value of pension benefits to workers, may thus reduce the direct wage compensation an employer must promise.
} 
Conceptualizing the value of PBGC insurance as a put option allows for its valuation using the no-arbitrage techniques developed to price options (Black and Scholes 1973) ${ }^{5}$. The standard methodology for pricing derivative securities involves constructing the instrument's replicating portfolio (the "synthetic" security), which generates the exact same cash flows at every date in the future in every possible future. Market forces ensure that the price of the derivative security must be close to the price of the hedge portfolio.

A number of authors have used this framework to analyze the value of PBGC insurance (e.g., Marcus 1987 and Pennacchi and Lewis 1994), and particularly the moral hazard arising from the very existence of PBGC insurance. Bodie (1990) suggests that for underfunded plans “... it may be optimal to exploit the put provided by PBGC insurance through a high-risk investment strategy."

\section{Insured Liability}

ERISA (and later the Pension Protection Act of 2006) prescribe that firms account for their pension liabilities using rates that implicitly reflect the possibility of default, yet these rates may not be appropriate for valuing the PBGC's liabilities. The PBGC exists to guarantee pension benefits. Because it will make payments that a plan sponsor cannot, it is inappropriate to use discount rates that reflect the possibility of the sponsor's default when calculating the PBGC's potential liabilities.

The fact that the PBGC's potential liability extends only to ABO benefits (subject to the payment cap), in conjunction with the fact that benefits paid by the PBGC are essentially risk-

\footnotetext{
${ }^{5}$ These techniques can themselves be viewed as a particularly powerful application of the basic principle that cash flows should be discounted at rates that reflect their risks.
} 
free, make the valuation of these liabilities relatively straightforward. The ABO is not affected by uncertainty about future wages and service, as the cash flows associated with the $\mathrm{ABO}$ are based completely on information known today (plan benefit formulas, current salaries, and current years of service). Mortality is relatively easy to forecast (probabilistically), and the uncertainty in these forecasts is largely idiosyncratic (i.e., uncorrelated with aggregate economic variables that may be related to discount rates) ${ }^{6}$. Pension promises related to termination liabilities, which are insensitive to wage risk, should thus be discounted at riskless rates of return (Sharpe 1976).

This valuation is most concretely done by simply pricing the defeasance portfolio. A plan's liabilities can be defeated (i.e., made null and void) by delivering a portfolio of securities that generate the income required to make all future benefit payments. The cost today of buying this replicating portfolio is the value of the liabilities. The defeasance portfolio can most easily be constructed using either true market annuities or default free bonds.

The advantage of defeasing the liabilities using market annuities is that these already account for the impact of mortality on expected payouts, making the construction of the replicating portfolio particularly simple. Defeasing the liabilities this way yields insurance industry annuity pricing of the liabilities. Such pricing may slightly overstate the true cost of liabilities, because the market for these annuities is not as transparent or competitive as the market for high quality bonds. That is, insurance industry annuity pricing reflects the provider's

\footnotetext{
${ }^{6}$ Plan experience suggests that the most commonly employed mortality tables have failed to adequately account for generational improvements in mortality. Mortality assumptions are an important driver of projected benefit payments, so this has tended to bias forecast liabilities downward.
} 
profit margins, which are likely higher than those enjoyed by market makers in the bond market. ${ }^{7}$ This is likely more than fully offset by the fact the credit quality of the PBGC is superior to that of even the best annuity providers, which means that the value of an annuity provided by these companies is lower than that of a similar annuity provided by the PBGC. The PIMS model also uses annuity prices that come from surveys, not transactions. While the American Academy of Actuaries reports only modest differences (3-5\%) between the PBGC's survey prices and actual transaction prices, these differences are magnified in firms' net pension liabilities. ${ }^{8}$

The advantage of defeasing the liabilities using default-free bonds is that this may most accurately reflect the true cost of the liabilities provided by the PBGC. This does require forecasting the effects of mortality on expected payments, but this is relatively simple and straightforward. Because the liabilities are basically nominal (i.e., not inflation protected), the bonds employed in the defeasance calculation should themselves be nominal. Using Treasuries would almost certainly yield a liability that overstates the liabilities' true value, because

${ }^{7}$ Insurance companies may also sometimes misprice annuities due to market imperfections. Koijen and Yogo (2013) argue that insurance companies were significantly underpricing annuities in late 2008 and early 2009, because of market losses that hurt their balance sheets, and statutory reserve regulations that allowed them to account for only a fraction of the true future insurance liability.

${ }^{8}$ For example, suppose a firm has $\$ 90$ of pension assets, and pension liabilities valued at $\$ 95$ when calculated using annuity prices derived from surveys and $\$ 100$ when calculated using annuity transaction prices. The firm's net pension underfunding is only $\$ 5$ when calculated using survey prices but $\$ 10$ when calculated using transaction prices, a difference of $100 \%$, despite the fact that the survey annuity prices are only $5 \%$ lower than the transaction prices. 
Treasuries enjoy a significant liquidity premium (i.e., are expensive) due to their use as a safehaven asset, and because they have special status as a collateral asset (Longstaff 2004; Krishnamurthy and Vissing-Jorgensen 2012). The true value of the liabilities is thus probably more accurately reflected by the cost of the defeasance portfolio constructed using agency securities, which are close to risk-free but do not enjoy the special status of treasuries.

While there are many subtle issues around the appropriate recognition and valuation of DB pension liabilities, valuing liabilities that the PBGC insures, is ultimately relatively straightforward. By law, the PBGC's liabilities are limited to the ABO. The only risk the insured $\mathrm{ABO}$ cash flows are exposed to is mortality risk, which is basically unpriced. These liabilities are thus effectively risk-free, and they should therefore be discounted at risk-free rates. These rates are probably best reflected by the yields on agency securities, which are extremely unlikely to default but do not carry the liquidity premium built into Treasury yields.

Discounting the distribution of expected future liabilities back to a current "value" is much more difficult. The PIMS User Manual explicitly states that the model should only be used to forecast possible outcomes, so it cannot be used to calculate a present value of these future liabilities. In practice, however, users of the model seem unable to refrain from doing so. The headline summary statistic that people use to talk about the funding status of the PBGC comes directly from discounting the expected future liability at risk-free rates, which is completely inappropriate. Moreover, this certainly understates the true magnitude of the PBGC underfunding.

Despite the fact that the evolution of the termination liabilities in the PIMS model is driven largely by the interest rate process, the timing and extent to which the PBGC is forced to assume these liabilities is driven in large part by market and macroeconomic risks. If the PBGC's 
underfunding is particularly large in 10 years, it will almost certainly be because the U.S. economy underperformed expectations. This is precisely the time at which any given level of underfunding will be particularly painful, and discounting the models' forecasted distribution of future underfunding fails to account for this reality.

Moving towards modeling the distribution of future liabilities in a manner that accounts for the price of risk (i.e., using a "risk-neutral" framework) would allow for calculating the present value of the future liabilities more accurately. This can be an important step for the PIMS system, as it would provide policymakers with information more relevant for decisionmaking. A proper valuation would account for the possibility of painful "tail events," and do so in a way that appropriately accounts for the pain associated with these relatively low probability events. This would also permit easier communication of the risks facing the agency with a single univariate statistic. 


\section{References}

Black, F. (1989). “The Tax Consequences of Long-Run Pension Policy," Financial Analysts Journal: 21-28.

Black, F., and M. Scholes (1973). "The Pricing of Options and Corporate Liabilities," Journal of Political Economy 81: 637-654.

Bodie, Z. (1990). "The ABO, the PBO and Pension Investment Policy," Financial Analysts Journal: 27-34.

Bulow, J. (1982). "What are Corporate Pension Liabilities?" The Quarterly Journal of Economics: $435-452$.

Cochrane, J. H., and C. L. Culp (2003). "Equilibrium Asset Prices and Discount Factors: Overview and Implications for Derivatives Valuation and Risk Management," in P. Field, ed., Modern Risk Management: A History. London, U.K.: Risk Books, pp. 57-92.

Fama, E. F. and K. R. French (1993). "Common Risk Factors in the Returns on Stocks and Bonds," Journal of Financial Economics, 33: 3-56.

Koijen, R. S. J., and M. Yogo (2013). “The Cost of Financial Frictions for Life Insurers,” NBER Working Paper No. 18321. Cambridge, MA: National Bureau of Economic Research.

Krishnamurthy, A., and A. Vissing-Jorgensen (2012). “The Aggregate Demand for Treasury Debt," Journal of Political Economy 120: 233-267.

Lintner, J. (1965). "The Valuation of Risk Assets and the Selection of Risky Investments in Stock Portfolios and Capital Budgets," Review of Economic Statistics 47: 13-37.

Longstaff, F. A. (2004). "The Flight-to-Liquidity Premium in U.S. Treasury Bond Prices," Journal of Business: 511-526. 
Lucas, D., and S. Zeldes (2006). "Valuing and Hedging Defined Benefit Pension Obligations The Role of Stocks Revisited.” Unpublished.

Marcus, A. (1987). "Corporate Pension Policy and the Value of PBGC Insurance," in Z. Bodie, J. B. Shoven, and D. A. Wise, eds., Issues in Pension Economics. Chicago, IL: University of Chicago Press, pp. 49-80.

Merton, R. C. (1974). "On the Pricing of Corporate Debt: The Risk Structure of Interest Rates," Journal of Finance 29: 449-470.

Merton, R. C. (1978). "On the Cost of Deposit Insurance When There Are Surveillance Costs," Journal of Business 51: 439-452.

Pennacchi, G. G., and C. M. Lewis (1994). "The Value of Pension Benefit Guaranty Corporation Insurance," Journal of Money, Credit and Banking: 735-753.

Ross, S. (1976). "The arbitrage theory of capital asset pricing," Journal of Economic Theory 13: $341-360$.

Sharpe, W. F. (1964). "Capital Asset Prices: A Theory of Market Equilibrium under Conditions of Risk," Journal of Finance 19: 425-442.

Treynor, J. L. (1961). "Toward a Theory of the Market Value of Risky Assets," Unpublished manuscript. 


\title{
Integrated Risk Management for Defined Benefit Pensions: Models and Metrics
}

\author{
Raimond Maurer \\ Finance Department, Goethe University \\ September 2013 \\ Michigan Retirement Research Center \\ University of Michigan \\ P.O. Box 1248 \\ Ann Arbor, MI 48104 \\ www.mrrc.isr.umich.edu \\ (734) 615-0422
}

\section{Acknowledgements}

This work was supported by a grant from the Social Security Administration through the Michigan Retirement Research Center (Grant \# 5 RRC08098401-05-00). The findings and conclusions expressed are solely those of the author and do not represent the views of the Social Security Administration, any agency of the Federal government, or the Michigan Retirement Research Center.

\section{Regents of the University of Michigan}

Mark J. Bernstein, Ann Arbor; Julia Donovan Darlow, Ann Arbor; Laurence B. Deitch, Bloomfield Hills; Shauna Ryder Diggs, Grosse Pointe; Denise Ilitch, Bingham Farms; Andrea Fischer Newman, Ann Arbor; Andrew C.

Richner, Grosse Pointe Park ; Katherine E. White, Ann Arbor; Mary Sue Coleman, ex officio 


\title{
Integrated Risk Management for Defined Benefit Pensions: Models and Metrics
}

\begin{abstract}
The Pension Benefit Guaranty Corporation (PBGC) insures private sector defined benefit (DB) pension plans when an employer becomes insolvent and is unable to pay its pension liabilities. In principle, the insurance premiums collected by PBGC should be sufficient to cover potential losses; this would ensure that PBGC could pay the insured benefits of terminated pension plan without additional external funding (e.g. from taxpayers). Therefore, the risk exposure of the PBGC from insuring DB pension plans arises from the probability of employer insolvencies; and the terminating plans' funding status (the excess of the value of insured plan liabilities over plan assets). This paper focuses on only the second component, namely the impact of plan underfunding for the operation of the PBGC. When a DB plan is fully funded, the PBGC's risk exposure for an ongoing plan is low even if the plan sponsor becomes insolvent. Thus the questions most pertinent to the PBGC are what key risk factors can produce underfunding in a DB plan, and how can these risk factors be quantified? We explore the most important risk factors that produce DB pension underfunding, namely investment risk and liability risk. Both are interrelated and must be considered simultaneously in order to quantify the risk exposure of a DB pension plan. We propose that an integrated risk management model (an Integrated Asset/Liability Model) can help better understand DB pension plan funding risk. We also examine the Pension Insurance Modeling System developed by the PBGC in terms of its own use of some of the building blocks of an integrated risk management model.
\end{abstract}

\section{Citation}

Maurer, Raimond (2013). “Integrated Risk Management for Defined Benefit Pensions: Models and Metrics," University of Michigan Retirement Research Center (MRRC) Working Paper, WP 2013-290(d). Ann Arbor, MI.

\section{Authors’ Acknowledgements}

The research reported herein was pursuant to a grant from the U.S. Social Security Administration (SSA) funded as part of the Retirement Research Consortium (RRC); the author also acknowledges support from The Pension Research Council at The Wharton School. All findings and conclusions expressed are solely those of the author and do not represent the views of the SSA or any agency of the federal government, the MRRC, the PRC, or The Wharton School at the University of Pennsylvania. All findings, interpretations, and conclusions of this paper represent the views of the authors and not those of the Wharton School or the Pension Research Council. (C)2013 Pension Research Council of the Wharton School of the University of Pennsylvania. All rights reserved. 


\title{
Integrated Risk Management for Defined Benefit Pensions: Models and Metrics
}

\author{
Raimond Maurer
}

\section{Introduction}

The Pension Benefit Guaranty Corporation (PBGC) is an agency of the U.S. federal government that insures private sector defined benefit pension (DB) plans when an employer becomes insolvent and is unable to pay its pension liabilities. When a plan is terminated, the PBGC takes over the plan assets and pays vested employees their future benefits up to certain limits (trusteed plans). For this insurance coverage, employers of ongoing plans (non-trusteed) must pay fixed/variable premiums to the PBGC. In principle, the insurance premiums collected by PBGC should be sufficient to cover potential losses; this would ensure that PBGC could pay the insured benefits of terminated pension plan without additional external funding (e.g. from taxpayers). Therefore, the risk exposure of the PBGC from insuring DB pension plans arises from two sources:

(1) the probability of employer insolvencies; and

(2) the terminating plans' funding status (the excess of the value of insured plan liabilities over plan assets).

This paper focuses on only the second component, namely the impact of plan underfunding for the operation of the PBGC. When a DB plan is fully funded (i.e. the value of plan assets is equal to the value of the plan liability), the PBGC's risk exposure for an ongoing plan is low even if the plan sponsor becomes insolvent. For this reason, the questions most pertinent to the PBGC are: what key risk factors can produce underfunding in a DB pension plan, and how can these risk factors be quantified? 
In what follows, we explore the most important risk factors that produce DB pension underfunding, namely investment risk and liability risk. Both are interrelated and must be considered simultaneously in order to quantify the risk exposure of a DB pension plan (Hustead and Mitchell 2001). Therefore researchers and practitioners have argued that there is a need for an integrated risk management model—also referred as Integrated Asset/Liability Model—to better understand $\mathrm{DB}$ pension plan funding risk. We also examine the Pension Insurance Modeling System (PIMS) developed by the PBGC in terms of its own use of some of the building blocks of an integrated risk management model.

The PIMS uses detailed information on liabilities of terminated and ongoing plans. It also implements a wide range of detailed legal rules, i.e. contribution requirements from the Pension Protection Act (PPA), rules from the U.S. tax code, and the way that fixed/variable PBGCpremiums are calculated. It also includes simple management rules on how the assets of the terminated and ongoing plans are invested. ${ }^{1}$ Based on seven key stochastic variables, ${ }^{2}$ PIMS

${ }^{1}$ PBGC assets are invested in a revolving and a trust fund. Plan specific asset returns (stocks and bonds) of ongoing plans are modeled using a set of factor-equations (see equation 5-10; PIMS Description, page 5-7) calibrated using historical Form 5500 information. It should be mentioned that PIMS do not include a time varying asset allocation depending on the funding status of the specific plan. Therefore moral hazard aspects, i.e. a possible increase of the equity exposure in the case of a (very) low funding status are not modeled.

${ }^{2}$ See Table 2-14 and calibrated equation 5-4 to 5-10 in PIMS Description (2010): Nominal interest rate, real stock return, equity-to-debt ratio, employment, cash-flow-to assets, firm equity, plan asset returns. Important deterministic user inputs are the real interest rate and productivity growth. 
specifies for each simulation path $\mathrm{i}=1, \ldots . \mathrm{I}$ and time period $\mathrm{t}=1, \ldots ., \mathrm{T}$ for each ongoing plan $\mathrm{m}=1, \ldots, \mathrm{M}$ and $\mathrm{n}=1, \ldots, \mathrm{N}$ terminated plan $^{3}:$

1) the funding status (value of plan assets minus actuarial value of plan liabilities)

2) the cash flows from assets, the premiums paid to PBGC from ongoing plans, and the benefits paid to retirees of terminated plans

3) the probability of insolvency for ongoing plans.

By doing so, PIMS considers both pure and parameter risk in the simulation procedure. The resulting simulations produce a wide range of potential future outcomes of claims. These outcomes are reported in various summary statistics, e.g. as distributions over time (using quantiles, averages) and/or as a stochastic present value of PBGC net financial position using the riskless interest rate to discount (on each path) future payments.

Overall, we conclude that the PBGC has developed a complex, reasonably sensible, and defensible stochastic model to predict the probability distribution of potential future losses for PBGC from both terminated and ongoing DB-plans. Additionally we outline two key areas where extensions of PIMS may be valuable in the future:

- Incorporate systematic mortality risk in the liability part of the model

- Model the complete term structure of interest rate instead of only a single interest rate (30-year government bonds).

Besides these two areas, the model should be expanded to include not only equity and bonds, but also real estate and alternative investments. And finally, the Conditional Value-at-Risk metric may be a useful way to communicate the model outcomes.

\footnotetext{
${ }^{3}$ Typical values are $\mathrm{I}=500$ runs, $\mathrm{T}=20$ years.
} 


\section{Liability Risk}

General aspects. DB plan liabilities evolve as a function of various demographic assumptions, economic assumptions, and assumptions about future benefit flows. The actuarial profession has established well-developed standards on how to set and work with such assumptions when evaluating the current liabilities of a pension plan. Yet the future realizations of these factors may differ from expectations, and/or the assumption may change which results in fluctuations in the value of the plan liabilities (liability risk). For example, actuaries use a specific mortality table to specify the present value of future benefits. But realized mortality rates for a specific pension plan could be higher or lower than those of the assumed mortality table. Such uncertainty is referred as idiosyncratic mortality risk. In addition, mortality can also change systematically because of unexpected improvements in survival probabilities (systematic mortality risk). Research shows that especially for long term liabilities like pension benefits, systematic mortality risk is an important and often underestimated risk factor. ${ }^{4}$

Figure 1 illustrates the impact of systematic mortality risk, ${ }^{5}$ indicating that the probability of living to advanced ages exhibits significant dispersion. For example, the probability of attaining age 70 spans the range from $79-93 \%$, with a median of $87 \%$. Thus the range of the expected lifetime remaining from age 20 varies between 56.7 and 73.8 years, with a median of 64.5 years. Thus a stochastic mortality model shows that future survival rates and years of life remaining are likely to substantially exceed those derived from the deterministic scenario.

Figure 1 here

\footnotetext{
${ }^{4}$ See Cairns et al. (2010).

${ }^{5}$ This section builds on Maurer et al. (2013).
} 
To indicate the economic cost of stochastic mortality, one can calculate the agedependent implied loadings for pre-selected confidence levels that an insurance company or a pension fund must charge for providing lifelong annuity benefits (deferred until age 67). For each initial age, these are derived by sampling 10,000,000 realizations of the stochastic mortality process.

Figure 2 here

Figure 2 shows that premium increases which take into account stochastic mortality can be substantial, especially for younger annuitants. For example, providers must charge 20-yearold buyers loadings of around $32 \%$ on top of the actuarially fair premium, to maintain a $99.99 \%$ solvency confidence level. At the $99.5 \%$ confidence level, loadings must amount to over $20 \%$ for this age group. At later ages, the dispersion of possible future mortality outcomes decreases and so does the implied loading. Nevertheless, at age 66, loadings required to meet the $99.99 \%$ $(99.5 \%)$ confidence level still amount to around $14 \%(9 \%)$.

Assumptions in the PIMS model. Overall, the liability section of PIMS relies on professional actuarial standards for evaluating the current liabilities of the DB pension plans they insure. In addition, the PIMS model provides a methodology to project the uncertainty of future liabilities by varying population dynamics (firm employment), interest rates and benefit growth. ${ }^{6}$ To discount future liabilities, PIMS uses the yield for corporate bonds. The corporate bond yield is a function of the (simulated) nominal interest rate for government bond plus a spread and an adjustment factor. Due to their long-term character, pension liabilities have a long duration and

\footnotetext{
6 Note: the stochastic evolution of benefit growth depends (indirectly) on the evolution of interest rates.
} 
therefore are sensitive to the discount rate selected. There is an ongoing debate as to whether a (higher) discount rate other than the yield for (quasi) risk-free government bonds is appropriate ${ }^{7}$

Yet systematic mortality risk is currently not incorporated in the PIMS model. A large literature has developed over the last two decades exploring the stochastic development of historical human mortality patterns. ${ }^{8}$ In their foundational work, Lee and Carter (1992) introduced a simple discrete-time one-factor model for the central death rate and employed it to describe the evolution of U.S. mortality rates. While this model was able to trace the (downward sloping) time trend in mortality, the one-factor approach implied perfect correlation of mortality innovations over all ages, an implication contradicted by empirical evidence. Subsequent stochastic mortality models seek to remedy this by taking a multi-factor approach (e.g. Cairns et

7 This debate is also referred as the difference between an actuarial versus an economic valuation of pension liabilities. Traditionally, actuaries choose the discount rate which reflects a reasonable projected expected return of the asset backing the pension liabilities. If the pension assets are partly invested in equities, the discount rate includes also an equity risk premium, which is from an ex ante perspective not realized. By contrast, many economists argue that the relevant number for discounting future pension payments is the riskless rate of interest rate reflecting the financing cost of the plan sponsor to build up a replicating portfolio. See Blake (2006:77).

8 For a detailed discussion of alternative approaches see Pitacco et al. (2009), Cairns et al. (2006a), as well as Cairns et al. (2010). 
al. 2006b; Renshaw and Haberman 2003). Currently, the parsimonious two-factor model ${ }^{9}$ by Cairns, Blake, and Dowd is widely used as a model for stochastic mortality.

\section{Investment Risk}

General aspects. The pension plan assets are invested in various categories, e.g. stocks, fixed income instruments, real estate, and alternative investments. The future returns of these assets typically fluctuate over time and could be lower than the assumed interest rate used to discount future benefits (investment risk). Fluctuating interest rates (a spot rate curve) are particularly important, because they simultaneously affect the development of the plan assets and the evaluation of plan liabilities. Therefore it is necessary to model the long run stochastic dynamics of interest rates and future returns on the various assets accumulated in the pension plan. Various models are documented in the literature, ${ }^{10}$ which also notes that the modeling of illiquid assets (e.g. real estate or alternative assets) represents a big challenge. ${ }^{11}$

9 Renshaw and Haberman (2003) examine the forecasting performance of various stochastic mortality models and show that the CBD model provides a good fit, especially for age 50 onwards; it is somewhat less accurate for younger ages. Nevertheless, since we calibrate and model mortality dynamics over the complete life-cycle (age 20-120) within a dynamic portfolio choice model, the CBD two factor-model is a good compromise between the empirical evidence, parsimonious structure, and computational burden (in terms of state variables).

${ }^{10}$ Many popular model use a first order vector autoregressive process (VAR 1); see Campbell et al. (2003) and Hoevenaars et al. (2008). More recent developments use a Markov-Regime Switching approach (see Guidolin and Timmermann 2007). While these models capture the short term (e.g. daily, weekly, monthly) probability distribution of risky assets reasonable (i.e. 
Specific comments on the PIMS model. Currently PIMS uses a VAR approach to model two asset classes, risky stocks and bonds. The returns for bonds (interest and capital gains) depend on the development of the nominal interest rate and a duration adjustment for capital gains. Stock returns are modeled independent identically distributed. The return on corporate bonds is assumed to depend on the interest rate level adjusted for a possible (but certain) spread. The model parameters are calibrated using U.S. data. Additional assets like real estate or alternative assets are not included in the model. The range of asset holdings for specific pension plans is approximated using historical Form 5500 information. PIMS also allows plans to smooth asset values within the context of the minimum PPA funding rules. Plan assets of PPGC are invested first in long term bonds (and T-bills) to immunize the liabilities. For the trust fund equity investments are allowed within limits.

Overall, the PIMS investment model is a reasonable approach, providing a good compromise between the tractability of the model (length, time of running the code and calibration of model parameters) and the need to use plan specific information. Useful extensions would include additional asset classes (e.g. real estate), the modeling of uncertainty of the spread for corporate bonds, and (most important) a complete term structure model for nominal interest rates.

skewness, excess-kurtosis), for long term returns it is not clear if the substantially higher complexity to calibrate such models is justified.

${ }^{11}$ See Appendix A for one way to model real estate investments. 


\section{Integrating Assets and Liabilities: The Key Importance of the Interest Rate}

Besides the budget equations and the correlations of (the residuals of) the stochastic variables, the nominal interest rate is of key importance for PIMS. The nominal interest rate enters in the following components in the PIMS model in several ways:

1. Actuarial Valuation of Liabilities of terminated/ongoing plans ${ }^{12}$

2. Minimum Contribution Rules according to PPA rules

3. Specifying the return on plan assets for ongoing plans (stock and bonds)

4. Specifying the return PBGC assets for terminated plans (stock and bonds)

5. Yield for corporate bonds $=(i+$ spread $) *$ adj. factor

6. Inflation rate $=(1+i) /(1+$ fix real interest rate $)-1$.

7. Nominal benefit (wage) growths (since inflation is related to the nominal interest rate)

8. Calculation of the stochastic present value of PBGC claims

In the current version of PIMS, the nominal interest is modeled and calibrated as a single stochastic variable for U.S. government bonds with a maturity of 30 years. Such an approach does not allow for any variation in the shape (curvature) of the term structure, nor does it include any uncertainty in credit spreads. This is not state of the art in Asset-Liability-Modeling, nor is it consistent with empirical fluctuations of the term structure. For example, the current term structure is very steep ( $0 \%$ for T-bills and $3 \%$ for 30 maturities). Given the key importance of the

12 "The interest assumption for the annul valuation of ongoing plans is currently based on the 24 months average of the corporate bond rates; captured via a single effective interest rate. Alternatively, the three segment rates can be used for PIMS valuation. During the simulation, the underlying bond rates are assumed to change by a stochastic adjustment process" (PIMS System Desc. 3-13)" 
interest rate for PIMS using only one single random variable may be too parsimonious. One way to extend PIMS would model the complete term structure of interest rates. Such a term structure can be used to discount future benefits ${ }^{13}$ and also to model the development of fixed income assets in terminated and ongoing plans. Various (arbitrage free) term structure models (including procedure to calibrate the parameters) are available ${ }^{14}$.

\section{Communication of Outcomes: Conditional Value-at-Risk}

One outcome from the PIMS model is the distribution of the stochastic present values of the agency's future net positions using a 10-year horizon (except for the 20 year probability of PBGC insolvency). One way to communicate this distribution by a risk measure is to use the Conditional Value-at-Risk of pension cost at a certain confidence level $x$ (e.g. 95\%). The $\mathrm{x} \%$ Conditional Value-at-Risk $(\mathrm{CVaR})$ is defined as the expected present value of total future net liabilities under the condition that its realization is greater than the Value-at-Risk (VaR) for that level. The CVaR framework as a measure of risk is in many ways superior to the commonlyused Value-at-Risk measure, i.e. the costs that will not be exceeded with a given probability. In particular, the $\mathrm{CVaR}$ focuses attention on a given percentile of a loss distribution, and it also accounts for the magnitude of losses in the distributional tails beyond this percentile ${ }^{15}$. The

13 In the sense of a replication bond portfolio to match future liabilities.

14 See Balduzzi et al. (1996) or the book by Cairns (2004). The Federal Reserve Bank uses a 3-factor model for the U.S. term structure:

http://www.newyorkfed.org/research/staff_reports/research_papers/9619.html.

15 For a detailed discussion of the advantages of the CVaR over the more widely acknowledged VaR see, e.g., Artzner et al. (1999). 
$\mathrm{CVaR}$ risk metric could be a promising way to communicate risk to policymakers. In addition, this risk measure is consistent with important theoretical properties (e.g. it is a coherent risk measure).

Figure 3 illustrates the $\mathrm{CVaR}$ of the (stochastic) present value of costs for different investment strategies that might be used to fund the benefits of a defined benefit pension plan. ${ }^{16}$ The range of the optimal portfolio is substantially smaller than for pure equity or bond investments, while investing only in real estate would result in an even smaller range. The overall level of costs resulting from following the optimal strategy is also substantially lower, compared to the pure real estate investment case. Figure 3 illustrates the benefit of diversification to minimize the worst-case risk of pension costs represented with the CVaR.

Figure 3 here

\section{Conclusions}

Overall, the PIMS model is an important tool for modeling the liability risk of pension plans insured by PBGC. There is, to my knowledge, no other documented model available that can do a comparable job. Nevertheless, there are several opportunities for extensions:

- Incorporating systematic mortality risk

16 The results are based on an ALM-study of a large (German) public DB pension plan; see Maurer et al. 2009. Here, pension costs are defined as the stochastic present value of regular and supplementary (additional required in an underfunding situation) into the pension plan by the plan sponsors using a 50 year horizon). An illustration of a general ALM model appears in Appendix B. 
- Incorporation of a stochastic investment model for the major asset classes beyond stocks and bonds (including real estate).

- The modeling of the full term structure of interest rate. 


\section{Appendices}

Appendix Figure A1 here

\section{Appendix A: Modeling Real Estate}

Deriving reliable return time series for real estate as an asset class is difficult due to the peculiarities of property investments ${ }^{17}$. In contrast to equity and bond indices, inhomogeneity, illiquidity, and infrequent trading in individual properties result in transaction-based real estate indices not being able to adequately describe the returns generated in these markets. Moreover, such price indices do not account for rental income, which constitutes a significant source of return on real estate investments. By contrast, it is comparably easy to construct indices that try to approximate the income on direct real estate investments by using the return on investing indirectly through traded property companies like real estate investment trusts (REITs). However, empirical evidence on these forms of indirect real estate investments suggests that they exhibit a more equity-like behavior ${ }^{18}$. These indices are therefore a much less than perfect proxy for direct real estate investments (see Hoesli and MacGregor 2000).

Appraisal-based indices are widely used representatives for real estate investments. These indices account for easy to sample continuous rental income as well as for returns from changes in property values, which are estimated through periodic appraisals by real estate experts. As individual properties' values are usually estimated only once a year and due to the fact that there

17 This section is based on Maurer et al. (2009). For discussion of design and characteristics of real estate indices we refer to Hoesli and MacGregor (2000, Ch. 4).

18 In a survey by Eichholtz (1997), correlations between common equities and property company shares range from 0.12 to 0.96 . 
is no single valuation date for all properties, not every return observation in the index can be substantiated with a new and observation date consistent appraisal of the overall property portfolio underlying the index. Moreover, annual appraisals often draw significantly on prior valuations. Consequently, returns derived from appraisal-based indices exhibit substantial serial correlation and low short term volatilities that understate the true volatility of real estate returns. Different methodologies have been suggested to reduce undue smoothing in real estate return time series, which subsequently will exhibit more realistic levels of volatility ${ }^{19}$. To overcome this problem, the approach developed by Blundell and Ward (1987) suggests transforming the original (smoothed) return series according to:

$$
r_{t}^{*}=\frac{r_{t}}{1-a}-\frac{a}{1-a} r_{t-1}
$$

where $r_{t}^{*}$ represents the unsmoothed return in $t$ and $a$ the coefficient of first-order autocorrelation in the return time series. Under this transformation, expected returns remain constant, $\mathrm{E}\left(r_{t}^{*}\right)=$ $\mathrm{E}\left(r_{t}\right)$, but the return standard deviation increases according to:

$$
\operatorname{STD}\left(r_{t}^{*}\right)=\operatorname{STD}\left(r_{t}\right) \sqrt{\frac{1-a^{2}}{(1-a)^{2}}} .
$$

19 Other methods to unsmooth real estate return time series have been suggested by among others - Firstenberg et al. (1988), Ross and Zisler (1991), Fisher et al. (1994). 


\section{References}

Artzner, P., F. Delbaen, J. Eber, and D. Heath (1999). “Coherent Measures of Risk,” Mathematical Finance, 9: 203 - 228.

Barkham, R., and D. M. Geltner (1994). “Unsmoothing British Valuation-based Returns without Assuming an Efficient Market," Journal of Property Research, 11: 81-95.

Balduzzi, P., S. Ranjan Das, S. Foresi, and R. Sundraram (1996). “A Simple Approach to Threefactor Affine Term Structure Models," Journal of Fixed Income, December: 43-52.

Blake, D. (2006). Pension Finance. West Sussex.

Blundell, G. F., and C. W. Ward (1987). "Property Portfolio Allocation: A Multi-factor Model," Land Development Studies, 4: 145-156.

Cairns, A. (2004). Interest Rate Models: An Introduction. Princeton, NJ: Princeton University Press.

Cairns, A., D. Blake, and K. Dowd (2006a). "Pricing Death: Frameworks for the Valuation and Securitization of Mortality Risk," ASTIN Bulletin, 36: 79-120.

Cairns, A., D. Blake, and K. Dowd (2006b). “A Two-factor Model for Stochastic Mortality with Parameter Uncertainty: Theory and Calibration," Journal of Risk and Insurance, 73: 687718.

Cairns, A., D. Blake, K. Dowd, G. Coughlan, D. Epstein, and M. Khalaf-Allah (2010). “A Framework for Forecasting Mortality Rates with an Application to Six Stochastic Mortality Models,” Pensions Institute Discussion Paper PI-0801. London, U.K.: The Pensions Institute. 
Campbell, J. Y.; Y. L. Chan, and L. M. Viceira (2003). “A Multivariate Model of Strategic Asset Allocation," Journal of Financial Economics, 67: 41-80.

Eichholtz, P. M. (1997). "Real Estate Securities and Common Stocks: A First International Look,” Real Estate Finance, 14: 70-74.

Firstenberg, P. M., S. A. Ross, and R. C. Zisler (1988). "Real Estate: The Whole Story,” Journal of Portfolio Management, 14: 22-34.

Fisher, J. D., D. M. Geltner, and R. B. Webb (1994). "Value Indices of Commercial Real Estate: A Comparison of Index Construction Methods," Journal of Real Estate Finance and Economics, 9: 137-164.

Guidolin, M. and A. Timmermann (2007). “Asset Allocation Under Multivariate Regime Switching," Journal of Economic Dynamics and Control, 31(11): 3503-3544.

Hoesli, M., and B. D. MacGregor (2000). Property Investment: Principles and Practice of Portfolio Management. Harlow: Pearson.

Hoevenaars, R. P., R. D. Molenaar, P. C. Schotman, and T. B. Steenkamp (2008). "Strategic Asset Allocation with Liabilities: Beyond Stocks and Bonds," Journal of Economic Dynamics and Control, 32: 2938-2970.

Hustead, E. C., and O. S. Mitchell (2001). "Public Sector Pension Plans," in O. S. Mitchell and E. C. Hustead, eds., Pensions in the Public Sector. Philadelphia: University of Pennsylvania Press, pp. 3-10.

Lee, R., and L. Carter (1992). "Modeling and Forecasting U.S. Mortality," Journal of the American Statistical Association, 87: 659-671.

Maurer, R., O. S. Mitchell, and R. Rogalla (2009): “Reforming German Civil Servant Pensions: Funding Policy, Investment Strategy, and Intertemporal Risk Budgeting,” in O. S. 
Mitchell and G. W. Anderson, eds., The Future of Public Employee Retirement Systems. Oxford: Oxford University Press, pp. 32-50.

Maurer, R., O. S. Mitchell, R. Rogalla, and V. Kartashov (2013). "Lifecycle Portfolio Choice with Systematic Longevity Risk and Variable Investment-Linked Deferred Annuities," The Journal of Risk and Insurance, forthcoming.

Pension Benefit Guaranty Corporation (PBGC) (2010). PIMS System Description, Version 1.0. Washington, DC: PBGC.

Pitacco, E., M. Denuit, S. Haberman, and A. Olivieri (2009). Modeling Longevity Dynamics for Pensions and Annuity Business. Oxford: Oxford University Press.

Renshaw, A., and S. Haberman (2003). "Lee-Carter Mortality Forecasting with Age-specific Enhancement," Insurance: Mathematics and Economics, 33: 255-272.

Ross, S. A. and R. C. Zisler (1991). "Risk and Return in Real Estate," The Journal of Real Estate Finance and Economics, 4(2): 175-190. 


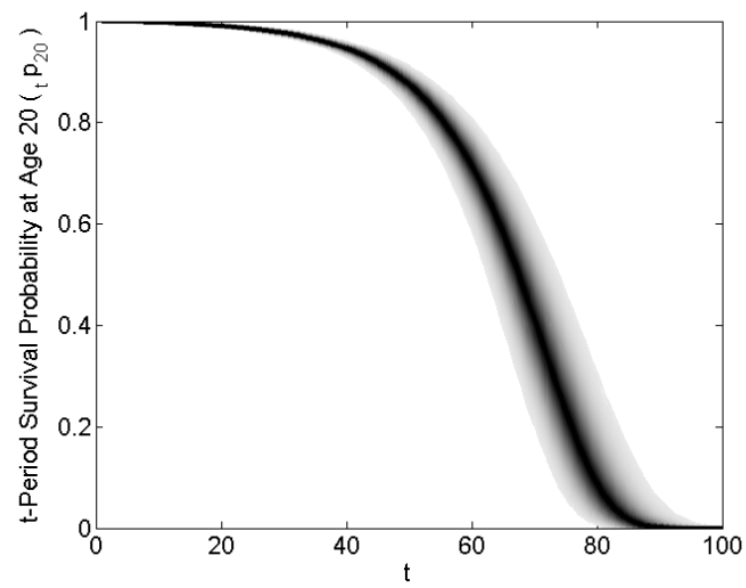

Figure 1. Systematic mortality risk: Distribution of survival probability: Age 20 female. Notes: Simulated distribution of age-20 female t-period survival probabilities (99\%:1\%) based on Cairns, Blake, and Dowd (2006b) mortality model (for parameters see text; $\mathrm{N}=10,000$ simulations). Darker areas represent higher probability mass. Source: Maurer et al. (2013). 


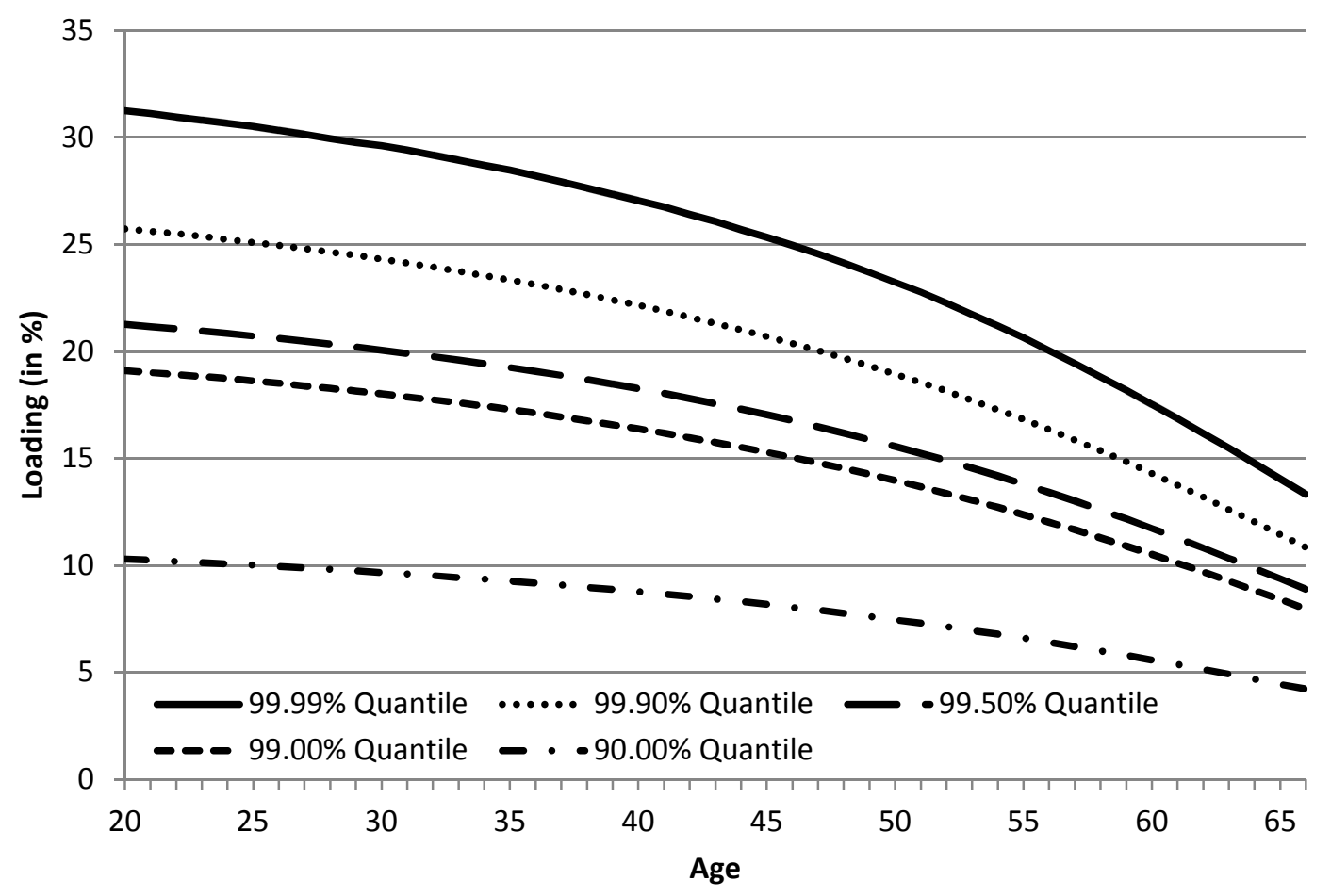

Figure 2. Stochastic mortality and risk charges for annuity benefits. Notes: The implied loadings represent additional premiums relative to the average number of required Fund Units (FUs) that must be charged to U.S. females for purchases at various ages to provide the VILDA at the specified confidence level. VILDA payments commence at age 67 with one initial FU and decrease thereafter according to the AIR (3\%). Confidence levels are based on the distribution of required FUs calculated for each of 10,000,000 simulated mortality paths using the Cairns, Blake, and Dowd (2006b) two-factor stochastic mortality model fitted to U.S. mortality tables from 1933-2007 (the assumed maximum age is 120). Source: Maurer et al. (2013). 


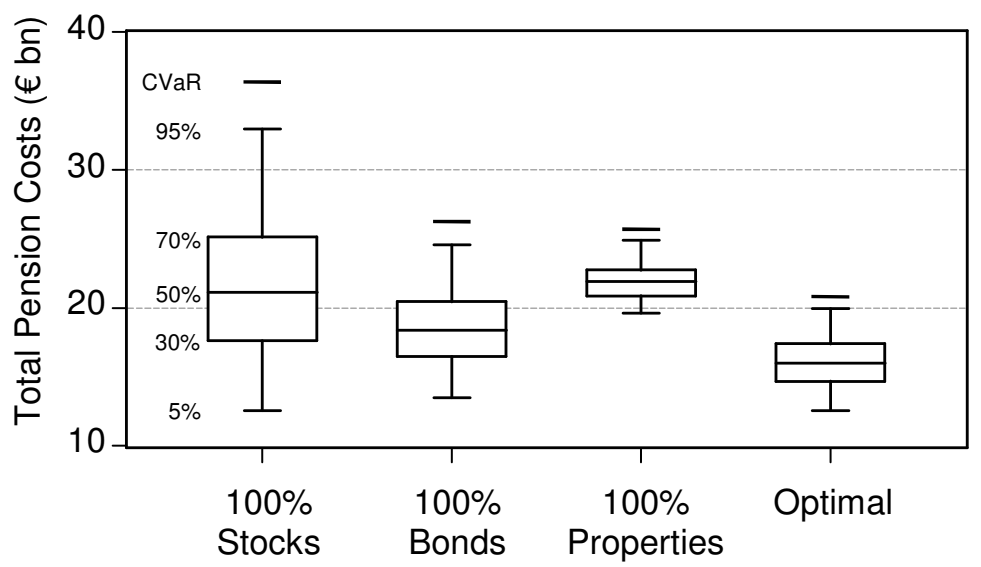

Figure 3. Illustration of $\mathrm{CVaR}$ to communicate the range of pension costs. Notes: Total Pension Costs defined as net of Regular and Supplementary Contributions using 3\% discount rate. Annotations refer to the respective percentiles of total pension cost distributions for various asset allocations. Source: Maurer, Mitchell, and Rogalla (2009). 


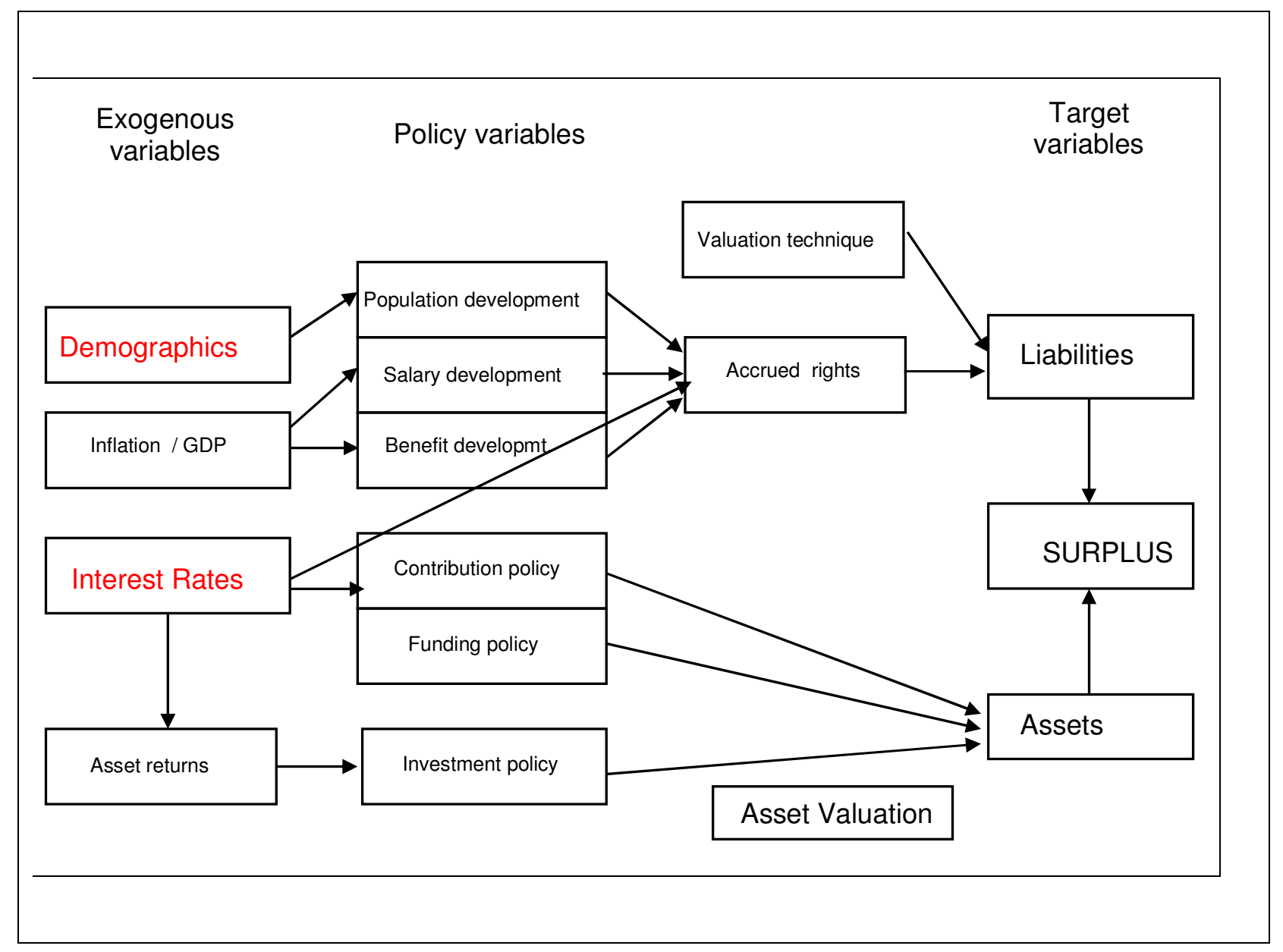

Figure A1. General structure of integrated ALM models. Source: Author's elaboration. 


\title{
Observations on Actuarial Assumptions and Models for Defined Benefit Pension Plans
}

\author{
Donald E. Fuerst \\ American Academy of Actuaries \\ September 2013 \\ Michigan Retirement Research Center \\ University of Michigan \\ P.O. Box 1248 \\ Ann Arbor, MI 48104 \\ www.mrrc.isr.umich.edu \\ (734) 615-0422
}

\section{Acknowledgements}

This work was supported by a grant from the Social Security Administration through the Michigan Retirement Research Center (Grant \# 5 RRC08098401-05-00). The findings and conclusions expressed are solely those of the author and do not represent the views of the Social Security Administration, any agency of the Federal government, or the Michigan Retirement Research Center.

\section{Regents of the University of Michigan}

Mark J. Bernstein, Ann Arbor; Julia Donovan Darlow, Ann Arbor; Laurence B. Deitch, Bloomfield Hills; Shauna Ryder Diggs, Grosse Pointe; Denise Ilitch, Bingham Farms; Andrea Fischer Newman, Ann Arbor; Andrew C. Richner, Grosse Pointe Park ; Katherine E. White, Ann Arbor; Mary Sue Coleman, ex officio 


\title{
Observations on Actuarial Assumptions and Models for Defined Benefit Pension Plans
}

\begin{abstract}
The goal of this paper is to review and comment on certain aspects of the Pension Insurance Modeling System (PIMS) and certain actuarial assumptions used by PIMS. The apparent stability of the deficit and funding ratio of the PBGC are partially dependent on a continued stream of premium payments from plan sponsors. However, derisking and other trends among retirement plans may change the pattern of premium income. Deterministic projections that supplement the stochastic simulations may enhance the understanding of the current deficit and the projected net claims over the next ten years.
\end{abstract}

\section{Citation}

Fuerst, Donald E. (2013). "Observations on Actuarial Assumptions and Models for Defined Benefit Pension Plans,” University of Michigan Retirement Research Center (MRRC) Working Paper, WP 2013-290(e). Ann Arbor, MI.

\section{Authors’ Acknowledgements}

The research reported herein was pursuant to a grant from the U.S. Social Security Administration (SSA) funded as part of the Retirement Research Consortium (RRC); the author also acknowledges support from The Pension Research Council at The Wharton School. All findings and conclusions expressed are solely those of the author and do not represent the views of the SSA or any agency of the federal government, the MRRC, the PRC, or The Wharton School at the University of Pennsylvania. All findings, interpretations, and conclusions of this paper represent the views of the authors and not those of the Wharton School or the Pension Research Council. (C2013 Pension Research Council of the Wharton School of the University of Pennsylvania. All rights reserved. 


\title{
Observations on Actuarial Assumptions and Models for Defined Benefit Pension Plans
}

\author{
Donald E. Fuerst
}

The Pension Insurance Modeling System (PIMS) is a stochastic modeling system used by the Pension Benefit Guaranty Corporation (PBGC) and other parties to project certain risk exposures over periods of up to 20 years in the future. There are two versions of the system, SEPIMS for single-employer plans and ME-PIMS for multiemployer plans. The PBGC uses PIMS projection results principally in its exposure report to provide information about the range of possible future scenarios the single and multi-employer programs could face and the ability of the PBGC to meet its obligations. Supplemental uses include generating financial projections to estimate the effect of various legislative proposals. This paper examines certain aspects of these projections and suggests possible alternatives to enhance the understanding of these projections. Here we deal primarily with the single-employer system, so references to PIMS generally mean SE-PIMS unless the context clearly refers to the multiemployer program.

\section{The Nature of New Claims}

PBGC generally experiences a new claim due to a distress termination of a defined benefit (DB) pension plan. PIMS projects new annual claims for the next 20 years. A new claim is essentially the difference between the present value (at the time of the new claim) of the estimated future benefit payments to participants of the plan, less the market value of the plan assets that the PBGC takes over. The claim includes only benefits guaranteed by the PBGC, not any benefits in excess of the guarantee. The claim may be further reduced by any amount recovered by PBGC from bankruptcy proceedings. When PIMS projects a new claim, the interest 
rate used to determine the present value is based on the stochastic model, and it could be more or less than the rate used to evaluate previously existing claims at the financial statement date.

The present value of projected new claims reported in the most recent Exposure Report (PBGC 2012a: 8) is $\$ 14$ billion at the 15th percentile, $\$ 34$ billion at the mean, and $\$ 55$ billion at the 85 th percentile. Each amount represents the present value of the difference between the gross claims (the present value of all future payments in each claim) and the present value of the assets taken over at the time of the claim.

\section{The PBGC Funded Ratio}

The $\$ 29.1$ billion deficit of the single-employer program on 9/30/2012 equates to a funded ratio of approximately 74 percent (assets of $\$ 82,973$ million divided by liabilities of $\$ 112,115$ million). The PIMS projections for the subsequent 10 years show a substantial range in the projected net position, from a $\$ 66$ billion deficit to a $\$ 1$ billion surplus. The median deficit is $\$ 29.9$ billion, a modest increase from the 2012 level. This median deficit equates to a funded ratio of approximately 77.6 percent based on mean liabilities (median liability was not disclosed in the exposure report, but would be somewhat less, producing a slightly higher funded ratio).

A preliminary look at these median projections might cause one to conclude that the PBGC financial situation is relatively stable. The deficit is projected to increase less than $\$ 1$ billion and the funded ratio increases by more than 3 percent. But the wide range of potential results serves as an immediate caution to such a conclusion, but there may also be other reasons to view this apparent stability skeptically. To understand one such reason, it is helpful to look at deterministic cash flow models of the PBGC's financial position. 


\section{Future Cash Flow Projections}

The PBGC Annual Report (PBGC 2012b) and the Exposure Report (PBGC 2012a) describe the agency's current and projected financial status, but these could be expanded to provide additional useful information. Both reports provide the present value of future benefits, without showing the cash flows used to make this calculation. The projected cash flows by calendar year, without any interest discounting, could provide further useful insight into the financial obligations.

The Exposure Report indicates that, in the 5,000 scenarios simulated in SE-PIMS, none produced an exhaustion of funds during the 10-year projection horizon. Perhaps this is reassuring, but it does not prove that serious problems do not exist beyond the 10-year projection.

The 2012 deficit of $\$ 29.1$ billion implies a scenario where the single-employer program would exhaust its funds if the future is as anticipated by all assumptions, and no additional premium revenue were received. While this is a hypothetical scenario, it could be the first step in a series of useful projections. The existing assets would be augmented by investment income at the rate of 3.28 percent per year and reduced by the benefit payments for all obligations currently recognized by the PBGC. Under these assumptions, funds would be exhausted at a future date before all obligations had been met. This date could be 10, 20, 30, or more years in the future. Based on current benefit payments of $\$ 5.3$ billion per year, the exhaustion date would likely be more than 20 years in the future, but benefit payments will probably increase in future years, causing the potential exhaustion date to arrive sooner than projected.

The next useful step would be to combine this deterministic projection of cashflows with the PIMS projection of future investment income for existing assets. PIMS models future 
investment income based on the asset allocation of the current portfolio (approximately 70 percent fixed income and 30 percent equity). The projected income from the current investment portfolios at the 15th percentile, median, and 85th percentile could be substituted for the deterministic income projection at 3.28 percent. The median and 85 th percentile projections would likely show an exhaustion date later than the 3.28 percent deterministic projection. The 15th percentile of investment income might shorten or extend the exhaustion date depending on the level of income. This comparison to the deterministic projection at 3.28 percent would provide a useful measurement of the expected gain resulting from the investment of part of the portfolio in equities as well as a measure of the additional risk resulting from this investment.

These measures of the cashflow projections provide additional information about the current status of the PBGC based on existing claims. These projections exclude additional assets the PBGC acquires in future years due to new distress terminations and additional premium income.

The deficit and funded ratio after 10 years under these projections could be compared to the deficit and funded ratio projection of the Exposure Report. This comparison would show the effect of future underwriting experience on the deficit over the projection period.

These additional projections would supply additional information concerning the effects of future premium collection and underwriting experience.

\section{Perverse Effect of New Claims}

At the median, PIMS projects underwriting losses in all future years. Despite this poor performance, the funded ratio improves over the 10-year projection period, and no projections indicate that the PBGC will run out of funds within 10 years. Why this apparent anomaly? As 
new claims occur, PBGC takes over both assets and liabilities of the terminated plans. The liabilities are greater, but the maturity of the plan and the duration of the new liabilities may be much different than PBGC's existing obligations. As new claims are added, if the duration of liabilities is longer than the duration of previous claims, the year in which assets will be exhausted can be extended. If the funded ratio of terminated plans (always less than 100 percent) is higher than the PBGC funded ratio before the new claim, the deficit will increase, but the funded ratio may improve marginally.

These apparent beneficial aspects of new claims are deceptive. Continued improvement depends on a continuing flow of these net claims. This might be possible in a robust and growing environment for pension plans, but in a world in which relatively few new plans are established and in which total coverage of plan participants is declining (PBGC 2010), a more difficult future may lie ahead. As the system gradually contracts, new claims will not extend the exhaustion of funds and may not affect the funded ratio, but instead will add to the total deficit.

\section{Assumptions Regarding Future Premiums}

PBGC currently projects future premium receipts assuming that only financially distressed companies will terminate their plans. Furthermore, there is no explicit assumption about changes in the size of existing plans. Yet in practice, many plans are shrinking, due to policies known as "derisking." A sponsor implementing a derisking policy may offer plan participants the opportunity to receive a lump sum payment in lieu of all future pension payments. Another derisking policy involves purchasing an annuity from an insurance company which will then provide all future benefits due. After either of these financial transactions, the plan has liabilities and assets, fewer plan participants, but often no less unfunded liability. That 
is, the decrease in assets and liabilities is generally about equal, so the risk exposure of the PBGC is not significantly affected. However, PBGC premium income is dependent on the number of plan participants (fixed premiums are $\$ 42$ per participant in 2013, $\$ 49$ per participant in 2014, and indexed to inflation thereafter). In 2012, multiple large pension plans offered lump sum distributions to thousands of participants or purchased annuities for retirees ${ }^{1}$.

The Pension Protection Act (PPA) changes adopted in 2006 regarding lump sum distributions became fully effective in 2012. These changes make lump sum distributions less expensive for plans than prior to 2012. Previous requirements based the interest rate for the lump sum calculation on 30-year Treasury rates, but now the interest rate is based on corporate bond rates. The higher rate for corporate bonds results in lower lump sum calculations, so the lump sum distribution is less expensive to the plan sponsor. The lower amount should make lump sums relatively less attractive to participants, but they have not seemed to significantly reduce the number of participants taking lump sums so far.

An increasing number of plans offer lump sum distributions as a regular option for all participants at retirement or termination of employment (Aon Hewitt 2013). Cash balance plans are an example of this type design.

Service providers to frozen defined benefit (DB) plans often advise designing "glidepath" strategies. A glidepath strategy usually involves increasing the funded ratio of the plan and gradually derisking the plan investments as the funded ratio improves. The ultimate goal is usually to terminate the plan using a standard termination procedure when the funded ratio exceeds 100 percent. After a standard termination, the PBGC no longer has risk exposure, but it also lacks the premium income associated with the plan.

\footnotetext{
${ }^{1}$ General Motors, Ford and Verizon initiated substantial pension settlements in 2012.
} 
From 1991 to 2011, annual annuity purchases never exceeded \$5 billion. Now, some observers project that the annuity purchase market for qualified plans over the next five years may range from $\$ 35$ billion to $\$ 100$ billion (Mercer 2013). This could significantly change PBGC premium collections.

The increasing trend of lump sum distributions as regular options in some plans, the trend to offer lump sums to some inactive participants, the increasing tendency of plans to purchase annuities, and the acknowledged glidepath strategies of some plans sponsors, all suggest that the PBGC should examine the impact of assuming declining numbers of participants in covered plans and less premium income in future years.

\section{Importance of the Premium Income Assumption}

The current PIMS projections do not anticipate a decline in plan coverage, and which may make it difficult to identify an impending risk to the PBGC. The current projections, at the median, show little growth in the agency's deficit and modest improvement in funded ratios over 10 years. This demonstrates that, in a stable pension system, one in which there continues to be many plan sponsors and in which overall participation remains stable, it is possible to continue a pension insurance program without ever funding the deficit. As long as premium income and investment income are adequate, benefit payments can be made to all beneficiaries for many years, perhaps indefinitely, without full funding of the deficit. Sufficient premium income can continually defer the date at which funds might be exhausted.

The situation changes dramatically if participation and premium income begins to decline. Reductions in participants due to lump sum distributions and annuity purchases reduce 
premium income. Standard terminations of glidepath plans eliminate all premium income for the plan, but do not reduce PBGC exposure since a fully funded plan poses little risk to the PBGC.

As participation declines while risk exposure remains at similar levels, premiums may need to be increased to sustain financial viability of the PBGC. But at some point increasing premiums can accelerate sponsor actions to further reduce participation in covered DB plans, thus producing little or no additional revenue.

A revised assumption about future premium growth combined with the cashflow projections suggested earlier would provide valuable insight into the effects of declining plan coverage.

\section{Contribution Assumptions}

The PIMS model assumes that companies make the minimum contribution required. Yet, PBGC notes and other studies (Society of Actuaries 2011) have confirmed, that many companies make plan contributions in excess of the minimum. PBGC acknowledges that this assumption may cause variable rate premium projections to be overstated. For variable rate premium projections only, an adjustment is made to plan assets based on recent historical variable rate premium experience to lessen or avoid this overstatement.

This limited adjustment could cause an overstatement of exposure in two ways. First, higher contributions that companies make reduce the agency's risk exposure. Not only is the variable rate premium reduced, but the actual risk exposure of the PBGC is also reduced. Second, basing the adjustment on the recent historical variable rate premium experience is unlikely to capture behavioral changes resulting from a doubling of the variable rate premium from 2013 to 2015. Plan sponsors will soon have twice the incentive to make additional 
contributions and that incentive will continue to increase as the variable rate premium has been indexed to inflation after 2014. To the extent that plan sponsors react to this new incentive to fund plans, the ultimate risk exposure of PBGC may be lowered.

Balancing this point however, the PBGC notes that the plans most likely to respond to these behavioral incentives are the plans with relatively healthy sponsors who are less likely to fall into bankruptcy and distress termination. Those sponsors in less favorable financial circumstances seem slower to respond to incentives to fund more. If this trend dominates, the more dangerous exposure of the less healthy sponsors would not be reduced.

\section{Actuarial Gain/Loss Analysis}

An actuarial valuation involves many estimates about future experience. As actual experience emerges over time, the annual actuarial valuation measures the estimated experience against the actual and adjusts future estimates to reflect what has been learned about actual experience. The Annual Report of the PBGC includes a Reconciliation of the Present Value of Future Benefits from the previous year to the current financial statement date. This reconciliation includes certain actuarial adjustments.

The Exposure Report could usefully add comparisons of past projections to emerging experience, to soon provide better information on the sensitivity of these assumptions. For example, the 2012 Annual Report indicates that total premium income increased substantially from $\$ 2.08$ billion to $\$ 2.62$ billion. All of this increase was attributable to an increase in variable rate premiums ( $\$ 0.93$ billion to $\$ 1.49$ billion). On the other hand, the flat rate premium for single-employer plans had a small decrease, indicating fewer overall participants in the insurance program. If sponsors significantly increase contributions to reduce variable premiums, overall 
premium income might fall. Much of the increase in variable premiums may be the result of lower interest rates and thus higher liabilities. Rising interest rates could significantly affect this variable premium income. Further, since many single-employer pension plans have significant equity exposure in their asset portfolios, a rise in equity prices could also lower future premium income.

Projected benefit payments compared to actual payments might give insights into the appropriateness of several assumptions, particularly mortality and expected retirement age. Projected benefit payments could be compared to actual payments in a manner that splits existing claims at the previous valuation and new claims since the previous valuation. Comparisons might be based on three- or five-year periods rather than annual to provide greater statistical relevance.

Another interesting assumption that would benefit from comparison to actual experience is the assumption that plans involved in a bankruptcy will only result in a claim to the PBGC if the funded ratio of the plan at bankruptcy is less than 80 percent. Further information concerning this 80 percent assumption might also provide a better understanding of the projections. In particular, is this assumption consistent with recent experience? Are plan sponsors that are involved in bankruptcy able to maintain or fund up a plan that is 80 percent or greater? What is the dollar weighted funded ratio of distress termination plans in recent years?

\section{Simplifications}

SE-PIMS uses the RP-2000 mortality table with projections for determining a plan's mortality experience during the projections and the amount of underfunding at termination (PBGC 2012a: 18). After termination a greatly simplified assumption is used with one composite table using only male mortality experience (PBGC 2012c). Several other simplifying 
assumptions are used - all plans have uniform asset allocation, only single-life annuities are valued, and a single effective interest rate used instead of segment curves or the full yield curve. These simplifications probably have little significance when compared to the much greater variability of interest rates, investment returns and bankruptcy rates. Still, it is curious why a system as complex as PIMS uses only male mortality experience and only single life annuities.

\section{Alternative Plan Types}

PIMS was primarily designed to model primarily final average pay and flat dollar per year of service pension plans. Other plans designs are handled by simplifications or scaling factors. But existing DB plans evolve, these simplifications may become less appropriate and in need of change.

For instance, career pay plans have been one way in which plan sponsors have moved to limit risk in their DB plans. By basing benefits on career average pay rather than pay in the last few years of employment, the benefit liability is less leveraged to pay increases and generally grows more slowly.

Cash balance plans are one of the few types of DB plans that are frequently being adopted as new plans. A cash balance plan has a much flatter growth curve than a traditional final pay plan or even a career pay plan. Normal costs and liabilities grow at different rates than traditional plans, and so the model will require different projections as inputs, to reasonably project future growth and exposure.

Cash balance plans, like other account-based plans, often offer a lump sum benefit at retirement. And traditional DB plans are now offering lump sum distributions as well. To the extent that PBGC takes over plans offering lump sum distributions, the participants remaining 
are a select group that elected annuities rather than lump sums. If they experience lower mortality and greater longevity, this can pose a larger obligation on the PBGC. This antiselection effect could gradually make the mortality table used by PBGC inadequate for the actual experience of more select groups.

\section{Conclusions}

PIMS provides modeling and simulations of multiple highly uncertain events and outcomes. Many of the actuarial assumptions used in the PIMS model are simplified to reduce complexity and computation time. Some of these assumptions might be considered overly simplistic in a valuation of a typical pension plan (e.g. one composite mortality table, all male, all single life annuities), but in the context of simulations that must model the frequency of uncommon events such as bankruptcy, the margin of error produced by the simplification is not likely to be significant.

The usefulness of PIMS output and analysis could be enhanced by incorporating some deterministic projections. Cash flow projections that provide the ultimate year in which PBGC assets would be exhausted under various assumptions might prove especially useful. Understanding the current deficit would be enhanced by showing how long the funds on hand can cover payments to current retirees. Incremental additions to this projection, adding the likely income from actual portfolios, would add to the understanding of the nature of the assets and how risky investments add to uncertainty and potential returns.

The apparent stability of the deficit and funded ratio of the PBGC depend on a continued stream of premium payments from DB plans. But the increasing trend of derisking pension plans 
through lump sum distributions, annuity purchases, and investment strategies designed to lead to standard termination may produce decreasing premium income in future years. 


\section{References}

Aon Hewitt (2013). "Press Release: Survey Reveals More Employers Plan to Offer Lump-Sum Pension Payouts in 2013," Lincolnshire, IL: February 13.

Mercer (2013). “Pension Risk Transfers Revisited,” Retirement Perspective: March 26.

Pension Benefit Guaranty Corporation (PBGC) (2010) PBGC Pension Insurance Data Book 2010, Tables S-31 and S-33. Washington, DC: PBGC.

Pension Benefit Guaranty Corporation (PBGC) (2012a). FY 2012 PBGC Exposure Report. Washington, DC: PBGC.

Pension Benefit Guaranty Corporation (PBGC) (2012b). Excellence in Customer Service, Pension Benefit Guaranty Corporation Annual Report 2012. Washington, DC: PBGC.

Pension Benefit Guaranty Corporation (PBGC) (2012c). PIMS User Guide. Washington, DC: PBGC.

Society of Actuaries (2011). "The Rising Tide of Pension Contributions Post-2008: How Much and When?" Society of Actuaries Research Project. Schaumburg, IL: Society of Actuaries. 


\title{
Actuarial Perspectives on Defined Benefit Pension Risk - Modeling Emerging Issues
}

\author{
Christopher M. Bone
}

Edth Limited LLC

September 2013

\author{
Michigan Retirement Research Center \\ University of Michigan \\ P.O. Box 1248 \\ Ann Arbor, MI 48104 \\ www.mrrc.isr.umich.edu \\ (734) 615-0422
}

\section{Acknowledgements}

This work was supported by a grant from the Social Security Administration through the Michigan Retirement Research Center (Grant \# 5 RRC08098401-05-00). The findings and conclusions expressed are solely those of the author and do not represent the views of the Social Security Administration, any agency of the Federal government, or the Michigan Retirement Research Center.

\section{Regents of the University of Michigan}

Mark J. Bernstein, Ann Arbor; Julia Donovan Darlow, Ann Arbor; Laurence B. Deitch, Bloomfield Hills; Shauna Ryder Diggs, Grosse Pointe; Denise Ilitch, Bingham Farms; Andrea Fischer Newman, Ann Arbor; Andrew C. Richner, Grosse Pointe Park ; Katherine E. White, Ann Arbor; Mary Sue Coleman, ex officio 


\title{
Actuarial Perspectives on Defined Benefit Pension Risk - Modeling Emerging Issues
}

\begin{abstract}
This paper reviews documentation provided on the Pension Benefit Guaranty Corporation's (PBGC’s) Pension Insurance Modeling System (PIMS). It also discusses priorities for future development of the system, based on emerging issues in pension plan design and environment, and it suggests particular emphasis be placed on improvements in refining the modeling of the multiemployer program.
\end{abstract}

\section{Citation}

Bone, Christopher M. (2013). “Actuarial Perspectives on Defined Benefit Pension Risk Modeling Emerging Issues.” University of Michigan Retirement Research Center (MRRC) Working Paper, WP 2013-290(f). Ann Arbor, MI.

\section{Authors' Acknowledgements}

The research reported herein was pursuant to a grant from the U.S. Social Security Administration (SSA) funded as part of the Retirement Research Consortium (RRC); the author also acknowledges support from The Pension Research Council at The Wharton School. All findings and conclusions expressed are solely those of the author and do not represent the views of the SSA or any agency of the federal government, the MRRC, the PRC, or The Wharton School at the University of Pennsylvania. All findings, interpretations, and conclusions of this paper represent the views of the authors and not those of the Wharton School or the Pension Research Council. (C2013 Pension Research Council of the Wharton School of the University of Pennsylvania. All rights reserved. 


\section{Actuarial Perspectives on Defined Benefit Pension Risk - Modeling Emerging Issues}

Christopher M. Bone

The Pension Benefit Guaranty Corporation (PBGC) Pension Insurance Modeling System (PIMS) is a stochastic model used by PBGC to evaluate the risks to its single employer and multiemployer programs, and to evaluate the range of potential financial statuses of the programs in the near future. Secondary uses of the program include legislative analyses of pension funding requirements and of program guarantees. The system has also been made available to outside users with an interest in modeling the overall U.S. pension system (PBGC 2012b). PIMS was initially implemented for the single employer program (SE-PIMS). More recently, a separate version of PIMS has been developed, using and significantly revising the core PIMS functionality to examine financing of PBGC's multiemployer program (ME-PIMS).

This paper is based on a review of documentation provided by PBGC regarding both SEPIMS and ME-PIMS, and various reports generated using the PIMS model; our review also suggests areas of further development and how they might be prioritized. Our view recognizes that development priorities are generally formulated within an environment of constrained resources and competing advice. Accordingly, we suggest prioritizing model development based on a quantified estimate of the impact of the changes on model results.

\section{The Status of the Multiemployer Program}

The development and deployment of the ME-PIMS program in 2009 was an important enhancement of PBGC's ability to model its potential risks. The effort was validated by the recent and unprecedented emergence in 2010 through 2012 of deficits reaching over $\$ 1$ billion in 
the Multiemployer Program (PBGC 2013b: Table M-1). These deficits are large not only in dollar terms, but also as a percentage of the resources of PBGC's Multiemployer program. Reported liabilities were almost four times the reported assets in 2012, and the 2012 deficit exceeded 50 times premium revenues (PBGC 2012a). Although premium amounts are scheduled to increase by $33 \%$ for 2013 , this is not nearly sufficient to repair the deficits facing the program (see Figure 1).

\section{Figure 1 here}

While one would not characterize the single-employer program as being in good health, its recent financial position shows a relatively more stable set of financial ratios than does the multiemployer program (see Figure 2).

Figure 2 here

The PBGC has used ME-PIMS to quantify the risk of insolvency in the program in recent reports (PBGC 2013a). These reports indicate a high likelihood of continued deterioration of program financial results and a significant probability that the program will run out of money if current law is continued. In fact, current law is not scheduled to be continued; current law funding rules are scheduled to expire at the end of the current Congressional session (i.e., after 2014). Expiration without further legislative action would result in the prior funding rules going back into effect, requiring even less funding of multiemployer plans and further increasing PBGC's risk of insolvency and participant risks of benefit losses.

These issues combine to suggest that legislative activity and analysis needs will be important in the near future, and that continued improvement in the capabilities of ME-PIMS should remain a high priority for PBGC staff. After considering the relative stability of the SE- 
PIMS system, maintenance and improvement of ME-PIMS should arguably be the highest priority for PBGC staff overseeing PIMS.

Quality assurance. PBGC has commissioned a peer review of ME-PIMS (Buck Consultants 2012) as well as listings of known issues compiled by its software vendor (Lynchval Systems 2012). PBGC summarized the major issues in a disclaimer to its recent report to Congress as four potential changes to assumptions in the model and two other changes to ME-PIMS algorithms (PBGC 2013a). PBGC explicitly stated that the agency could not predict with confidence how these changes would alter model results. Not addressed in the disclaimer were the comments in the peer review report regarding: (a) system documentation; (b) ability to make programming changes; (c) system structure/organization; and (d) output. These comments in the peer review report generally amplify comments provided by the software vendor. It is important not to lose sight of these additional comments.

When an actuarial model is being developed to include new capabilities and new users, it is always a struggle to allocate resources to document quality assurance processes and to ease the testing and tabulation of results. But it is important that PBGC document the steps it takes to assure the quality of data inputs, verify the correctness of individual runs to test different policies, and ensure that the analyses are correct and complete. Written documentation that specifies the processes used to ensure accurate modeling allows management to better control the quality of the modeling process, particularly when modeling needs are urgent. While detailed documentation was not provided for review, agency comments indicate that PBGC has drafted a quality assurance procedures manual. The author encourages PBGC staff to periodically review these procedures and follow through on the recommendations in the peer review report (Buck Consultants 2012) regarding process and documentation and those in the system software vendor 
report (Lynchval Systems 2012) regarding replicability of results under different system configurations.

In establishing and revising quality assurance processes, PBGC may wish to informally confer with chief actuaries in other agencies that sponsor complex models, and also to reach out to professional actuarial organizations for assistance in assembling groups willing to share information on their processes. Given the rapidity of computational system changes, informal benchmarking may be more effective in designing or redesigning quality assurance policies that work within PBGC's constraints than more formal survey processes.

Modeling cutbacks in participant benefits. The primary use of ME-PIMS is to look at risk from the perspective of PBGC's balance sheet. A secondary use of the model is to evaluate legislative proposals for changes to the rules that affect multiemployer program guarantees, premium levels, withdrawal liability rules, and funding requirements.

A useful addition to the model would be the ability to quantify reductions in participants' accrued benefit rights. After decades where federal pension law was increasingly protective of accrued benefit rights, the Pension Protection Act (PPA) reversed course and allowed for certain cutbacks in accrued benefits (including reductions in early retirement subsidies) in the context of multiemployer plans deemed Critical and forced to adopt a rehabilitation plan. ME-PIMS models these types of behavior changes by plan sponsors. PBGC also applies cutbacks to guaranteed benefit levels when plans enter various stages in preparation for, or actual receipt of, financial assistance from PBGC. ME-PIMS also models these cutbacks (PBGC 2009).

Given the financial prospects for PBGC's current multiemployer program, legislative proposals are emerging (Defrehn and Shapiro 2013) that may provide additional methods of partially cutting back benefits for participants in severely underfunded plans as a preferable 
alternative to ultimate reliance on an, even smaller, level of PBGC guaranteed benefits. It could be helpful to policy-makers if PBGC could capture and report on the amount of benefit reduction generated in ME-PIMS at different stages, both in terms of the percentage reduction in benefits for participants in any year and the present value of such benefit reductions. This information would allow more informed comparison of the risks to participants from different legislative proposals (in addition to analyzing the risks to PBGC and the amount of increases in funding requirements).

SE-PIMS modeling of future benefit accruals. The past decades have seen many changes in the design of single employer pension plans, most of which have tended to lower the rate of future benefit accruals. Also many employers have adopted new forms of pension plans designed to more directly link benefits to the lump sum value of the compensation represented by the pension plan. Such plan designs, commonly referred to as cash balance and pension equity plans, are not currently modeled in PIMS, although there are plans to begin modeling cash balance plans (PBGC 2010: Section 1.2). Further, as rates of inflation have slowed and defined contribution (DC) account balances matured, many sponsors have changed the mix of retirement programs they provide to employees, cutting back or sometimes eliminating future accruals when updating pension plan designs. While it was once common for sponsors to amend career average pay plans to keep benefits up to date with salary changes and to provide ad hoc inflation adjustments to retirees, these activities have slowed dramatically of late. Further, more than a 
third of private DB pensions have in some way frozen benefit accruals (PBGC 2013b: Tables S$36, \mathrm{~S}-37)^{1}$

PBGC's documentation acknowledges many of these changes are not reflected in its current model. For instance, PBGC does not model career average plans directly, but instead models a final average pay plan that provides equivalent current benefits. (PBGC 2010: Section 1.2) This has the effect of presuming future benefit changes in the career average pay plan which appear increasingly unlikely. (PBGC has plans to review this item.) Similarly, PBGC cannot model complicated plan benefit formulae, and it is not able to model many forms of intermediate plan freezes such as "soft" freezes or reductions in the rate of future benefit accruals.

PIMS documentation indicates that when the system is "trued-up" to match the liabilities reported on the Form 5500 and its schedules, the resulting normal cost has been overstated by about $30 \%^{2}$ (PBGC 2010: Section 1.2). Normal cost is a broad measure of the cost of benefits being earned. For this reason, overstatements in the normal cost may be indicative of a general overstatement in future liabilities. PBGC agency comments indicate that they have implemented changes to the system to separately true-up normal cost. Yet, this will not necessarily fix the problem of potentially overstating future benefit accruals, to the extent that PIMS ages the

\footnotetext{
${ }^{1}$ As of $2011,36.1 \%$ of Single-Employer Plans were partially or fully frozen and another $5.1 \%$ of plans were closed to new entrants. These plans covered $27.6 \%$ and $12.8 \%$, respectively, of participants in active plans.

2 "An empirical test of the Schedule B/SB current liability normal cost amounts versus PIMS calculated results for 2007 shows an aggregate overstatement of the PIMS starting normal cost of $30 \% . "$
} 
population and continues to apply the unadjusted plan terms. In fact, it has the potential to further exacerbate the problem. ${ }^{3}$

How material these changes in plan design would be is unclear. Recent changes in pension law may better tie the funding of new accruals to the periods when they are earned. Many have speculated that the majority of the PBGC's exposures are "baked in" to the existing system. For this reason, it would be helpful for the PBGC to first use the PIMS model to quantify the relative contribution of future benefit accruals to its risk profile. It could do so by running PIMS with an assumption that all plans freeze and entirely cease future benefit accruals. To the extent that this test quantifiably demonstrates that PBGC's risk profile is primarily derived from existing benefit accruals, improvements to the model to refine the modeling of future benefit accruals may take on a low priority. But to the extent PBGC saw significant portions of its future risk arise from new benefit accruals, further research could help identify the source of that risk

${ }^{3}$ PIMS documentation is unclear on the specific coding used in the module that revalues the plan liabilities in future years. Portions of the documentation describe the plan population being aged and then valued directly under the terms of the plan (e.g. projected to each age of potential decrement with a benefit based on service to that point). Under this approach, end-stage adjustments to the normal cost will not reduce the rate of future accruals under the plan but will instead lead to the generation of liability losses, continuing to present a plan with larger liabilities due to future benefit accruals than are appropriate. Furthermore, by treating the phantom accruals as liability losses rather than as normal costs, the accruals would be amortized over time, making the plan appear to be worse funded than before the programming change to separately true-up normal cost. Thus careful testing is required to ensure that end-stage adjustments to the normal cost improve the model accuracy. 
by industry and plan type. Then higher priority would be needed to better reflect recent trends in plan design.

\section{Treatment of Contributions in SE-PIMS}

The reports generated using SE-PIMS make inconsistent assumptions regarding the employer contribution behaviors. For purposes of modeling the future funded status of plans, PIMS assumes that plan sponsors will make the minimum contribution possible to the plan, including using up any prepayment credits ("credit balances") established due to sponsors contributing more than required in the past. Simultaneously, for purposes of modeling premium revenues, PBGC assumes that certain companies will improve the funded status of their pension plans, thereby reducing the amounts of variable rate premium collected (PBGC 2010: Section 3.4.7). Both assumptions cannot be simultaneously appropriate when modeling the path followed by an individual plan in a specific projection path. The resulting projections will only be reasonable if the resulting inconsistent assumptions do not materially affect results.

The use of the assumption that sponsors contribute at the minimum level is also quite inconsistent with experience since the new single-employer pension provisions went into effect. Furthermore, by embedding an assumption of minimum contributions, a progressive bias is introduced into the universe of pension plans' funded status. This bias grows with each projection year, such that the universe of plan funded status converges to a universe that has contributed at the current law minimum basis. Since PBGC's bankruptcy model assigns a higher likelihood of bankruptcy to sponsors of less well funded plans (PBGC 2010: Section 6.4), this serves to increase the relative probability that plan sponsors will be modeled as going bankrupt. By assuming that no sponsors pre-pay their pension contributions during good times, it also 
marginally increases the net pension contributions due in subsequent modeled downturns, leading to additional cash flow pressures and further increasing the risk of bankruptcy (see Figure 3).

Figure 3 here

Finally, the PIMS bankruptcy model assigns an $80 \%$ threshold value on funded status, assuming that if the sponsor's pension plans are, in aggregate, funded at more than $80 \%$, the plan sponsor will be able to marshal adequate resources in bankruptcy to avoid the picking up of the plan liabilities by PBGC (PBGC 2010: Section 4.2.6). PBGC presents this $80 \%$ threshold as a single number, but over time it moves from an assumption that the plan is $80 \%$ funded today, to an assumption that the plan will be $80 \%$ funded if the sponsor contributes only the minimum in the future.

Thus, the assumption that plan sponsors will fund at the minimum level increases both the projection of the number of sponsors that will go into bankruptcy in each future year and the likelihood that the bankruptcy will generate a claim. Finally, it assumes that the universe from which claims are drawn will be progressively less well funded than the case would be if current sponsor behavior were to be modeled.

The documentation provided by PBGC justifies this assumption without quantification, stating: "Plan sponsors often contribute more than the minimum required by law, and they create credit balances. However, firms in bankruptcy seldom have positive credit balances. Thus, estimates of expected loss based on the assumption that firms pay merely the minimum contribution, is a reasonable assumption of behavior" (PBGC 2010: Section 2.3.5). But this argument appears to fail due to circularity in subsequent modeled years. Furthermore, the argument assumes that the only path to a zero credit balance at bankruptcy is generated by 
contributing at the minimum contribution level, ignoring changes under PPA that will have the effect of forcing many sponsors to forego the future use of prepayment credits ("burn credit balances") when plans fall below a certain funded status. This second path would also lead to bankrupt sponsors having a zero credit balance, but at higher asset levels than would obtain had the sponsor followed a minimum funding path.

Finally, the treatment of contributions above the minimum level is inconsistent with the treatment of contributions below the minimum level. PBGC's documentation notes that minimum contributions are often not made in the year a sponsor declares bankruptcy. It adjusts for this by backing the final contribution out of the assets (PBGC 2010: Section 4.2.8). PBGC does not assume that every sponsor fails to make minimum contributions just because sponsors in bankruptcy fail to do so. It would appear that PBGC could take a similar approach to credit balances at plan termination (subtracting them from the assets), rather than assuming that no plan sponsors made contributions in excess of the minimum contribution amount as this is clearly contrary to observed experience.

Based on the documentation, it should be possible to quantify the effect of using consistent contribution amounts within SE-PIMS by applying various assumptions to contribution behavior. There are two tests of interest. First is the comparison of results across projections with different contribution behavior assumptions. Second is the relative risk of bankruptcy shown in the $10^{\text {th }}$ year to that in the first year, as well as the relative funded status of plans hitting the $80 \%$ threshold, within projections based on a particular assumption. Both of these tests should be applied to determine whether this inconsistent assumption materially affects results. 
Integration with risk management operations and information. PBGC maintains a department focused on risk mitigation and management. Through a combination of programs (e.g., the "early warning program", or the "4062 program"), PBGC monitors corporate events affecting the sponsors of many of the largest underfunded plans it insures (PBGC 2000). PBGC's 2012 report cited the agency's success in averting the termination of the American Airlines plans, keeping $\$ 12$ billion off PBGC's books (PBGC 2012a). PBGC has recently announced changes to the 4062 program to focus it primarily on large employers assumed to present a risk to the agency (PBGC 2012c).

PBGC's early warning and 4062 programs have resulted in negotiated agreements with the sponsors of many plans. Typically these agreements provide for additional protections to PBGC by providing for: (1) additional cash contributions to a pension plan; (2) letters of credit to secure promises to make future pension contributions or to backstop underfunded pension plan liabilities; (3) security interests in certain company assets; and (4) guarantees by exiting (better financed) members of a controlled group (PBGC 2000). These guarantees directly affect some of the most risky plans that SE-PIMS models. Additional cash contributions, negotiated by PBGC's risk management program, will be reflected in subsequent years as credit balances, but typically PBGC negotiates an agreement with the sponsor that does not allow the plan sponsor to use those credit balances. That is, typical provisions require the preservation of the credit balance when measured on an annual basis, but allow temporary access during a plan year. Letters of credit, security interests, and guarantees all affect the amount of assets available to PBGC as recovery, if an underfunded plan terminates. Yet information on these agreements does not appear to be coded in SE-PIMS, even though the model makes assumptions about the amount available as 
recovery and assumes (contrary to agreements negotiated with PBGC) that credit balances are spent in future projection years.

Failure to reflect the terms of PBGC's risk mitigation programs in its risk modeling software would appear to have two undesirable results. First, modeled outcomes may overstate PBGC's actual risk. Given the concentration of risk in PBGC's single employer program, this may be a significant item. Second, failure to reflect the results of the risk mitigation strategy in the risk modeling program deprives agency management of a tool to evaluate the advantages of policy changes to risk management programs, such as those recently announced for the 4062 program.

Finally, attention to the risk mitigation strategy and its results in SE-PIMS leads to the recognition that opportunities for risk mitigation are very different in the multiemployer program and raises the issue of whether risk mitigation tools and strategies should be made available to PBGC for that program through legislative or regulatory innovation. The ability to model any such proposals and their effect on plan, PBGC, and participant finances would better inform any such proposals.

Of course, incorporating new data into PIMS is an extensive process that would require additional resources that might better be dedicated to more significant development opportunities. For this reason, we suggest that PBGC begin by assigning quantified upper and lower range bounds on the SE-PIMS model results which would flow from the incorporation of data from the early warning, 4062, and other risk mitigation programs such as were used in the American Airlines case.

Mortality assumptions. PIMS was initially designed on the analogy of modeling the occurrence of net claims under a casualty insurance program that insures against rare events. But once a 
claim has been accepted, PBGC functions much as a life insurer / annuity provider, whose risks are based largely on investment returns and mortality. PIMS models different investment return environments, but it does not assign any additional risk for the chance that mortality rates will differ from an assumed base rate.

This likely is influenced by PBGC's highly unusual approach to setting mortality and interest rates used to value liabilities. At PBGC's inception, PBGC had no mortality experience with which to determine pricing, so instead set up the agency set up a process to survey annuity insurer pricing. PBGC then took a standard industry mortality table and solved for the interest rates needed to closely replicate average prices from the annuity survey. In recent years, PBGC has had sufficient data to study mortality among a large fraction of the single employer plans it has trusteed and has reflected those mortality rates to a limited extent. But the agency continues to use the same approach to setting the combination of interest rates and revised mortality, to match the average settlement prices derived from its annuity survey. This has led to situations where PBGC has determined that it needed to strengthen its mortality assumption (i.e. assuming longer lives) being tied to a weakening of the interest rate assumptions, so that the resulting maturity values continue to match the survey. ${ }^{4}$

A problem with this approach is that it implicitly assumes that the price for settlement annuities in the insurer survey represents the price it would cost to cover a program with PBGC's

${ }^{4}$ SE-PIMS documentation indicates that a similar approach is taken to determine the mortality table used in SE-PIMS, but in this case mortality rates are adjusted so as to approximate settlement rates when interest rates are based on Treasury rates, rather than PBGC's valuation rates (PBGC 2010: Section 4.2.1). Comments by Agency indicate that this is an error in the documentation which will be corrected. 
mortality. In other words, it assumes that the insurers are pricing a longevity risk that is identical or very similar to PBGC's. Furthermore, it assumes that mortality rates will be the same for PBGC's single employer program and multiemployer program, despite differences in longevity rates demonstrated in the literature based on factors including geography, union membership, lifetime income, and educational attainment. These factors could easily generate significant differences in mortality rates between those underlying PBGC's annuity survey and the rates experienced by the populations for whom it will provide benefits.

In the U.K., there is widespread interest and a robust annuity market, which in conjunction with increases in life expectancy, has led to increased interest in models for projecting increases in life expectancy. This has also prompted new ways to manage the risk of changes in assumed mortality risks by insurers in both the U.K. and U.S. In the U.S., plan sponsors are also beginning to recognize and value the effects of assuming excess longevity risk, and to incorporate the issue qualitatively in discussions about pension derisking (Banham 2013). PIMS does not currently model this aspect of risk.

Moreover, there are reasons to question whether the current process of setting rates to match an insurer survey is likely to become increasingly divergent from PBGC's own experience. This is due to the issue of selection as reflected in insurer prices due to participants being offered lump sums.

Insurer group annuity pricing has historically been thought to reflect some adverse selection due to the common practice of allowing participants the option of a lump sum at plan termination, instead of receiving an annuity from the insurer (this is particularly common during times when interest rates are high; Society of Actuaries Group Annuity Experience Committee 1996). Recent plan "derisking" options at certain large employers have also featured the option 
of a lump sum vs. annuitization (Banham 2013). In addition, newer plan designs have tended to include the option of taking a lump sum at termination or retirement. Indeed this is more or less a standard feature of cash balance and pension equity plans now, and it is also common in other plans. But, PPA restricts the ability of participants to utilize this option in poorly funded plans which are, of course, those more likely to land at PBGC in the future. Hence PBGC's experience of adverse selection is likely to increasingly diverge from that experienced by insurers in its annuity survey.

The issue of how PBGC should adjust its valuation practices to reflect changes in longevity and the annuity market goes beyond PIMS. But it is notable that PIMS has no provision to model the risk of mortality rates differing from the assumed base case, nor for the rate of improvement in mortality to differ from that assumed. This is likely to be a more important consideration for ME-PIMS, where cash flow testing of projected dates of insolvency is much in demand. The ability of ME-PIMS to directly model cash flows, as opposed to the use of maturity values in SE-PIMS (PBGC 2009), may make it both important and easier to address this issue first within the ME-PIMS system. But, because the duration of the standard ME-PIMS runs typically extend out only one or two decades, the impact of this assumption may be minor during the projection period. For this reason, we suggest that PBGC staff first quantify the likely effect of adding mortality risk to the model before adding this to a future improvements list.

\section{Conclusions}

The pressures to develop and use the ME-PIMS model are increasing due to the rapid deterioration of the multiemployer program finances and the need to enact replacement legislation for the expiring multiemployer provisions under PPA. We agree with the Category 1 
recommendations of the ME-PIMS peer review panel, and strongly suggest that ME-PIMS be the highest development priority for PBGC resources. It is also important that PBGC undertakes changes while recognizing the need to address system, documentation, and ease of use issues, all of which are important in being able to produce high quality analysis under high pressure and short timeframes.

Here we have noted several areas of concern in SE-PIMS regarding the modeling of employer contributions, the link between PIMS and PBGC risk mitigation strategies, the modeling of future rates of benefit accrual, and PBGC's mortality assumption development. Since time and resources are constrained, we suggest that PBGC quantify the upper and lower bounds of these issues and prioritize changes in the model based on this information. 


\section{References}

Banham, R. (2013). “The Great Pension Derisking,” CFO Magazine. April 15.

http://www3.cfo.com/article/2013/4/retirement-plans_derisking-defined-benefit-pension-

plans

Buck Consultants (2012). “ME-PIMS Peer Review Report,” Letter from Buck Consultants to Larry Shirley of the Pension Benefit Guaranty Corporation. Berwyn, PA: Buck Consultants, September 12.

DeFrehn, R. G., and J. Shapiro (2013). "Solutions Not Bailouts: A Comprehensive Plan from Business and Labor to Safeguard Multiemployer Retirement Security, Protect Taxpayers and Spur Economic Growth." A Report on the Proceedings, Findings and Recommendations of the Retirement Security Review Commission of the National Coordinating Committee for Multiemployer Plans (NCCMP). Washington, DC: NCCMP. http://webiva-downton.s3.amazonaws.com/71/59/b/39/1/Solutions_Not_Bailouts.pdf

Lynchval Systems (2012). "Multiemployer PIMS Known Limitations in ME-PIMS.”

Pension Benefit Guaranty Corporation (PBGC) (2000). "PBGC's Early Warning Program." Technical Update 00-3. Washington, DC: PBGC. http://www.pbgc.gov/res/other-guidance/tu/tu00-3.html

Pension Benefit Guaranty Corporation (PBGC) (2009). "PIMS Multiemployer Technical Specification - Model PBGC Net Position in ME-PIMS.” Washington, DC: PBGC.

Pension Benefit Guaranty Corporation (2010). "PIMS System Description for PIMS SOA 'Core’ vFY09.1 Version 1.0.” Washington, DC: PBGC. 
Pension Benefit Guaranty Corporation (PBGC) (2012a). Annual Report 2012. Washington, DC: PBGC. http://pbgc.gov/documents/2012-annual-report.pdf

Pension Benefit Guaranty Corporation (PBGC) (2012b). "A Brief History of PIMS." Washington, DC: PBGC.

Pension Benefit Guaranty Corporation (PBGC) (2012c). October 2012 Guidelines for Enforcement of ERISA section 4062(e). Washington, DC: PBGC. http://www.pbgc.gov/Documents/4062(e)-enforcement-of-guidelines.pdf

Pension Benefit Guaranty Corporation (PBGC) (2013a). PBGC Insurance of Multiemployer Pension Plans -Report to Congress required by the Employee Retirement Income Security Act of 1974, as amended. Washington, DC: PBGC. http://www.pbgc.gov/documents/pbgc-five-year-report-on-multiemployer-pensionplans.pdf

Pension Benefit Guaranty Corporation (PBGC) (2013b). PBGC Pension Insurance Data Book, 2011. Washington, DC: PBGC. http://www.pbgc.gov/documents/pension-insurance-data-tables-2011.pdf Society of Actuaries Group Annuity Experience Committee (1996). "Group Annuity Mortality," Transactions of the Society of Actuaries 1993-94 Reports: 3-41.

Society of Actuaries (2011). “The Rising Tide of Pension Contributions Post-2008: How Much and When?" Schaumburg, IL: Society of Actuaries http://www.soa.org/files/research/projects/research-2011-10-rising-tide-report.pdf 


\section{Ratio Net Position to Total Premium Revenue}

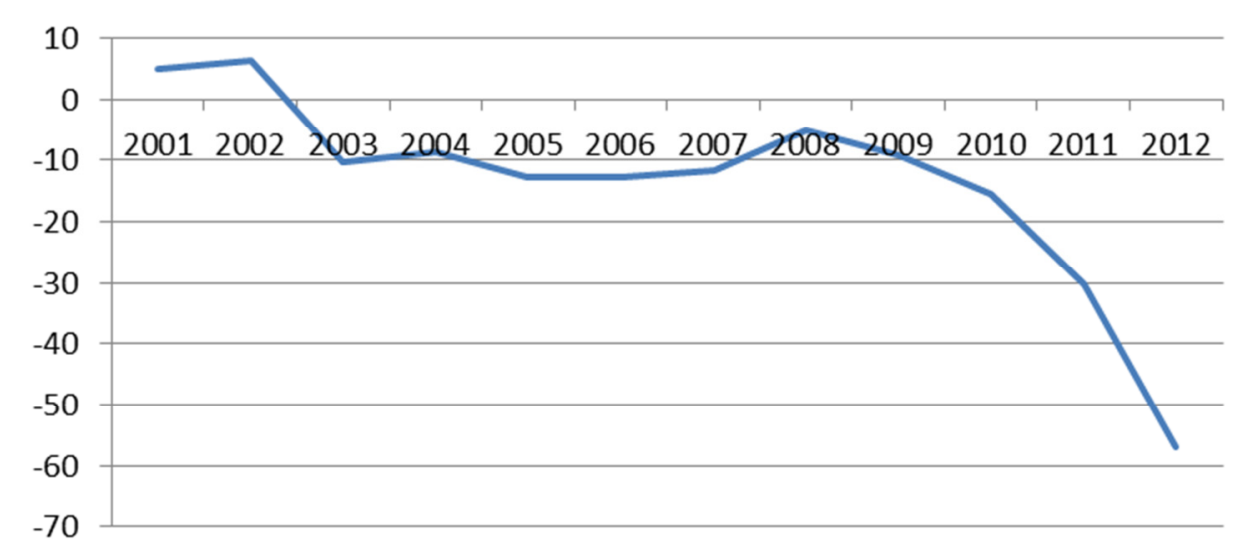

Figure 1. Multiemployer program - ratio of PBGC's fiscal position to premium income. Source: PBGC (2012a, 2013b). 


\section{Ratio Net Position to Total Premium Revenue}

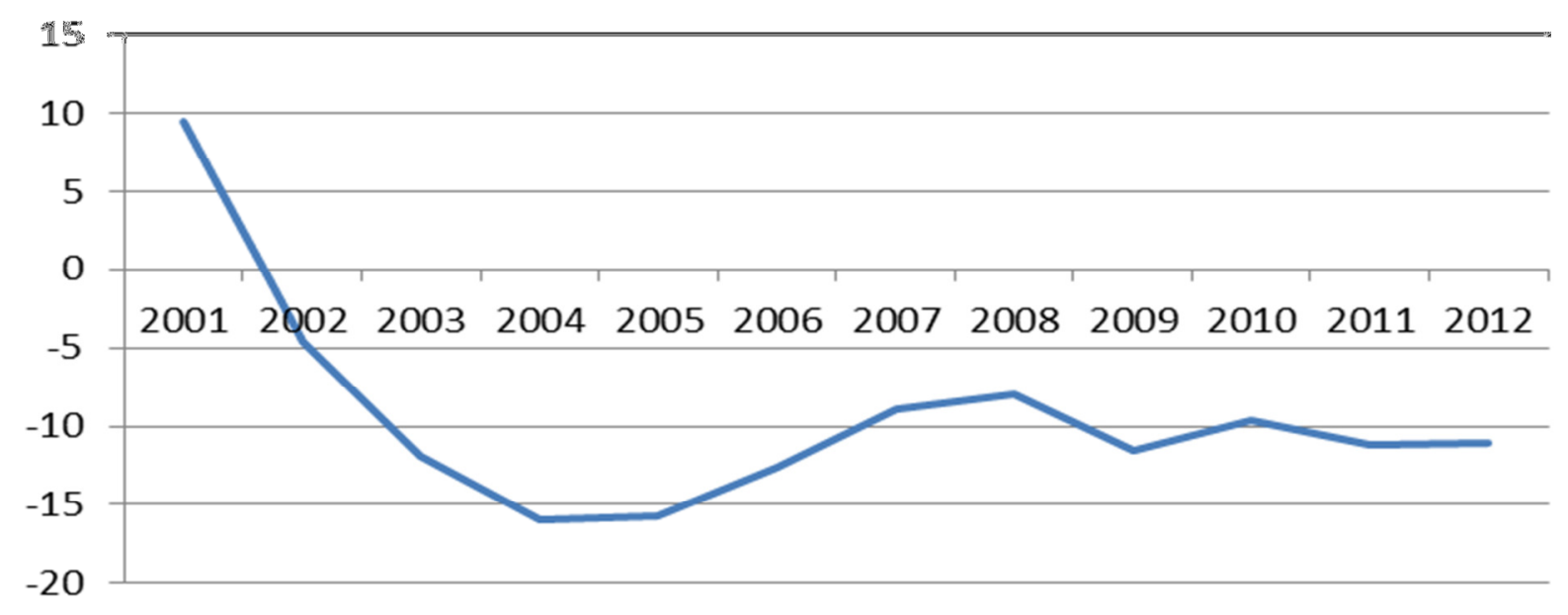

Figure 2. Single employer program - ratio of PBGC's fiscal position to premium income. Source: PBGC (2012a, 2013b). 
HISTORICAL CONTRIBUTIONS (2000 - 2009)

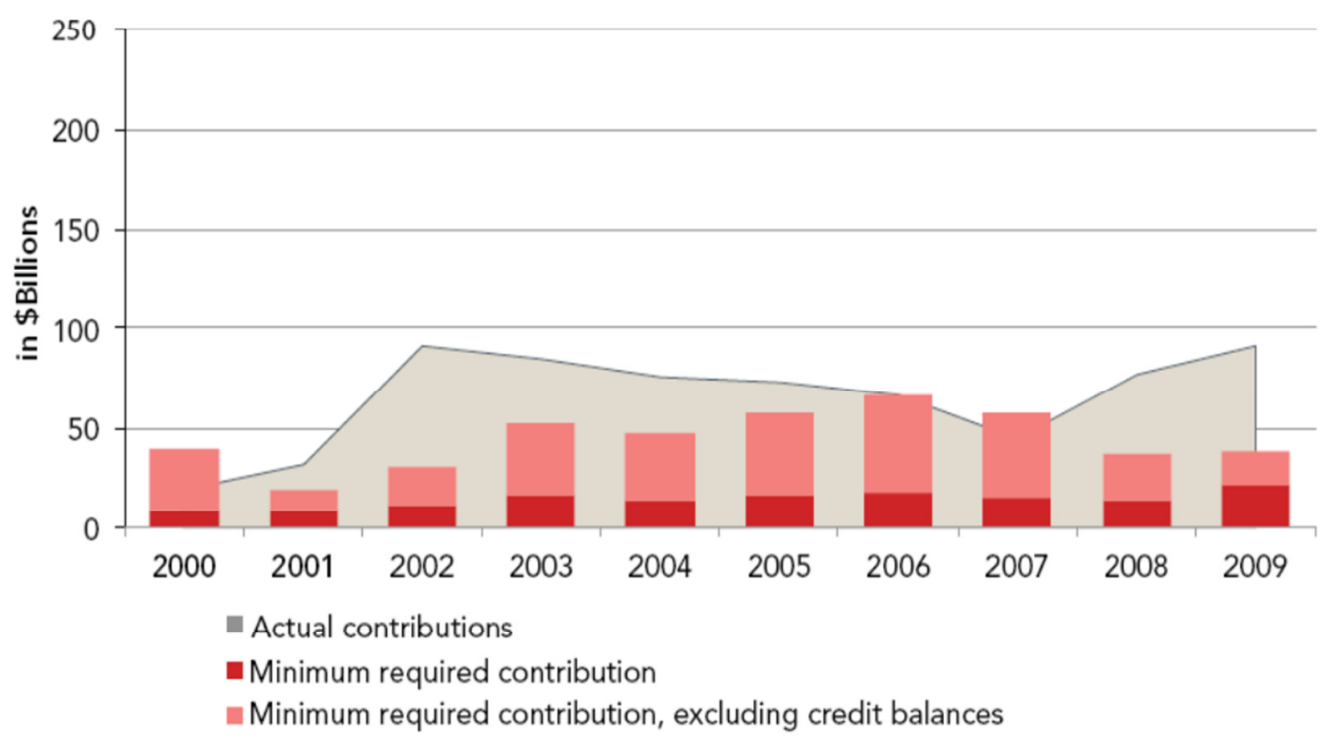

Figure 3. Single employer program - contributions vs. minimum required contributions. Source: Society of Actuaries (2011). 


\title{
An Actuarial Perspective on Pension Plan Funding
}

\author{
Donald J. Segal \\ Society of Actuaries
}

September 2013

\author{
Michigan Retirement Research Center \\ University of Michigan \\ P.O. Box 1248 \\ Ann Arbor, MI 48104 \\ www.mrrc.isr.umich.edu \\ (734) 615-0422
}

\section{Acknowledgements}

This work was supported by a grant from the Social Security Administration through the Michigan Retirement Research Center (Grant \# 5 RRC08098401-05-00). The findings and conclusions expressed are solely those of the author and do not represent the views of the Social Security Administration, any agency of the Federal government, or the Michigan Retirement Research Center.

Regents of the University of Michigan

Mark J. Bernstein, Ann Arbor; Julia Donovan Darlow, Ann Arbor; Laurence B. Deitch, Bloomfield Hills; Shauna Ryder Diggs, Grosse Pointe; Denise Ilitch, Bingham Farms; Andrea Fischer Newman, Ann Arbor; Andrew C. Richner, Grosse Pointe Park ; Katherine E. White, Ann Arbor; Mary Sue Coleman, ex officio 


\title{
An Actuarial Perspective on Pension Plan Funding
}

\begin{abstract}
The Pension Benefit Guaranty Corporation (PBGC) was established by the Employee Retirement Income Security Act (ERISA) to provide “insurance guarantees” for qualified pension plans insufficiently funded to provide accrued vested benefits. The PBGC's annual reports on the liabilities for plans it has taken over and the agency's assets show that the Single Employer Program has seen this "net position” vary from a surplus of almost $\$ 10$ billion in 2000, to a deficit of over $\$ 29$ billion in 2012. The PBGC uses a proprietary Pension Insurance Modeling System to model future scenarios for their obligations. This paper offers observations on future pension plan funding and how this could affect the PIMS model, based on the current environment, and how the agency might respond to change.
\end{abstract}

\section{Citation}

Segal, Donald J. (2013). “An Actuarial Perspective on Pension Plan Funding,” University of Michigan Retirement Research Center (MRRC) Working Paper, WP 2013-290(g). Ann Arbor, MI.

\section{Authors’ Acknowledgements}

The research reported herein was pursuant to a grant from the US. Social Security Administration (SSA) funded as part of the Retirement Research Consortium (RRC); the author also acknowledges support from The Pension Research Council at The Wharton School. All findings and conclusions expressed are solely those of the author and do not represent the views of the SSA or any agency of the federal government, the PRC, or The Wharton School at the University of Pennsylvania. In addition, the opinions expressed by the author do not represent those of the Society of Actuaries or any other organization of which I am a member. All findings, interpretations, and conclusions of this paper represent the views of the authors and not those of the Wharton School or the Pension Research Council. (C2013 Pension Research Council of the Wharton School of the University of Pennsylvania. All rights reserved. 


\title{
An Actuarial Perspective on Pension Plan Funding
}

\author{
Donald J. Segal
}

The Pension Benefit Guaranty Corporation (PBGC) is a federal agency established by the Employee Retirement Income Security Act (ERISA), whose purpose is to provide "insurance guarantees" up to a certain level for qualified pension plans unable to continue in existence and not funded to a level sufficient to provide accrued vested benefits to their participants and beneficiaries. Each year the PBGC issues a report on the liabilities for plans it has taken over and the assets that the agency has on hand to provide those benefits. The Single Employer Program has seen this "Net Position" vary from a surplus of almost $\$ 10$ billion in 2000, to a deficit of over $\$ 29$ billion in 2012 .

The reasons behind this variance are many and complex. The PBGC has been employing a proprietary system, the Pension Insurance Modeling System (PIMS), to model future scenarios for their obligations. Other experts will address the intricacies and assumptions inherent in this system. Here I offer my observations on future pension plan funding and how this could affect the PIMS model.

The PBGC confronts many risks. Can these risks and potential changes be included in the model? If an objective is to make the agency more resilient, then this is what could be done and what could be recognized in the PIMS model. My thoughts here do not represent an exhaustive analysis of the funding requirements under Internal Revenue Code Sections 412 and 430. Rather, I scan the current environment for pension plan funding, to provide an idea of what might be proper. My focus is less on how to improve the environment, but more to explore on how the agency might respond to change. 
The issue can be stated very simply. To improve funding in the private sector qualified pension plan system in the United States, sponsors must put more money into the plans. Ideally, every plan should be funded to the point where assets are equal to actuarial liabilities for benefits accrued to date. Then if the PBGC took over a plan because the plan sponsor was unable to continue in business, or filed for bankruptcy, the risks assumed by the PBGC would be relatively low. If it only were that simple!

There are many facets to the issue of funding defined benefit (DB) pension plans in the United States today, including the following:

- Assets yields have been fluctuating widely and wildly, although the equities market is now at a record high;

- Bond yields are at record lows;

- The interest rate environment is uncertain because of federal policy;

- Congress last year reduced minimum funding requirements to raise revenue for other purposes;

- Plan sponsors are unhappy with the way pension expense has been hitting the balance sheet because of the unstable and generally declining interest rate environment; and

- Plan sponsors are freezing and/or terminating DB plans because of the volatility in the pension expense.

There is also the basic issue of what to do with the existing PBGC deficit. The current PIMS model considers these variables and models various possible future scenarios. 


\section{The Current Environment}

Large corporate pension plans in the United States are currently not well funded. Several studies exist exploring the relationship between assets and liabilities for a selected universe of plans. For example, the Milliman (2013) Corporate Pension Funding Study looked at 100 U.S. public companies with the largest DB pension plan assets, ${ }^{1}$ and it found that the excess of projected benefit obligations over market value of assets (the "funding deficit") stands at a record high. The year-end discount rate also fell to a record low (4.02\%). The funded ratio of assets to projected benefit obligations (PBO) was also at a record low, despite excellent 2012 market returns above expected returns and large contributions. And the pension expense for this universe was at a record high.

As an example, in the footnotes to the 2012 AT\&T annual statement (AT\&T 2012: 44), the company stated that for the year ending December 31, 2012, it decreased its discount rate by $1.00 \%$, resulting in an increase in the pension plan benefit obligation of $\$ 7.0$ billion. For the year ending December 31, 2011, it decreased the discount rate by $0.50 \%$, resulting in an increase in the pension benefit obligation of $\$ 3.4$ billion. As another example, the footnotes to IBM's annual statement for 2012 (IBM 2012) stated that the decrease in the discount rate by $0.80 \%$ resulted in an increase in the PBO of $\$ 3.4$ billion; for the year ending December 31, 2011, the decrease in the discount rate of $0.60 \%$ resulted in an increase in the $\mathrm{PBO}$ of $\$ 4.2$ billion. When interest rates go up, these numbers will reverse, but meanwhile, the pain persists. The same is happening with funding (but more about that later).

\footnotetext{
${ }^{1}$ The 2013 report covered plans for which a 2012 annual report was released by March 7, 2013.
} 
What this all points out is that the record low interest rates are killing DB pension plans, discouraging sponsors from maintaining them (because of the "hit" on the balance sheet), and boosting the deficit of the PBGC.

The FY 2012 PBGC Exposure report (PBGC 2012) comments in several places on the effect that interest rates have had on the PBGC deficit and For instance, the agency stated: "Interest rates affect how we calculate obligations... Changes in this interest rate have a big effect

on these calculations." In the Overview of PIMS, again we see "Changes in interest rates have a big effect on this calculation - the higher the interest rate by which we calculate what we owe, the lower the present value of the obligations (liabilities) reported on our balance sheet." The current PIMS addresses these variables.

\section{The PBGC Deficit and Legacy Costs}

The PBGC Annual Reports and Data Books (PBGC 2013a,b,c) show that the net financial position of the PBGC Single-Employer Program for 1980 through 2011 (assets/liabilities) has varied from a low of $31.3 \%$ in 1986 , to a high of $187.2 \%$ in 2000 . This picture obviously depends on the interest rate environment and the status of financial markets, generally. Since 2002, the funded ratio has been below 90\%. And the PBGC Annual Reports show that the interest factors used to value the PBGC Single-Employer Program liabilities declined well over 300 basis points from 2008 to 2012 (6.66\% for 20 years, $6.47 \%$ thereafter in 2008, to $3.28 \%$ for 25 years, $2.97 \%$ thereafter for 2012 ).

A major concern is the PBGC deficit, more specifically the "legacy cost," as opposed to the ongoing cost. As referred to above, PBGC liabilities have grown faster than its assets in recent years, due to the decline in interest rates. The PBGC 2012 Annual report showed a one- 
year increase of more than $\$ 10$ billion in liability due to the decline in interest rates. The PBGC defines the term "underwriting gain or loss" to be equal to its premium income minus all administrative expense and the unfunded liability of plans for which it assumes responsibility during a year. So even if the premium structure, as amended by recent legislation, were sufficient to support any new obligations assumed by the PBGC, the deficit arising from past plans assumed remains problematic.

A key question is whether it is good insurance practice to ask current "policyholders," i.e., those sponsors who currently have ongoing DB plans, to pay claims for policyholders of past generations. No insurance company would last, based on this premise. Maintaining a system that requires current plan sponsors to pay for this legacy deficit from the past will only serve to encourage these plan sponsors to terminate their DB plans and leave the system.

The American Academy of Actuaries (2012) has addressed this issue, defining goingforward costs as those associated with the risks of ongoing coverage by the PBGC, excluding legacy costs. Legacy costs were defined as those that associated with existing or imminent claims, such as plans for which the PBGC has already assumed liability or that it is expected to assume in the near future. The important actuarial principle states that, "Applying basic insurance principles, premiums for going-forward costs should be adequate and appropriately risk-related. The traditional insurance model, however, does not adequately address legacy costs." The Academy went on to observe that adequate premiums must fully cover expected going-forward claims and administrative costs. The risk-related premium should reflect the relative insurance cost of a plan, the extent of the PBGC's potential obligation, and the probability of the PBGC assuming that obligation (a classic insurance approach). But the Academy also observed that legacy costs already incurred are clearly not insurable events, and 
these are not associated in any meaningful way with ongoing plan sponsors contributing into the system: "That group would not bear the legacy costs in an insurance model; if they did, the price of the insurance would exceed the true value of the coverage, and thus provide a market incentive for the insured to decline coverage or move their business to another insurer."

But this is exactly what is happening. Plan sponsors with existing DB plans are exiting the system. Among the reasons is the legacy cost they are being asked to bear. The Academy Issue Brief then goes on to suggest several options for allocating this legacy cost, including to assign the full legacy cost to current plan sponsors, spread over a number of years (the current approach); or to assign only a portion of the legacy cost to current plan sponsors and find another source of funds.

An added function of PIMS could be modeling various alternatives for addressing the issue of legacy costs vs. ongoing costs. Congress has granted the PBGC increased authority over premiums, so PIMS must model the effect of various schemes for increasing premiums and the effect on the financial health of the PBGC.

\section{Encouraging the Formation of New Defined Benefit Plans}

If we are concerned about the funding of DB plans and the concomitant health of the PBGC, one solution is to encourage the formation of new DB plans. To this end, several recent surveys indicate that employees remain very interested in having a DB pension. If an employer offers a DB plan, this is more attractive than only having a defined contribution (DC) plan where 
the entire investment risk is on the employee. The idea of a benefit payable for life is becoming more attractive to employees as they start thinking about retirement, even at younger ages. ${ }^{2}$

For instance, the National Institute of Retirement Security (2013) recently found that Americans are highly supportive of traditional (DB) pensions. Some $83 \%$ of those surveyed reported favorable views of pensions, and $82 \%$ felt that retirees with DB plans were more likely to have a secure retirement. Among Millennials, $89 \%$ believed that those with DB pensions would have a more secure retirement than those without, and $94 \%$ said that the lack of pensions for Baby Boomers is creating stress for families and the economy.

Thus far, PIMS does not explicitly recognize the formation of new DB plans. Accordingly, we believe it useful to briefly look at the kinds of DB plans that may be adopted in the future and how PIMS could adjust for them. We know that many employers say they do not want to face the cost unpredictability of DB plans. Looking back into the past, however, we find that the cost of career average plan formula (also known as a current pay plan) can be just as predictable as a DC plan. In fact, this can be even more predictable than a $401(\mathrm{k})$ match, because the latter depends on employee behavior which is unpredictable. A plan sponsor wishes to know what the plan cost will be, each year. While there is mortality risk, actuaries can model that. There is investment risk, but investment managers can help with that.

Cash balance plans may be an attractive way to manage these risks in the future. Since the passage of the 2006 Pension Protection Act (PPA), cash balance plans can credit earnings

${ }^{2}$ We do not elaborate here on the shortcomings of defined contribution plans including the employee bearing investment risk, leakage, and insufficient money being put away for retirement. In fact, leakage is one of the major impediments to saving for retirement, as the money intended for retirement may be spent on houses, debt, education, vacations, etc. 
credited to each participant's account based on plan's trust fund return, subject to a floor of zero. One can also put a maximum on the rate credited. A good design will have both the floor and ceiling determined on a cumulative basis, not year-by-year. In this way, the investment gain or loss can be minimized over time, and the funding effect can be spread over a few years where it will ideally even out. In other words, there should be a good match between employer contributions and new liabilities in these new plans. This can lessen the risk borne by the PBGC (not to mention the premium income) and improve funded ratios. With a career average plan, the sponsor decides if and when he will put in a past service update. The career average plan does not have the "blank check" aspects of a plan where the formula is based on final average earnings. When the sponsor puts in a past service update, he will know exactly what it will cost.

Another way to implement good plan design is to eliminate lump sum payments. Sponsors may encourage lump sums because it removes the plan's liability off the firm's books and reduces PBGC premiums. But most would agree that this is not good retirement income design.

Still a different approach would move to a contributory DB plan. Under current law, employee contributions in corporate plans are on a post-tax basis. Changing the law to permit (and encourage) employee contributions to DB plans on a pre-tax basis (as is done with 401(k) plans) would help. Among other desirable effects, such as the employee helping to fund the plan, this would omit that ugly exclusion ratio calculation at retirement, wherein the portion of the benefit that is non-taxable is determined.

An even more radical idea would be to change the law to permit employer matches to employee 401(k) deferrals to be made as accruals in a DB plan. 
All of these ideas could help bring back DB plans, which would be potentially attractive to the PBGC and good for employee retirement planning. PIMS could readily be modified to model future changes such as these.

\section{“Derisking” of Defined Benefit Plans: Effects on Large Pension Plan Sponsors}

One idea spreading among large pension plan sponsors is "derisking," that is offering lump sums and annuity purchases to retired and vested terminated participants and beneficiaries. Three notable implementers of this practice in 2012 were Ford, General Motors, and Verizon. The idea is to get the plan's liability off the plan sponsor's books, thereby lowering the actuarial and investment risks and passing them on to a reliable third party (a large, stable insurance company). Derisking also lowers subsequent PBGC premiums paid by plan sponsors. Speaking in actuarial terms, there is an interplay between the amount of the lump sums paid, the cost of the annuity purchase, and the liabilities held for both funding and accounting purposes. Often, the amount paid out can exceed the liabilities held, because of the difference in actuarial assumptions used.

The Milliman Corporate Pension Funding Study (2013) noted that, despite a $\$ 45$ billion reduction in plan obligations due to these activities across their universe, total pension obligations were at a record high because of the decline in discount rates used to measure ongoing obligations. In the short term at least, because of this "assumption whipsaw," derisking 
strategies may not reduce the apparent actuarial unfunded accrued liability and the PBGC variable rate premium owed by plan sponsors. ${ }^{3}$

An interesting side note is that Verizon retirees filed a class-action suit over the transfer of the obligation from Verizon to Prudential in November 2012, claiming that the conversion to an annuity would strip participants of the protections of federal law. In March 2013, a federal judge ruled that the suit could proceed, and as of this writing, it is unclear if this suit will add to the PBGC's risk. This development, and other similar ones, must be integrated into a longer-term overhaul of the PIMS modeling framework.

\section{Future DB Plan Contributions}

MAP-21 provided for interest rate relief in the minimum funding requirements under ERISA for qualified DB plans, as a revenue raising measure for the federal government. But this will not really produce long-term relief, as it merely changed the pattern of the employer contributions to pensions. Only reducing this year's contributions just increases future contributions.

Prior to the passage of the legislation, a Society of Actuaries (2012) study used the PIMS model to undertake projections evaluating the MAP-21 changes. Among its major findings were that aggregate contributions requirements would initially be significantly lower than under current law, but they would be expected to rise each year until they ultimately exceeded the amounts that would have been required under current law. Moreover, the percent of obligations

${ }^{3}$ The PBGC per capita premium which is rising and will continue to rise as a result of the Moving Ahead for Progress in the 21st Century Act [MAP-21]. The PBGC per capita premium, which was $\$ 19$ as recently as 2005, will be \$49 in 2014 (adjusted for inflation thereafter). 
funded would fall in the short term due to lower contributions, but it would eventually return to the levels expected under current law as contributions increase thereafter. In other words, the bill was predicted to have significant short-term effects of lowering contribution requirements and funded levels, but it did not address longer term volatility and long-term contribution concerns. The report also noted that, to the extent that plans defaulted during this period of the lag in contributions, there would be greater claims on the PBGC. It is unclear whether and how the PIMS model recognizes such law changes affecting future funding.

\section{Actuarial Standards}

It is also worth noting that actuarial standards play a key role in this discussion. Minimum funding requirements for qualified pension plans are set by statute. Over the years, actuarial discretion in selecting assumptions has been restricted, as the law now dictates interest rates and mortality rates for funding. The actuary's judgment is now limited to turnover rates, retirement ages, and forms of benefits (though everything in aggregate must be reasonable in the judgment of the actuary). Beyond the requirements of the law, a good actuary will also discuss a long term funding policy with the plan sponsor to provide for reasonable, stable, long-term funding costs that will satisfy the minimum requirements of the law.

Actuarial standards of practice require disclosure of all assumptions, methods, data used, etc. in presenting results and advice. Reasonableness of assumptions cannot merely be claimed. For major assumptions, the actuary needs to go through a process to come up with a reasonable assumption and often this calls for some degree of quantification. For an actuary, coming up with a funding recommendation or policy means more than just generating the numbers. It also 
involves an assessment of the short- and long-term effects of what is being recommended, seeking to ensure the long-term sound funded status of the plan.

\section{Conclusions}

The outlook for future funding of DB plans depends on several factors. The Internal Revenue code and ERISA, as modified by Congress periodically, dictate minimum funding requirements. But to see a real improvement in the funded ratios of private pension plans and of the PBGC's net position, there will have to be a recovery (meaning an increase) in Treasury bond rates and corporate bond rates. These are the drivers in the valuation of liabilities, and PIMS currently models these scenarios.

Yet even more critical to the survival of the PBGC and the defined benefit pension model would be a new approach to plan design. In our view, this could encourage DB maintenance and new plan formation. Pension designs of the career average variety are less susceptible to variations in market performance and much more predictable in cost and expense. Sensitivity analysis with PIMS would help evaluate how such changes can shape the future of the DB plan world and its insurance provider. 


\section{References}

American Academy of Actuaries (2012). Examining the PBGC Premium Structure. Issue Brief (April). Washington, DC: American Academy of Actuaries.

http://www.actuary.org/files/publications/IB_on_PBGCPremium_120426.pdf

AT\&T (2012). AT\&T Inc. 2012 Annual Report. Dallas, TX: AT\&T.

http://www.att.com/Investor/ATT_Annual/2012/downloads/ar2012_annual_report.pdf

IBM (2012). 2012 IBM Annual Report. Armonk, NY: IBM.

http://www.ibm.com/annualreport/2012/bin/assets/2012_ibm_annual.pdf

Milliman (2013). 2013 Corporate Pension Funding Study. Seattle, WA: Milliman.

http://www.milliman.com/expertise/employee-benefits/products-tools/pension-funding-

$\underline{\text { study/ }}$

National Institute of Retirement Security (NIRS) (2013). Pensions and Retirement Security 2013: A Roadmap for Policy Makers. Washington, DC: NIRS.

Pension Benefit Guaranty Corporation (PBGC) (2012). FY 2012 PBGC Exposure Report.

Washington, DC: PBGC. http://www.pbgc.gov/documents/2012-exposure-report.pdf

Pension Benefit Guaranty Corporation (PBGC) (2013a). PBGC Annual Report [1996-2012].

Washington, DC: PBGC. http://www.pbgc.gov/res/annual-reports.html

Pension Benefit Guaranty Corporation (PBGC) (2013b). Pension Insurance Data Book [19962011]. Washington, DC: PBGC. http://www.pbgc.gov/res/data-books.html

Pension Benefit Guaranty Corporation (PBGC) (2013c). Pension Insurance Data Tables [20102011]. Washington, DC: PBGC. http://www.pbgc.gov/res/data-books.html 
Society of Actuaries (SOA) (2012). Proposed Pension Funding Stabilization: How Does It Affect the Single-Employer Defined Benefit System? Schaumburg, IL: SOA. 


\title{
Modeling Risk-based Pension Insurance Premiums in the UK
}

\author{
Martin G. Clarke
}

Pension Protection Fund

September 2013

\author{
Michigan Retirement Research Center \\ University of Michigan \\ P.O. Box 1248 \\ Ann Arbor, MI 48104 \\ www.mrrc.isr.umich.edu \\ (734) 615-0422
}

\section{Acknowledgements}

This work was supported by a grant from the Social Security Administration through the Michigan Retirement Research Center (Grant \# 5 RRC08098401-05-00). The findings and conclusions expressed are solely those of the author and do not represent the views of the Social Security Administration, any agency of the Federal government, or the Michigan Retirement Research Center.

Regents of the University of Michigan

Mark J. Bernstein, Ann Arbor; Julia Donovan Darlow, Ann Arbor; Laurence B. Deitch, Bloomfield Hills; Shauna Ryder Diggs, Grosse Pointe; Denise Ilitch, Bingham Farms; Andrea Fischer Newman, Ann Arbor; Andrew C. Richner, Grosse Pointe Park ; Katherine E. White, Ann Arbor; Mary Sue Coleman, ex officio 


\title{
Modeling Risk-based Pension Insurance Premiums in the UK
}

\begin{abstract}
This paper describes how the Pension Protection Fund (PPF) in the U.K. quantifies and prices the risks it carries. It also discusses how the PPF interprets these outcomes in terms of a levy or premium to be charged to the pension plans that it protects. PPF has existed since 2005: it has experienced rapid growth as a consequence of the failure of U.K. pension scheme sponsors and the persistent underfunding of their plans, and it has withstood the global financial crisis, partly due to the Fund's ability to charge a levy consistent with the risks it faces and its skill in securing stakeholder acceptance of its process. Considering the example of the U.S. Pension Benefit Guaranty Corporation (PBGC), the PPF was able to introduce the world's first risk-based pension protection levy, a key step in winning stakeholder support for the pricing mechanism; the components of the levy-setting process are described in this paper. We examine the PPF's goal to be self-sufficient by 2030. We also review the framework whereby investment and levy strategies can be evaluated in the context of the PPF's long-term objectives, and we describe the internal model at high level to compute measures of success of different strategies. The Board has been able to use this framework to assess the impact of a change to the basis of indexation of PPF compensation, the cost of removing its compensation cap, and the effect of a potential change in pension scheme funding valuations to permit smoothing of discount rates.
\end{abstract}

\section{Citation}

Clarke, Martin G. (2013). “Modeling Risk-based Pension Insurance Premiums in the UK,” University of Michigan Retirement Research Center (MRRC) Working Paper, WP 2013-290(h). Ann Arbor, MI.

\section{Authors’ Acknowledgements}

The research reported herein was pursuant to a grant from the US. Social Security Administration (SSA) funded as part of the Retirement Research Consortium (RRC); the author also acknowledges support from The Pension Research Council at The Wharton School. All findings and conclusions expressed are solely those of the author and do not represent the views of the SSA or any agency of the federal government, the PRC, or The Wharton School at the University of Pennsylvania. In addition, the opinions expressed by the author do not represent those of the Society of Actuaries or any other organization of which I am a member. All findings, interpretations, and conclusions of this paper represent the views of the authors and not those of the Wharton School or the Pension Research Council. (C2013 Pension Research Council of the Wharton School of the University of Pennsylvania. All rights reserved. 


\title{
Modeling Risk-based Pension Insurance Premiums
}

\author{
Martin G. Clarke
}

\section{Introduction and Summary}

This paper describes how the Pension Protection Fund (PPF) in the U.K. quantifies and prices the risks it carries. We also discuss how the PPF interprets these outcomes in terms of a levy or premium to be charged to the pension plans that it protects.

PPF has been in existence only since April 2005, but it has experienced rapid growth as a consequence of the failure of pension scheme sponsors in the U.K. and the persistent underfunding of their pension plans. The entity has so far withstood the global financial crisis, maintaining a strong financial position despite the hazardous economic climate. Part of that success lies in the Fund's ability to charge a levy consistent with the risks that the Fund faces and its skill in securing stakeholder acceptance of the process by which it does this.

In establishing the PPF, U.K. legislators considered the experience of and lessons learned from the Pension Benefit Guaranty Corporation (PBGC) in the United States. Foremost amongst those learnings was the need for greater flexibility and independent control of the levy. Indeed the PPF was able to introduce the world's first risk-based pension protection levy, a key step in winning stakeholder support for the pricing mechanism. The PPF levy is currently $£ 630 \mathrm{~m}$ or approximately a 5 basis point charge on scheme liabilities.

The components of the levy-setting process are described in this paper, along with the history and growth of the PPF as well as its legislative function. We also review the PPF's Funding Strategy, which is the context in which strategic decisions are made by the Board of the PPF. In establishing a clear funding objective - namely to be self-sufficient by 2030 - the Board has a publicly declared goal against which its progress can be tracked and its needs for financial resources evaluated. Without such a structure, the PPF believes there would be much less acceptance of the levy requirements within its stakeholder community. We also 
review the framework whereby investment and levy strategies can be evaluated in the context of the PPF's long term objectives, and describe the internal model at high level to compute measures of success of different strategies. In a separate exercise the Board has set its risk appetites and agreed a minimum level of long term security against its funding target in much the same way that a financial company (bank or insurer) would do to optimize its capital usage. The sensitivity analysis of the results that the PPF derives each year helps the Board assess changes to its levy needs. As well as shifts in the risk landscape, the Board has been able to use this framework to assess the impact of a change to the basis of indexation of PPF compensation (from Retail Prices Index to Consumer Prices Index), the cost of removing its compensation cap and the effect of a potential change in pension scheme funding valuations to permit smoothing of discount rates.

The PPF's internal model is a stochastic tool that encompasses the main financial and economic risks faced by the Fund. It incorporates many behavioral assumptions such as the rate of closure of defined benefit plans and the shift over time to less risky investment strategies. The model produces distributions of outcomes and allows the Board to understand both the expected outturn and the range of possibilities. Such output is used by the Board to inform its periodic decisions about the size of the PPF levy, using risk-based and schemebased elements.

We conclude our discussion with a review of four lessons from the U.K. experience that may be applicable to the PBGC in the United States.

\section{The Pension Protection Fund}

The PPF was created in response to concerns about the fate of members of underfunded defined benefit (DB) pension schemes should the scheme sponsor become insolvent. In 2002 and 2003, publicity around cases such as Allied Steel and Wire highlighted 
the growing number of instances in which employees in these circumstances were left with very much lower levels of pension than expected. This contributed to what many described as a "pension crisis" undermining public confidence in final salary pension schemes in the U.K.

The idea of a Central Discontinuance Fund had been considered by the Pension Law Review Committee a decade previously but it was not considered appropriate to pursue the idea at that time. But in 2003 the Government decided to act, announcing its plans in a Pensions White Paper to create the PPF in order to provide compensation for members of private sector, defined benefit pension schemes which wound up on the employers' insolvency with insufficient assets to meet their liabilities. The 2003 White Paper culminated in the Pensions Act 2004, and in April 2005 the PPF was formed.

\section{Figure 1 here}

Established as a Statutory Corporation, the PPF is run by a Board that is independent of the U.K. Government. Powers conferred on the Board give it responsibility inter alia for managing the calculation and application of the Pension Protection Levy and setting the Fund's investment strategy. A primary driver for conferring these powers on the Board was to ensure that the activities of the PPF would be independent of, and not have to be underwritten by, the Government and ultimately taxpayers.

Broadly speaking, the PPF provides two levels of compensation to pension plan participants. For individuals that have reached their scheme's normal pension age or, irrespective of age, are either already in receipt of survivor's pension or a pension on the grounds of ill health, the PPF will generally pay 100 percent of the pension in payment immediately before the insolvency event. For the majority of people under their scheme's normal pension age, the PPF will generally pay 90 percent of the pension the individual had accrued (including revaluation) immediately before the insolvency event. The individual's compensation is revalued in line with the increase in inflation as measured by the Consumer 
Prices Index (CPI) between the assessment date and the commencement of compensation payments. This revaluation is subject to a cap of 5 percent compound per annum in respect of compensation attributable to pensionable service prior to 6 April 2009, and a cap of 2.5 percent compound per annum in respect of compensation attributable to pensionable service on or after 6 April 2009.

Compensation for plan participants is subject to an overall annual cap. In April 2012, this cap was $£ 30,644.85$ at age 65 after application of the 90 percent factor, with the cap being adjusted according to the age at which compensation comes into payment. Once compensation is in payment (for either category of member), the part that derives from pensionable service on or after 6 April 1997 is indexed each year in line with CPI inflation capped at 2.5 percent.

While the PPF has the ability to alter the Pension Protection Levy (subject to certain statutory limits) to meet its liabilities, in extreme circumstances it can also reduce compensation. First, revaluation and indexation can be reduced by the PPF. Second, levels of compensation can be reduced by the Secretary of State on the recommendation of the Board of the PPF. To date, the PPF has not articulated the circumstances in which these powers might be exercised and for the purpose of its financial management such scenarios are not explicitly modeled.

In order to fulfill its broader statutory objectives, the PPF must have sufficient funds to pay compensation to the members it protects. The agency's revenue currently derives from four sources: the assets of pension schemes that transfer into the Fund, recoveries from the insolvent sponsoring employers of those schemes, the annual Pension Protection Levy, and returns on invested assets. Table 1 shows the development of the PPF balance sheet in the eight years 2005/2006 to 2012/2013.

\section{Table 1 here}


In the above table, the funding ratio is based on the assets and liabilities of the Fund, measured according to PPF valuation assumptions. These data include those of schemes in assessment that are anticipated to transfer to the Fund. Claims are measured in terms of the deficits of schemes entering an assessment period in the relevant year, in accordance with the actuarial basis set under the terms of Section 179 of the Pensions Act 2004.

Although short term prospects for the PPF may be challenging owing to the current global economic climate, the long term decline in private sector DB provision and the influence of regulation towards improved funding levels both tend to suggest that the risk to the PPF balance sheet is likely to diminish over time. A number of factors are likely to contribute to this, including regulatory intervention, a move to liability-driven investment, and the overall decline in the number of schemes as they transfer their liabilities to the insurance regime, enter the PPF, or otherwise become ineligible for PPF protection.

Against this background, the PPF recognizes that there will come a point in time when the Fund is unable to rely on surviving schemes to amortize any deficit it may have accrued. The PPF's current objective therefore is to become self-sufficient by 2030 .

\section{Funding strategy}

The PPF's financial operating model. Most financial firms have clear objectives around which they build their business strategies and track performance. In the case of the PPF, its stated vision is "To protect peoples' futures" and its mission is "To pay the right people the right amount at the right time." A number of financial objectives might be congruent with these statements. The PPF Board's objective is to fulfill its vision and mission, taking into account the totality of the PPF financial model, namely its assets and liabilities from both past and future claims, and its levy income. 
The PPF's financial operating model is illustrated in Figure 2 This shows the flows of money into the Fund and the outputs from the investment processes, being the compensation payable to former members of pension schemes that have transferred into the PPF.

Figure 2 here

The PPF financial objective is self-sufficiency. It is inevitable that the PPF will continue to experience failure of scheme sponsors and consequently future claims. A claim is quantified by the PPF as the size of the scheme's deficit as of the date of insolvency, measured according to the PPF's published Section 179 valuation guidance and assumptions. In particular, it should be noted that the Section 179 deficit is assessed by reference to PPF compensation levels rather than the full benefits under the scheme's rules. It is however likely that the impact of claims on the Fund will decline over time, because:

- The long term expectation is that pension scheme funding will improve on account of the efforts of trustees, sponsors, and the Pensions Regulator;

- Schemes are expected to participate increasingly in risk mitigation strategies such as funding triggers, and interest rate and longevity hedging;

- Current activity points to growth in pension buy-out and buy-in activity that reduces risk to the Fund. It is expected that the market capacity for liability de-risking will increase over the coming years from its present level; and

- The trend towards closure of schemes to new entrants and new accrual is expected to continue, as is the increasing preference for defined contribution schemes as the solution to employer-sponsored pension provision.

There are, of course, scenarios where these expectations might not be met and which must be included in any financial analysis of the PPF. Nevertheless, over a long period, the expected decline in the scale of claims on the Fund is likely to lead to a point when the off- 
balance-sheet risks (namely the risks associated with future claims on the Fund) are much less significant than the on-balance sheet risks.

Any funding shortfall experienced by the PPF at that time would become a significant burden on the remaining levy payers. Furthermore, as the level of risk in the eligible defined benefit universe shrinks over time, it would be desirable for the Pension Protection Levy to reduce in proportion. Indeed, the PPF New Levy Framework introduced from 2012/2013 onwards has a "bottom up" principle, in which the levy payable by an individual scheme is closely related to that scheme's own risk characteristics. It would be unsatisfactory if, several years hence, a large levy needed to be raised to deal with a substantial PPF shortfall at a time when the base of levy-paying schemes had shrunk considerably and almost all of them were well funded.

The PPF therefore believes that there needs to be a Funding Horizon by which time the PPF should be "self-sufficient".

What is meant by self-sufficiency? The use of the term "self-sufficiency" is becoming increasingly common in pensions work. It is important, however, that the term is carefully defined to avoid misunderstanding. In the context of its Financial Objective, the PPF has defined "self-sufficiency" to mean having sufficient assets to cover liabilities without the need to take future risk for which future levies would be required, specifically:

- Being fully funded on a reasonably risk-free measure of liabilities;

- Having removed exposure to interest rate and inflation risk as far as possible;

- Having removed exposure to financial market risk as far as possible; and

- Having acquired protection against residual risks such as longevity and residual insolvency risk.

Self-sufficiency therefore implies that the PPF would no longer need to raise levies in order to maintain its funding position. The use of the phrase "reasonably risk free" recognizes 
that there are no truly risk free assets, so it means that the Fund at that point in time would not need to take additional investment risk. In practice, this means a mark to market valuation of the liabilities, by reference to a notional portfolio of assets consisting of cash plus appropriate zero-coupon interest rate swaps contracts and inflation swaps contracts plus gilt strips (or notional gilt strips). In order to achieve this target, it is the PPF's intention to remove risk gradually over a period of time, using market instruments where available and cost-effective.

The alternative to this strategy is to allow risk to the PPF balance sheet to persist in the long term. This may lead to a potentially lower levy in the run-up to the end of the Funding Horizon but with increased probability of a sizeable deficit thereafter. This, in turn, could necessitate substantial levies on schemes still extant beyond the Funding Horizon, should investment, longevity, or credit conditions prove adverse.

The funding horizon. The PPF has considered how it should quantify the expected decline in the risk of insolvency and at what point to draw the line in terms of setting a funding target. The deliberations of the PPF Board in 2010 concluded that 20 years was an appropriate timescale to aim for (i.e. the year 2030), although it accepted that there was an element of subjectivity in this choice.

The length of the Funding Horizon is important in ensuring the Pension Protection Levy follows a balanced and stable trajectory over time. A short horizon may lead to the PPF charging excessive levy over the short term, as it aims for the Fund to become self-sufficient in the face of persistent financial risk. On the other hand, an extended horizon would increase the likelihood of the Fund falling short of self-sufficiency at a point where there remains little potential for continued levy.

It is important to note that self-sufficiency is only a target for the year 2030. During the funding period, the PPF must accept the risk of further claims, and it has determined that 
it will assume a certain amount of investment risk during this period. This strategy serves to mitigate the impact on the Pension Protection Levy, through the expectation of investment returns in excess of the "risk-free" rate.

The PPF Board chose the 20-year horizon after considering the following factors:

- The maturing profile of its liabilities;

- The expected decline in its exposure to the effects of sponsor insolvencies; and

- The decreasing size of the eligible universe of levy payers.

In broad terms, the Board considered that the risk to the PPF, both within and outside the Fund, was likely to be much diminished by 2030, and this was the primary reason for the choice of 2030 as the Funding Horizon.

Owing to the closure of many schemes to new entrants and accruals, and especially those schemes most likely to be candidates for PPF entry in future, the duration of PPF liabilities is expected to shorten over the same timescale. This gave further support to a strategy that aims to focus solely on matching the liabilities rather than taking investment risk after a point in time. Figure 3 below shows the maturing profile of PPF liabilities. ${ }^{1}$ It is projected that by 2030 :

- The average age of DB scheme members will have increased from 56 to 71 (pensioner average age rising from 68 to 76, non-pensioner average age moving from 47 to 59); and

- Around 70 percent of scheme members will be pensioners, up from around 40 percent today.

As a result, the duration of the Fund's liabilities is expected to reduce from 21 years to 12 years. This facilitates the matching of compensation payments using conventional investment

\footnotetext{
${ }^{1}$ The spike at around age 65 is also reflected in population statistics and is partly explained by the post-war baby boom.
} 
techniques, as a smaller proportion of liabilities is projected to fall outside the term of longdated gilts.

Figure 3 here

Claims and scheme membership projections therefore point to a much improved risk environment for the PPF balance sheet in 2030. If the Fund arrives at this date in a sound funding position, with assets that match its liabilities as far as possible and with arrangements in place to protect it from residual risks, there should only be a low risk of the Fund failing to meet its financial obligations. A 20-year period from 2010 has therefore been set as the horizon over which the Board will seek to achieve a resilient balance sheet.

While the PPF has stated an intention to target self-sufficiency over a 20-year horizon, this timeframe is not considered by the Board to be immutable. A shorter time horizon than 2030 would be appropriate if risks to the PPF were much reduced at an earlier juncture. On the other hand, stressed economic conditions and persistent risk could imply an extension of the Funding Horizon beyond 2030.

Protecting against residual longevity and unexpected claims risk. Risk to the PPF balance sheet will not be entirely eliminated by 2030 . The Fund aims to remove market, interest rate, and inflation risk using appropriate investment techniques. Nevertheless, the risk of unexpectedly high claims and member longevity is likely to persist. The Fund will also need to deal with operational hazards, such as the risk of counterparty insolvency and the risk of an expense overrun. The materiality of counterparty risk undoubtedly requires further analysis and monitoring. The possibility of an expense overrun also requires monitoring and will become more material when the Fund reaches maturity.

It may be possible to protect against a proportion of residual longevity and unexpected claims risk. Instruments to hedge longevity, for instance, are already available. But the markets providing insurance against these residual risks remain at a relatively early 
stage of development, compared to the pool of potentially insurable liabilities. The Fund's liabilities are expected to grow substantially to 2030. It is currently unclear whether such markets will be sufficiently large and sophisticated to absorb the full extent of PPF claims and longevity risk. The PPF therefore considers it prudent to target a Funding Margin above best-estimate liabilities in order to protect against these residual risks. At the same time, it recognizes that it must balance the interests of different generations of levy payers and members in determining the size of this margin.

In order to identify a suitable margin, the Board considered stochastic modeling of longevity and claims using the PPF's own internal model (the Long-Term Risk Model, described below). The first step was to produce an expected PPF and scheme profile at 2030 using model output, credit transition matrices, and current mortality tables. A range of scenarios was then generated for insolvencies over five years and longevity over the outstanding lifetime of the Fund. This was applied to the expected PPF and scheme profile at 2030, providing a set of outcomes for claims and PPF funding. From these outcomes, it was possible to examine the protection against combined longevity and claims risk provided by various sizes of reserve. The estimated relationship between the size of margin and the extent of protection is illustrated below in Figure 4 .

\section{Figure 4 here}

The PPF is targeting a Funding Margin equivalent to 10 percent of liabilities to protect, with 90 percent confidence, against unexpected claims over five years and longevity over the outstanding lifetime of the Fund. This target will not be static over time, however; it will be re-evaluated against changing economic and demographic circumstances. A useful comparator for the 10 percent margin is the embryonic IORP solvency initiative in Europe which, though unlikely to be realized for many years, proposes an eight percent solvency capital margin above the value of the liabilities for pension funds. 


\section{Funding framework}

The risk return trade-off for the PPF. The number, size, and shortfall in respect of those schemes that enter the PPF are beyond the PPF's control, but the investment strategy and the size of the levy that the PPF seeks to raise are clearly within its control. The PPF's Funding Framework is a useful tool with which a range of decisions, including those related to levy and investment strategies, can be evaluated. Such a framework also represents a rational basis for communicating with key stakeholders.

Development of the PPF Funding Framework has leaned heavily on the language and principles applied to both pension funds and insurance undertakings. For example, Urwin et al. (2001) refer to the financial mission of a pension fund including key financial goals; secondary financial goals and the risk measure. And in the insurance context, Shaw et al. (2010) note the main components of economic capital to be risk measure; probability threshold and time horizon, the most well-known examples of which are the one-year $99.5 \%$ Value at Risk (VaR) found in insurance.

The PPF's probability threshold is in effect a guideline probability of reaching the Financial Objective over the Funding Horizon. This was established in 2010 when the PPF Board expressed comfort with a probability of reaching the Financial Objective over 20 years of 80 percent, known as the "probability of success." In reaching this position, which was also subject to informal stakeholder consultation and subsequent exposure through the publication of the Funding Strategy, the Board had to accept that success cannot be guaranteed under a principle that the possibility of any adjustment to compensation levels or indexation would not be formally incorporated into its financial planning. 
In order to be able to express its appetite for financial risk and to provide a quantification that will facilitate analysis of risk return trade-offs, the PPF has selected two risk measures:

- A downside risk measure (sometimes referred to as drawdown) being the maximum deficit reached by the Fund under the $90^{\text {th }}$ percentile adverse scenario. It is a comprehensive measure that combines both the insurance risks of future claims on the Fund and the asset and liability risks of the Fund's annuity book. The measure reflects the near worst case scenario where the Fund may inherit potentially irrecoverable deficits and is used to inform the Board on strategic levy and investment decisions; and

- The second risk measure is the volatility of the funding level assuming no further claims on the Fund. This measure reflects short term uncertainty in the PPF's own funding level and is used to express the Board's appetite for investment and funding risk and to inform more detailed day to day investment decisions.

The sensitivity of the downside risk and probability of success measures to controllable factors such as investment strategy and levy collections, and to key assumptions such as current scheme and the PPF funding levels, is shown in Table 2.

Table 2 here

As noted above, the practical risk return trade-offs available to the PPF center on the investment and levy strategies of the Fund. Under a new policy introduced for the 2012/2013 year, levy parameters are now set triennially following an analysis of the Funding Framework. In addition to the quantitative outputs such as those from the internal model within the Funding Framework, the Board will also consider qualitative issues such as the balance between protection and affordability of the PPF levy. 


\section{PPF's Internal Model}

The PPF's Long-Term Risk Model. Internal models are more commonly associated with risk capital assessments within insurance entities. Although the PPF is not a capitalized entity like an insurance company, an internal model can nevertheless help to assess the full extent and range of risk that the PPF faces. Such assessments are vital to a number of core PPF decisions, most notably those on the total Pension Protection Levy and on the design of an appropriate investment strategy.

The PPF has developed a model capable of capturing, quantifying and expressing the potential impact of all primary risks to the PPF balance sheet: the so-called Long-Term Risk Model (LTRM). The LTRM is a stochastic claims and balance sheet model that generates an extensive range of asset return, insolvency and longevity scenarios over a chosen time horizon, and on this basis projects a distribution of possible PPF balance sheet outcomes.

The projection process begins with the generation of 1,000 economic scenarios. Each economic scenario is a set of projected paths for relevant asset prices (including bond yields, equity prices and risk-free rates). These are obtained from a third party supplied Economic Scenario Generator (ESG). The largest PPF-eligible pension schemes are modeled individually, with the remaining schemes pooled into groups according to demographic and risk similarities.

To capture insolvency risk, the PPF models pension scheme sponsors transitioning each year between eight different credit ratings, ranging from AA to D (where D constitutes a default). The probability of transitioning to a given credit rating depends on the sponsor's current rating, its industry sector, the current state of the economy, and the company's own idiosyncratic risk. This latter element reflects the fact that companies face their own unique risks that are uncorrelated with their industry and the wider economy. The PPF uses 500 different scenarios of idiosyncratic risk. Each of the 500 risk scenarios is mapped to each of 
the 1,000 economic scenarios (providing 500,000 scenarios in all); with the insolvency dynamics adjusted to reflect the degree of stress at play in the economy. Funding paths therefore combine with insolvency dynamics to determine the profile and size of claims on the Fund (see Figure 5).

Figure 5 here.

PPF assets and liabilities are rolled forward under each scenario, taking account of investment returns and movements in the discount rate. It is assumed that the PPF balance sheet is unaffected by changes to interest and inflation rates owing to the Fund's policy of hedging out these risks. The funding of schemes in the PPF-eligible universe is rolled forward in a similar manner. These deficits are transferred onto the PPF balance sheet at the point at which they occur. Levy collections are also modeled explicitly, taking into account the main features of the PPF's New Levy Framework, for example the way that funding risk varies under different economic scenarios. The result is a distribution of PPF balance sheet outcomes over a chosen horizon that takes account of all primary funding risks. Figure 6 shows the distribution of balance sheet outcomes from the Fund's 31 March 2012 base case.

\section{Figure 6 here}

The value of liabilities at any particular time step is expressed in terms consistent with the contemporaneous market parameters (such as interest rates and inflation assumptions) which underlie the market value of the assets. The PPF uses a stochastic mortality model that allows for rates of mortality improvement to vary in different scenarios. The table currently used is generated by the Cairns-Blake-Dowd (2007) mortality model with the cohort and curvature effects.

Modeling assumptions and limitations. In projecting forward the PPF balance sheet, the LTRM models the behavior of asset returns and scheme sponsor insolvencies. Modeling techniques are insufficient, however, to capture many of the additional dynamics affecting 
pension scheme risk, especially those relating to "scheme behavior". In these cases, subjective assumptions are used, a selection of which includes the following:

- Scheme contributions are determined in accordance with current recovery plans, as reported to the Pensions Regulator;

- Schemes reduce the risk of their investments over time (migrating on average to 85 percent allocation to long-dated bonds); and

- No new schemes become eligible for PPF protection.

Where assumptions such as the above are material to the risk assessments or decisions being made, it is important that their choice is appropriately governed and that the effect of these choices is explored. In the case of the PPF, key model assumptions are set at the Board level and their impact assessed through the use of sensitivities.

The internal model is not subject to uniformly-applied assumptions regarding the risk premia for investment in equity or other return-seeking asset classes. Instead, as noted above, asset returns are generated stochastically by the ESG. Observed data and current market information inform long-term averages around which stochastic projections fluctuate. In the projections carried out at an effective date of 31 March 2012, the risk-free investment return, in this case the short-term return on cash stabilizes at a long-term average of around 5 percent per annum, with an average risk premium for equity investment of around 3.5 percent per annum. Sponsor insolvency probabilities are assumed to exhibit a degree of correlation with equity market conditions.

For the modeling of interest rates, there is an implicit assumption of mean reversion which could disguise the exposure to extreme and historically unprecedented market scenarios. Since these seemingly unlikely scenarios may represent significant financial risks to the Fund, their effect should be explored through further analysis. Stress testing of the key risk metrics is carried out using assumptions devised from economic analysis of potential 
future scenarios of the world economy. These stress tests are used to study the resilience of the Fund to various shocks, identify exposures and assist with the planning of mitigations.

As with any financial or economic model, it is important to exercise appropriate caution when analyzing LTRM output. Economic models are not infallible; there is no guarantee that future outcomes will conform to dynamics observed in present and past data. In order to minimize the risk of misleading output, care must be taken to review and update the model on a regular basis and to reconcile its results to previous output and known outcomes.

\section{Pricing and Sharing the Risk}

Overview of the PPF charging mechanism. The Pension Protection Levy is determined in two steps. First, the Board determines the aggregate amount of levy funding that it wishes to collect. This amount is then divided up between schemes according to their risk for the estimated Risk-Based Levy (RBL) component, and according to their size for the estimated Scheme-Based Levy (SBL) component. Prior to the 2012/2013 levy year this was an annual exercise This approach was, to a large extent, a "top-down" charging mechanism in that an individual scheme levy was a function of the total to be collected and that scheme's risk characteristics relative to the general population.

The PPF Board moved to a triennial cycle from 2012/2013 onwards. Under the new arrangement, the levy parameters are fixed for the three years so that levy payers have greater predictability of costs during that period (though the system has less predictability of levy income). During each three-year period, therefore, the levy will be "bottom-up" whereby an individual scheme's levy depends solely on that scheme's individual risk factors and the aggregate levy will be the sum of the individual levies. This new framework has several features: 
- Parameters of the levy formula are fixed for at least three years so that individual levies move in line with individual scheme risk;

- The impact of market volatility is reduced by a smoothing mechanism and there is an allowance for individual schemes' investment risk in the calculation of the underfunding level;

- Emphasis is shifted away from insolvency risk towards underfunding risk, with a compression in the scale of insolvency probabilities and the number of levy bands reduced from 100 to 10 ; and

- The levy rates themselves include a margin to accord more closely to market pricing levels, with the result that the range in rates between strong and weak sponsors is much narrower.

Setting the levy estimate. In setting its levy requirements, the PPF Board is mindful of remaining on track to achieve its funding objective by the end of its chosen Funding Horizon in 2030. The Board has expressed a level of comfort for the probability of achieving this objective set at $80 \%$ in 2010 , but which is expected to gradually increase and converge to $100 \%$ by 2030 . The levy decision is informed by analysis from the internal model described previously, together with appropriate sensitivity and scenario analyses. In particular, one of the outputs of the model is the probability of achieving the PPF's Funding Objective. In addition to the quantitative information and mindful of the limitations of models, the Board exercises considerable judgment and takes into account a wide range of qualitative factors in making a levy decision.

The Pension Protection Levy cannot, under the Act, exceed a Levy Ceiling initially fixed by the Secretary of State for Work and Pensions; it is now indexed annually in line with National Average Earnings. For the 2012/2013 levy year the ceiling was $£ 934 m$. The Pensions Act also specifies a $25 \%$ cap on any year-on-year increase in the levy estimate. 
Indeed following the first year of the new levy arrangement, in which the level of risk through underfunding rose dramatically as long bond yields hit historic lows, the Board had to intervene to restrain the increase in the levy estimate to ensure continued affordability.

Sharing the PPF levy among schemes. The PPF Levy comprises a "Risk-Based Levy" (RBL), based on individual scheme risk factors, and a "Scheme-Based Levy" (SBL) which depends only on the size of the scheme and is set in proportion to scheme liabilities on a Section 179 basis. The estimated SBL must not represent more than $20 \%$ of the estimated total levy collection. In effect the SBL is a cross-subsidy of the levy of small schemes by larger ones, and the PPF has stated that it will be set at a level to cover only the cost of any capping of the RBL that may be made on grounds of affordability.

The Pensions Act requires the Board to take at least two risk factors into account in the calculation of the RBL, namely underfunding and insolvency risk. The Board may also take investment risk into account and, from 2012/2013, it has begun to do so by basing its formula on values of assets and liabilities that are stressed according to an adverse investment scenario.

Figure 7 here

\section{Conclusions}

Here we provide an explanation of the PPF levy-setting process, explain the framework around which the levy decisions are made, and outline the success measures designed to show the robustness of the Fund on a prospective basis. Some of the methodology was derived from the insurance sector, but the PPF approach differs from a typical insurance pricing approach because of its unique structure.

A proprietary insurance company would calculate the premium as the expected cost of claims plus the cost of servicing the capital that is held against the risk and which represents 
the level of security that is being adopted by the company. PPF, of course, is not a proprietary model; its resources are the future levies that are raised - a sort of contingent capital - and it has no real basis for establishing a unit cost of capital. However the process of setting the aggregate levy requirements using stochastic methods that evaluate the risks and direct a level of pricing consistent with the Board's risk tolerance or risk appetite is very similar to a proprietary model, albeit in conceptual terms.

The parallels continue into the division of levy between the 6,300 eligible schemes where the levy rates, which formerly were based on one year probabilities of default and are now closer to market rates that implicitly incorporate a cost of capital. These levies thus reflect the contribution to risk of individual schemes. Nevertheless it must be remembered that this stage of the process is essentially a levy-sharing exercise, not an individual riskpricing exercise. PPF does, however, monitor its levy amounts against the premium that would be charged by a commercial insurer with capital costs to bear.

The paper has also shed a light on the complexities of the risk landscape that must be factored into the levy pricing mechanism. PPF's claims experience has typically been a steady flow of new claims, but the amounts vary markedly. Deficits inherited range from those counted in single millions of pounds right up to over half a billion pounds. PPF has yet to experience a sustained increase in claim frequency, although one is often predicted in connection with the economic recovery. The PPF is still vulnerable to an extremely large claim, albeit an unlikely one. Capturing these risks in a single model is challenging, and then the risk is also affected over the long term by the behaviors of scheme Trustees and indeed the changing landscape of regulation. Both factors must be considered either in a base case or in a sensitivity analysis. 


\section{Postscripts: Lessons from the U.K. experience}

If I were to address what the U.S. pension protection regime might learn from its younger and much smaller counterpart in the United Kingdom, I would identify four areas to consider (with much humility):

A levy that is consistent with the cost of risk. The ability to set a levy that is linked to the financial requirements of the Fund and is shared out among insured plans according to individual plan risk has helped maintain the PPF resilience throughout the global financial crisis.

In aggregate, the claims on the PPF, as measured by the Section 179 deficits of schemes entering the Fund, has represented $97 \%$ of the aggregate levy collected during PPF's eight years of existence. The Fund has gained a measure of stakeholder acceptance for the levy through a clear financial objective and by linking the individual scheme levy to the risk posed to the PPF by that scheme. This is in contrast to the U.S. regime, in which the levy is based on scheme memberships and has not been sensitive to the level of risk in the system.

So far, the U.K. has been able to build a margin into its levies and has avoided a legacy issue of large inherited deficits becoming too great, or even irrecoverable. Were such a situation be allowed to develop, it would become harder to gain stakeholder acceptance to pay for both the prospective and the inherited risks. In the U.S., it seems that this position has been reached and that any move towards a risk-led approach to levies may have to be accompanied by measures to deal with the legacy issues.

Clearly expressed financial objectives. As noted above, the PPF has set a very clear financial objective, namely, to be self-sufficient by 2030. This has provided a firm quantitative framework to evaluate levy and investment strategies, as well as providing a mechanism for informed stakeholder engagement with the Fund's financial resilience. By contrast, the PBGC's financial objectives are not as clear and its investment strategies have 
oscillated at times, between the conflicting priorities of hedging downside liability risks and aggressive growth strategies. The PIMS model focuses on a 10 year time horizon and analyzes the funding level at that time, without having the firm context of knowing what the target is. In many ways this is understandable, but it is not conducive to good planning or stakeholder dialogue.

Given the almost overwhelming legacy issues faced by the PBGC today, it might seem that any strategy is destined to fail unless substantial external funding is acquired. In my opinion, this should not deter the PBGC from constructing a financial objective that accepts reality while attempting to make realistic improvements using levies and investment strategies. I am drawn to the concept of an objective that seeks to guarantee the pensions payable over a period of $\mathrm{x}$ years and to increase that period incrementally in each future year. Such a framework would accept the reality that the PBGC cannot guarantee all its current commitments without some future injection of funds. It would also encourage the protection of downside liability risks in order to make the guaranteed payments and allow some flexibility to take investment risks in the expectation that these will be rewarded and allow the funding position (and the guarantee period) to improve. This would further enable the modeling work of PIMS to become more relevant and enable better dialogue on the real issues facing the PBGC.

Ownership and governance of investment risks. The clarity that PPF has achieved through its governance arrangements means that ownership of, and appetite for, risks in general and investment risk in particular is well understood and highly transparent. In particular, the PPF Board has set a budget for investment risk that is delegated through its investment committee to the executive and its external fund managers. The Fund has established a notional portfolio of low risk investments that replicate its liabilities and that is consistent with its valuation assumptions. This replicating portfolio forms the investment benchmark 
from which performance and risk are measured. The investment committee devises a multiasset investment strategy to optimize long term performance against the benchmark whilst remaining within the Board's risk tolerance. Generally this strategy will hedge away unrewarded risk and allocate money to a diversifying range of asset classes with their own benchmarks that collectively seek to outperform the replicating portfolio by a target of $1.8 \%$ per annum. The accountability for the collective performance of these strategic benchmarks lies with the investment committee. The execution strategies within each asset class and the risk and performance of the assets in relation to asset class-specific benchmarks are the responsibility of the in-house investment team and the external managers they select.

Such a structured approach paired with clear statements of risk appetite are not evident within the governance arrangements of PBGC. Investment performance is measured against a soft benchmark of a blend of equity and bond investments, but this benchmark is simply a comparator. It does not appear to feature in the roles and responsibilities of the various links in the investment chain, crucially, it bears no relation to the liabilities of PBGC.

One consequence of this is that the ownership and governance of the mismatching risks between assets and liabilities are not immediately clear. Yet the management of performance and risk within the whole investment area is likely to be compromised by insufficiently clear objectives.

Model assumptions and limitations. The PPF has a comprehensive internal model that is used for risk analysis and strategy evaluation, but as with all such models, it has limitations and the users of such models should be aware of these limitations. In the case of the PPF, the Board owns the model assumptions and is therefore encouraged at a high level to be familiar with the key assumptions and their materiality. Members of the Board also undertake training on financial models and how they can engage with and challenge model outputs, for example 
by applying tests of reasonableness. The main assumptions in the PPF model are also published each year within the PPF's annual review of its funding strategy.

Good actuarial practice encourages the providers of actuarial information and model outputs to understand the purposes for which the information will be used. Where decisions are to be made or opinions formed from that information, then those assumptions material to the decision should be clearly stated and, where appropriate, sensitivities used to illustrate the effect of differences in the material assumptions.

Models such as that used by the PPF or the PIMS model used by PBGC can become victims of their own inherent complexity. Of necessity, there are many components such as the economic and market factors that influence investment performance and also insolvency rates, assumptions about behaviors such as scheme closures, buy outs, or pensions commutation, and regulatory effects. This makes it difficult to properly inform the users of the model about the limitations and sensitivities to changes in material assumptions.

A model's utility as a practical tool is formed by the clarity of the purpose for which it is being used, the governance around its assumptions, and a clear understanding of its limitations and a quantification of its sensitivity to changes in key assumptions. A great deal of effort can go into the design, build, and the assumption-setting, and in many respects this is a continuous process of iteration. But unless there is clarity of purpose and a good sense of materiality, this effort can simply become a misplaced search for elusive perfection. 


\section{References}

Cairns, A. J. G., D. Blake, K. Dowd, G. D. Coughlan, D. Epstein, A. Ong, and I. Balevich (2007). “A Quantitative Comparison of Stochastic Mortality Models using Data from England and Wales and the United States," North American Actuarial Journal, 13(1): $1-35$.

Pension Protection Fund (PPF) (2006). Annual Report \& Accounts 2005/06. London, UK: The Stationery Office.

Pension Protection Fund (PPF) (2007). Annual Report \& Accounts 2006/07. London, UK: The Stationery Office.

Pension Protection Fund (PPF) (2008). Annual Report \& Accounts 2007/08. London, UK: The Stationery Office.

Pension Protection Fund (PPF) (2009). Annual Report \& Accounts 2008/09. London, UK: The Stationery Office.

Pension Protection Fund (PPF) (2010). Annual Report \& Accounts 2009/10. London, UK: The Stationery Office.

Pension Protection Fund (PPF) (2011). Annual Report \& Accounts 2010/11. London, UK: The Stationery Office.

Pension Protection Fund (PPF) (2012). Annual Report \& Accounts 2011/12. London, UK: The Stationery Office.

Pension Protection Fund (PPF) (2013). Annual Report \& Accounts 2012/13. London, UK: The Stationery Office. Forthcoming.

Pension Protection Fund (PPF) and The Pensions Regulator (2006). The Purple Book: DB Pensions Universe Risk Profile. London, UK: PPF. 
Pension Protection Fund (PPF) and The Pensions Regulator (2007). The Purple Book: DB Pensions Universe Risk Profile, 2007. London, UK: PPF.

Pension Protection Fund (PPF) and The Pensions Regulator (2008). The Purple Book: DB Pensions Universe Risk Profile, 2008. London, UK: PPF.

Pension Protection Fund (PPF) and The Pensions Regulator (2009). The Purple Book: DB Pensions Universe Risk Profile, 2009. London, UK: PPF.

Pension Protection Fund (PPF) and The Pensions Regulator (2010). The Purple Book: DB Pensions Universe Risk Profile, 2010. London, UK: PPF.

Pension Protection Fund (PPF) and The Pensions Regulator (2011). The Purple Book: DB Pensions Universe Risk Profile, 2011. London, UK: PPF.

Pension Protection Fund (PPF) and The Pensions Regulator (2012). The Purple Book: DB Pensions Universe Risk Profile, 2012. London, UK: PPF.

Pension Protection Fund (PPF) and The Pensions Regulator (2013). The Purple Book: DB Pensions Universe Risk Profile, 2013. London, UK: PPF. Forthcoming.

Shaw, R. A., A. D. Smith, and G. S. Spivak (2010). "Measurement and Modelling of Dependencies in Economic Capital,” British Actuarial Journal, 16(3): 701-721.

Urwin, R. C., S. J. Breban, T. M. Hodgson, and A. Hunt (2001). "Risk Budgeting in Pension Investment," British Actuarial Journal, 7(3): 319-364. 
- The PPF universe of eligible DB schemes comprises 6,300 pension schemes with 12 million members and aggregate liabilities of $£ 1 \mathrm{tn}$, measured under the basis set in accordance with Section 179 of the Pensions Act 2004.

- 550 pension schemes with, in total, over 150,000 members have transferred to the PPF. An additional 250 schemes with 150,000 members are in a PPF assessment period during which the scheme is assessed for PPF entry.

- The PPF's balance sheet has grown significantly to the point where, as at $31 \mathrm{March}$ 2013, an estimated $£ 13$ billion of assets are under direct PPF management, with a further $£ 6$ billion of assets managed by schemes that are in an assessment period.

Figure 1. Key facts about the PPF (as at end March 2013). Source: PPF (2006-2013); PPF and The Pensions Regulator (2006-2013).
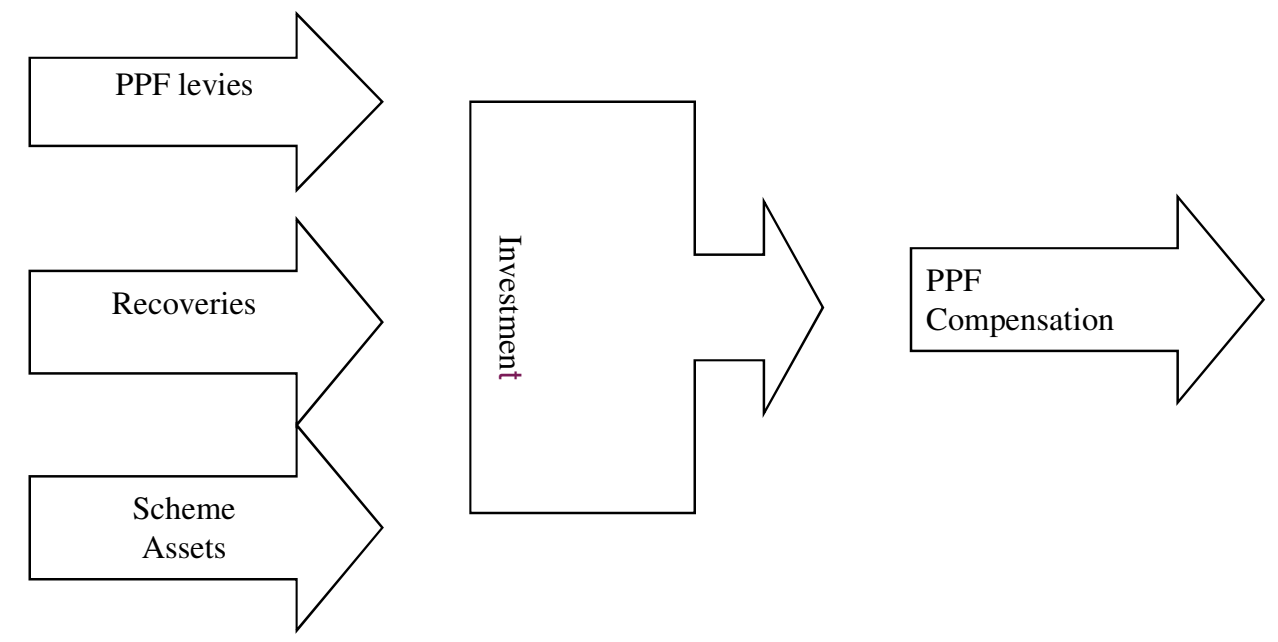

Figure 2. The PPF financial operating model. Source: Author's elaboration. 


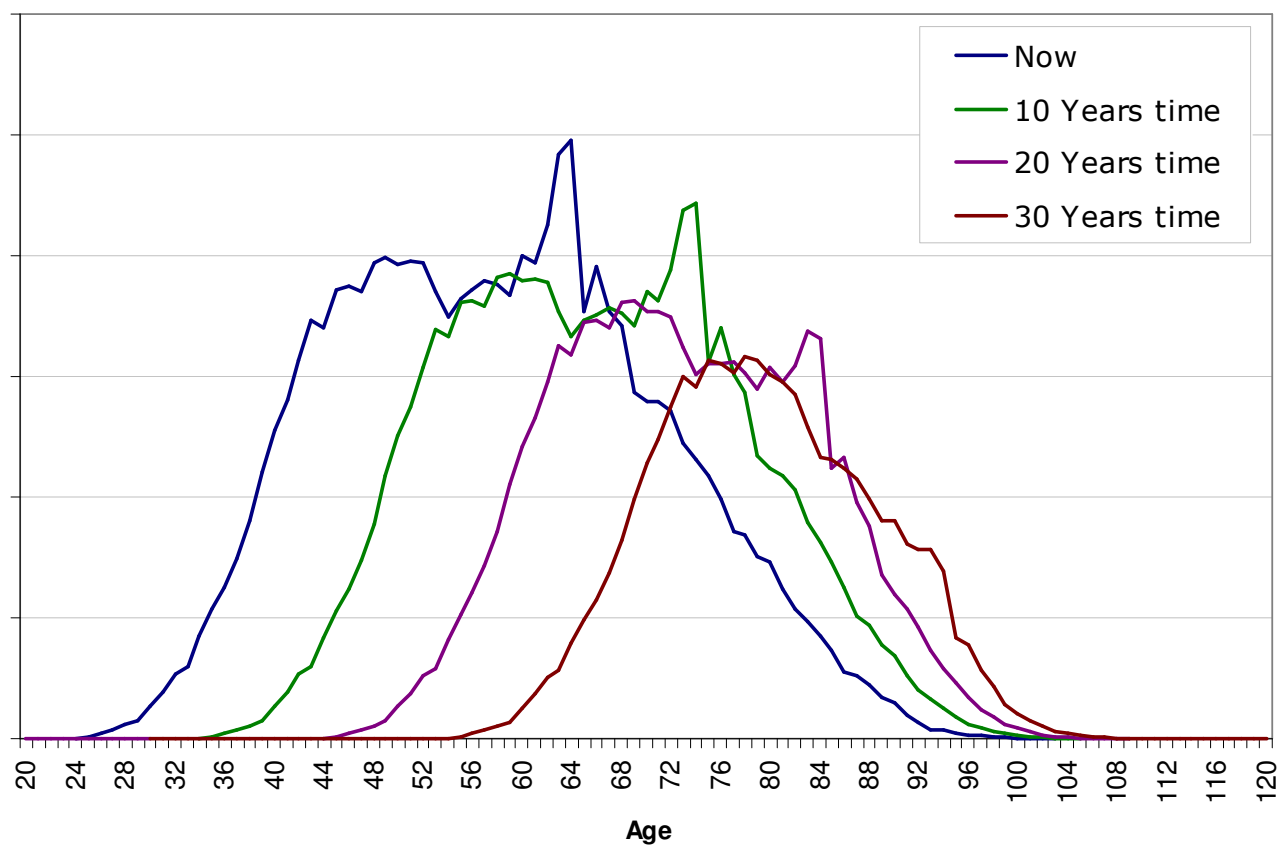

Figure 3. Projected development of the age profile of PPF membership. Source: Author's elaboration.

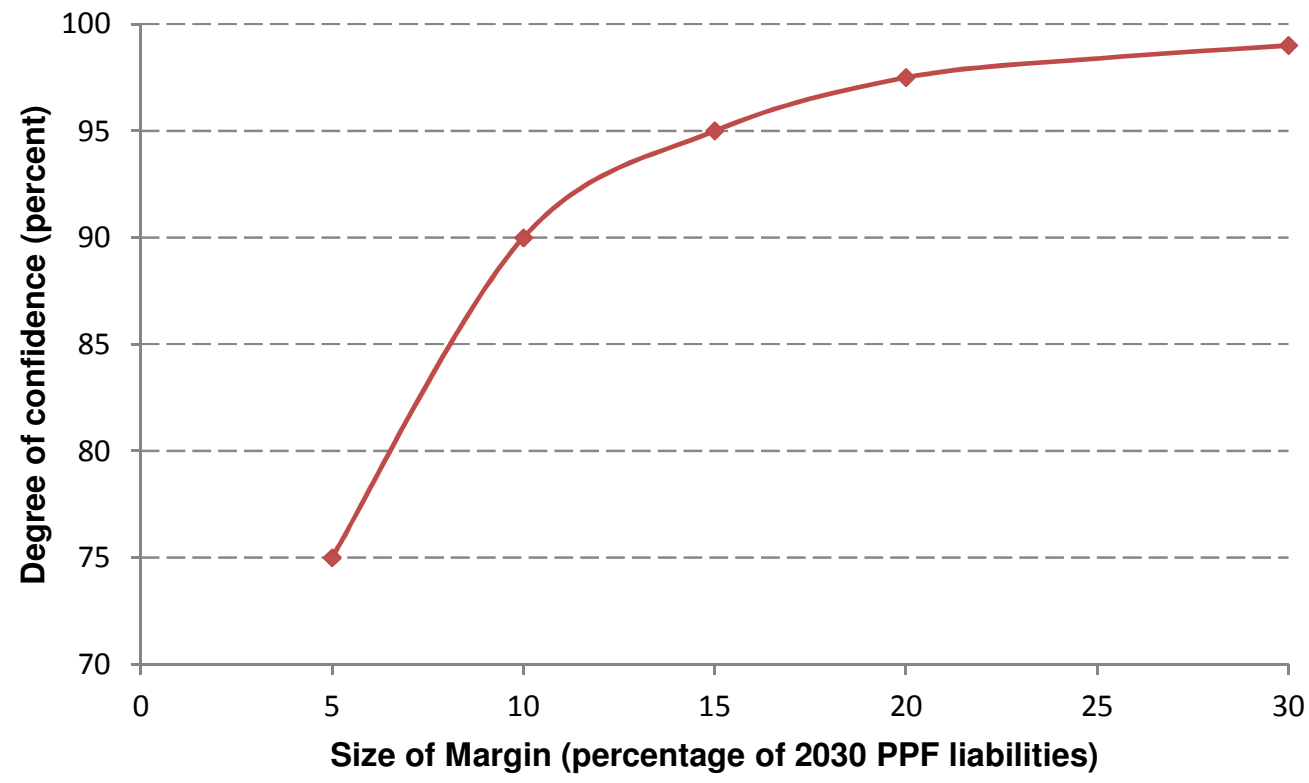

Figure 4. Funding margins for combined longevity and claims risk. Source: Author's elaboration. 


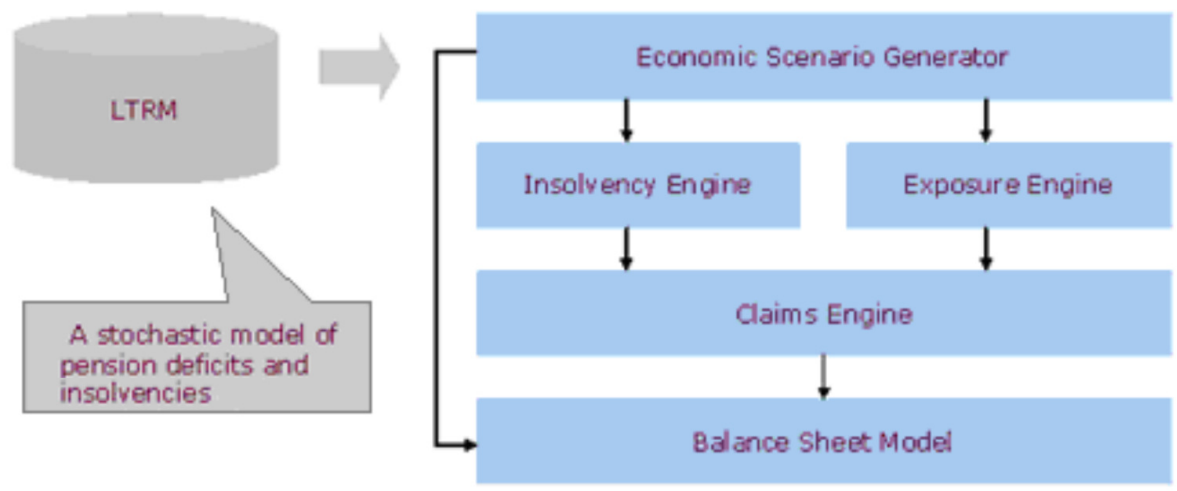

Figure 5. The internal model. Note: A third party economic scenario generator feeds two sub-modules that create consistent insolvency and exposure experiences respectively, combining to form distributions of PPF claims experience and balance sheet. Source: Author's elaboration.

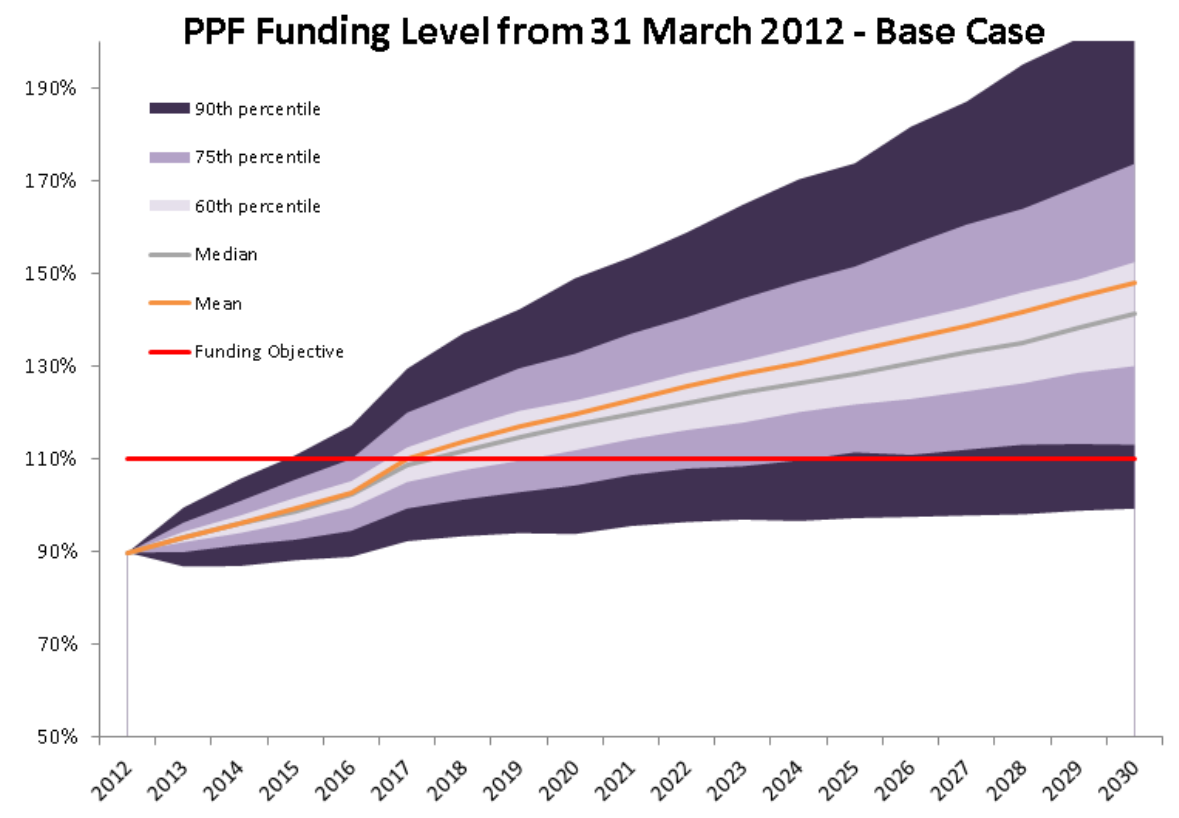

Figure 6. Distribution of balance sheet outcomes from the PPF's 31 March 2012 base case.

Source: PPF (2006-2013); PPF and The Pensions Regulator (2006-2013). 
Figure 7. PPF levy formula 2012/2013.

\section{Risk based levy $($ RBL) $=$ Underfunding (U) X Insolvency Risk (IR) X Levy Scaling Factor (LSF)}

Where

$U$ is the value of the scheme liabilities less the value of its assets and less any deficit reduction contribution made since the last valuation date. If $U$ is negative and the scheme is in surplus then the RBL is zero.

For the purposes of the above the assets and liabilities are stressed according to an adverse scenario to reflect investment risk.

$U$ may be further reduced if a contingent asset such as a bank or parental guarantee has been approved.

RBL is capped at $0.75 \%$ of unstressed liabilities.

IR is a rate ranging from 0.0018 for the strongest sponsors up to 0.04 for the weakest. There are 10 categories in total.

$L S F=0.89$ for $2012 / 2013$

Scheme Based Levy (SBL) = Liabilities (L) X Scheme Based Multiplier (SBM)

Where:

$S B M=0.000085$

Source: PPF (2006-2013); PPF and The Pensions Regulator (2006-2013). 
Table 1 PPF Assets, Liabilities, Claims, and Levy Experience

\section{PPF Balance Sheet Development}

\begin{tabular}{|c|c|c|c|c|c|c|c|c|}
\hline Financial Year & $05 / 06$ & $06 / 07$ & 07/08 & 08/09 & $09 / 10$ & $10 / 11$ & $11 / 12$ & $12 / 13$ \\
\hline Assets (£m) & 2,086 & 4,409 & 5,554 & 9,330 & 12,257 & 14,043 & 16,513 & 18,898 \\
\hline Liabilities (£m) & 2,429 & 5,018 & 6,071 & 10,560 & 11,863 & 13,366 & 15,444 & 17,906 \\
\hline Funding & $86 \%$ & $88 \%$ & $91 \%$ & $88 \%$ & $103 \%$ & $105 \%$ & $107 \%$ & $106 \%$ \\
\hline \multicolumn{9}{|l|}{ Ratio } \\
\hline $\begin{array}{l}\text { Claims in Year } \\
(£ \mathrm{~m})\end{array}$ & 485 & 442 & 318 & 721 & 285 & 373 & 375 & 1,000 \\
\hline $\begin{array}{l}\text { Levy collection } \\
(£ \mathrm{~m})\end{array}$ & 137 & 271 & 585 & 651 & 592 & 663 & 596 & 630 \\
\hline
\end{tabular}

Source: PPF (2006-2013); PPF and The Pensions Regulator (2006-2013). 
Table 2 Sensitivity of Downside Risk and Probability of Success

\section{Scenario}

Base case as at $31^{\text {st }}$ March 2012

Levy reduced by $10 \%$

25 bps reduction in asset returns (excluding cash and government bonds)

Initial PPF funding reduced by 10 percentage points

Length of recovery plans increased by three years

Reduced funding owing to a $10 \%$ reduction in scheme technical provisions.

\section{Probability of Downside risk (£bn) success $(\%)$ \\ 84 \\ 10}

82

11

82

11

79

12

83

11

79

15

Source: PPF (2006-2013); PPF and The Pensions Regulator (2006-2013). 


\title{
Measuring and Explaining Pension System Risk
}

\author{
Frank J. Fabozzi \\ EDHEC Business School, EDHEC Risk Institute \\ September 2013 \\ Michigan Retirement Research Center \\ University of Michigan \\ P.O. Box 1248 \\ Ann Arbor, MI 48104 \\ www.mrrc.isr.umich.edu \\ (734) 615-0422
}

\section{Acknowledgements}

This work was supported by a grant from the Social Security Administration through the Michigan Retirement Research Center (Grant \# 5 RRC08098401-05-00). The findings and conclusions expressed are solely those of the author and do not represent the views of the Social Security Administration, any agency of the Federal government, or the Michigan Retirement Research Center.

\section{Regents of the University of Michigan}

Mark J. Bernstein, Ann Arbor; Julia Donovan Darlow, Ann Arbor; Laurence B. Deitch, Bloomfield Hills; Shauna Ryder Diggs, Grosse Pointe; Denise Ilitch, Bingham Farms; Andrea Fischer Newman, Ann Arbor; Andrew C.

Richner, Grosse Pointe Park ; Katherine E. White, Ann Arbor; Mary Sue Coleman, ex officio 


\title{
Measuring and Explaining Pension System Risk
}

\begin{abstract}
We discuss pension system risk in the United States by focusing on the investment policy and the methodology for the valuation of the liabilities of the Pension Benefit Guaranty Corporation (PBGC). We offer suggestions as to how the PBGC should consider modifying the Pension Insurance Modeling System. The issues of investment policy and liability valuation are not two distinct topics. As emphasized here, the proper valuation of liabilities provides a benchmark for the PBGC to use as a starting point for the establishment of its investment policy and then for assessing investment performance.
\end{abstract}

\section{Citation}

Fabozzi, Frank J. (2013). “Measuring and Explaining Pension System Risk,” University of Michigan Retirement Research Center (MRRC) Working Paper, WP 2013-290(i). Ann Arbor, MI.

\section{Authors' Acknowledgements}

The research reported herein was pursuant to a grant from the US. Social Security Administration (SSA) funded as part of the Retirement Research Consortium (RRC); the author also acknowledges support from The Pension Research Council at The Wharton School. All findings and conclusions expressed are solely those of the author and do not represent the views of the SSA or any agency of the federal government, the PRC, or The Wharton School at the University of Pennsylvania. In addition, the opinions expressed by the author do not represent those of the Society of Actuaries or any other organization of which I am a member. All findings, interpretations, and conclusions of this paper represent the views of the authors and not those of the Wharton School or the Pension Research Council. (C2013 Pension Research Council of the Wharton School of the University of Pennsylvania. All rights reserved. 


\title{
Measuring and Explaining Pension System Risk
}

\author{
Frank Fabozzi
}

The purpose of this paper is to discuss pension system risk in the United States by focusing on the investment policy and the methodology for the valuation of the liabilities of the Pension Benefit Guaranty Corporation (PBGC). Based on this discussion, I offer a few suggestions as to how the PBGC should consider modifying the Pension Insurance Modeling System (PIMS). The issues of investment policy and liability valuation are not two distinct topics. As emphasized here, the proper valuation of liabilities provides a benchmark for the PBGC to use as a starting point for the establishment of its investment policy and then for assessing investment performance.

The PBGC can best be described as an insurer with little control over key financial decisions that might permit it to increase the likelihood of accomplishing its overarching mandate. Under the Employee Retirement Income Security Act of 1974 (ERISA), its mission is to preserve defined benefit (DB) plans it insures and protect the beneficiaries of those plans. The agency's inability to employ strategies available to private insurers and the influence of political issues associated with decisions made by Congress makes the management of the PBGC one of the most challenging tasks faced by any financial institution.

The PBGC has acknowledged that, based on its current funded status and investment policy, the probability is high that it will have insufficient funds to pay all future benefits due current beneficiaries. For example, as of September 30, 2012, the single-employer program deficit was $\$ 29.1$ billion and the multiemployer programs 
deficit was $\$ 5.2$ billion. It will be quite difficult for the PBGC with its current asset portfolio as well the premiums expected to be generated, to fully meet its obligations in the long run. Moreover, given the methodology for the valuation of liabilities as explained below, there is good reason to believe that the program deficits may be understated.

It would seem that a reasonable goal would be to maintain the program as long as possible with the hope of eventually putting as small a deficit as possible to the U.S. government. Although it is true that the federal government does not stand behind the PBGC's obligations as explicitly stated under ERISA, an April 28, 2008 letter from the Congressional Budget Office to Congressman George Miller (Chair of the Committee on Education and Labor), states that "an implicit expectation exists among many market participants and policymakers that taxpayers will ultimately pay for benefits should PBGC be unable to meet those obligations" (CBO 2008).

Consequently, it is not a surprise that the General Accountability Office (GAO) highlighted the PBGC as a "high risk" agency in its report to the U.S. Congress starting in 2003. In the GAO's February 14, 2013 update, the progress made by the PBGC and actions by Congress to address the agency's weaknesses were acknowledged, but the GAO concluded: "Because of long-term challenges related to PBGC's governance and funding structure, PBGC's financial future is uncertain" (GAO 2013: 26).

The need for a critical review of the PBGC's investment policy is twofold. First, the plan's investment policy changes periodically. By investment policy, we mean the asset allocation among major asset classes (equities, fixed income, real estate, and alternative assets such as private equity). Guidance as to the proper asset allocation policy 
is needed so that those responsible for making that decision - the PBGC's Board of Directors includes the Secretaries of Labor, the Treasury, and Commerce - and those responsible for implementing the investment policy in selecting and evaluating the performance of asset managers — the staff of the PBGC — will better understand the implications of their actions. Moreover, should the PBGC need to obtain external funding through the issuance of non-government guaranteed debt, the questions raised here will be those that potential investors and credit rating agencies must examine. The major issue to be raised by these parties has to do with the agency's actual deficit. When making their estimate of the deficit, they are not likely to use the rules that currently govern the PBGC in estimating the value of liabilities. Instead, potential investors and credit rating agencies will likely employ a methodology similar to the one described in this paper, rather than the methodology used by PIMS.

In what follows, I first provide some background information and I describe the challenges faced by the PBGC. Then I describe the issues associated with liability valuation, and two general investment policies that the PBGC has pursued since 1974. Next I discuss alternative investment policy strategies along with benchmark construction for asset managers engaged by the PBGC. These are also useful in the evaluation of the PBGC's investment policy.

\section{Brief Review of PBGC Management Issues}

In this section, I briefly describe the decisions available to the PBGC to mitigate the risk of failing to accomplish its mandate. There are two separate insurance programs under the PBGC's purview - single-employer and multiemployer plan insurance 
programs. For the single-employer plan there is a "revolving fund" and a "trust fund." Because the trust fund for the multiemployer plan ran of funds, there is only a revolving trust.

The revolving fund results from premium payments received from sponsors of insured plans. It is a budgetary account (i.e., the cash flow appears in the federal budget). The revolving fund can only be invested in debt guaranteed by the U.S. government.

The trust fund, reflecting accumulated assets from terminated plans, is a nonbudgetary account (i.e., the assets from terminated plans are not part of the federal budget). The funds must be invested in compliance with the investment policy approved by the Secretaries of Labor, Treasury, and Commerce. Although the staff of the PBGC does not manage the funds, it does make four critical investment decisions. First, based on the PBGC's investment policy (asset allocation), the staff determines which professional asset managers to engage. Second, in the selection of asset managers for each asset class, it decides on whether active or passive managers should be engaged. Third, the staff determines the benchmarks to be used, and fourth, the staff evaluates performance of external managers.

To meet claims not covered by plan assets or obtained from terminated plan sponsors, no funding can be obtained from the federal government. This is because there are no appropriations from general revenues to cover any claims. Instead, funding sources are limited to investment returns, premiums received, and assets from terminated plans taken over by the PBGC. 
These premiums are established by Congress. In 1974 when ERISA was established, the premium was set at $\$ 1$ per participant for single-employer plans and $\$ 0.50$ per participant for multiemployer plans. The per participant rate has been raised over time, and also adjusted for the financial health of the plan as measured by the amount of underfunding of the vested plan.

Liabilities. PBGC's liabilities must be projected and then valued so that the agency's deficit can be determined. Moreover, and this is critical, the structure of the liabilities will need to be determined and integrated into the investment policy.

Measuring the agency's liabilities involves projections for current beneficiaries whose benefits are covered by the PGBC, and also for beneficiaries whose plans are projected to be terminated within the year (probably terminations). For the former, standard actuarial models are employed to determine payments. Although there are improvements in actuarial modeling, particularly dealing with the treatment of longevity risk, this exercise is not as complicated as projecting the claims to be paid to future beneficiaries arising from (probably) terminated plans. Unlike a typical insurer that may refuse an applicant seeking insurance based its underwriting standards, the PBGC cannot make such a business decision. Moreover, such plans often have substantial underfunding, resulting in an increase in the PBGC's deficit.

One obvious way to reduce the likelihood of receiving assets of terminated pension plans is to require one or more of the following: larger contributions, higher premiums for underfunded plans, or lower guaranteed payments. But such risk mitigation policies are currently unavailable to the PGBC's management. Unlike an insurer, the first 
two can adversely impact the viability of current plans covered by the PBGC, while the last is a politically sensitive issue.

Instead, it seems that the best that can be done is to prepare for the terminated plans, working with the sponsors of troubled plans, and, in the case of bankruptcy, litigating to obtain recovery of additional assets. These practices are currently being pursued. In projecting future financial status, the PBGC uses PIMS to estimate both single-employer and multiemployer exposure. The model, discussed in other technical panel papers, does not provide one prediction but instead uses simulation to obtain a range of possible outcomes. The model continues to be improved.

Once projections of future liabilities are obtained, the next step is to value those liabilities. This is done by discounting the projected liabilities by a suitable set of discount rates. What that discount rate or rates should be has been the subject of considerable debate, to be reviewed below. Given the importance of liability valuation to the design of investment policy, construction of benchmarks given to asset managers, and the evaluation of PBGC performance, the topic is not merely a theoretical issue in financial economics.

\section{The Challenge}

Managing a private insurer is far less challenging than managing the PBGC since the former has many tools and much managerial discretion. For instance, private insurers have the following:

1. The ability to set risk-based premiums as determined by its actuaries;

2. The ability to refuse entities seeking insurance; 
3. The ability to reinsure to lay off any risk (i.e., can determine what risk to retain and which risk to sell off); and

4. The ability to raise funds in the capital market.

In contrast, for the PBGC, options are quite different. The agency:

1. Cannot set its own premiums;

2. Is required by law to accept qualified defined benefit plans regardless of their level of underfunding;

3. Cannot reinsure, making it difficult to lay off risk; and

4. Cannot raise funds in the capital market.

Not only are premium levels under the control of Congress, but also the setting of a fair premium could have an adverse impact on system-wide surviving plans, increasing their likelihood of being terminated. This is unique to the PBGC as an insurer wherein a realistic premium increase could boost underfunding, despite an increase in premium income.

One limitation of both the single-employer and multiemployer PIMS is that they are predictive models. In the case of PIMS applied to single-employer plans, there is no feedback to deal with possible responses by the corporate management of insured plans to changes in PBGC or Congressional policy. The PIMS model designed for the multiemployer plans does include the probability that there might be mass withdrawal from a given plan or the possibility of plan insolvency before any such mass withdrawal. However, from the perspective of an individual employer, the PIMS model does not anticipate how individual employers might respond to changes in PBGC or 
Congressional policy. Accordingly, a longer-term project would develop a model to allow for behavioral responses to policy changes.

\section{Crucial Role of the Benchmark}

Given these constraints and restrictions on effective management of the PBGC, one might think about re-designing its governance structure and investment strategy. However, instead we discuss how to create an investment strategy that will improve the current investment process, so as to improve the financial health of the PBGC. The process for doing so begins with the establishment of the appropriate benchmarks for (1) determining the asset allocation policy, and (2) evaluating performance. The critical component in this process is the development of a customized benchmark.

Investment Policy. The agency's investment policy fundamentally pertains to its asset allocation decision. Although there is frequent mention in the PIMS documentation that asset allocation is tied to its liability structure, it is unclear how the link is made in PIMS.

Historically, the agency's asset association policy has alternated between a "maximize long-term returns" and a "liability-driven investment" (LDI) strategy. More specifically:

- From 1974 to 1990 , the investment policy was designed to allow for greater equity exposure in order to maximize expected returns within acceptable levels of risk;

- From 1990 to 1994 , the investment policy was designed primarily to reduce balance-sheet volatility that arose from a mismatch between the sensitivity to 
interest rates changes of the PBGC's assets and liabilities through greater exposure to fixed-income securities with long duration (i.e., LDI strategy);

- From 1994 to 2004, the investment policy returned to that pursued in 1974 to 1990, seeking to maximize expected returns within acceptable levels of risk by permitting greater exposure to equities;

- From 2004 to January 2008, there was a return to an investment policy of reducing balance-sheet volatility (LDI strategy). The asset allocation policy permitted from $15 \%$ to $25 \%$ of asset exposure to equities and $75 \%$ to $85 \%$ exposure to fixed-income securities;

- In February 2008 to April 2011, the investment policy shifted to a "45-45-10" policy: $45 \%$ equities, $45 \%$ fixed income, and $10 \%$ alternative investments (i.e., private equity and real estate). The view in designing this policy was that the PBGC should take advantage of its long-term investment horizon and target the generation of better returns to provide a greater probability of satisfying its longterm obligations (i.e., maximize long-term returns strategy); and

- In May 2011, the PBGC adopted a new policy of targeting 30\% equity and other non-fixed income assets and $70 \%$ fixed income assets. On adopting this policy, the Board gave the following reason: "The investment policy objective is to maximize total return within a prudent risk framework that incorporates PBGC's fixed obligations and asset composition of potential trusteed plans" (PBGC 2012a: 35). That is, it is a return to the LDI strategy.

It is interesting to note that these policy recommendations have come from external advisors, though the recommendations have been evaluated by other government 
agencies. For example, the 45-45-10 policy adopted in February 2011 which represented a major shift in the allocation policy was based on an analysis of the Rocaton Investment Advisors. The Congressional Budget Office (CBO) reviewed the assumptions underlying the PBGC's decision to shift to the 45-45-10 policy and assessed its potential for affecting the PBGC's ability to meet its obligations to retirees and for increasing costs to taxpayers. In commenting on the new investment policy to Congressman George Miller, Chair of the Committee on Education and Labor in the U.S. House of Representatives, the CBO in April 2008 wrote:

“The new strategy is likely to produce higher returns, on average, over the long run. But the new strategy also increases the risk that PBGC will not have sufficient assets to cover retirees' benefit payments when the economy and financial markets are weak. By investing a greater share of its assets in risky securities, PBGC is more likely to experience a decline in the value of its portfolio during an economic downturn-the point at which it is most likely to have to assume responsibility for a larger number of underfunded pension plans. If interest rates fall at the same time that the overall economy and financial markets decline, the present value of benefit obligations will increase, and the pension plans likely to be assumed by PBGC will be even more underfunded as a result" (CBO 2008: 2).

The CBO's further comments are noteworthy because they highlight the distinction between the much-abused principle of portfolio construction using the classical mean- 
variance framework to obtain diversification while ignoring the critical nature of the liability structure (i.e., the timing of the obligations). The CBO wrote:

"It is widely accepted that an investor benefits from having as diversified a portfolio as possible, given an established level of risk tolerance. A portfolio containing a mixture of risky securities will generally pose less risk to an investor than a portfolio consisting of just a single risky asset. Most observers would agree that the portion of assets allocated to equities and other risky securities should be well-diversified in order to maximize return for a given level of risk.

There is a significant difference, however, between the riskiness of PBGC's asset portfolio and the risk posed by the new investment strategy to the corporation's funded status - the difference between the value of PBGC's assets and the present value of its liabilities. That is, although Rocaton's analysis suggests the new investment strategy offers greater expected returns with lower risk to the assets held in PBGC's portfolio, that strategy reduces the timing match between the corporation's future pension obligations and cash-flow streams from its investments. The increased risk to funded status is illustrated in principle on page 28 of Rocaton's report in a graphic that is reproduced in this letter (see Figure 1). In particular, "Alternative \#5" (which most closely represents the new strategy) is further to the right than the "current target" (which represents the recent strategy)" (CBO 2008: 4). 
Liability valuation. The underlying principle in the valuation of an asset or a liability is that it should be discounted at a risk-appropriate interest rate. The rate should be based on the rate that can be earned on market-traded investment vehicles.

If one accepts the notion that a set of liabilities should be valued at the cost necessary to defease those liabilities by purchasing a portfolio of risk-free securities, then the appropriate investment vehicles are the securities traded in the U.S. Treasury market. ${ }^{1}$ Although Treasury securities are not default-free, they are still viewed as the benchmark for risk-free rates around the world, as well as providing a liquid market for creating a portfolio for defeasing a liability stream. This means that not one or two Treasury coupon rates should be used for discounting liabilities, but a set of Treasury spot rates. Spot rates are the theoretical rates that the U.S. Department of the Treasury would have to pay if it elected to issue zero-coupon Treasury securities with different maturities. There are welldeveloped analytical methodologies (e.g., bootstrapping) and econometric techniques for deriving theoretical spot rates from Treasury coupon rates. In fact, Treasury spot rates are used in arbitrage-free pricing of fixed income cash and derivative instruments.

The PBGC's liabilities can be viewed as a yield curve of monthly benefit payments. The argument in favor of using Treasury spot rates is that the present value of the liabilities represents how much the U.S. Department of the Treasury would have to issue in Treasury securities to pay off the projected liabilities. Investors and credit rating agencies would view liabilities in the determination of their value.

\footnotetext{
${ }^{1}$ A long-time proponent of establishing customized benchmarks based on liabilities for public and private defined benefit plans, as well as the PBGC is Ronald J. Ryan, CEO of Ryan ALM, Inc. See Ryan (forthcoming).
} 
How does this compare with the PIMS treatment of the liabilities? In the PBGC's 2012 Actuarial Report, the interest rate used as of September 30, 2012 was $3.28 \%$ of liability obligations for the first 25 years, and $2.97 \%$ thereafter. Although the longer-term rate is in line with Treasury rates (roughly $2.92 \%$ in 2012), the fixed rate for under 25 years was far greater than for 25-year Treasuries (3.28\% versus $2.54 \%)$. The difference was even greater at the short-end of the yield curve, where 5-year and 10-year Treasuries, for example, offered a yield of only $0.76 \%$ and $1.8 \%$, respectively. Consequently, the projected liabilities for the first 25 years were considerably undervalued.

The PBGC report, "FY 2012 PBGC Exposure Report" (PBGC 2012b), prepared to satisfy requirements in Section 4008 of ERISA, included an Appendix titled "Overview of PIMS." Here the following statement appeared:

“Throughout this report, we express all future outcomes in present value terms (i.e., discounted back to 2012). Each scenario's outcomes are discounted based on the 30-year Treasury bond yields projected for that scenario, regardless of whether the underlying simulated cash flows are generated from holdings of equities, high-yield bonds, corporate bonds, or U.S. Treasury bonds."

Here the same problem arises: by using of a single discount rate rather than a term structure of Treasury spot rates, projected liabilities and therefore the deficit are underestimated. Given that short-term rates (due to a steep Treasury yield curve) as of this writing are far lower than the 30-year Treasury rate used in the simulations by PIMS to calculate the present value of liabilities, there is likely to be a considerable understatement of the value of the PBGC's liabilities and deficit. 
The Financial Accounting Standards Board (FASB), in its Financial Accounting Statement (FAS) 87, has explained how to value pension liabilities of plan sponsors. Here plan liabilities must be priced as high-quality zero-coupon bonds whose par values match the liability payment amounts, and whose maturities match the liability payment dates. More precisely, the selection of discount rates is explained in Paragraph 186 of FAS 106 (December 15, 1990) as follows:

"The objective of selecting assumed discount rates is to measure the single amount that, if invested at the measurement date in a portfolio of highquality debt instruments, would provide the necessary future cash flows to pay the accumulated benefits when due. Notionally, that single amount, the accumulated postretirement benefit obligation, would equal the current market value of a portfolio of high-quality zero coupon bonds whose maturity dates and amounts would be the same as the timing and amount of the expected future benefit payments."

Although the FASB refers to pension liabilities of plan sponsors, the valuation is equally relevant to the PBGC's liabilities.

Moreover, in a June 1993 letter to corporations, the Securities and Exchange Commission (SEC) Guidelines on FAS 87 were set forth as follows:

"The SEC staff believes that the guidance that is provided in paragraph 186 of FASB 106, for selecting discount rates to measure the postretirement benefit obligation, also is appropriate guidance for measuring the pension benefit obligation."

The SEC letter states further that: 
"Rates that cannot be justified or are just too high will be passed on to the SEC's enforcement division for further action. The enforcement division could require restatement of the company's financial statements, as well as seek to impose civil or criminal penalties."

Apparently the SEC believes that the FASB guidelines are important enough for reporting entities to invoke such consequences for failure to comply.

While the above arguments about using a term structure of interest rates rest on sound principles of valuation, the issue still remains as to what financial instrument should be used. The FASB, for example, states in Paragraph 44 of FAS 87:

"In making those estimates, employers may also look to rates of return on high-quality fixed income investments currently available and expected to be available during the period to maturity of the pension benefits."

It is clear that it should be a high-quality fixed income instrument. I have argued above that it should be Treasury rates. Historically, there have been some who have argued that the rate on double A (AA or Aa) or triple A (AAA or Aaa) rated corporate bonds should be used. The SEC, for example, qualified "high quality" to include corporate bonds with those ratings. But there are four problems with using double-A or triple-A rated corporate bonds. ${ }^{2}$ First, these are not viewed as free of default risk. A portion of the yield offered on corporate bonds reflects both default risk and liquidity risk. Second, there are major problems with corporate bond indices used to represent the corporate AA and AAA markets. Third, few corporate bonds are available with a duration in excess of 15 years, while pension liabilities are far longer than 15 years. Finally, one of the reasons for using

\footnotetext{
${ }^{2}$ These problems are discussed further in Ryan and Fabozzi (2003).
} 
a term structure to create a portfolio of high-quality fixed income instruments is to defease the projected liabilities. Yet the size and liquidity of the AA and AAA rated corporate bond market is such that a defeasance is not possible.

The PBGC currently discounts its future benefits obligations using an interest rate that approximates the discount rate used in the private-sector annuity market. But there are several problems with this rate. The rates for the 1-25 and 25 year plus periods reflect annuity rates. But annuity rates are not really market rates but individually negotiated rates. Consequently, the first problem with annuity rates as candidates for discounting is that the same rate is not available to all market participants. Second, there is not a market determined set of zero-coupon rates. Third, the annuity providers are subject to default risk. Finally, the market may not be large enough to defease the PBGC's projected liabilities.

Although I have argued that liabilities should be discounted at Treasury spot rates, one might argue that the projections for terminated plans as projected by PIMS are not known with certainty. As a result, it might be argued that these liabilities might warrant a higher discount rate depending on the likelihood associated with the projection. Nevertheless, it is crucial for PIMS to include a term structure model for Treasury securities and to use the resulting set of rates to discount liabilities. Not only will this provide the proper valuation of liabilities and deficit, it is the benchmark that can be used to establish investment policy and performance evaluation. 


\section{Proposed Solutions}

This section takes as given that there is no reasonable way to move the PBGC from an unhealthy, high-risk agency to a healthy agency. Accordingly, the proposed solutions we discuss next seek to minimize the cost of an eventual bailout, should that be necessary as determined by Congress.

Our solutions do not deal with the strategy of raising premiums or reducing benefits, since these are beyond the control of the PBGC. The CBO noted these other solutions in the letter to Chairman Miller referred to earlier, writing:

"The Congress could address the issue of structural underfunding in three ways:

- Set premiums at a level that will cover expected shortfalls from future claims;

- Reduce retirees' benefit payments; or

- Tighten funding rules for insured plans."

In what follows, I focus instead on the investment policy and performance evaluation.

Investment policy. As explained earlier, the PBGC's investment policy must take into account its liability structure. One approach would construct a portfolio of Treasury securities that defease the future liabilities. There are still risks associated with longevity risk and uncertainty about future liabilities due to new obligations from bankrupt plans. Moreover, as of this writing, the prevailing level of low interest rates makes it difficult to support such a proposal. It would be interesting to assess the performance of such an investment strategy and compare it to the current funding status of the PBGC, had such a policy been instituted in 1974. Although this strategy may be unacceptable now, it still remains the basis for formulating a benchmark by which to compare the PBGC's investment policy. 
Consideration of the liability structure alone is not sufficient, given the uncertainty about future liabilities inherited from bankrupt plans. Instead, consideration can also be given to the factors that will drive future liabilities. This broader view of the liability structure is analogous to portfolio construction on the asset side, wherein factor exposure is considered. In the case of the PBGC, this means using its models to determine what sectors/industries are highly likely candidates for bankruptcy/plan termination. That information would then be used to set investment policy. For instance, in its current allocation both in fixed income and equities, the PBGC's external managers can be told that their performance will be evaluated against some customized index. The customized index would take into account the potential exposure to plans in sectors that the PBGC might inherit. So if several firms in industry $\mathrm{X}$ were estimated to have a high probability of being taken over by the PBGC, avoiding industry $\mathrm{X}$ in establishing a benchmark for asset managers would be appropriate. This would call for the development of a benchmark that minimized exposure to troubled industries where the PBGC had identified its exposure. $^{3}$

In fact, not only is minimizing exposure to such industries or sectors warranted: risk mitigation might also call for short positions in such industries. Assuming that the PBGC could not short the stock of such firms nor write put options on them, there are

\footnotetext{
${ }^{3}$ On page 38 of the PBGC's 2012 Annual Report, the following is stated about custom benchmarks: "The custom benchmarks include similar securities and are weighted combinations of sub-sector benchmarks. PBGC is able to redeem composite assets upon request." However, it unclear whether reference to a custom benchmark means the same type of customization suggested in this proposal.
} 
more acceptable alternatives in the equity market to implement this strategy. For instance, exchange-traded funds (ETFs) for targeted industries/sectors could be shorted, as well as index put options that benefit from difficulties in an industry or sector. The decision as to the type of exposure (ETFs versus contingent-type positions) will depend on the likelihood that the PBGC project problems in an industry or sector inheriting plans from bankrupt firms. In the case of fixed income (bond) indices, again there can be customization of the benchmark to avoid troubled industries or shorting exposure can be obtained by taking positions in credit derivatives.

Learning the PBGC's exposure to industries/sectors would this become an integral part of its risk management program. Currently, the PBGC indicates that:

"Throughout the year, we conduct due diligence on our processes and the investment management firms. Our due diligence includes regular communication with the management firms, enabling us to stay updated on matters affecting the agency's investment program, including the agency's portfolio, the portfolio's performance, and firm changes." (PBGC 2012a: 20)

This due diligence process would benefit from identification of aggregate exposure to positions driving potential future liabilities.

There is an implementation issue associated with this proposal, involving the signaling of information to the financial markets when benchmarks are established as described. The signaling of concerns by the PBGC could cause external managers to take positions in the portfolio of their other clients that could accelerate the difficulties in the troubled industries or sectors. Yet there is a solution to this signaling problem. Although 
the PBGC does not manage funds internally, it should be able to hire staff that can employ an overall strategy so as to obtain the target exposure to an industry. To do so would require external managers reporting their exposure periodically to the PBGC. The PBGC staff would then offset this exposure with ETFs and/or derivatives and take additional positions to accomplish the target exposure it seeks. 


\section{References}

Congressional Budget Office (CBO) (2008). Letter to the Honorable George Miller: A Review of the Pension Benefit Guaranty Corporation's New Investment Strategy. April 24.Washington, DC: CBO.

http://www.cbo.gov/sites/default/files/cbofiles/ftpdocs/91xx/doc9156/04-24-miller-

$\underline{\text { pbgc_letter.pdf }}$

Pension Benefit Guaranty Corporation (PBGC) (2012a). Annual Report 2012. Washington, DC: PBGC.

http://pbgc.gov/documents/2012-annual-report.pdf

Pension Benefit Guaranty Corporation (PBGC) (2012b). FY 2012 Exposure Report. Washington, DC: PBGC.

http://www.pbgc.gov/documents/2012-exposure-report.pdf

Ryan, R. J. (Forthcoming). The U.S. Pension Crisis: What We Need To Do Now to Save America's Pensions. Palm Beach Gardens, FL: Ryan ALM.

Ryan, R. J., and F. J. Fabozzi (2003). "The Pension Crisis Revealed," Journal of Investing 12(3) (Fall 2003): 43-48.

U.S. Government Accountability Office (GAO) (2013). GAO's 2013 High-Risk Series: An Update. GAO-13-359T. Washington, DC: GAO.

http://www.gao.gov/assets/660/652166.pdf 


\title{
Joint Risk of DB Pension Underfunding and Sponsor Termination: Incorporating Options-Based Projections and Valuations into PIMS
}

\author{
Deborah Lucas \\ Sloan School of Management, Massachusetts Institute of Technology \\ September 2013 \\ Michigan Retirement Research Center \\ University of Michigan \\ P.O. Box 1248 \\ Ann Arbor, MI 48104 \\ www.mrrc.isr.umich.edu \\ (734) 615-0422
}

\section{Acknowledgements}

This work was supported by a grant from the Social Security Administration through the Michigan Retirement Research Center (Grant \# 5 RRC08098401-05-00). The findings and conclusions expressed are solely those of the author and do not represent the views of the Social Security Administration, any agency of the Federal government, or the Michigan Retirement Research Center. 


\title{
Joint Risk of DB Pension Underfunding and Sponsor Termination: Incorporating Options-Based Projections and Valuations into PIMS
}

\begin{abstract}
When a private pension plan sponsor with an underfunded plan becomes insolvent, the difference between the value of the plan's assets and its termination liabilities represents a liability for the Pension Benefit Guaranty Corporation (PBGC). Hence, accurately modeling the joint statistical distribution over time of defined benefit (DB) pension underfunding and sponsor terminations is critical for estimating PBGC's prospective cash flows and evaluating its financial position. It appears that the current Pension Insurance Modeling System (PIMS) approach to modeling risk does a reasonable job of capturing its statistical properties effects on PBGC cash flows, though some aspects of the might be improved and metrics expanded. The paper outlines how an options-based approach to modeling the joint distribution of defaults and underfunding in PIMS might be implemented while preserving the strengths of the current model. Moving to an options-based approach would allow PIMS to be used to estimate the fair values of future liabilities. Such an approach could have a significant effect on the perceived financial position of PBGC.
\end{abstract}

\section{Citation}

Lucas, Deborah (2013). “Joint Risk of DB Pension Underfunding and Sponsor Termination: Incorporating Options-Based Projections and Valuations into PIMS,” University of Michigan Retirement Research Center (MRRC) Working Paper, WP 2013-290(j). Ann Arbor, MI.

\section{Authors’ Acknowledgements}

The research reported herein was pursuant to a grant from the US. Social Security Administration (SSA) funded as part of the Retirement Research Consortium (RRC); the author also acknowledges support from The Pension Research Council at The Wharton School. All findings and conclusions expressed are solely those of the author and do not represent the views of the SSA or any agency of the federal government, the PRC, or The Wharton School at the University of Pennsylvania. In addition, the opinions expressed by the author do not represent those of the Society of Actuaries or any other organization of which I am a member. All findings, interpretations, and conclusions of this paper represent the views of the authors and not those of the Wharton School or the Pension Research Council. (C2013 Pension Research Council of the Wharton School of the University of Pennsylvania. All rights reserved. 


\title{
Joint Risk of DB Pension Underfunding and Sponsor Termination: Incorporating Options-Based Projections and Valuations into PIMS
}

\author{
Deborah Lucas
}

\section{Introduction}

When a plan sponsor with an underfunded plan becomes insolvent, the difference between the value of the plan's assets and its termination liabilities represents a liability for the Pension Benefit Guaranty Corporation. Hence, accurately modeling the joint statistical distribution over time of defined benefit pension underfunding and sponsor terminations (henceforth referred to as defaults) is critical for estimating PBGC's prospective cash flows and evaluating its financial position.

Modeling that joint distribution in a stochastic model such as PIMS could be accomplished in a variety of ways. In choosing between modeling approaches, considerations include whether salient statistical properties of historical data can be matched, whether the approach is conceptually sound, tractability, transparency, and auditability. Also important is whether the approach provides the information needed to answer important questions about the financial position of the PBGC, the value of the insurance it provides, and how those quantities would be affected by various types of policy changes.

Based on the documentation made available to reviewers, it appears that the current approach in PIMS to modeling the joint risk of underfunding and default does a reasonable job of capturing its statistical properties and its effects on the distribution of projected PBGC cash flows, although some aspects of the implementation might be improved and it would be helpful if the metrics provided to evaluate performance were expanded. 
Most importantly, the current approach has a fundamental but correctable shortcoming it does not allow PIMS to be used to answer questions about valuation of future streams of cash flows. ${ }^{1}$ Currently PBGC does not disclose information on the fair value of prospective costs and revenues on its financial or budgetary accounting statements, although it reports the value of assets and liabilities from trusteed plans on a fair value basis. Moving to a modeling strategy in PIMS that accommodates fair value estimation of prospective cash flows, and reporting those results, would allow policymakers and the public to evaluate the overall financial condition of PBGC on a consistent and economically interpretable basis. ${ }^{2}$

In what follows, I outline how an options-based approach to modeling the joint distribution of defaults and underfunding in PIMS might be implemented while preserving the strengths of the current model. Moving to an options-based approach would allow PIMS to be used to estimate fair values of future liabilities. The changes also would simplify and make more transparent some aspects of risk modeling, while preserving PIMS detailed modeling of other system features such as firm-level liabilities and their evolution, demographics, and program rules for the size and timing of benefit payments. It is likely that such changes would have a significant effect on the perceived financial position of PBGC. For example, CBO (2005) reported that valuing PBGC's prospective net liabilities using an options-based approach doubled their estimated value relative to discounting the same expected liabilities at Treasury rates, as is PBGC's current practice.

\footnotetext{
${ }^{1}$ However, PIMS is used to calculate actuarial present values based on discounting with Treasury rates.

${ }^{2}$ See Lucas (2012) for a more complete discussion of fair value estimates for federal guarantee programs.
} 


\section{Options-based Approach to Projecting and Valuing Future PBGC Cash Flows}

Pension insurance is a type of put option. Specifically, pension insurance gives a firm that sponsors defined benefit pension plans the right to "put" or transfer their underfunded plans to the PBGC in the event that it becomes insolvent, in exchange for annual premiums. As such, sponsor financial distress and plan underfunding are the two key determinants of PBGC's prospective costs.

Future sponsor failures, plan underfunding, and stock market performance are correlated events. Those correlations have a first-order effect on the value of PBGC insurance, and also they affect the distribution of PBGC's prospective cash flows. When the pace of economic activity slows, firm revenues, stock market values and interest rates all tend to decline. These changes increase both the probability of financial distress for sponsors and plan underfunding. The more severe a downturn, the greater the likely number of failures and the extent of underfunding in plans insured by PBGC. The correlation between downturns and high-cost periods for the PBGC is also strengthened by the fact that, as sponsors become more distressed, they are less likely to make required pension contributions, and that the PBGC will tend to experience lower recovery rates during downturns. Some of those correlations can be clearly seen in historical data on bond defaults and recovery rates on bonds. For example, Figure 1 shows the positive correlation between corporate bond defaults and the business cycle and the negative correlation between recovery rates and the business cycle. Figure 2 shows that those relationships are particularly pronounced for speculative-grade firms (those rated below investment grade).

Figures 1 and 2 here 
The correlations between sponsor failures, plan under-funding, and stock market performance have important implications for valuing PBGC's prospective cash flows. Because future liabilities of the PBGC will tend to be relatively high during economic and stock market downturns, and relatively low when times are good, and because the value of economic resources is higher in downturns than in upturns, the fair or market value of those liabilities is higher than the present value of expected future liabilities currently reported by the PBGC (which do not account for the cost of correlated risk). The fair value of future premium payments also is affected by market risk, but there are two partially offsetting effects: Premium collections have tended to rise during downturns because the variable portion of premiums on average increases. However, during downturns it is more probable that sponsors would fail to make required premium payments.

The discrepancy between fair value estimates and the present value estimates that PBGC currently reports arises from the choice of discount rates. Specifically, the current PIMS procedure uses Treasury rates for calculating discounted values. Present values derived using Treasury rates are often described as "actuarial present values," which differ from fair or market values because they neglect the effect of market risk on value. Specifically, the discount rates that the market would use to calculate the value of future PBGC payouts to beneficiaries is lower than the 30-year Treasury rates (increasing the present values of those prospective cash outflows), and the discount rates the market would apply to insurance premiums are higher (decreasing the present value of those prospective cash inflows).

The most important benefit of an options-based approach is that it generates fair value estimates for PBGC insurance and other cash flow streams such as premium payments - implicit in an options-based approach is a set of market discount rates that properly value prospective 
PBGC cash flows. Although an options-based approach may initially seem more complicated than alternative approaches to risk-adjusting discount rates, an options-based approach has the advantage of reliability. Attempts to infer market discount rates using other approaches tend to be more difficult and error-prone. A further benefit of an options-based approach is that it provides a relatively parsimonious framework for projecting defaults and underfunding, but one that has enough flexibility to capture the time path, volatility and correlation structures of those quantities that are observed in aggregate time series data and cross-sectional firm data.

PBGC insurance is sometimes referred to as a "compound put option" because PBGC is liable for a company's pension obligations only if the company is bankrupt and if its dedicated pension assets fall short of the value needed to cover vested pension obligations (see Figure 3). That is, the plan can be significantly underfunded with no ultimate cost to the PBGC if the plan assets increase to cover the liabilities before the firm fails. Conversely, fully or overfunded plans still represent a risk to the PBGC because future declines in plan asset value or increases in liability value can cause it to become underfunded.

Figure 3 here

Compound put options cannot be accurately valued using standard options pricing models like the Black Scholes Merton model. However, advances in numerical options-based modeling of default probabilities, (along the lines of Crosbie and Bohn 2003), and the implementation of a related stochastic "risk-neutral" valuation model for PBGC by the Congressional Budget Office (described in CBO 2005), demonstrate the feasibility of using an options-based model for the PBGC while maintaining a realistic representation of many of the programs' complexities. 
In options-based approaches to default modeling, a key insight is that firm default is also a type of put option. When the market value of a firm's assets fall below some trigger point (usually represented as a function of the firm's short and long-term liabilities), it is in the interest of the firm's shareholders to default rather than to honor the liabilities. Thus the likelihood of default depends on the statistical properties of the firm's assets and liabilities, which in turn may depend on other variables such as the performance of the aggregate stock market. Plan assets, some of which are typically invested in the stock market or in assets correlated with the stock market, are also exposed to stock market risk. Figure 4 gives an example of the evolution of a firm's asset values that ultimately ends in insolvency. Figure 5 shows the hypothetical evolution of plan assets over the same period. In the example of Figures 4 and 5, even though the firm is insolvent PBGC experiences no loss because plan assets exceed termination liabilities. Optionsbased approaches effectively look at the costs to PBGC across all possible joint paths of firm assets and plan assets.

Figures 4 and 5 here

A complete explanation of how default probabilities and underfunding levels are linked to aggregate stock market realizations and other variables in an options-based approach is beyond the scope of this report, although I would be pleased to discuss specific alternatives for implementation in more detail with PBGC staff. At an abstract level, those linkages are captured in a natural way by explicitly linking the probability distribution of the future financial condition of sponsors (importantly, firm market asset values and leverage) and plan funding levels with the stochastic path of realizations of stock market outcomes, calibrated so as to reproduce the joint distribution of defaults and underfunding seen in historical data. Differences across firms are generated by modeling stochastic firm-specific shocks that are uncorrelated with market returns 
and that reflect the firm-specific volatilities implied by market data. The correlation between individual sponsors and the market will vary depending on the sponsor's estimated equity and asset betas (which are measures of correlation with the market).

For a more complete description of an options-based implementation that follows that logic and that seems to me to be satisfactory in most respects, see Appendix C of CBO (2005). Yet, as discussed below, a shortcoming of CBO's (2005) model relative to the current PIMS implementation is that pension liability growth is not carefully modeled, and CBO assumes that liability growth is uncorrelated with market conditions. It would be feasible and desirable to combine PIMS more detailed modeling of plan liabilities with an options-based approach to modeling defaults and underfunding.

\section{Comparison with PIMS Modeling Approach}

To evaluate the changes to PIMS that would be necessary to incorporate into it an options-based approach to valuing future cash flows, it is useful to take an inventory of the similarities and differences between the current PIMS implementation and an options-based approach.

The two approaches share fundamental similarities in their structures and logic. Those include the fact that both are calibrated to make key economic and demographic variables and stochastic driving processes consistent with historical statistics. The simulated paths of the variables predicted by the model are generated using those calibrated stochastic shock processes. Some shocks are assumed to be independent across firms and across time, while others are correlated. Both models calculate future PBGC liabilities along each simulation path firm-byfirm, with the outcome dependent on whether a firm meets the conditions for default and on its 
pension funding level when it defaults. Stochastic probabilities of firm defaults are correlated with plan underfunding and with an aggregate variable related to the health of the economy. Both approaches also incorporate the rules that determine premium contribution rates and payouts to plan participants.

There are also key differences between the two approaches. For one, whereas many variables and shocks are used as inputs into the statistical model of bankruptcy probabilities used in PIMS, the options-based approach generally abstracts the various sources of uncertainty into two: (1) a common shock which is the priced portion of which is related to aggregate stock returns, and (2) an idiosyncratic firm-specific shock. In an options-based approach, there are more explicit linkages over time in the behavior of each sponsor's financial condition and funding status: The common and idiosyncratic shocks affect the evolution over time of a firm's asset values and liability values, and plan asset and plan liability values. (In principle it would be possible to include additional shocks in an options-based model as long as they are assumed to represent risks not priced by the market.)

Under the options-based approach, the explicit dependence of firm funding levels and default events on a common aggregate shock to stock returns in the options-based model allows the various cash flows of interest (e.g., future liabilities and premium payments) to be derived as functions of the realizations of aggregate stock market returns. That relationship allows the cash flows to be valued as stock market derivatives. Specifically, a standard approach can be used to calibrate a version of the model in terms of so-called "risk-neutral probabilities." The fair value of PBGC's future obligations can then be calculated based on the expected values of future cash flows, weighted by their risk-neutral probabilities, discounted to the present at the risk-free rates in the model. 


\section{Implications of Moving to Options-based Approach}

We next highlight some of the important implications of moving to an options-based approach. As described above, the fundamental differences from the current PIMS approach would be to (1) change the modeling of the relation between asset returns, funding levels and sponsor default probabilities; and (2) incorporate the market price of risk through the asset returns process in present value calculations. Apart from those two differences, the comparisons described below are on an "all else equal" basis: Quantities such as the mean and variance of asset returns, portfolio composition, the statistical properties of future liabilities and so forth are assumed to be the same as in the current PIMS implementation. The purpose of implicitly holding other assumptions fixed in the discussion here is to facilitate comparisons; I have not attempted here to evaluate the reasonableness of most of those assumptions.

A. The fair market rate for discounting future payouts is less than the risk-free rate because of the market risk associated with the put options written by PBGC. The present value of prospective PBGC liabilities therefore would be significantly higher than PIMS estimates, which currently use Treasury rates for discounting future benefit payments. Correspondingly, the implied insurance premiums that would need to be collected from sponsors in order to cover those liabilities would be higher.

Discussion. Currently PBGC discounts its liabilities for future benefits with interest factors that, together with the mortality table used by PBGC, approximate the price in the private-sector annuity market at which a plan sponsor or PBGC could settle its obligations. Under an optionbased approach, that practice would still be used for liabilities arising from plans that had already been terminated, and possibly for probable terminations. For liabilities already incurred, discount 
rates based on annuity rates generate fair value estimates of liability values. However, applying annuity rates to prospective liabilities produces estimated costs that are significantly lower than the fair value costs of those liabilities. Hence, the lower effective discount rates associated with an option-based approach would only apply to projections of contingent liabilities arising from future insolvencies of underfunded plans.

The effect of using options-based (market) discount rates would be to significantly increase the present value of liabilities arising from future plan terminations, and to increase the fair value insurance premiums for active plans (i.e., the premiums that would need to be charged to cover the liabilities). The probable magnitude of those effects was illustrated in CBO (2005), which compared the present value of prospective liabilities of the PBGC in 2005, using market discount rates versus Treasury rates over horizons ranging from 10 to 20 years. The effect of taking the cost of market risk into account was to approximately double the present value costs (see Table 1). Translating that effect into premiums, the fair value premium would be roughly double the estimated breakeven premium estimated using Treasury rates. ${ }^{3}$

Table 1 here

B. The investment policy that would reduce the risk of PBGC's exposure to future losses would involve a short position in the stock market, or equivalently the purchase of stock market put options.

Discussion. Adopting an options-based approach in PIMS would underscore the observation made by a number of financial experts, that PBGC's current policy of investing a significant

\footnotetext{
${ }^{3}$ The precise mapping from estimates of the present value of liabilities to the adjustment needed to premium rates to recover the present value is more complicated because it would take into account the correlation of premium collections with market conditions.
} 
portion of the assets it manages in the stock market has the effect of doubling down on stock market risk, increasing the volatility of PBGC's net position and the risk to taxpayers, and reducing transparency. For already-terminated plans or probable terminations, PBGC would minimize its risk by investing in primarily in bonds with durations matched to its pension liabilities. To hedge against the risk of future underfunded plan terminations, the options-based approach implies taking a short position in the stock market, for instance by using S\&P index futures or buying S\&P put options.

C. Volatility in PBGC's reported financial condition that arises from individual sponsor moving in and out of the group identified as creating a "reasonably possible exposure" could be eliminated if that portion of PBGC's financial reports were replaced with options-based estimates of the present value of future losses.

Discussion. The options-based approach could be used as an alternative to the current statistics reported by PBGC on its "reasonably possible" exposure. Under our alternative, rather than identifying at-risk sponsors by a variety of criteria (such as below-investment grade credit ratings or missed minimum funding contribution), the potential future liabilities from all sponsors (based on analysis of those above some threshold size) could be taken into account each year. Estimates of future exposure would be less volatile because, whereas attributes like credit ratings or missed payments move in discrete jumps, the factors that affect the probability and severity of a plan terminating tend to vary more smoothly with market conditions. It should be noted that the volatility in reported financial condition associated with identifying specific at-risk firms also would be reduced by using PIMS current approach to estimating the value of future liabilities.

At the same time, adoption of an options-based approach would not preclude identification and analysis of sponsors that represent pending terminations and probable losses. 
In fact, a separate analysis of those plans (as is done now) is clearly important for disclosing the near-term developments likely to significantly affect PBGC's financial position.

\section{Conclusions}

Incorporating an options-based approach into PIMS for estimating the joint distribution of default probabilities and underfunding, and using the model to infer market discount rates for valuing PBGC insurance, would improve the information available to policymakers and the public on PBGC's finances. This would also make PIMS a more versatile tool for policy analysis. Most importantly, it would provide fair value estimates of the value of PBGC insurance, a quantity not now provided by the PBGC. Such a change appears to be technically feasible, and it would build on the existing strengths of PIMS in incorporating detailed modeling of prospective benefit obligations and program rules.

In terms of the technical feasibility of moving to an options-based approach, PIMS already utilizes stochastic simulation to project cash flows, and its logic takes into account the statistical correlations between variables that are assumed to drive sponsor default probabilities and underfunding. The main technical change that would be required in PIMS would be to reengineer the statistical processes driving those key quantities to link them more explicitly to a model of stock market risk. The resulting distributions of defaults and underfunding, both at the plan and aggregate levels, would be calibrated to be consistent with historical data, both crosssectional and time series. With that change in the characterization of the driving statistical process, it would be straightforward to incorporate risk-neutral pricing of all PBGC cash flows, which in turn would make it possible to report on the market values of PBGC insurance, premium payments, and other cash flows associated with the program. 
The main cost to PBGC of moving to an options-based approach would be the time and effort it would take to implement, test, document, and communicate the changes, and the risk that errors would be introduced. Those costs might be mitigated by the availability of information from the Congressional Budget Office (CBO) on how they implemented an optionsbased approach in a related model designed to evaluate the cost of prospective PBGC liabilities and policy options.

Finally, reviewers were tasked with answering three specific questions:

1. What improvements over the short and medium term might render the PIMS models more accurate in terms of the insurance function of the pension insurance system?

2. What improvements can be implemented in PIMS to make the models better-suited to alternative policy simulations (e.g., changes in premium structures, investment profiles, or funding rules)?

3. What new ways of communicating results would help stakeholders better understand the results?

In light of this analysis, my recommendations would be (1) make it a priority to develop the capacity to value on a fair value basis prospective cash flows using PIMS by implementing an options-based approach; (2) use that capacity to report the effects of policy changes on the system's fair value financial position; and (3) to replace the current present value estimates of reasonably possible losses and other quantities with fair value estimates in PBGC's financial reports and other publications. 


\section{Appendix: Comments on Specific Modeling Assumptions and Possible Alternatives}

The purpose of this Appendix is to indicate some specific types of changes that could be made to the PIMS model that might generally improve the accuracy and transparency of the model, and that would facilitate a transition to an options-based approach to projecting and valuing future PBGC cash flows. My understanding of current modeling practices is primarily based on PBGC (2009); some statements from that document are included below in quotations. A caveat is that some of my comments may reflect misunderstandings of the documentation or the model, but it is hoped that those might point to places where current practices might be clarified.

In PIMS, the change in the log of nominal interest rates is modeled as an autoregressive process or a random walk. By contrast, modern models of interest rates generally feature meanreversion. Section 5 defends assuming a random walk and expresses concern that a meanreverting model would falsely push rates to historical levels. However, that long-run parameter can be chosen to correspond to the best available forecast given current and future expected policies as well as historical data.

More generally, for all PIMS input variables and model parameters, the forecasts employed should be as forward-looking as possible, informed by historical data but also taking into account structural changes in policies or the economy. The heavy reliance on historical regressions over very long historical periods should be reexamined, in light of recent changes for all key variables. For instance, academic and practitioner estimates of the equity premium have generally declined relative to historical averages.

In any case, if the real rate is held constant and only inflation varies, it would seem more sensible to directly statistically model the inflation process. 
On the stock return, the disturbance term is "assumed to be drawn from the joint normal distribution of economy-level disturbances." The volatility of aggregate stock returns is a variable that can be measured fairly precisely, and it seem misleading to rhetorically equate it to economy-level disturbances in that real economic variables (e.g., employment, output, inflation) are much less volatile than the stock market. Getting the risk of stock returns right is important both for projecting levels of underfunding and for finding the fair value of PBGC liabilities (because they are contingent claims on the stock market). If the real interest rate is assumed to be constant, it seems inconsistent to assume that real stock returns could have a temporal drift. It appears that in the practical implementation described later in the documentation, stock returns are modeled as a random walk and volatility is consistent with historical data, which seems appropriate.

Estimating the evolution and distribution of firm employment over time is clearly important for calculating the distribution of termination liabilities. However, it seems to add unnecessary complexity to also use it as a determinant of firm bankruptcy probabilities. Whereas firms do tend to shed workers when they are distressed, the assumption about the random variable driving employment does not really add new information about bankruptcy probabilities, which ultimately must be calibrated to match empirical levels and correlations. Simulating firm cash flow as an indicator of financial health also seems like an unnecessary complication that captures a real world correlation, but one that is not helpful in the context of the model for improving on estimates of default rates. The distribution of future bankruptcies can be calculated using simpler methods that depend on fewer variables. Under a more parsimonious options-based approach, parameters can be calibrated to match historical probabilities of and cross-firm correlations of bankruptcy. 
To implement an options-based approach, the modules used to calculate bankruptcy probabilities as described in equation (2-25) could be replaced by a structural model of bankruptcy probabilities as in CBO (2005). Such a model would depend on aggregate stock returns, the idiosyncratic risk associated with individual firms or industries' equity returns and firm asset betas, the firm's initial leverage, a model of leverage adjustments over time, and a rule for triggering bankruptcy based on the difference between estimated firm assets and firm liabilities. In that setup, model parameters can be adjusted to ensure that realized bankruptcy rates correspond to historical frequencies for firms of different credit ratings and other characteristics. Those same drivers would be used under an options-based approach to consistently model firm pension assets and the probability of underfunding for each firm over time. PIMS incorporates much more plan-specific information about pension liabilities, employee demographics, benefit payments, and so forth than does $\mathrm{CBO}$, and that additional information could continue to be used to generate estimates of future liabilities that are likely to be more accurate than those from the more stylized CBO (2005) model.

"This value of firm equity is not directly used by any calculation of firm bankruptcy probability or pension funding." This is surprising in light of the fact that standard structural approaches to estimating bankruptcy rest heavily on firm equity value as an indicator of bankruptcy.

"Following previous models, PIMS uses plan sponsor data from the Compustat database. These data include time series on market assets, book debt, equity value, cash flow, employment, and industry affiliation." Compustat does not report the market value of assets because it does not estimate the market value of debt; those values must be estimated, for instance using an options pricing model as in $\mathrm{CBO}$ (2005). 
The return on plan assets appears to be the same for all sponsors looking at the Chapter 2 description. But as noted in Chapter 5, actual investment policies vary across firms, with some taking more risk than others. To the extent that more at-risk firms follow riskier investment strategies, taking into account that source of heterogeneity would tend to increase projected PBGC liabilities and costs. Data on plan asset composition is available for many of the sponsors, particularly for the larger publicly-traded firms. It is not clear whether that information is incorporated into the model, or whether variation is randomly assigned. It seems relatively straightforward to incorporate actual differences across plans. And as others have noted, it would be sensible to expand the asset modeling to include a larger number of asset classes to better capture investment behavior by firms.

It is not clear that the approach of creating partner firms is the best way to capture the distribution of outcomes associated with smaller firms. An alternative would be to directly model key aspects and correlations of the drivers of liabilities, default rates, and underfunding for smaller firms, relying on available data for those types of firms and setting parameters to match historical outcomes in terms of default correlations, probabilities, funding levels, and so forth.

In Chapter 5 the critical model correlations generally are evaluated in terms of how they were inferred from historical data. That is useful information, but the critical question for evaluating the model is whether the critical model outputs, such as the distribution of (under)funding levels and the default rates for firms with different characteristics, are in line with historical data. That analysis occurs to some extent in Chapter 6, particularly for the critical bankruptcy estimates. What isn't reported and is less clear is whether the implied bankruptcy probabilities remain reasonable as the model is simulated forward. That is, the inputs into the logit model evolve for each firm over time, and it seems important to check that the distribution 
of bankruptcy rates for instance in the $10^{\text {th }}$ year looks as reasonable as the distribution in the $2^{\text {nd }}$ year of a simulation.

The discussion of mean reversion in the documentation is apparently inconsistent with PBGC's current practices. It states, "When applied to the firm equations, mean reversion processes have the additional complication that all firms revert to the same mean." In practice, PIMS does use mean reversion for firm ratios, and it uses different mean reversion levels in some cases (as for the financial industry).

It would be surprising if driving stochastic process for the model-the system of equations (5-4) to (5-10)-were stationary over the entire 70 -year period that the estimates are based on (or even for the relatively volatile 1972-1998 period used to estimate some covariances). It would be helpful to provide information about parameter stability across subperiods. The model seems to be used most often to make projections 10 years out. If parameter estimates do seem to vary across different historical periods, the best model for the next 10 years may be quite different than one estimated using 70 years of data.

The documentation notes that only a fraction of plan sponsors have credit rating data available, which limits the direct use of credit ratings and their transition probabilities as a way to evaluate bankruptcy probabilities. However, academic papers show that credit ratings can be predicted with a fair degree of accuracy from the types of data that are available in Compustat. Hence pseudo-ratings could be estimated for firms that could be used to evaluate whether the model-implied default patterns over time conformed to historical experience.

The introductory chapter of PBGC (2009) notes that pension insurance is related to a put option on the stock market, and it surveys the older literature on valuing PBGC insurance using an options-based approach. But this discussion fails to recognize is that it is possible to 
numerically implement an options-based approach to forecasting and valuing cash flows using more modern approaches, along the lines developed by Moody's KMV and implemented in CBO $(2005)^{4}$. Those developments demonstrate the feasibility of an options-based approach that captures other important dimensions of system complexity. They also underscore the significant difference that approach makes in terms of implied valuations. It would be appropriate to include an updated version of that introductory discussion that notes those developments in future versions of PIMS documentation.

${ }^{4}$ See Crosbie and Bohn (2003) for a description of the KMV model. Hsieh et al. (1994), Marcus (1987), and Pennachhi and Lewis (1994) are older examples of options-based approaches. 


\section{References}

Congressional Budget Office (CBO) (2005). "The Risk Exposure of the Pension Benefit Guarantee Corporation," CBO Study. Washington, DC: CBO.

Crosbie, P. and J. Bohn (2003). "Modeling Default Risk," Moody's KMV. http://business.illinois.edu/gpennacc/MoodysKMV.pdf

Hsieh, S.-J., A., and K. R. Ferris. (1994). "The Valuation of PBGC Insurance Using an Option Pricing Model," Journal of Financial and Quantitative Analysis, 29: 89-99.

Lucas, D. (2012). "Valuation of Government Policies and Projects," Annual Review of Financial Economics.

Marcus, A. (1987). "Corporate Pension Policy and the Value of PBGC Insurance," in Z. Bodie, J. Shoven, and D. Wise, eds., Issues in Pension Economics. Chicago, IL: University of Chicago Press, pp. 49-80.

Pennacchi, G. G. and C. M. Lewis. (1994). "The Value of Pension Benefit Guaranty Corporation Insurance," Journal of Money, Credit and Banking, 26(3): 735-753.

Pension Benefit Guarantee Corporation (PBGC) (2009). "Pension Insurance Modeling System PIMS System Description for PIMS SOA ‘Core’ (vFY09.1).” Washington, DC: PBGC. 


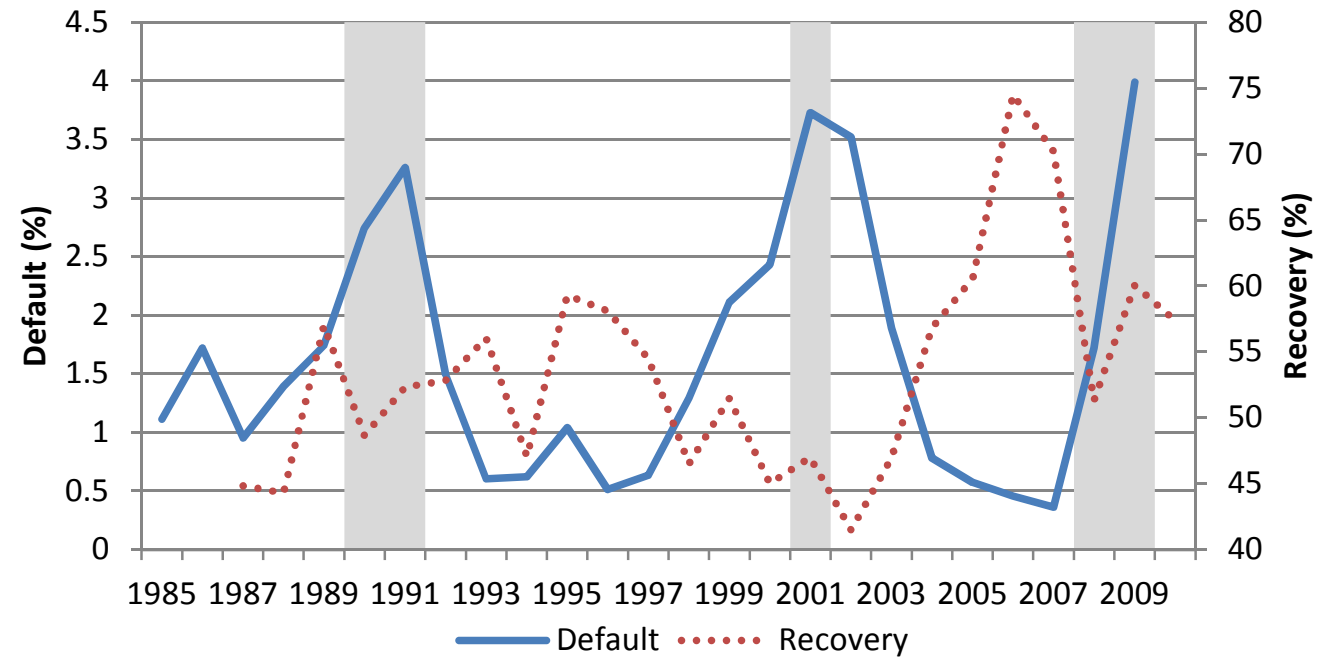

Figure 1. Corporate bond default and recovery rates. Source: Congressional Budget Office based on data from "Default, Transition, and Recovery: S\&P 2009 Annual Global Corporate Default Study and Rating Transitions," Table 1 (March 2010), and data from Standard and Poor's CreditPro (1/28/11). Shaded areas indicate periods of recession as identified by the NBER. 
Mean Discounted Recovery Rates (Default Year) Versus Speculative-Grade Default

Rates $^{*}$

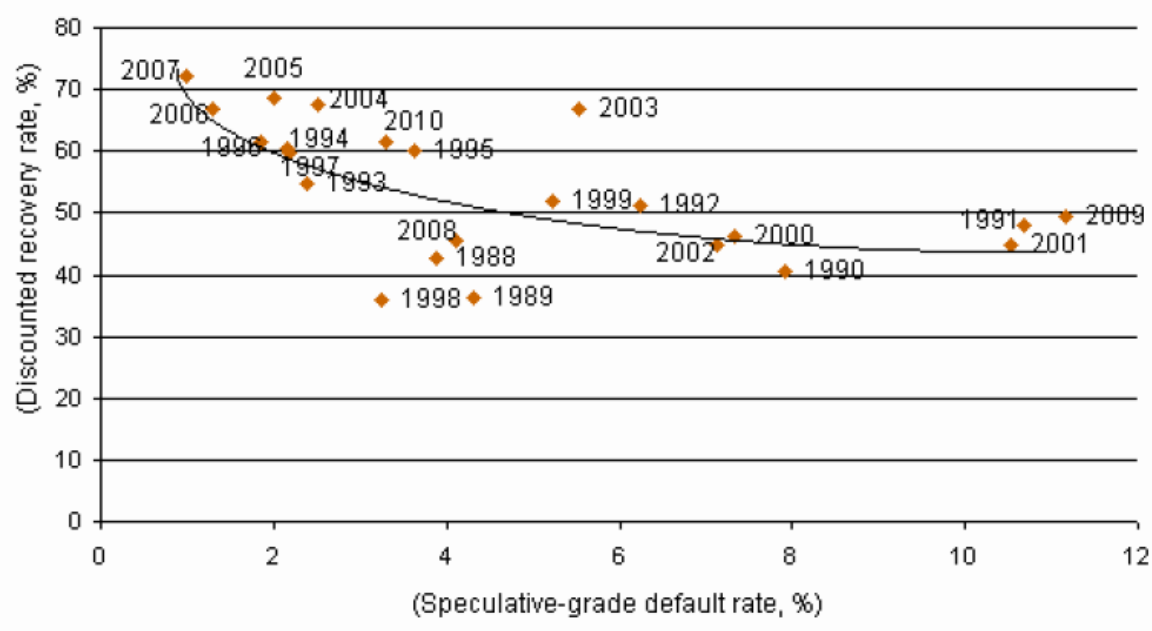

*Tallied by the year of default. Includes only bank debt and bonds that have defaulted. Sources: Standard \& Poor's CreditPro@ and Standard \& Poor's Global Fixed Income Research.

Figure 2. Mean discounted recovery rates (default year) versus speculative-grade default rates.

Sources: Standard \& Poor’s CreditPro® and Standard \& Poor's Global Fixed Income Research.

(C) Standard \& Poor's 2011. 


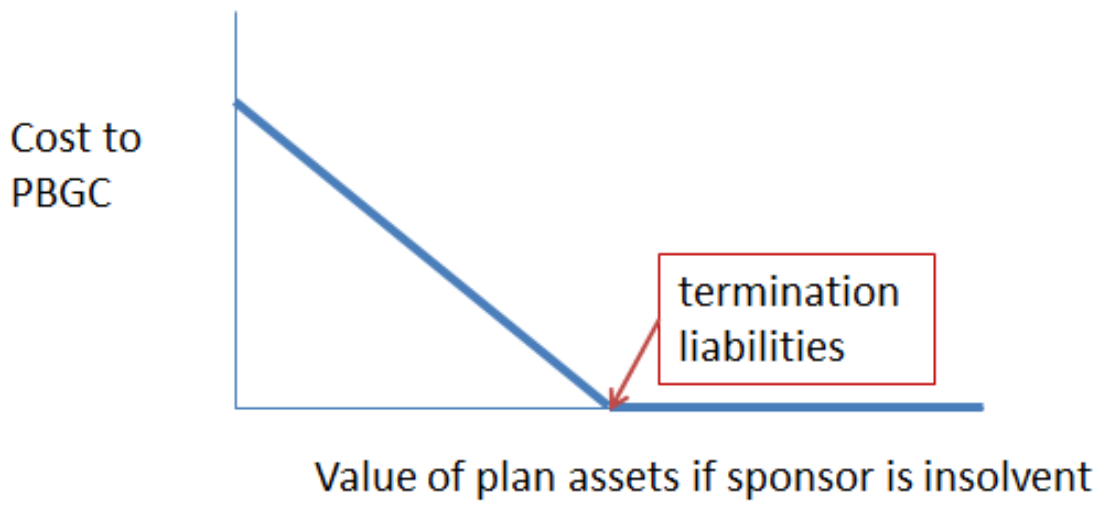

Figure 3. Insurance as a put pption. Source: Author's elaboration. 


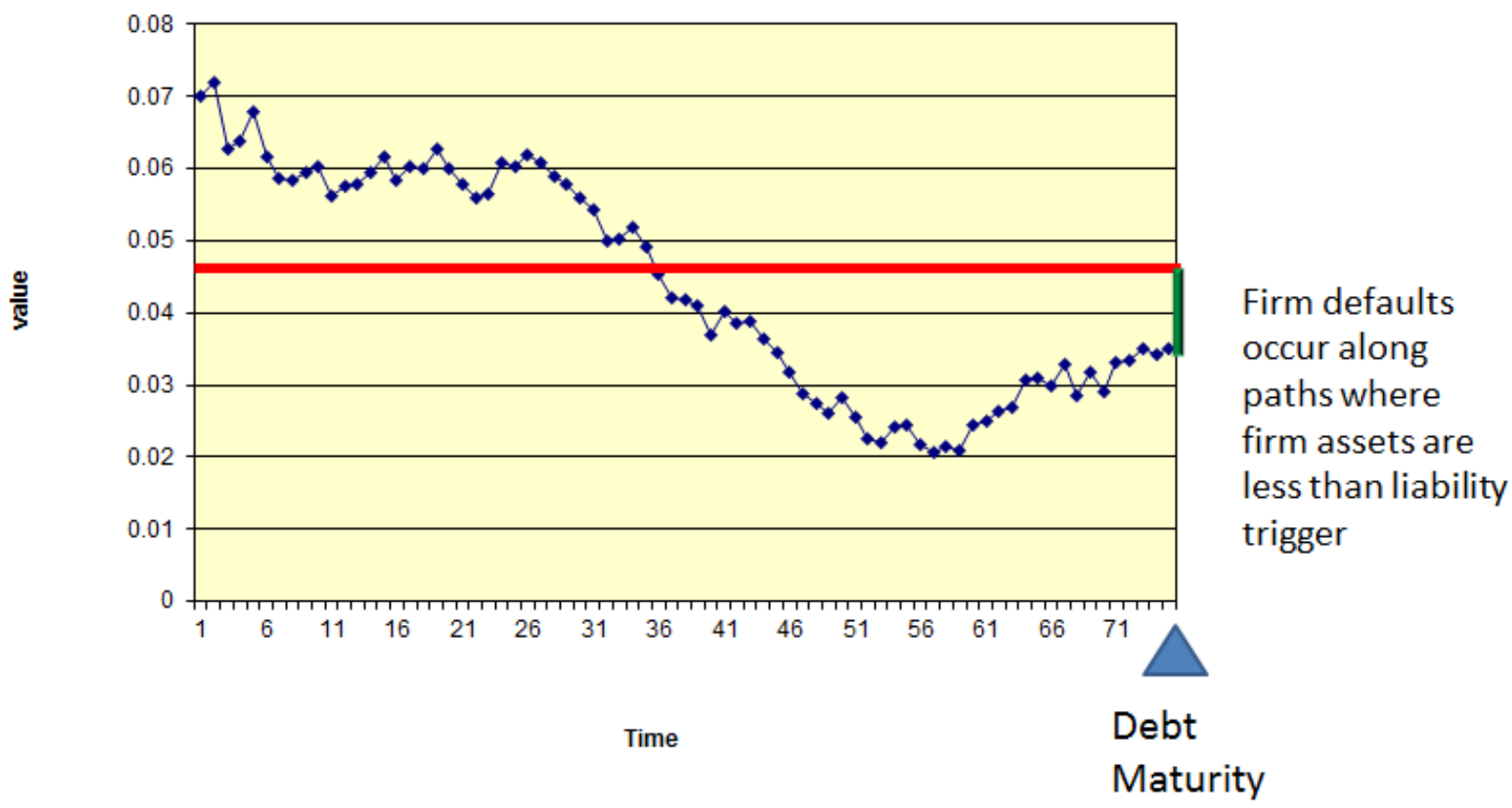

Figure 4. Sample time path of firm assets. Source: Author's elaboration. 


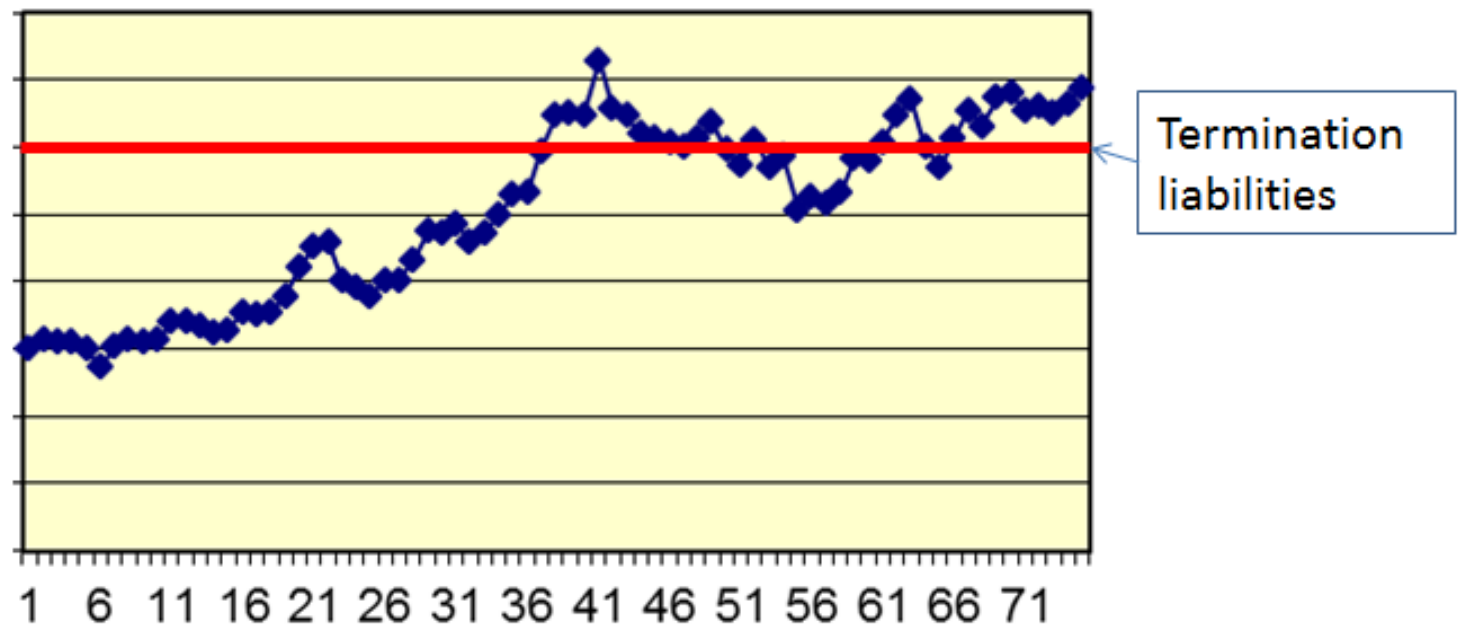

Time

Figure 5. Sample time path of plan assets. Source: Author's elaboration. 
Table 1 PBGC's Prospective Net Costs for Single-Employer Plans Over 10-, 15-, and 20Year Horizons

\section{PBGC's Prospective Net Costs for Single-Employer Plans Over 10-, 15-, and 20-Year Horizons}

\begin{tabular}{lcc}
\hline (Billions of dollars) & $\begin{array}{c}\text { Discounted Value at } \\
\text { Treasury Rates, } \\
\text { Excluding } \\
\text { Cost of Risk }\end{array}$ & $\begin{array}{c}\text { Market Value, } \\
\text { Including } \\
\text { Cost of Risk }\end{array}$ \\
\hline $\begin{array}{l}\text { 10-Year Net } \\
\text { Costs }\end{array}$ & 32.4 & 63.4 \\
$\begin{array}{l}15 \text {-Year Net } \\
\text { Costs }\end{array}$ & 45.8 & 95.7 \\
$\begin{array}{l}20 \text {-Year Net } \\
\text { Costs }\end{array}$ & 55.0 & 118.6 \\
\hline
\end{tabular}

Source: Congressional Budget Office.

Notes: Numbers do not include the accumulated deficit

Discounting the average insurance loss at a Treasury rate yields the amount that, if invested in Treasury securities today, would grow to cover the average of future expenses. It is not, however, enough to pay an insurer to cover the cost of the entire distribution of future expenses, which is what the higher market-value cost represents.

a. Estimated price that a private insurer would charge, in addition to current premiums, to accept the obligations arising from terminations over the indicated time period.

Notes: Numbers do not include the accumulated deficit. Discounting the average insurance loss at a Treasury rate yields the amount that, if invested in Treasury securities today, would grow to cover the average of future expenses. It is not, however, enough to pay an insurer to cover the cost of the entire distribution of future expenses, which is what the higher market-value cost represents. $a$. Estimated price that a private insurer would charge, in addition to current premiums, to accept the obligations arising from terminations over the indicated time period.

Source: Congressional Budget Office (2005). 


\title{
Evaluating Pension Insurance Pricing
}

\author{
David F. Babbel \\ Charles River Associates \\ September 2013
Michigan Retirement Research Center
University of Michigan
P.O. Box 1248
Ann Arbor, MI 48104
www.mrrc.isr.umich.edu
(734) 615-0422

\section{Acknowledgements}

This work was supported by a grant from the Social Security Administration through the Michigan Retirement Research Center (Grant \# 5 RRC08098401-05-00). The findings and conclusions expressed are solely those of the author and do not represent the views of the Social Security Administration, any agency of the Federal government, or the Michigan Retirement Research Center.

\section{Regents of the University of Michigan}

Mark J. Bernstein, Ann Arbor; Julia Donovan Darlow, Ann Arbor; Laurence B. Deitch, Bloomfield Hills; Shauna Ryder Diggs, Grosse Pointe; Denise Ilitch, Bingham Farms; Andrea Fischer Newman, Ann Arbor; Andrew C.

Richner, Grosse Pointe Park ; Katherine E. White, Ann Arbor; Mary Sue Coleman, ex officio 


\title{
Evaluating Pension Insurance Pricing
}

\begin{abstract}
The Pension Benefit Guaranty Corporation (PBGC)'s Pension Insurance Modeling System (PIMS) model has taken on the Herculean task of modeling in detail and under many scenarios the cash outflows associated with the pension obligations they have assumed. This paper's comments are focused almost entirely upon PBGC's termination liabilities, and address four pressing issues: (1) the need to discount the liability stream by current riskless interest rates instead of using corporate bond rates that reflect credit risk, call risk, and other risks, or using some ad hoc prescribed average of past rates; (2) the need to use a term structure of interest rates; (3) the need to employ more useful investment management benchmarks; and (4) how to implement a relevant and rigorous liability benchmark.
\end{abstract}

\section{Citation}

Babbel, David F. (2013). “Evaluating Pension Insurance Pricing,” University of Michigan Retirement Research Center (MRRC) Working Paper, WP 2013-290(k). Ann Arbor, MI.

\section{Authors’ Acknowledgements}

The research reported herein was pursuant to a grant from the U.S. Social Security Administration (SSA) funded as part of the Retirement Research Consortium (RRC); the author also acknowledges support from The Pension Research Council at The Wharton School. The author is grateful for helpful discussions with Olivia Mitchell and Mark Meyer. However, all findings and conclusions expressed are solely those of the author and do not represent the views of the SSA or any agency of the federal government, the MRRC, the PRC, The Wharton School at the University of Pennsylvania, or Charles River Associates. 


\section{Evaluating Pension Insurance Pricing \\ David F. Babbel}

\section{Introduction}

Significant progress has been made since I first reviewed the PIMS model some 17 years ago, and I applaud the painstaking efforts to create a model sufficiently rich in detail to encompass many and perhaps most of the complexities that face PBGC in carrying out its mission. In particular, the PIMS model has taken on the Herculean task of modeling in detail and under many scenarios the cash outflows associated with the pension obligations they have assumed. I commend them for this work.

My comments are focused almost entirely upon PBGC's termination liabilities. They will touch upon several areas that are germane to carrying out PBGC's valuation and insurance pricing mission, are complementary to the cash flow modeling they have already done, and which by comparison are relatively easy to implement. All of them will help the PIMS model to be more firmly ensconced in principles consistent with fundamental financial economics, which is a precursor to adequate insurance pricing. I will address four issues I deem most pressing: (1) the need to discount the liability stream by current riskless interest rates instead of using corporate bond rates that reflect credit risk, call risk, and other risks, or using some ad hoc prescribed average of past rates; (2) the need to use the entire term structure of interest rates; (3) the need to employ more useful investment management benchmarks; and (4) the way to implement a relevant and rigorous liability benchmark. 


\section{Insights from Financial Economics on Proper Discount Rates ${ }^{1}$}

One of the most significant advances in private pension valuation that has occurred over the past few years was the adoption by the accounting and actuarial professions of a set of discount rate protocols that result in valuations closer to their fundamental economic value (i.e., their present value) than what was reported years ago. ${ }^{2}$ These revised standards were having a beneficial, albeit short-lived spillover impact on the discount rates used by PBGC, as plan sponsors had to begin shoring up their insufficient assets. ${ }^{3}$ When coupled with the commendable

${ }^{1}$ An early discussion on the valuation of corporate pension liabilities, from a corporate viewpoint, is provided by Bulow (1982, pp. 436-7) in which conditions are specified under which well-funded corporate pensions should be valued at riskless rates of interest. In the case of "a severely underfunded plan, the firm's pension liability is less than the present value of workers' benefits. The difference is made up by PBGC through its 'insurance' program, and is often referred to as the "pension put"” (Bulow, Mørck, and Summers, 1987, p. 84).

${ }^{2}$ Not everyone is on board with the new discount rate protocols, as evidenced by the recent debate raging in the Wall Street Journal between finance professionals and actuaries. The actuaries charged with valuing public pensions continue to discount them by the returns they expect on the supporting asset portfolios based on historical rates of return rather than by current rates that reflect the characteristics of promised payouts to pensioners and current cots of meeting them. See Andy Kessler's “The Pension Rate-of-Return Fantasy” (op-ed, April 10, 2013 and the three rebuttal Letters to the Editor appearing on April 19, 2013.

${ }^{3}$ The beneficial effect was reversed, however, with the recent mandated changes in discounting protocols, which will be discussed later. 
initiative the current administration has recently proposed to let PBGC determine its own insurance rates, we are on the threshold of substantial advancement, but setting premium rates adequately will require proper valuation of pension liabilities that the assets and premiums are designed and required to fund.

In the past, private pension liabilities were discounted by expected returns on the asset portfolios supporting them, according to various accounting and actuarial standards. This resulted in a strong temptation for some plan sponsors, fiduciary duties notwithstanding, to rush to the bottom of the investment quality spectrum, as using the higher discount rates generally associated with lower quality assets could result in lower reported values of pension liabilities, higher reported plan surpluses (or lower reported plan deficits), and better-looking financials for the firm. The absurdity of this earlier approach is that by making pension asset portfolios riskier through loading the asset portfolio with low-grade bonds and equities, the linked discount rates on liabilities could make much of the reported liabilities vanish. ${ }^{4}$ Unfortunately, but predictably, many plan sponsors succumbed to this temptation, which led, in part, to heavy claims upon PBGC. This would have been less likely to happen had pension liabilities been properly valued in the first place.

Below I will discuss three lines of thinking in financial economics that support the use of riskless interest rates for valuing PBGC termination liabilities.

\footnotetext{
${ }^{4}$ Above, I underscored "reported" for a good reason, and invoke Abraham Lincoln's observation to justify it. Said he, "If you call a tail a leg, how many legs has a horse? Five? No, four. Calling a tail a leg doesn't make it a leg." Similarly, reporting a liability at a reduced value does not reduce its actual value at all.
} 
The cost of funds is determined by the use of funds, not their source. If investor X provides me with $\$ 100,000$ to invest, and I provide her returns that are identical in riskiness to the S\&P 500 returns over time, she will expect of me returns commensurate with the S\&P 500. If, on the other hand, I provide her returns that are identical in risk with Treasury bills, she will require of me returns commensurate with T-bills. In both cases, the source of funds is the same investor, but the cost of capital differs, depending on the use of funds. This is a fundamental economic insight from corporate finance as well as securities markets. If the investor doesn't like the return pattern she is receiving, she can recoup her entire investment by selling her income stream rights to someone who is perfectly happy with that return pattern and then turn around and invest her funds with a manager who accedes to her risk/return preferences. Indeed, the same investor may require several different rates of return for separate components of her overall portfolio, each exhibiting distinct patterns of returns. Thus, the cost of funds is not determined by their source, but by their use.

In the case of private pensions, the plan sponsor makes funded promises and backs those promises with supplemental funding, if necessary. In the event of problems, PBGC guarantees the payments, both in terms of timing and amounts, up to the statutory maximum annual payment for each pensioner. Thus, from the plan beneficiaries' standpoint, the payments are riskless; hence, it is appropriate to utilize riskless rates of interest to present-value those payments that are fixed, and within the statutory limit. As for PBGC, it is responsible only for those payments within the statutory limit, so it should also value them by using the appropriate riskless rates of interest.

Disparate expected returns have same certainty-equivalent riskless return. Expected and required rates of returns depend upon the relevant risks assumed. As far as I am aware, none of 
the prevailing valuation models used in modern finance would justify discounting PBGC termination liabilities with bond yields that incorporate risks not germane to PBGC or its beneficiaries (e.g., credit risk, illiquidity, call risk, etc.). ${ }^{5}$ Moreover, there has never been an accepted finance theory or valuation model that would calculate the present cost of funding an existing guaranteed pension liability using an average of past rates of interest - whether riskless or risky. As I understand it, by the time a pension liability has been transferred to PBGC, the pension is closed to further contributions, and liabilities are fixed going forward, contingent only upon uncertain longevity. Accordingly, the expected future cash flows can be recast into their present value by taking into account only the time value of money using appropriate riskless interest rates. Longevity risk is either not priced directly (as it is diversified among a large population), or the population longevity drift over time cannot be hedged well using available traded instruments. In either case, such risk must be handled through the maintenance of an adequate plan surplus, actuarially determined. But the present value of expected future cash flows is computed using appropriate risk-free interest rates.

Prevailing asset pricing models show how expected rates of return adjust to reflect the relevant risks assumed by investing in a set of assets or pricing a set of liabilities. In some models, those priced risks include only those that are non-diversifiable. In others, they may relate to factors that the market considers priced factors, while ignoring the rest. In any case, the models arrive at similar riskless rates of interest. If retirement payments were merely a pass-

\footnotetext{
${ }^{5}$ An excellent, non-technical review of mainstream financial thought regarding the valuation of pensions is provided by the former editor of the Financial Analysts Journal in the Editors Corner column, which is highly recommended reading. See Arnott (1995).
} 
through from the supporting asset portfolio, such as in a typical 401(k) defined contribution program, it would be appropriate to value the "pensions" using discount rates similar to those characteristic of the asset portfolio, which would render them at the current market value of assets. However, it would be totally inappropriate to value guaranteed, fixed pension liabilities based on the riskiness of the supporting asset portfolio, when the recipients of the pensions are promised and guaranteed timely and full payments of prescribed amounts. This is true whether the asset portfolio is maintained by the corporate plan sponsor or PBGC. ${ }^{6}$

The Merton Model can be used to show the pension valuation components. In the spirit of the Merton Model (1974), the market value of a pension liability to a corporate plan sponsor, $L$, can be decomposed into two components: its present value taking into account only the time value of money, $P V(\mathrm{~L})$, and reduced by the option devolving from limited liability to default upon the required payments and put the obligation to PBGC, $P O$. This latter expression is known by plan sponsors as "the PBGC put." Thus,

$$
L=P V(L)-P O
$$

The value of this put option implicitly held by the corporate plan sponsor will vary, depending on how adequately the plan is funded. This will be a function of the amount of plan surplus, the nature of the assets and surplus supporting the pension promises, and the corporation's ability to supplement these, when necessary. The $P O$ will be more valuable to the corporation under two circumstances: by having inadequate surplus in the plan, and by having assets whose cash flow characteristics diverge from those of the plan's obligations, which we

\footnotetext{
${ }^{6} \mathrm{I}$ am abstracting here from any "haircut" that might be imposed on certain plan liabilities above the statutory coverage limits that are transferred to PBGC from the corporate plan sponsor.
} 
will call an asset-liability mismatch. The risks of a mismatch can be alleviated with sufficient surplus. Absent such a surplus, assets that are subject to default or to value swings different than those swings in liability values will pose a risk to the pension plan that increases the value of the put option to default. This put option value will be increased further to the extent that the corporation has inadequate resources to supplement the plan assets in the event of an adverse swing in mismatched asset and liability values. If the plan assets are default free and the asset and liability cash flows are appropriately matched, there will be no adverse effects occasioned by changing market conditions upon the economic balance sheet of the plan sponsor, because plan surplus will be immunized from such changes. The excuse for mismatching assets and liabilities in an attempt to smooth the impact of changing market conditions on the accounting balance sheet is a reflection only of accounting concerns and the actuarial practices that accommodate them, where the reporting protocols are designed in a way that is inconsistent with the underlying economics. We will not concern ourselves with these accounting issues, as they are beyond the scope of our economic analysis and in any case can be ameliorated by prudent and overdue reforms.

In any case, what relates to PBGC is simply the present value of the pension liability, adjusted for any statutory limits on benefits paid. It has no offsetting value of a put option to default to an outside agency other than to the federal government itself, which officially does not provide a guaranty on private pension obligations beyond that granted by PBGC. Thus, from PBGC's standpoint, the present value of expected pension liability payments is what matters, together with adequate surplus to support adverse deviations in covered population longevity. Additional surplus would be required to compensate for electing to continue to hold plan assets with credit risk. Still more surplus would be needed to the extent that PBGC adopts investment 
programs inconsistent with maintaining an asset portfolio matched to the timing of its liabilities. Also, to the extent that PBGC needs funds above and beyond those in its "general account," it would presumably borrow from the Treasury at or near Treasury rates. In all of these cases, the present value of the liabilities is not affected; rather, the amount of surplus required to satisfy the liabilities is altered.

Exactly what useful information in conveyed by current valuation protocols? Not much. The information content of what is currently being represented in accounting statements as private pension liabilities is minimal, and sometimes misleading or unhelpful to PBGC. First of all, the present value of the liabilities, which is useful information, is simply not provided. Second, the pension values that are reported do not embed the present value of the pension liabilities together with the firm-specific "PBGC put." Thus, from what is provided, the value of the firm-specific "PBGC put" cannot be discerned because the present values of liabilities cannot merely be subtracted from reported values to derive the (negative of) "the PBGC put." The discount rates used in typical valuations reflect neither the particular plan sponsor's asset portfolio nor its plan surplus. For example, consider a plan with long duration default-free assets backing its liabilities. The plan could still be very risky if the amount of default-free long-term assets is insufficient to cover fully the liabilities, including an adequate plan surplus to handle longevity uncertainty. Alternatively, a plan with lots of surplus but with assets that behave quite differently from the liabilities they must cover may pose just as much risk to PBGC.

The discounting of expected cash flows that is done currently in rendering the reported private pension liabilities is not based on sponsor-specific or plan-specific risk factors. Instead, pension values that are reported typically use discount factors that incorporate an amalgam of various long-term investment grade corporate bond yields which may have very little to do with 
a particular plan sponsor's financial situation or the portfolio supporting its liabilities. If that blending of such yields is weighted by the market values of issued bonds, the single-A-rated bonds occupy an inordinate share of that average and thus draw the overall average quality toward the lowest end of bonds in the various A-grades. Even if the categories are equally weighted, the average yield is below AA quality, as the convexity of yield levels across descending credit ratings from AAA to A assures an average yield that is between AA and A. Thus, the base rates used by plan sponsors to discount and report their liabilities are clearly much higher than those that would reflect the risks of the guaranteed liabilities.

This results in a substantial understating of liabilities by plan sponsors. How substantial? Assuming an average duration of 14 years for pension liabilities and a 200 basis point spread between the Treasury discount rates and the lower-than-AA base corporate rates used to discount the liabilities, I would estimate about a $28 \%$ understatement of liabilities, not including the additional surplus assets required to offset longevity extension risks. ${ }^{7}$ When another (on average)

\footnotetext{
${ }^{7}$ Note, PBGC uses factors enlisted by private insures when assuming liabilities of terminated plans. These factors incorporate a reduction from base reference rates (often A-rated long-term corporates) to provide for profit and a surplus to cushion against average asset defaults and adverse experience. However, insurers do not price their pensions to be riskless and occasionally default on them. In such cases, there may be some coverage granted through state insolvency guaranty programs, but unlike PBGC coverage, such program coverage is based on the present value of remaining obligations ranging form $\$ 100,000$ to $\$ 500,000$, depending on the state, rather than covering the full monthly amounts owed (up to the annual statutory limits) over the
} 
150 basis points are added under the MAP-21 25-year smoothing of corporate yields program, the reported values will underestimate the present-valued cost of funding the liabilities by more than $49 \%$, not including the money surplus needed to secure the promises. This will result in a very heavy economic price to pay and an extraordinary burden will be placed on PBGC to pick up the pieces from the use of these discount factors. Think of it simply. Assets are reported at current market values, and those values are consistent with current discount rates appropriate to their risk. The present values of the assets are therefore equal to their market values. However, the calculated values of the guaranteed liabilities have nothing to do with present values, nor current discount rates, nor the present cost of funding them, and what discount rates are used have nothing to do with the guaranteed nature of the payments that must be made to satisfy the liabilities. Thus, there is simply no way using only current measures of assets and liabilities to approximate the plan deficits and exposure to PBGC. These protocols place PBGC in an unenviable position, and the US taxpayers with a potential liability that can be met only if they are extremely lucky by taking this gamble.

Essentially, what has happened is worse - much worse - than the government issuing $\$ 100$ billion in Treasury bonds and investing those proceeds in common stock, junk bonds, and corporate bonds of varying qualities. If this were a sound bet, why wouldn't the government simply issue a couple of trillion dollars and invest the proceeds in the stock market and bond market, to bail out the deficit? But it is worse, because what the actual bet being conducted is tantamount to issuing government debt in an amount that is far less than the true value of the

pensioners' remaining lifetimes. In many cases, the guaranty programs will result in considerably less coverage for pensioners. 
liabilities it is assuming, and taking the inadequate proceeds from the debt issuance and investing them in risky securities of far lower value than the liabilities being assumed. In such a case, the risky invested assets must not only do well, but must do extraordinarily well to first close the deficit before a surplus can begin to be built. Many financial institutions and investors and have entered into insolvency pursuing such a risky course.

\section{Using the Term Structure of Interest to Discount Liabilities}

I understand that by statute, PBGC is directed to derive and use a set of two interest factors based upon a set of private insurers' group annuity prices to calculate a value of its pension liabilities. ${ }^{8}$ Until this is changed to be more in line with accepted principles of financial economics, such factors must continue to be used. However, by my way of thinking, just because PBGC is directed to use a set of discount factors derived from private insurers' group annuity prices (together with an assumed mortality table) to calculate $\underline{a}$ value does not mean that it cannot also conduct further analysis to determine the actual present values of its liabilities. In fact, if it wishes to set premiums pursuant to the plan risks it assumes, such calculations would be required as a first step in understanding the risks imposed upon it.

I see no compelling reason today for PBGC, or anyone else for that matter, to estimate the value of pension liabilities using a single interest rate factor, or even two interest rate factors, each applying to a different band of timing for cash flows. Seventeen years ago this had some merit from a practical viewpoint, as there were many different term structure of spot interest rate

\footnotetext{
${ }^{8}$ The procedure is explained in http://www.pbgc.gov/news/other/res/pbgc-procedure-interestfactors.html.
} 
(pure discount) models but none readily available in the public domain. Today there is an excellent term structure of spot interest rates model in the public domain, updated daily by the Federal Reserve. It has passed the test of time and certainly provides adequate estimates of the spot interest rates that apply to each term to maturity. ${ }^{9}$

An alternative and equally good way to derive appropriate interest rate factors is to simply use the yields of zero-coupon Treasury STRIPS of various maturities. These are available daily on any Bloomberg terminal. The interest rate factors from such instruments will closely approximate those from the Federal Reserve model. ${ }^{10}$

A third way to estimate the value of pension liabilities is by using stochastic interest rate models. It has been shown elsewhere that where cash flows are contingent on emerging future interest rates, it is necessary to utilize stochastic interest rate valuation models to properly model the cash flows and capture their present values. However, where the cash flows are fixed by contract, and related only to factors (e.g., uncertain longevity) that are not contingent upon interest rates, you will get the same exact present value whether you use the present term structure of interest rates to value the cash flows or a suitable stochastic interest rate valuation model. ${ }^{11}$ Indeed, the way that stochastic interest rate valuation models are calibrated is to ensure

$\overline{9}$ See Gurkaynak, Sack, and Wright (2007) with data posted at: http://www.federalreserve.gov/pubs/feds/2006/

${ }^{10}$ Suffice it to say that because of the greater fungibility of coupon strips relative to principal strips, a yield curve based on coupon strips is generally preferred for valuation purposes. See Sack (2000).

11 The various classes of stochastic interest rate models are detailed in Babbel and Merrill (2000). 
that they render the same present values as term structure models do when applied to fixed future cash flows. Clearly, then, there is no need to go through the hassle of using stochastic interest rate valuation models to determine the present values of such cash flows, which would be characteristic of fixed pensions in payout mode. However, in the case of pensions that are still in the accumulation phase, there may be future payouts that are contingent on the evolution of wage or price inflation, which are at least loosely related to nominal interest rates over time. In such cases, the employment of stochastic interest rate valuation models could be indicated. An alternative is to utilize the real term structure of interest published daily by the Federal Reserve, ${ }^{12}$ when cash flows are related to emerging inflation rates.

One reason to avoid use of interest rate factors derived from a survey of insurers' annuity prices is that their annuity prices conflate various elements that should have no bearing on what it costs PBGC to cover such plans. More will be said about this below.

Another reason is that the annuity prices quoted by many insurers are typically based on yields-to-maturity of long-term AA-rated or A-rated bonds. From those yields are subtracted a number of basis points to adjust for adverse selection, longevity risk, capital contribution, and in some cases expected asset defaults. (For example, in the 1980s and early 1990's, investment banks and insurers would often use the long-term A-rated bond yields, subtract 75 basis points from them, and then discount projected benefits in determining the liability for assuming a pension.) Moreover, insurers have the protections of limited liability, as they do have the option to default on their obligations.

\footnotetext{
${ }^{12}$ See: http://www.treasury.gov/resource-center/data-chart-center/interest $\underline{\text { rates/Pages/TextView.aspx?data }=\text { realyield }}$
} 
A third reason to avoid the use of interest rate factors derived from a survey of insurers' group annuity prices is that the resulting (essentially equivalent) yields-to-maturity themselves are not useful except in valuing something whose value is already known. ${ }^{13}$ They cannot be used to value something with cash flows that are any different than those of the particular instrument from which they were derived. Spot rates of interest, on the other hand, can be used properly to value anything whose cash flows are either fixed beforehand or are otherwise independent of the evolution of interest rates over time.

A fourth reason stems from the fact that a bond's yield-to-maturity can be approximated by the dollar-duration weighted average of the underlying spot rates of interest. ${ }^{14}$ Because a long-term bond typically has a cash payment of principal at maturity that is perhaps twenty to sixty times higher than the size of the intervening cash flows from interest, and because its payment date is twenty to thirty years away, the dollar duration of principal repayment is huge relative to any other payment. This places an inordinate weight upon the single underlying spot rate of interest associated with that particular cash flow in deriving its contribution to the calculated yield-to-maturity. While this may work with ordinary bonds, I know of no pension payout pattern that could justify placing such a weight on one particular cash flow far distant into the future. The distortion by using a discount factor ultimately based on such a yield to value pensions is particularly pronounced if there is slope (either positive or negative) in the term structure of spot rates of interest. Therefore, I can see no justification for using an interest rate factor that is ultimately based on underlying bond yields-to-maturity.

${ }^{13}$ See Santomero and Babbel (2001: 77, 99-101).

${ }^{14}$ A proof is provided by Santomero and Babbel (2001: 150-151). 
An argument against using the term structure of spot interest rates for valuing pension liabilities is that the pension obligations and payouts may extend far beyond the 30-year maximum range of the term structure. Of course, this limitation applies equally to the use of yields-to-maturity, which also typically max out at around 30 years. One approach is to simply apply the longest spot interest rate available to cash flows exceeding the range of the term structure. This approach, however, will surely result in an undervaluation of distant cash flows. The primary reason for this is that positive "gain from convexity" grows as a function of the square of duration. ${ }^{15}$ This is apparent in Figure 1, Panels A-C, examined closely. In the latter two panels, a secant is drawn between the high and low values of 30-year and 60-year zeros,

${ }^{15}$ The term "gain from convexity" is defined as the asymmetrically positive gain in value that is associated with a decrease in interest rates relative to the lower loss in value that would occur with an equal rise in interest rates. The asymmetry arises simply from the mathematics of geometric discounting factors, where the discount factors are raised to exponents reflecting the terms to maturity. For example, a 50 b.p. drop in yields from $8 \%$ to $7.5 \%$ on a 15 -year zerocoupon bond will produce a $\$ 22.73$ rise in the value of a bond, from $\$ 315.24$ to $\$ 337.97$, whereas a 50 b.p. rise in yields to $8.5 \%$ will result in a price drop of only $\$ 21.06$ in that same bond. (In these calculations, I have used straightforward spot rates of interest to discount the cash flows, and not the contrived bond-equivalent yields used in practice, although the point remains the same.) As maturity lengthens, a zero-coupon bond will reflect an increasingly greater disparity in price rises versus price declines, as the mathematics of geometric compounding become more pronounced. A description of gain from convexity, its calculation and importance is given by Santomero and Babbel op cit, pp. 153-158. 
respectively, to demonstrate the increasing convexity with term-to-maturity. The amount of convexity in these two instruments is shown by the areas between the secants and their respective value curves whose end points are connected by the secants. Clearly, there is a much larger area of convexity in the 60-year zero value plot and in the 30-year zero value plot. Accordingly, as traders take into account the available gains from convexity in their pricing, long-term yields begin to decline as convexity becomes the dominating factor. Any student of the term structure of interest can observe this common phenomenon, as the impact of convexity tends to cause spot rates to begin falling beyond 15-28 years. For example, in Figure 2, I have plotted some randomly selected zero-coupon yield curves across various dates. On each yield curve, I have placed a mark at the peak yield. Note that the peaks do not occur at the longest term. I have plotted monthly yield curves from 1941 to 2013 and the findings shown in Figure 2 are typical of what I've found. Exceptions are rare.

\section{Figures 1 and 2 here}

This reduction cannot be said to be related to expectations for reduced interest rates in the distant future, but is simply an artifact of the mathematics of convexity. ${ }^{16}$ Therefore, a more reasonable approach would be to use longer-term rates that begin at the 30 -year spot rate and gradually diminish as term increases over the next 30 years by as much as $1-2 \%$, depending on current volatility. (Higher interest rate volatility creates the opportunity for investors to benefit more from exposure to positive convexity, and hence gives rise to lower long-term yields.) This

\footnotetext{
${ }^{16}$ Our expectations for future interest rates beyond a few years out have little basis and beyond 30 years are nothing more than a guess without support. See Dybvig and Marshall (1996). This article considers credit risk, volatility, expectations, duration and convexity.
} 
approximation would still be a conservative way to estimate the pension liabilities. A way to approximate more closely the unobserved very long-term spot rates is to model them stochastically by maintaining constant the expected value of future short rates and their volatility and then deriving mathematically the long rates by capturing the increasingly dominating effect of convexity as time extends. In either case, it will be noted that the use of increasing spot rates as time extends beyond 30 years is simply inappropriate and will underestimate the cost of funding pension liabilities.

\section{Investment Management}

The 2012 Pension Benefit Guaranty Corporation Annual Report provides some detail on pages 35-44 about its asset management program. Although not my primary focus in this commentary, I offer some observations next.

Overall, it appears to me that a very careful set of protocols and safeguards has been designed and that conflicts of interest are minimized. Annual assurance statements, an internal control committee, and external audits form a portion of their management oversight.

PBGC summarizes its approach to investment management on p. 35 of its Annual Report as follows:

"PBGC uses institutional investment management firms to invest its assets, subject to PBGC's oversight and consistent with the Corporation's investment policy statement approved by its Board. PBGC does not determine the specific investments to be made but instead relies entirely on its investment managers“ discretion in executing investments appropriate for their assigned investment mandates. PBGC does ensure that each investment manager adheres to PBGC 
prescribed investment guidelines associated with each investment mandate and measures each investment manager's performance in comparison with agreed upon benchmarks.” (PBGC 2012: 35.)

It then goes on to explain the segmentation of its investment portfolio, the asset allocations to each segment, and targeted return benchmarks that are prescribed for managers of each of its segments. The equity investments fall into two categories: Global Public Stock and Private Markets. The Global Public Stock sector is further divided into a segment called U.S. Public Stock, which is comprised of U.S. Equity Securities and Real Estate Investment Trusts, and into another segment called International Public Stock. Private Markets include private equity, private debt, and private real estate funds. For example, the "investment policy establishes a 30 percent target asset allocation for equities and other non-fixed income assets, and a 70 percent asset allocation for fixed income." Within these broad categories, finer distinctions are made. For example, the equity investments fall into two categories: Global Public Stock and Private Markets. The Global Public Stock sector is further divided into a segment called U.S. Public Stock, which is comprised of U.S. Equity Securities and Real Estate Investment Trusts, and into another segment called International Public Stock. Private Markets include private equity, private debt, and private real estate funds. Within the fixed income portfolio, there are categories for Treasuries, TIPS, Long Duration, Core, Developed Markets, High Yield, and Emerging Markets. Money Market is a separate category.

Each of these investment categories is assigned carefully selected performance benchmarks or target returns. These benchmark indices are among the best known in the investment community, developed by Barclays, J. P. Morgan, and others. However, it is not clear to me that any of these benchmarks have anything to do with assets outperforming the pension 
liabilities that they are destined to fund. Simply calculating the total rate of return on the assets and comparing it with any of the widely available generic stock and bond indexes is not sufficient. It is virtually impossible that such an index or combination of indices would mirror the insurer's actual liabilities. The stock and bond market indices couldn't be expected to match the duration of PBGC's liabilities, not to mention their convexity characteristics or other measures of interest rate sensitivity (e.g., to yield curve twists, duration drift, or changing volatility).

\section{Establishing a Pension Liability Benchmark}

A primary consideration for a pension insurer in assessing the quality of investment management, particularly if outsourced such as is the case with PBGC, is whether the pension assets have outperformed the pension liabilities.

To determine whether investment assets have indeed outperformed PBGC's liabilities, it must first determine how its pension liabilities have performed. Because pension liabilities are not traded on an organized public exchange, it is not possible to monitor their behavior directly and on a continual basis. Therefore, a liability benchmark must be devised, based on traded securities that will mirror changes in values of the pension liabilities. ${ }^{17}$

\footnotetext{
${ }^{17}$ Not every variable influencing the value of liabilities can be mirrored by action in the capital markets. In pensions the mortality risk cannot be so mirrored. We will work only with the impacts of changes in the Treasury yield curve because the known effects of those changes overwhelm any of the more esoteric factors we could hypothesize.
} 
Two characteristics of a pension liability benchmark are of utmost importance. First, the benchmark must be based on traded securities for which an active market exists. This will allow PBGC to get reliable quotes on a timely basis. Second, and more importantly, the benchmark must behave in a manner that closely parallels the present value of the liabilities over time and under disparate economic circumstances. For example, it should exhibit duration, convexity, and sensitivity to other broad market forces in which one can take an investment position similar to that of the liabilities. The difficulty of evaluating certain complex pension liabilities should not be underestimated. Nonetheless, it must be the starting point for developing an appropriate investment strategy from an asset/liability management perspective.

The valuation methods are based on replicating the cash flows of the pension liabilities with capital market instruments and pricing the resulting replicated portfolios with market prices. This technology gives PBGC the ability to translate its non-traded liabilities into equivalent capital market portfolios for which there are active markets and therefore reliable price quotes. Consequently, it is possible to track the market value of PBGC's pension liabilities over time, even though they are not actively traded. This process differs from the usual approach of calculating only a yield and a duration of the liabilities as benchmarks for the asset portfolio characteristics. The mimicking portfolio has the desirable properties that (1) returns reflect the shape of the yield curve and the cost of any embedded options, and (2) the effects of important sources of interest rate risk other than just duration — such as convexity and changing volatility — are directly incorporated. As noted, many insurers may depend upon duration as the only characterization of the changes in the value of liabilities. However, our suggested approach allows a richer representation of the risk and return properties of liabilities, and also one that easily can be replicated for historical analysis, if desired. 
Using a liquid, traded securities portfolio that mimics the liabilities allows for a straightforward computation of a liability total-rate-of-return index against which the performance of the assets can be measured. Outperforming this liability index ensures that the asset managers are, in fact, acting in a manner consistent with increasing the value of PBGC's economic surplus (or reducing the size of its deficit). The current practice of measuring asset managers against a set of arbitrary market indices not only does not ensure this result but gives management of PBGC, Congress and the taxpayers incorrect information about the status of PBGC. Indeed, it would be quite possible for outside investment managers to exceed each of their target indices yet not contribute positively to PBGC's financial wellbeing. ${ }^{18}$ This is because there is no close relationship between the way that the value of the pension liabilities behaves over time and the target indices that have been chosen by PBGC.

While a well-constructed portfolio that mimics a mature book of business should not vary dramatically over time, its composition may change as pensions age and new pension liabilities are assumed. Consequently, it will be necessary to reevaluate the liabilities periodically and rebalance the liability benchmark if appropriate.

\section{Example of a Simple, Appropriate Liability Benchmark}

${ }^{18}$ This would have happened during the recent deep recession, for example, when spreads widened considerably between A-rated long bonds and long Treasury rates. Also and more obviously, beating a stock market benchmark that fell by $40 \%$ would not have helped much against a (correctly valued) liability that rose in value over the same period. 
Consider a closed pension plan in payout phase, assumed by PBGC. After plotting out the scheduled and expected payment pattern, one could fund it with a portfolio of Treasury zerocoupon bonds, each maturing on a date and in an amount to satisfy the pension outflows. The price of such a bond portfolio could easily be monitored over time and serve as a basis for measuring the present value of the remaining pension liability. If the liability extends beyond the maturity range of Treasury zeros, other measures could be taken, as described earlier, to handle the very long-term obligations. This liability benchmark would change over time as payment obligations are satisfied, year-by-year, and when the prices of zeros change occasioned by changes in market interest rates. This kind of benchmark based on a portfolio of zeros, or another based on what is known as a "dedicated bond portfolio" wherein bonds are purchased in varying amounts and maturities in such a way that their aggregate payments at any time are identical to those of a portfolio of zeros, is appropriate. There may be slightly less expensive ways to effectively fund the same liabilities with the same level of funding risk - for example, if the investment managers carefully measure and match the duration, convexity, and drift of the

pension liabilities. ${ }^{19}$ But for practical purposes, using the portfolio of zeros benchmark is sufficient.

For more complex patterns of liability payments, additional Treasury-based securities and their derivatives may be needed to adequately mirror the liability duration, convexity and drift.

\section{Levels of Performance Measurement}

${ }^{19}$ These approaches are described and tested in Babbel (1983). 
Armed with the concept of liability benchmarks, we are now prepared to measure whether our assets are outperforming our liabilities. Performance attribution requires first a measure of performance so that there is something to attribute! A useful starting point is to compare the spread between the actual total rate of return on the combined investment portfolios and the total rate of change on the overall liability benchmark. We recommend that PBGC investment managers continue to measure their asset performance on a total-rate-of-return basis, but compare their performance to the total rate of change on a liability benchmark carefully constructed to reflect the costs of their liabilities. This liability benchmark (i.e., "liability proxy") could be decomposed into various sector benchmarks, where each would be assigned to separate investment managers, but would be weighted so that in aggregate they would match the overall liability benchmark. A comprehensive performance measurement system will provide for evaluation of performance at several levels, ${ }^{20}$ as illustrated in Figure 3.

Figure 3 here

PBGC could calculate its asset values and liability proxy on a monthly basis. An assumption would be required for handling intra-month cash flows. Typically, these are assumed to occur in the middle of the month.

Chaining together monthly total costs and returns allows PBGC to calculate a timeweighted rate of return over any long-term horizon. It eliminates the impact of the actual timing

20 A detailed presentation of how to implement such a comprehensive performance measurement system was derived by Goldman Sachs and is described in Babbel, Stricker and Vanderhoof, (1990, 1994) and Babbel (1992). 
of cash flows over which PBGC and its investment managers have no control. This allows for unbiased comparisons of performance.

Using a liability benchmark is appropriate for measuring the performance of asset portfolios funding PBGC's liabilities.

\section{Epilogue: Not in My Backyard, or Kicking the Can Down the Road?}

In designing a portfolio of securities to serve as liability and sub-liability benchmarks, we recommend the selection of U.S. Treasury securities, their derivatives, and other securities of minimal default risk. There are several reasons why we favor the inclusion and predominance of these securities:

- They are liquid and widely traded, and price quotes are easily obtained.

- They are typically the benchmark used for valuing other asset classes and are starting to be used as a benchmark for valuing insurance liabilities as well.

- Their diversity of characteristics allows them to be combined into portfolios that can emulate the market value behavior of almost any default-free cash flow stream.

Summary: Not in my backyard, or kicking the can down the road? When a private pension plan is transferred from the sponsoring company to a private insurance company, as I understand it, PBGC's obligations with respect to that plan are relieved at that point. If the insurer later becomes insolvent, PBGC will not be obligated to assume the pension liabilities. There may be limited coverage through the National Association of Life and Health Guaranty Association (NOLHGA) or its state counterparts, but there is no federal responsibility other than some oversight to ensure that the Plan liabilities have been transferred to what USDOL has termed 
"the best available annuity provider," which is an aspiration with heavy connotations, albeit subject to various interpretations. This eventuality is what we refer to as "not in my backyard."

However, when a private pension plan's obligations and assets are transferred to PBGC, to the extent that PBGC is using discount rates to value its obligations derived from a survey of private insurers' group annuity purchase prices (wherein each insurer has the protection of limited liability and the option to default), we refer to this action as simply "kicking the can down the road." To satisfy its liabilities, PBGC can do one of two things. Either it can invest in an appropriate set of riskless, matched assets, and maintain an adequate surplus to handle longevity uncertainties and other contingencies in order to provide the promised benefits, or it may invest pension assets in whatever kind of portfolio it deems best, providing, however, that it maintains sufficient excess economic surplus in the plan to cover asset defaults, longevity drift, and additional contingencies arising from holding such unmatched assets. Otherwise, PBGC is, in essence, simply transferring the liabilities from one risky pension provider to another (i.e., itself). Sooner or later, this will come back to bite them, or the taxpayers who probably will ultimately have to pay even though they currently provide no explicit guarantee against risky behavior followed by PBGC. We learned this from the Fannie Mae and Freddy Mac financial debacles of 2008 .

I should note here that current pension valuations by PBGC simply reflect the statutory guidelines imposed upon it. We have found, in another context, that sound actuarial operating principles are sometimes sacrificed on the altar of short-term political expediencies, such as what happened in the two-year reduction in Social Security rates that occurred in 2011-12. More direct evidence that this can occur, to the detriment of PBGC's own solvency prospects, is the recent looting of private pensions in an effort to fund a highway program through a change prescribed 
for discount factors used in valuing pension liabilities (the Moving Ahead for Progress in the 21st Century [MAP-21]). Using a moving average of past discount rates is unjustified from a finance-theoretic viewpoint. Even the Federal Government is unable to sell any of its bonds at or near face value if they offer interest based on averaged historical rates. The prices garnered will always reflect current market interest rates. This sort of accounting subterfuge and gimmickry may be sufficiently complex to keep it off the radar screen of most news outlets and voters, but knowledgeable people recognize it for what it is. 


\section{References}

Arnott, R. D. (2005). “The Pension Problem: On Demographic Time Bombs and Odious Debt." Financial Analysts Journal 61(6): 12-17.

Babbel, D. F. (1983). "Duration and the Term Structure of Interest Rate Volatility," in Innovations in Bond Portfolio Management: Duration Analysis and Immunization, G. Bierwag, G. Kaufman, and A. Toevs, eds. New York: JAI Press, 1983.

Babbel, D. F. (1992). "Measuring Investment Performance in an Asset/Liability Context," in Managing Asset/Liability Portfolios. Charlottesville, VA: Association for Investment Management and Research.

Babbel, D. F., and C. Merrill (2000). Valuation of Interest-Sensitive Financial Instruments. Society of Actuaries, Wiley Publishers, revised ed.

Babbel, D. F., and C. Merrill (2005). "Real and Illusory Value Creation by Insurance Companies," Journal of Risk and Insurance 72(1): 1-21.

Babbel, D. F., R. Stricker, and I. T. Vanderhoof (1990). "Performance Measurement for Insurers," Financial Institutions Research. New York, NY: Goldman Sachs.

Babbel, D. F., R. Stricker, and I. T. Vanderhoof (1994). "A Modern Approach to Performance Measurement for Insurers," in Operations Research Models in Quantitative Finance, R. L. D’Ecclesia and S. A. Zenios, eds. Heidelberg, Germany: Physica-Verlag.

Bulow, J. I. (1982). "What Are Corporate Pension Liabilities?” Quarterly Journal of Economics 97(3): 435-452.

Bulow, J. I., R. Mørck, and L. H. Summers (1987). "How Does the Market Value Unfunded Pension Liabilities?” in Issues in Pension Economics, Z. Bodie, J. B. Shoven, and D. A. 
Wise, eds. Chicago, IL: University of Chicago Press.

Dybvig, P. H., and W. J. Marshall (1996). "Pricing Long Bonds: Pitfalls and Opportunities," Financial Analysts Journal 52(1): 32-39.

Gurkaynak, R. S., B. Sack, and J. H. Wright (2007). “The U.S. Treasury Yield Curve: 1961 to the Present," Journal of Monetary Economics 54(8): 2291-2304 (with data posted at: http://www.federalreserve.gov/pubs/feds/2006).

Merton, R. C. (1974). “On the Pricing of Corporate Debt: The Risk Structure of Interest Rates," Journal of Finance 29(2): 449-470.

Sack, B. (2000). “Using Treasury STRIPS to Measure the Yield Curve," FEDS Working Paper 2000-42. Washington, DC: Division of Monetary Affairs, Federal Reserve Board of Governors.

Santomero, A. M., and D. F. Babbel (2001). Financial Markets, Instruments and Institutions, $2^{\text {nd }}$ ed. New York, NY: McGraw-Hill Irwin. 
Figure 1.

Panel A. Zeros have varying degrees of convexity.

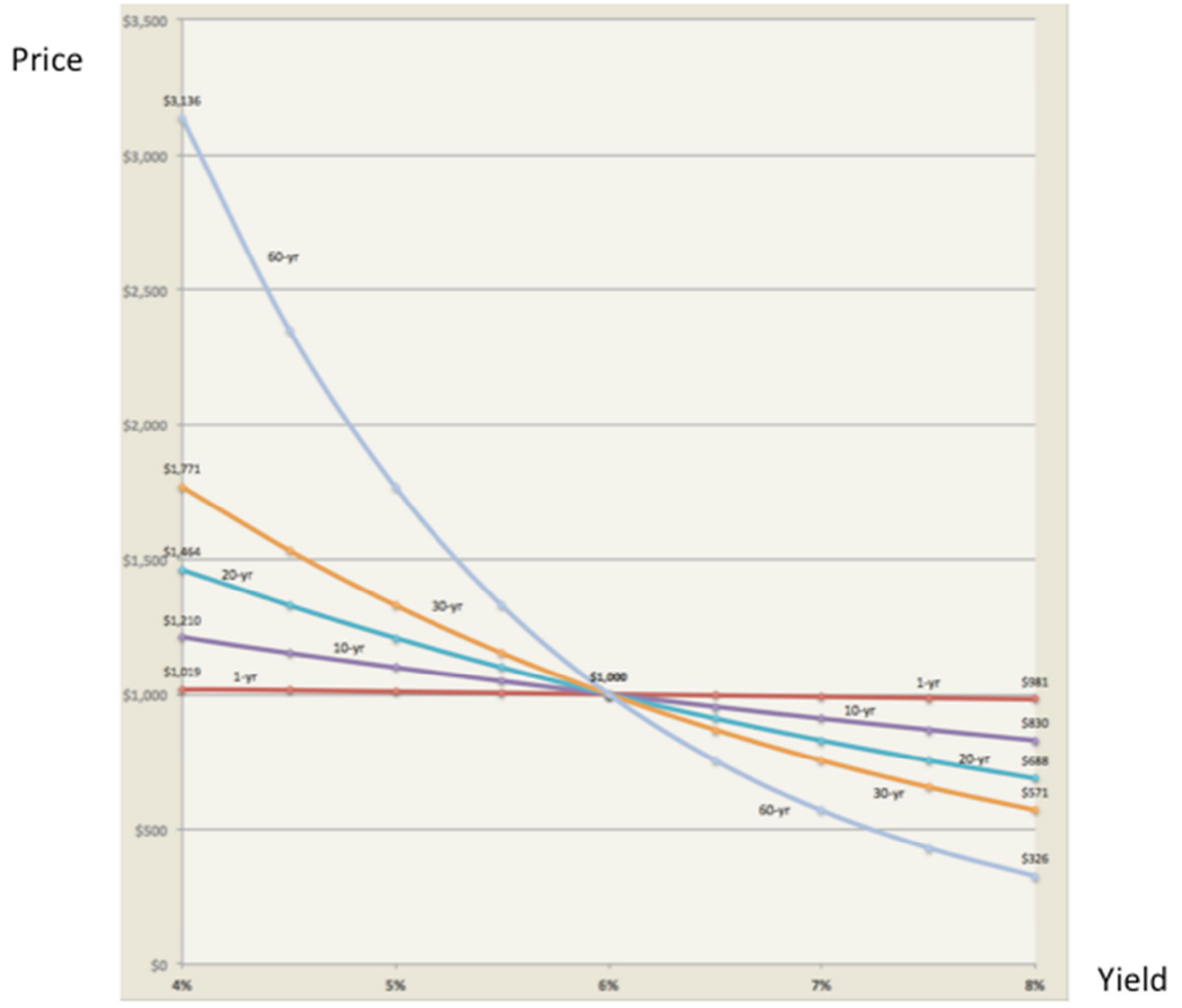


Panel B. Secant showing gain from convexity of 30-year zero.

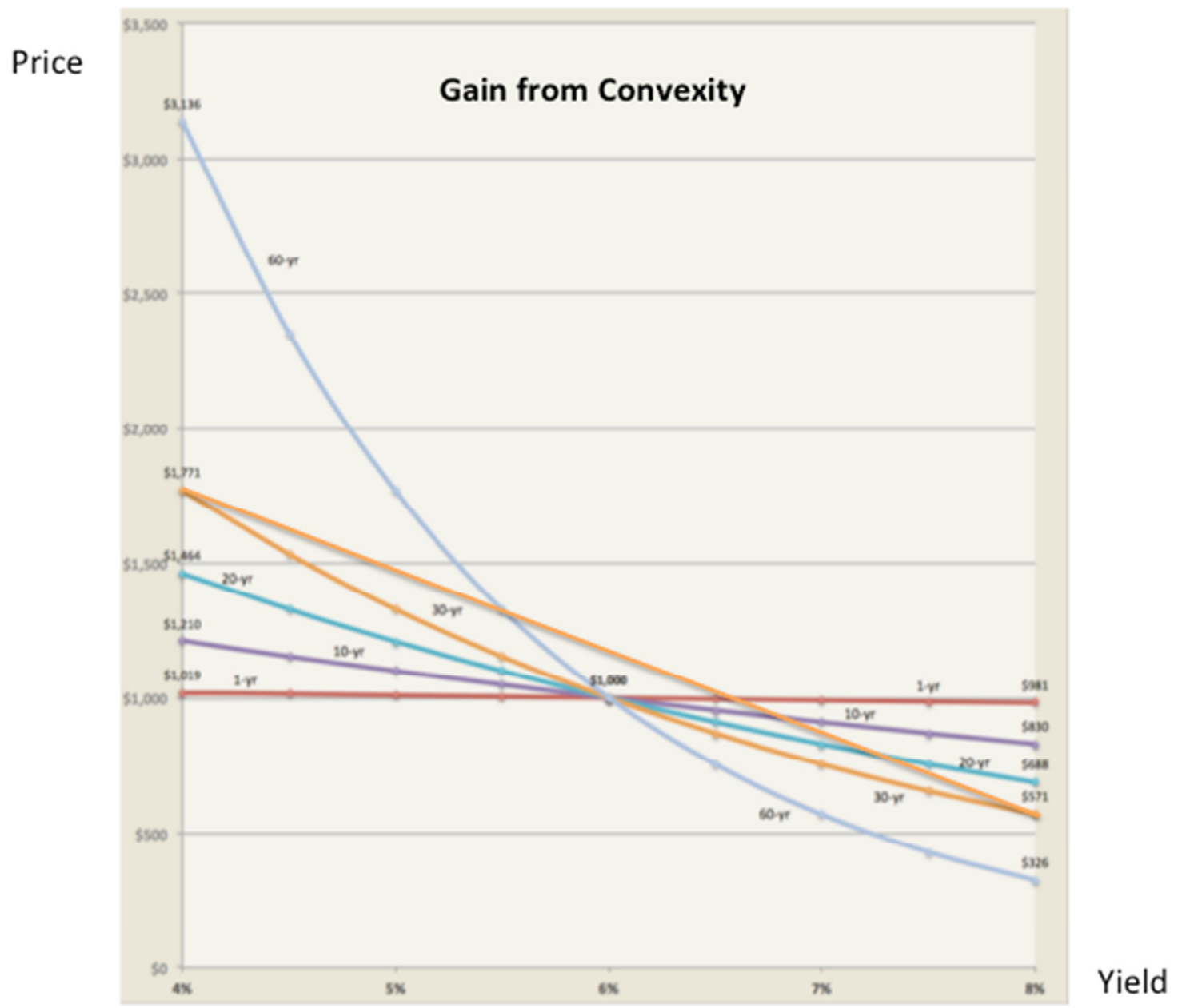


Panel C. Secant showing larger gain from convexity of 60-year zero.

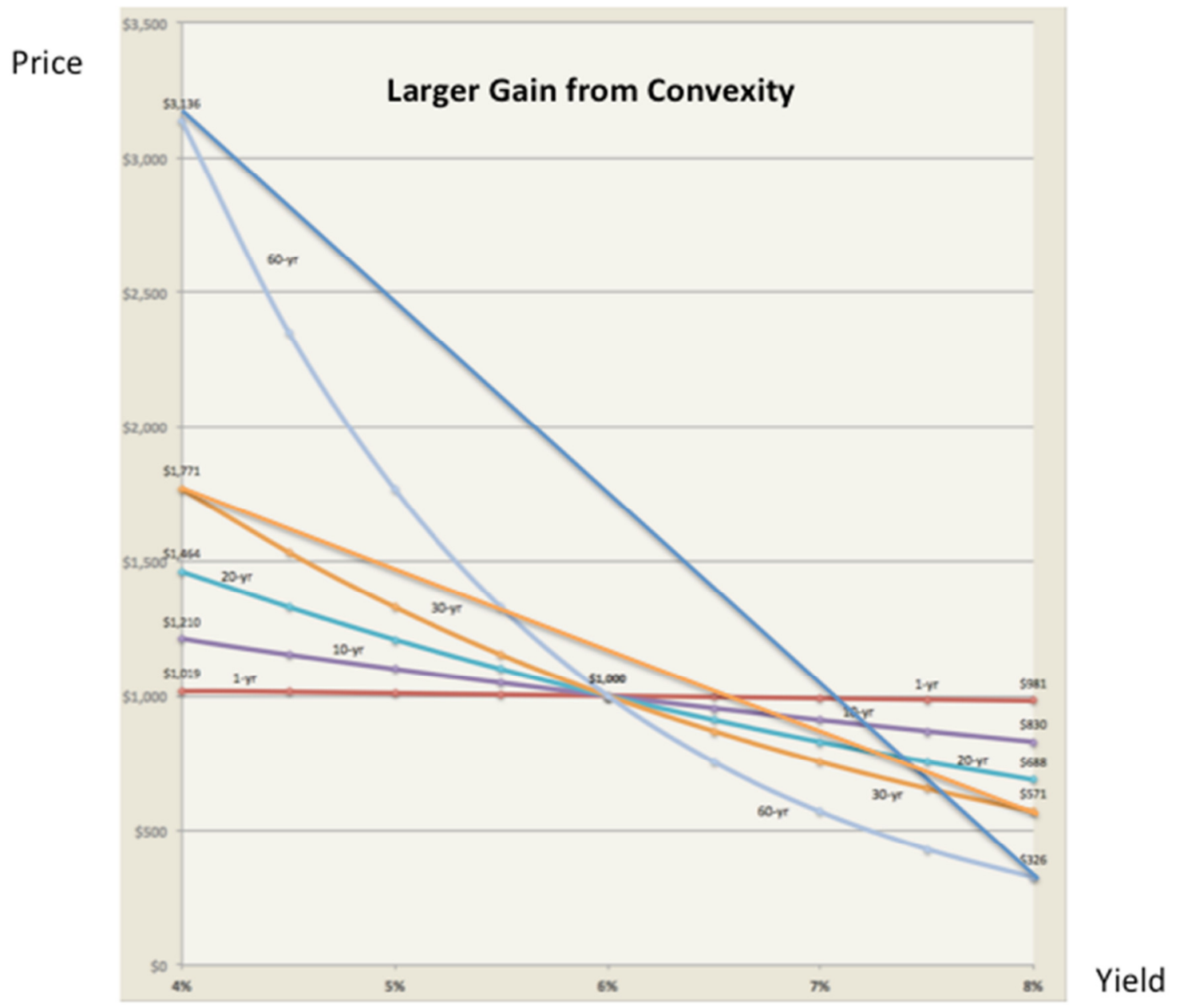

Figure 1. Notes: Panel A: Zeros have varying degrees of convexity; Panel B: Secant showing gain from convexity of 30-year zero; Panel C: Secant showing larger gain from convexity of 60year zero. Source: Author's calculations. 


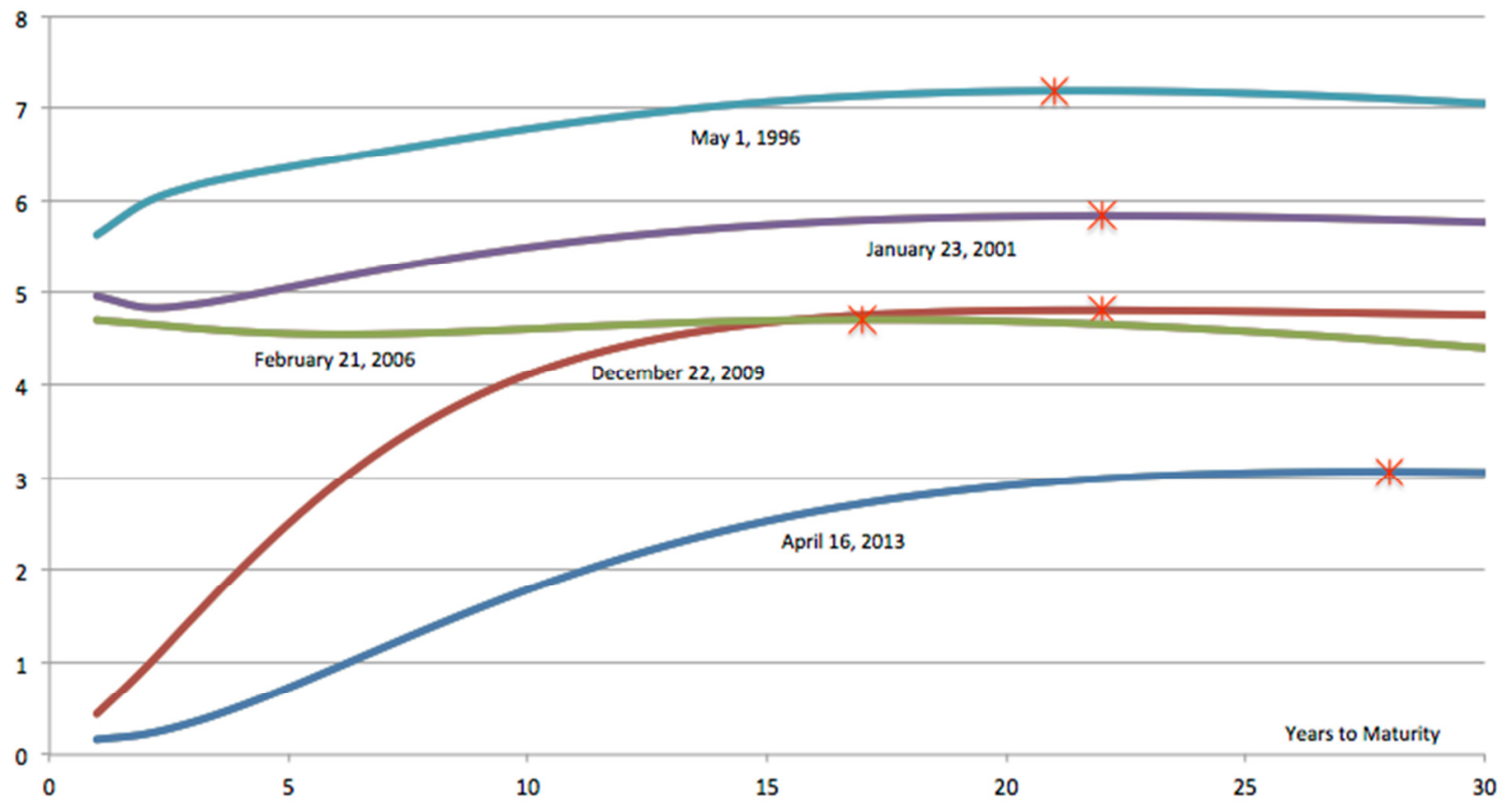

Figure 2. Maximum spot interest rates at various dates. Source: Author's calculations. 


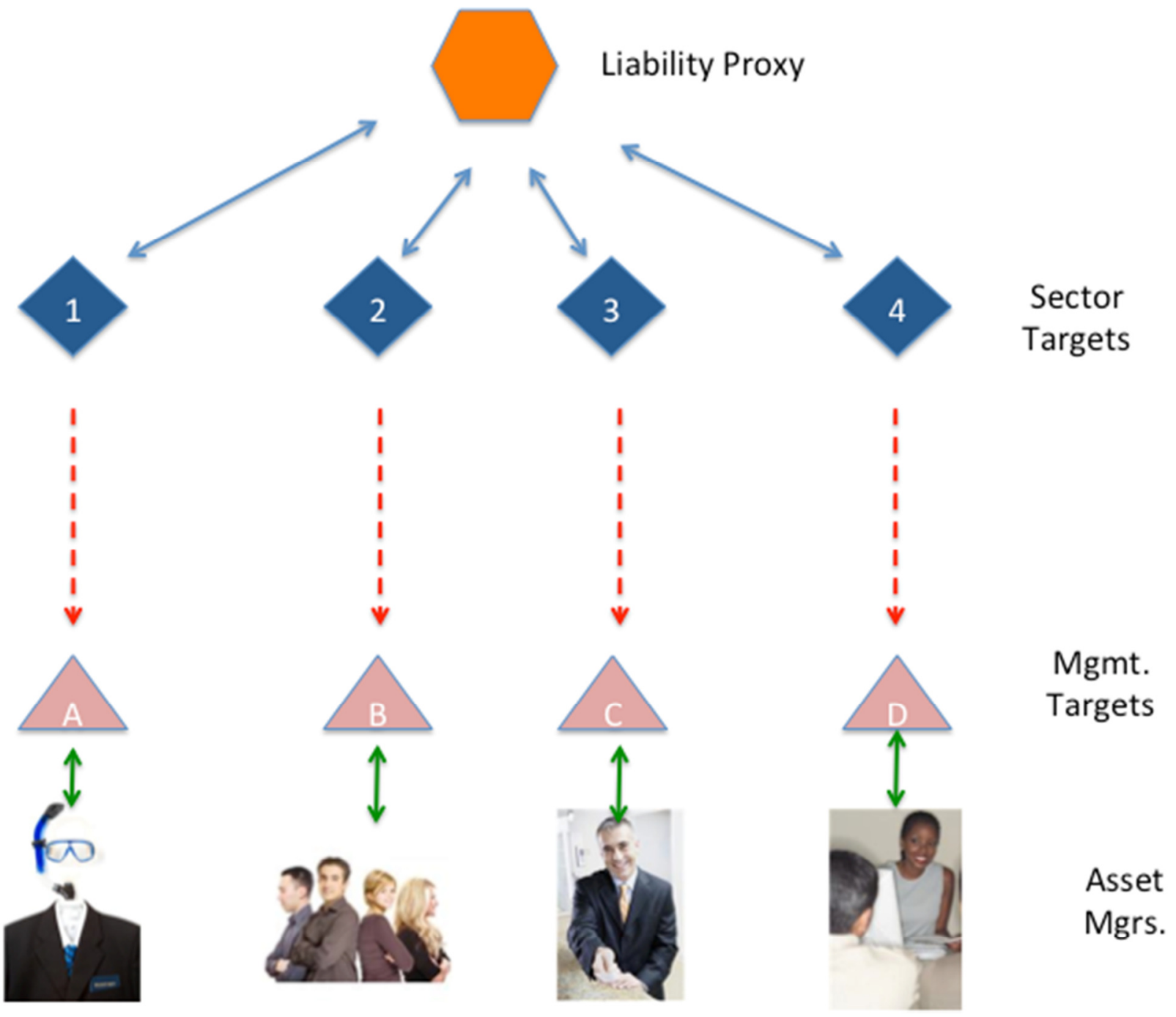

Figure 3. Establishing a liability benchmark for asset management and performance evaluation. Source: Author's illustration. 